


\title{
Depicting Architecture: Houses of the Imagination
}

\author{
by Marwa Tawfiq \\ Bachelor of Architectural Science, Ryerson University, 2015 \\ A thesis presented to Ryerson University \\ in partial fulfillment of the requirements for the \\ degree of Master of Architecture \\ Toronto, Ontario, Canada, 2017 \\ (C) Marwa Tawfiq, 2017
}




\section{Author's Declaration}

I hereby declare that I am the sole author of this thesis. This is a true copy of the thesis, including any required final revisions, as accepted by my examiners.

I authorize Ryerson University to lend this thesis to other institutions or individuals for the purpose of scholarly research.

I further authorize Ryerson University to reproduce this thesis by photocopying or by other means, in total or in part, at the request of other institutions or individuals for the purpose of scholarly research.

I understand that my thesis may be made electronically available to the public. 
Depicting Architecture: Houses of the Imagination

Marwa Tawfiq

\section{Abstract}

Depictions (drawings, models) play a significant role in giving architecture form through the use of various techniques and mediums of expression. These forms of depictions invite an experimental design approach and generate critical thinking in design. The aim in this thesis is to look at architecture critically and investigate design approaches to enhance architectural ideas through varying forms of depiction such as drawing, painting, sculpture, and digital media. Experimentally driven design processes have the potential to push ideas to greater heights in the architectural discipline. Architectural depiction that pursues ideas or notions that may never be built are significant forms of production that push design thinking into other territories; they are in and of themselves architecture. Specifically, the design of a 'House of the Imagination' becomes a vehicle in the thesis for experimental architectural ideas and provides an alternative setting for architectural form making. 


\section{Acknowledgements}

My sincere gratitude goes out to a distinguished few.

Thanks to John Cirka, for always encouraging me and pushing me in the right directions. I will always cherish the valuable conversations and advice you've given me during this journey.

Thanks to Colin Ripley for always challenging me for the better and posing the necessary questions.

Thanks to Kendra Smith for being a supportive figure and providing constructive feedback.

Thanks to my loving parents, Raied \& Fetooh, who I can never thank enough for all they have given and provided for me. Their love and support has made this journey easier every step of the way. This, I owe to them.

Thanks to my supportive siblings and one nephew, Mohammad, Huda, Ali, Nora, and Adam, for always being there for me when I needed them most. Their support always encouraged me to do better.

Thanks to my grandma, Nooria, for her continuous prayers.

Thanks to my best friends, Yasmeen and Ban, who were both able to be of great support in my journey, despite the long distances between us. 


\section{Table of Conents}

Author's Declaration iii

Abstract

Acknowledgements

Table of Contents

List of Figures

\section{$\mathrm{V}$}

vii

viii

xi

1 | Introduction

2 | Depictions

2.1 Architecture as a Visual Art 2

2.2 Drawing 3

2.2.1 Drawing in the $15^{\text {th }}$ Century 8

2.2.2 Drawing in the 20 ${ }^{\text {th }}$ Century 13

2.2.3 Drawing the Visually Seen 16

2.2.4 Drawing the Imagined 21

2.3 Methods, Mediums, and Techniques 22

2.4 Depictions in the Digital Age 25 
3 | Experimental Design

3.1 Speculative Depiction 29

3.2 Imagination 32

3.3 Depicting Place 38

4 | Precedents \& Design Philosophies 42

5 | Houses of the Imagination

5.1 Home and The House 63

5.2 Houses: Air, Ground, Water 67

5.3 Modest Mansion: Mountain Shoreline 83

5.3.1 Unified 84

5.3.2 Fragmented 109

5.3.3 The Mansion 125

6 | Depicting Architecture 140

$\begin{array}{ll}\text { Appendix } & 142\end{array}$

$\begin{array}{ll}\text { Bibliography } & 177\end{array}$ 


\section{List of Figures}

Cover: Watercolour Drawing of The Modest Mansion

Source: Marwa Tawfiq

Figure 1: Florence Cathedral Dome Drawing by Filippo Brunelleschi, 1436

Source: Alamy Limited, "Stock Photo - FLORENCE: BRUNELLESCHI, Italy. accessed 14 April 2017, http://www.alamy.com/stock-photo-florence-brunelleschincross-section-of-filippo-brunelleschis-design-95498630.html.

Figure 2: Santa Maria Novella's façade by Leon Alberti, 1458

Source: "Initlabor - Marta Michelutti - Tra Musica E Architettura - Terza Parte", Digilander.Libero.It, accessed 14 April 2017, http://digilander.libero.it/initlabor/ musica-architettura-michelutti/musica-architettura-marta3.html.

Figure 3: Exploratory Journal Drawings by Leonardo da Vinci, 1480's

Source 1: Clayton Cogmon Jr., "Leonardo Da Vinci - The Anatomical Artist - Drawing Academy", Drawing Academy, 2014, http://drawingacademy.com/leonardoda-vinci-the-anatomical-artist.

Source 2: "Leonardo Da Vinci'S Map Of Imola", Quaerentia, 2010, https://markmeynell. wordpress.com/2010/04/12/leonardo-da-vincis-map-of-imola/.

Source 3: Jeffrey Levy, "Casenetwork Medical Hall Of Fame: Leonardo Da Vinci Casenetwork", Casenetwork, 2014, http://casenetwork.com/casenetworkmedical-hall-fame-leonardo-da-vinci/.

Figure 4: Carbon Pencil Delineations by Hugh Ferris, 1910's-1920's

Source: Roxana Wax, "The Metropolis Of Tomorrow - Hugh Ferriss | Graphicine", Graphicine.Com, 2014, http://www.graphicine.com/the-metropolis-of-tomorrow-hugh-ferriss/.

Figure 5: Continuous Monument by Superstudio, 1969

Source: Mood Moods, "I SUPERSTUDIO SUPERARCHITETTURA I", Moodmoods. Wordpress.Com, 2014, https://moodmoods.wordpress.com/2014/02/26/superstudio-superarchitettura/.

Figure 6: No Stop City by Archizoom, 1969

Source: AJ Artemel, "Retrospective: Archizoom And No-Stop City”, Architizer, 2013, http://architizer.com/blog/archizoom-retrospective/.

Figure 7: Balloon for Two by Haus-Rucker-Co, 1967

Source: "Haus-Rucker-Co: Architectural Utopia Reloaded", Archdaily, 2014, http:// www.archdaily.com/582842/haus-rucker-co-architectural-utopia-reloaded.

Figure 8: Drawing the Visually Seen

Source: Marwa Tawfiq

Figure 9: Drawing the Imagined

Source: Marwa Tawfiq

Figure 10: Watercolour and Ink drawings by Eloise Bound, 2017

Source: Isabelle Bonte, "Fil De Fer", Deferestmonfil.Com, 2017, http://www.deferestmonfil.com/galeries/fil-de-fer/. 
Figure 11: Portal Shifting by Bryan Cantley, 2016

Source: Bryan Cantley, “Form:Ula”, Facebook.Com, 2017, https://www.facebook. com/474516022600890/photos/a.474517202600772.133269.47451602260089 0/1330668376985646/?type=3\&theater.

Figure 12: Incubator by Smout Allen at Bartlett School of Architecture, 2016

Source: Smout Allen, "2016 Incubator", Smout Allen, 2017, http://www.smoutallen.com/home-ground-2015-2.

Figure 13: Imaginary Prisons by Giovanni Battista Piranesi, 1750

Source: "Imaginary Prisons: Giovanni Battista Piranesi Prints | Princeton University Art Museum", Artmuseum.Princeton.Edu, accessed 14 April 2017, http:// artmuseum.princeton.edu/object-package/giovanni-battista-piranesi-imaginary-prisons $/ 3640$.

Figure 14: Metropolitan Basilica by Étienne-Louis Boullée, 1778-1788

Source: Roxana Wax, "Étienne Louis Boullée - Cenotaph | Graphicine", Graphicine. Com, 2016, http://www.graphicine.com/etienne-louis-boullee-cenotaph/.

Figure 15: Cenotaph to Newton by Étienne-Louis Boullée, 1784

Source: Roxana Wax, “Étienne Louis Boullée - Cenotaph I Graphicine”, Graphicine. Com, 2016, http://www.graphicine.com/etienne-louis-boullee-cenotaph/.

Figure 16: Genius Loci by Anastasia Savinova, 2016

Source: Anastasia Savinova, "Welcome To Anastasia Savinova", Anastasia Savinova, 2017, http://anastasiasavinova.tictail.com/.

Figure 17: Sketches of the Dream House by Marco Frascari, 1993

Source: Marco Frascari and Federica Goffi, Marco Frascari's Dream House, 2017.

Figure 18: NASA Surveyor by Diller and Scofidio, 2012

Source: Mats Behrbohm, "NASA Surveyor 7 Vs. Diller Scofidio", Matslovesit. Blogspot. Ca, 2012, http://matslovesit.blogspot.ca/2012/01/nasa-surveyor-7-vs-dillerscofidio.html.

Figure 19: Diamond Museum C by John Hejduk, 1967

Source: "Cite A Website - Cite This For Me", S-Media-Cache-AkO.Pinimg.Com, 1967, https://s-media-cache-ak0.pinimg.com/originals/af/c7/26/afc726b5aba0dcbed8f9bbf65ac87c81.jpg.

Figure 20: House I, Housell, House III by Peter Eisenman, 1968-1971

Source1: Peter Eisenmana, “HOUSE I", Eisenmanarchitects.Com, 1968, http://www. eisenmanarchitects.com/house-i.html.

Source2: Peter Eisenman, “HOUSE II", Eisenmanarchitects.Com, 1970, http://www. eisenmanarchitects.com/house-ii.html.

Source3: Peter Eisenman, "HOUSE III", Eisenmanarchitects.Com, 1971, http://www. eisenmanarchitects.com/house-iii.html. 
Figure 21: House VI by Peter Eisenman, 1975

Source: Peter Eisenman, "HOUSE VI", Eisenmanarchitects.Com, 1975, http://www. eisenmanarchitects.com/house-vi.html\#images.

Figure 22: Sketches by Also Rossi, 1980's

Source1: Cameron McEwan, "Aldo Rossi I Architecture Of Analogy", Cameronmcewan. Wordpress.Com, 2012, https://cameronmcewan.wordpress.com/tag/aldorossi/.

Source2: Cameron McEwan, "Sketch Studies After Architect Aldo Rossi", Architecture Of Analogy, 2010, https://cameronmcewan.wordpress.com/2010/10/20/ sketch-studies-after-architect-aldo-rossi-2/.

Figure 23: Micromegas by Daniel Libeskind, 1979

Source: fosco lucarelli, "Daniel Libeskind'S "Micromegas" (1979)", SOCKS, 2012. http://socks-studio.com/2012/03/24/daniel-libeskinds-micromegas-1979/.

Figure 24: Einstein's Tomb by Lebbeus Woods, 1984

Source: Geoff Manaugh, "Lebbeus Woods, 1940-2012", BLDGBLOG, 2012, http:// www.bldgblog.com/2012/10/lebbeus-woods-1940-2012/.

Figure 25: High House by Lebbeus Woods, 1994

Source: Lebbeus Woods, "HIGH HOUSES", LEBBEUS WOODS, 2010, https://lebbeuswoods.wordpress.com/2010/02/23/high-houses/. Your Bibliography: Woods, Lebbeus. "HIGH HOUSES". LEBBEUS WOODS, 2010.

Figure 26: Strategic Plot by Perry Kulper, 1997

Source: "Drawing Architecture - Conversation With Perry Kulper", Archinect, 2012, http://archinect.com/news/article/54767042/drawing-architecture-conversation-with-perry-kulper.

Figure 27: Thematic Drawing by Perry Kulper, 2001

Source: "Spotlight: Perry Kulper", Archimorph, 2011, https://archimorph. com/2011/10/12/spotlight-perry-kulper/.

Plug in City by Peter Cook, 1962-64

Figure 28: Victoria Patricia, "Plug-In City (1964). Archigram.", PROYECTOS 7 / PROYECSource: TOS 8, 2013, https://proyectos4etsa.wordpress.com/2013/01/16/plug-in-city1964-archigram/.

Figure 29: Cities Moving by Ron Herron, 1964

Source: Karl Fabricius, "Archigram's Walking City: A 60'S Architectural Vision Of The Future", Scribol.Com, 2009, http://scribol.com/art-and-design/architectureart-and-design/archigrams-walking-city-a-60s-architectural-vision-of-thefuture/.

Figure 30: Window and Fragments by Richard Ferrier, 1994

Source: “October | 2012 |", Rcrdarch.Wordpress.Com, 2012, https://rcrdarch.wordpress.com/2012/10/. 
Figure 31: Iron Wire Models by Isabelle Bonte, 2017

Source: Isabelle Bonte, "Fil De Fer", Deferestmonfil.Com, 2017.

http://www.deferestmonfil.com/galeries/fil-de-fer/.

Figure 32: L.A. Recalculated by Smout Allen, 2015

Source: Laura Allen and Mark Smout, "LA Recalculated”, Smout Allen, 2015, http://www.smoutallen.com/larecalculated.

Figure 33: Charcoal Drawing

Source: Marwa Tawfiq

Figure 34: Early Drawing Study of Home, 2015

Source: Marwa Tawfiq

Figure 35: Figurative Sketches of Houses of Air, Ground, Water

Source: Marwa Tawfiq

Figure 36: Conceptual Pencil Sketches

Source: Marwa Tawfiq

Figure 37: Blind Contour Drawings of Houses

Source: Marwa Tawfiq

Figure 38: Sectional Continuous Contour Drawings of Houses

Source: Marwa Tawfiq

Figure 39: Watercolour Drawings of Houses

Source: Marwa Tawfiq

Figure 40: Watercolour Drawings of Houses

Source: Marwa Tawfiq

Figure 41: Clay Houses

Source: Marwa Tawfiq

Figure 42: Mixed Media Houses

Source: Marwa Tawfiq

Figure 43: Charcoal Drawing

Source: Marwa Tawfiq

Figure 44: Charcoal Drawings of Unified Modest Mansions

Source: Marwa Tawfiq

Figure 45: Charcoal Drawing of a Unified Modest Mansion

Source: Marwa Tawfiq

Figure 46: Collaged Depictions of Unified Modest Mansions

Source: Marwa Tawfiq

Figure 47: Collaged Depiction of a Unified Modest Mansion

Source: Marwa Tawfiq 
Figure 48: Collaged Depiction of a Unified Modest Mansion Source: Marwa Tawfiq

Figure 49: Collaged Depiction of a Unified Modest Mansion Source: Marwa Tawfiq

Figure 50: Layered Drawings of a Unified Modest Mansion Source: Marwa Tawfiq

Figure 51: Axonometric Painting of a Unified Modest Mansion Source: Marwa Tawfiq

Figure 52: Painted Plan of a Unified Modest Mansion Source: Marwa Tawfiq

Figure 53: Axonometric Painting of a Unified Modest Mansion Source: Marwa Tawfiq

Figure 54: Digital Plan and Elevation of a Unified Modest Mansion Source: Marwa Tawfiq

Figure 55: Digital Render of a Unified Modest Mansion Source: Marwa Tawfiq

Figure 56: Digital Axonometric Depiction of a Unified Modest Mansion Source: Marwa Tawfiq

Figure 57: Physical Modesls of Unified Modest Mansions Source: Marwa Tawfiq

Figure 58: Physical Modesls of Unified Modest Mansions Source: Marwa Tawfiq

Figure 59: Watercolour Drawing Source: Marwa Tawfiq

Figure 60: First Iteration of the Fragmented Mansion - Watercolourr and Ink Source: Marwa Tawfiq

Figure 61: First Iteration of Mansion Fragments - Fragments Source: Marwa Tawfiq

Figure 62: Second Iteration of the Fragmented Mansion - Watercolour and Ink Source: Marwa Tawfiq

Figure 63: Second Iteration of the Fragmented Mansion - Fragments Source: Marwa Tawfiq

Figure 64: Third Iteration of the Fragmented Mansion - Watercolour and Ink Source: Marwa Tawfiq 
Figure 65: Third Iteration of the Fragmented Mansion - Fragments Source: Marwa Tawfiq

Figure 66: Digital Series of the Fragmented Mansion Source: Marwa Tawfiq

Figure 67: Digital Axonometric Depiction of The Mansion Source: Marwa Tawfiq

Figure 68: Watercolour Iterations of The Mansion Source: Marwa Tawfiq

Figure 69: Digital Overlapped Elevations of The Mansion Source: Marwa Tawfiq

Figure 70: Digital Overlapped Sections of The Mansion Source: Marwa Tawfiq

Figure 71: Lower Floor Plan of The Mansion Source: Marwa Tawfiq

Figure 72: Central Floor Plan of The Mansion Source: Marwa Tawfiq

Figure 73: Upper Floor Plan of The Mansion Source: Marwa Tawfiq

Figure 74: Physical Model of The Mansion Source: Marwa Tawfiq

Figure 75: Figurative Sketches of Houses of Air, Ground, Water Source: Marwa Tawfiq

Figure 76: Conceptual Spatial Layering Source: Marwa Tawfiq

Figure 77: Sectional Continuous Contour Drawings of Houses Source: Marwa Tawfiq

Figure 78: Watercolour Drawings of Houses Source: Marwa Tawfiq

Figure 79: Figurative Watercolour Drawing of Houses Source: Marwa Tawfiq

Figure 80: Clay Houses Source: Marwa Tawfiq

Figure 81: Figurative Watercolour Drawing of Houses Source: Marwa Tawfiq 
Figure 82: Black and White Silhouettes of Houses

Source: Marwa Tawfiq

Figure 83: Rough Sketches of Houses

Source: Marwa Tawfiq

Figure 84: Rough Sketches of Houses

Source: Marwa Tawfiq

Figure 85: Physical Models of a Unified Modest Mansion Source: Marwa Tawfiq

Figure 86: Digital Model of a Unified Modest Mansion Source: Marwa Tawfiq

Figure 87: Physical Modesls of Unified Modest Mansions Source: Marwa Tawfiq

Figure 88: Rough Sketches of The Modest Mansion Source: Marwa Tawfiq

Figure 89: Painted Tape from Watercolour Iteration of The Mansion Source: Marwa Tawfiq

Figure 90: Plans of The Mansion Source: Marwa Tawfiq

Figure 91: Elevations of The Mansion Source: Marwa Tawfiq

Figure 92: Sections of The Mansion Source: Marwa Tawfiq

Figure 93: Render of The Mansion's Entrance / Seating Area Source: Marwa Tawfiq

Figure 94: Render of The Mansion's Courtyard Source: Marwa Tawfiq

Figure 95: Experiential Depiction of The Mansion Source: Marwa Tawfiq

Figure 96: Rough Physical Model of The Mansion Source: Marwa Tawfiq

Figure 97: Physical Model of The Mansion Source: Marwa Tawfiq 


\section{1 | Introduction}

Depiction is the term used in this thesis to refer, first, to the diverse range of media and modes of expression used in the production of architecture, and, second, to argue for an expanded role within the architectural design practice. Emphasis will be placed on the design modes of drawing and modeling in a range of media.

Architecture is a form of expression and a communication tool. It communicates ideas, thoughts, and concepts, through visual, tactile, and material means. Depictions play a significant role in giving architecture form using varying techniques and mediums of expression. Drawings in the form of contract documents or working drawings play a significant role in communicating architectural intentions to contractors. However, this form of drawing is not a focus here. Depiction, as it is used here, refers to a different form of expression. Depictions, whether through drawing, painting, sculpture, or digital media, have the potential to yield speculative design approaches and enhance architectural ideas through critical design thinking. This thesis will analyze forms of depiction and the role that drawing and speculative architecture has played in the discipline in the past, in order to look at architecture through a critical lens. The thesis will further examine experimentally driven design approaches to show how these enhance both the design process, and architectural ideas. The acts of drawing and model-making are capable of introducing alternative modes of expression to architecture, where practitioners potentially formulate a different understanding of ideas. Depictions of a speculative nature are significant works because they push design thinking in new directions, generating valuable insights that are, in themselves, a form of architecture.

In this thesis, the act of designing houses of the imagination is a vehicle to investigate architectural ideas and generate forms using a speculative mode of design. Depiction is a tool to generate form and communicate it through visual means. Through this speculative method of design, this thesis will embark upon a form of architecture that is imaginative and poetic in essence. It is an architecture that is made real through the mediums and methods of production that exist only in the depiction. 


\section{2 | Depictions}

\subsection{Architecture as a Visual Art}

Architectural depictions are forms of expression: thoughts, ideas, and concepts communicated through visual means. Even models, which have a tactile component, are mostly studied visually to understand spatial and material relationships. To depict is to present an idea using creative techniques as a visual communication tool. Depictions are forms of production that magnify architectural ideas through their process and their critical construction. Architecture is a form of visual art. As with other visual art forms such as drawing, painting, and sculpture, architecture employs diverse mediums to represent objects and communicate feelings. As writer Edward Warder Rannells has observed in The Study of Architecture as Art: "[s]o it is that we study architecture as art, not science, and we approach it through history." "While visual art consists in a range of disciplines, these disciplines are not necessarily mutually exclusive. Forms can be integrated with others, creating a different collective entity. Drawing, painting, and sculpting are each of themselves essential forms within the discipline, which are integral to the visual communication of architectural ideas and the generation of architectural forms. Architectural depictions are not limited to one method or form production. The contribution of other art disciplines to the production process and to the final work unfolds differently for different projects. Architectural design is not reducible to representation; design is a form of knowledge that uses techniques of depiction to bring ideas into the material world. As American Architect Peter Eisenman once said in an interview with The Architectural Review journal, "[d] rawing is a form of thinking... [When I draw] I'm not trying to represent something; I'm trying to make it real."2

Depictions within architecture are critically formulated works that challenge the status quo and conventional forms of drawing. They present architectural ideas through every stage of its design process. 
They can be either conceptual or practical in nature. Putting forward ideas first envisioned mentally into a depiction allows the designer to analyze different concepts as they develop throughout the design process. Depictions therefore become modes of learning and of advancing architectural ideas. A design process that uses depiction is one that develops gradually through different moments and methods of expression. An experimental design environment that encourages the free development of architectural concepts through diverse forms of depiction can therefore enhance the architectural design process. This kind of design environment allows for a less constricted space of expression and experimentation. This in turn allows for the production of more critically driven designs, because it is within such a space that concepts can be formulated and explored through a variety of mediums and across different perspectives.

A key part of the depiction process entails experimenting with different mediums to portray conceptual ideas and to express them using the appropriate tools. Amongst the most prominent forms of depiction, drawing is often the basis of the overall design process. Drawing can be the fastest method of expressing an idea, as the designer quickly sketches out their most preliminary thoughts. Drawing, in its varying forms and techniques, adds value to the architectural process, and can be found at the preliminary as well as the final stages of design. Different methods of depiction have also been produced within the discipline of drawing. Drawing techniques have advanced tremendously over time with the advent of new software programs and other advanced tools of expression. With reference to the role that drawing has played in the past, and the significance it still holds today, the following section will look at its vital role within the architectural design process.

\subsection{Drawing}

Drawing has played a significant role in the architectural design process, both historically and into the $21^{\text {st }}$ century. In this, architecture is hardly unique. Drawing is of primary significance to many 
disciplines, whether in its roughest or its most detailed forms. The term drawing itself has a dual meaning, as a noun and a verb, a thing and an action. The former is defined as a picture or diagram made with a pencil, pen, or crayon rather than paint, ${ }^{3}$ whereas the latter denotes the action of sketching in lines (or, metaphorically, in words) to delineate or depict. ${ }^{4}$ The act of drawing allows for an alternative form of expression of thought. As artist and animator William Kentridge, has noted, "[t]he activity of drawing is a way to understand who we are and how we operate in the world." 5

Drawing can be classified in a variety of ways. For example, phenomenologist Edward Casey suggests that drawing can be understood in terms of four categories of mapping: mapping of, mapping for, mapping with/in, and mapping out. The first, mapping of, describes the representational form of drawing, one that is exact and represents an object as is. The second form of drawing, mapping for, is also representational but acts as a support for a mapping of drawing, for example in the form of a rough or preliminary sketch. This drawing is imprecise and quick in its depiction. These two forms of drawings are forms that, in architecture, objectify a building through its exact geometry, measurements and dimensions. The next two forms of drawing, mapping with/in and mapping out are more abstracted forms of drawing that depict in a poetic manner. ${ }^{6}$ Mapping with/in refers to a type of drawing that can give a sense of what it feels like to be in a place; it reflects on the experience of something. This form of drawing has no definite direction. Finally, mapping out refers to drawing of a poetic character that impacts the viewer and communicates an experience to them in order to move them in a similar way as it had moved the artist/designer. Casey argues that the significance of drawing or mapping is not held only in the representational form of drawing, but in a drawing that poetically speaks about the experience of a place. As Alberto Pérez-Gómez and Angeliki Sioli remark, "If we want a present and future architecture that may contribute to overcome the impoverishment of our built environments, it is paramount 
that we engage architecture's tools of representation under the terms of drawing with/in and drawing out."

Given the categories Casey established, drawing can be further categorized into two general forms, first being drawing the visually seen and second drawing the imagined. Both forms of drawing play a vital role in developing an important position within architectural discourse. As both are methods of drawing, they each have their own uses and reasoning within depiction. While the first depends highly on visual perception and what the eye can see, the second depends on the mind to perceive ideas to draw them. Drawing the visually seen has the more precise objective of drawing an exact subject matter. It aims at representing a physical subject that is present within the designer's physical realm through drawing. Drawing the imagined is different. It depends on the designer's creative skills and ability to communicate abstract thoughts through visual means. This form of drawing speaks in more poetic terms and depicts in a conceptual manner. In either method, drawing plays a significant role within a design process and in the process of translating architectural ideas into architectural form in particular.

\subsubsection{Drawing in the $15^{\text {th }}$ Century}

Given the varying forms of drawing that exist today, it is useful to take a historical perspective on the use of drawing in architecture, to see how this has changed over time. The Renaissance period marked a very important time for the establishment of drawing within the visual arts in general, and in architecture in particular. At that time, drawing was used as a tool to work out complex ideas. Drawings were made in order to record exact measures and details that were required to build with more precision. This system provided a highly efficient basis on which to transform designs into built forms. Drawing and construction became inseparable architectural methods. Since this time, drawing has continued to help develop and shape 


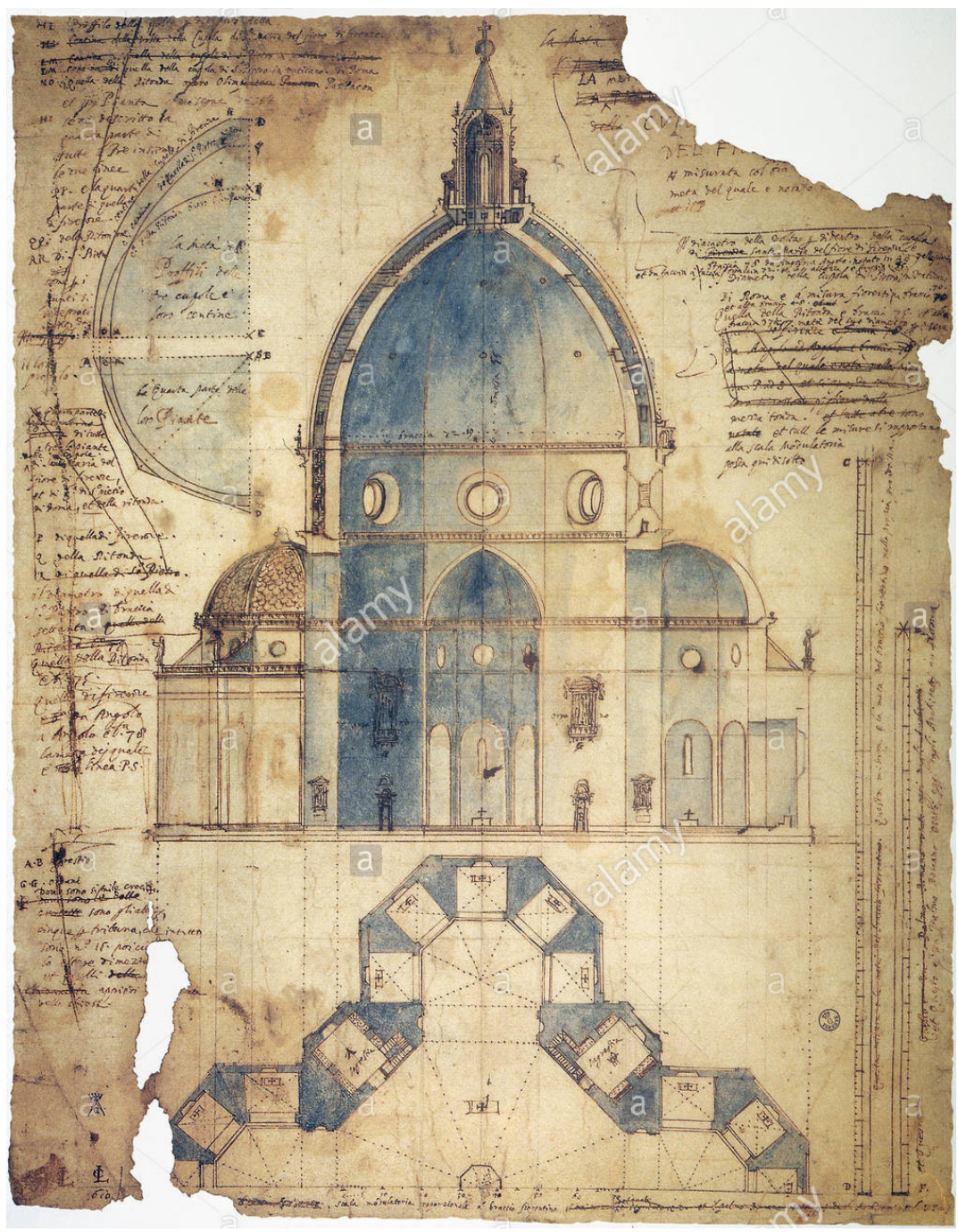

Fig. 1

Florence Cathedral Dome Drawing by Filippo Brunelleschi, 1436 


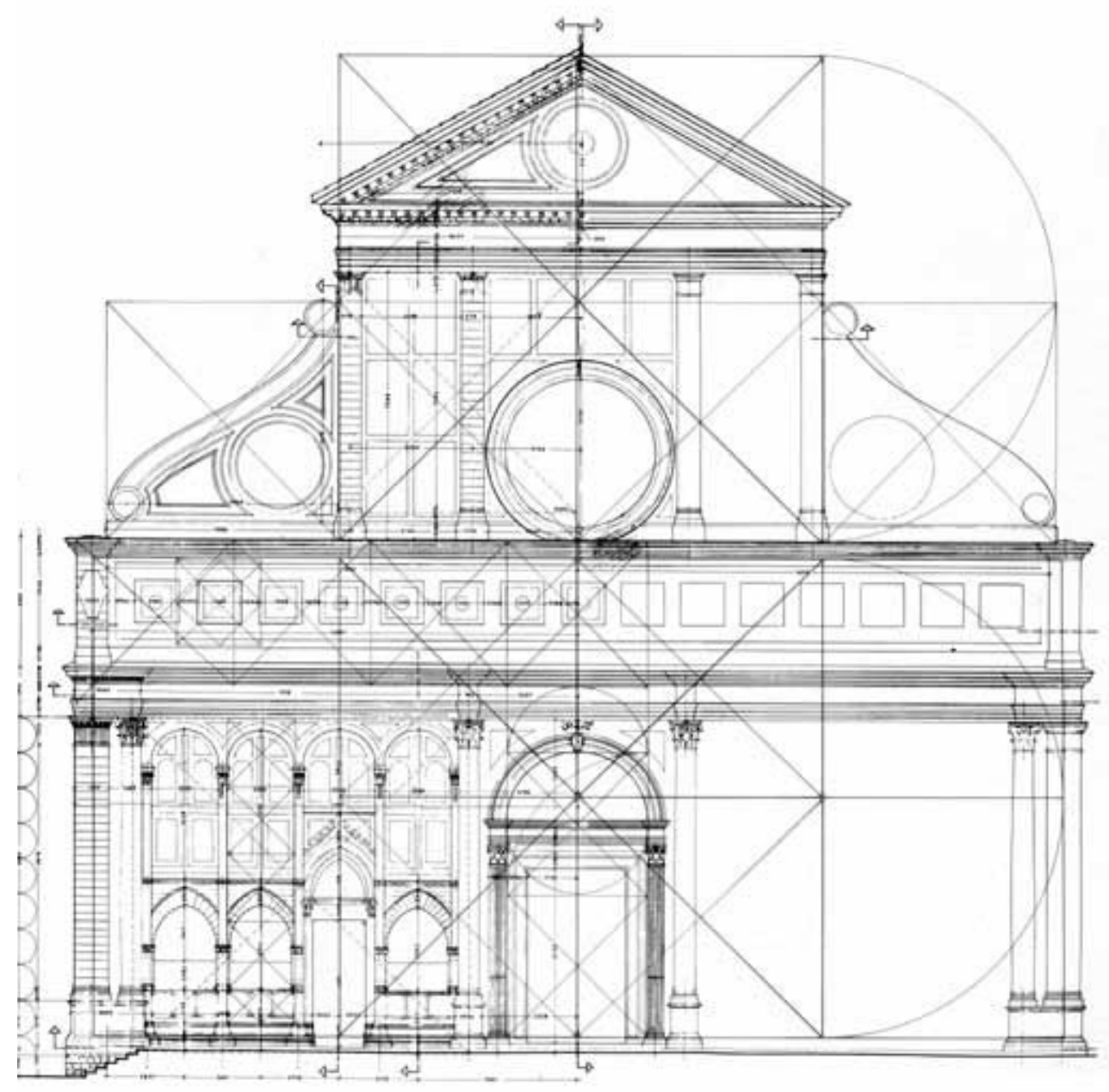

Fig. 2

Santa Maria Novella's Façade by Leon Alberti, 1458 

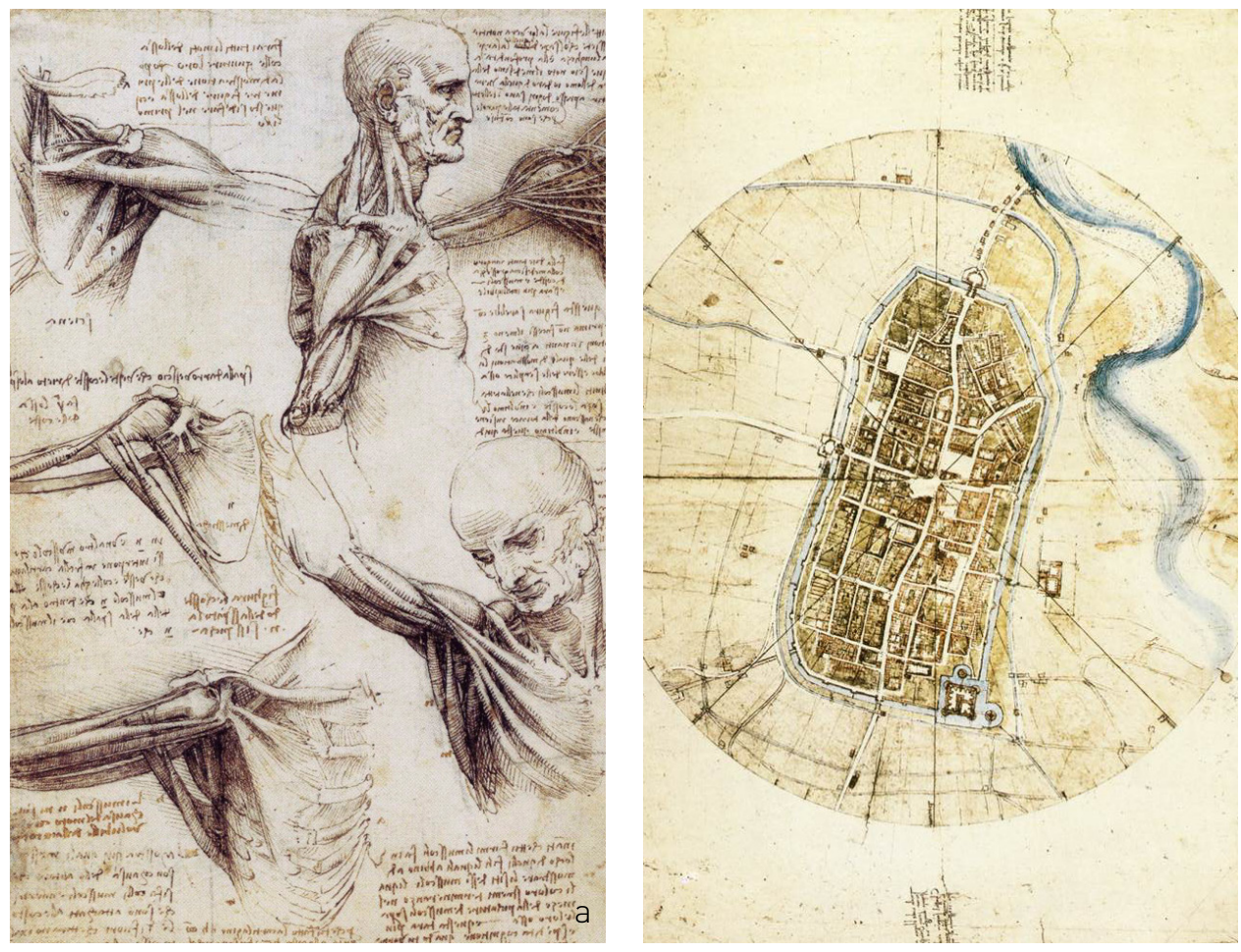

Fig. 3

Exploratory Journal Drawings by Leonardo da Vinci, 1480's

architectural thought and practice over the past 500 years. ${ }^{8}$ While this is taken for granted today, in the early Renaissance, drawing represented a new way of expressing ideas in architecture. This section will therefore analyze the history of drawing and other forms of depiction in architecture.

In the early $15^{\text {th }}$ century, architectural drawings were combined with theory, and a new form of awakening and interest was raised. Filippo Brunelleschi was an important figure in this awakening. A well-known Italian architect of the early Renaissance, Brunelleschi had a passion for visual arts, mathematics, and mechanics. Drawing on these interests he combined scientific and theoretical knowledge and became the first to study perspective drawings in detail. His self-educated persona allowed him to develop scientific perspective construction through his sense of proportion and visual harmony of masses. His practical and theoretical knowledge allowed him to advance in his artistic and architectural practice and his use of draw- 

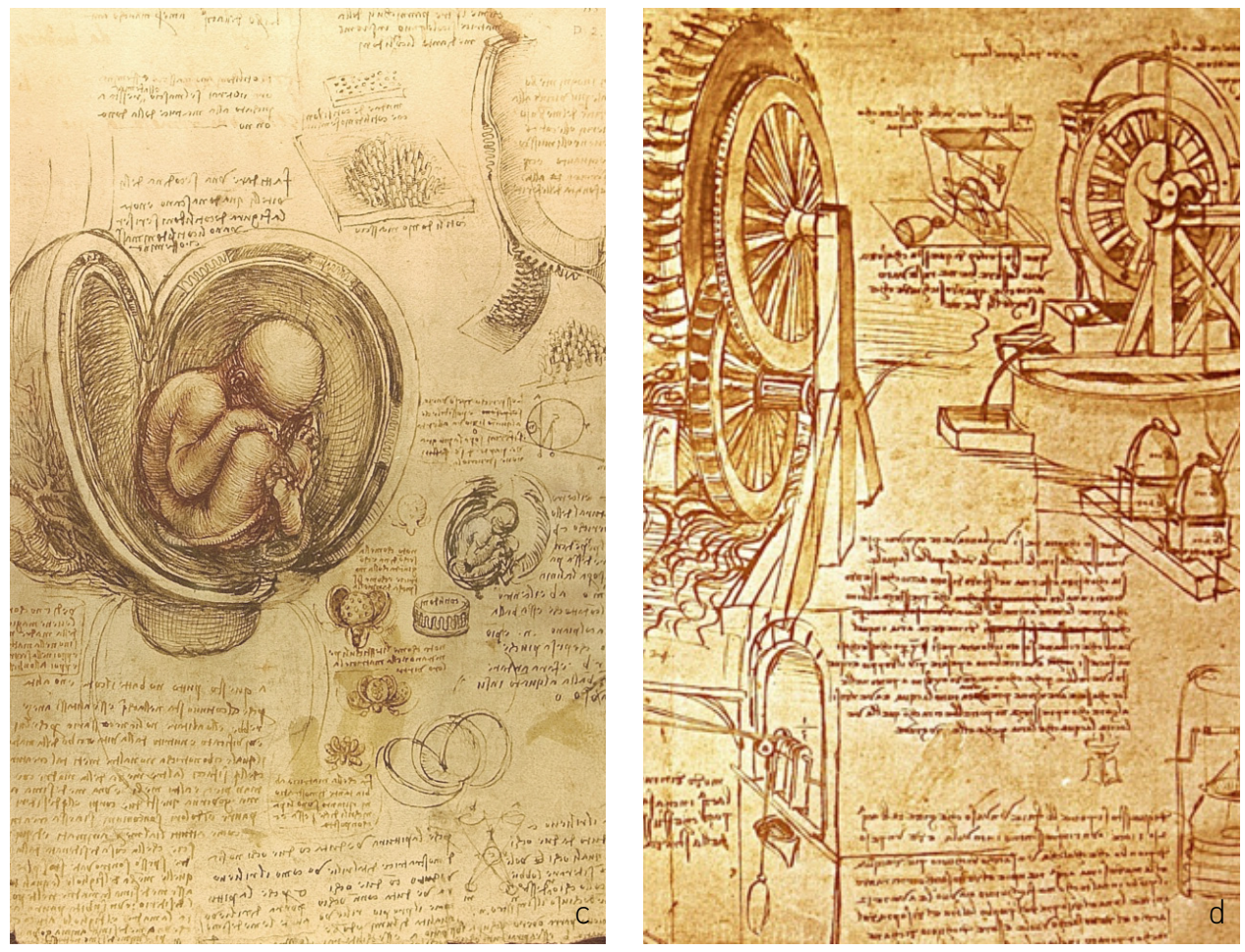

ings and models was integral to these advancements in architectural expression.?

Brunelleschi played a significant role in the completion of the dome of the Florence Cathedral in 1436. The cathedral was under construction from 1367 to 1418 . But then a practical challenge arose which halted further construction. The walls forming the support of the dome were built to a diameter larger than any existing domes, making the completion of the cathedral almost impossible. Brunelleschi was selected in 1418 to help complete the construction of the cathedral. Using his scientific and theoretical design approach, he developed a comprehensive system, represented in drawings and models, which was instrumental in the completion of the cathedral. His designs included a proposal for a double shell for the dome, models for every shape of brick used, and scaffolding and hoisting apparatus for the transportation of materials. Through drawing as a form of communication, Brunelleschi was able to present illustrated solutions that helped the builders complete the cathedral. ${ }^{10}$ 

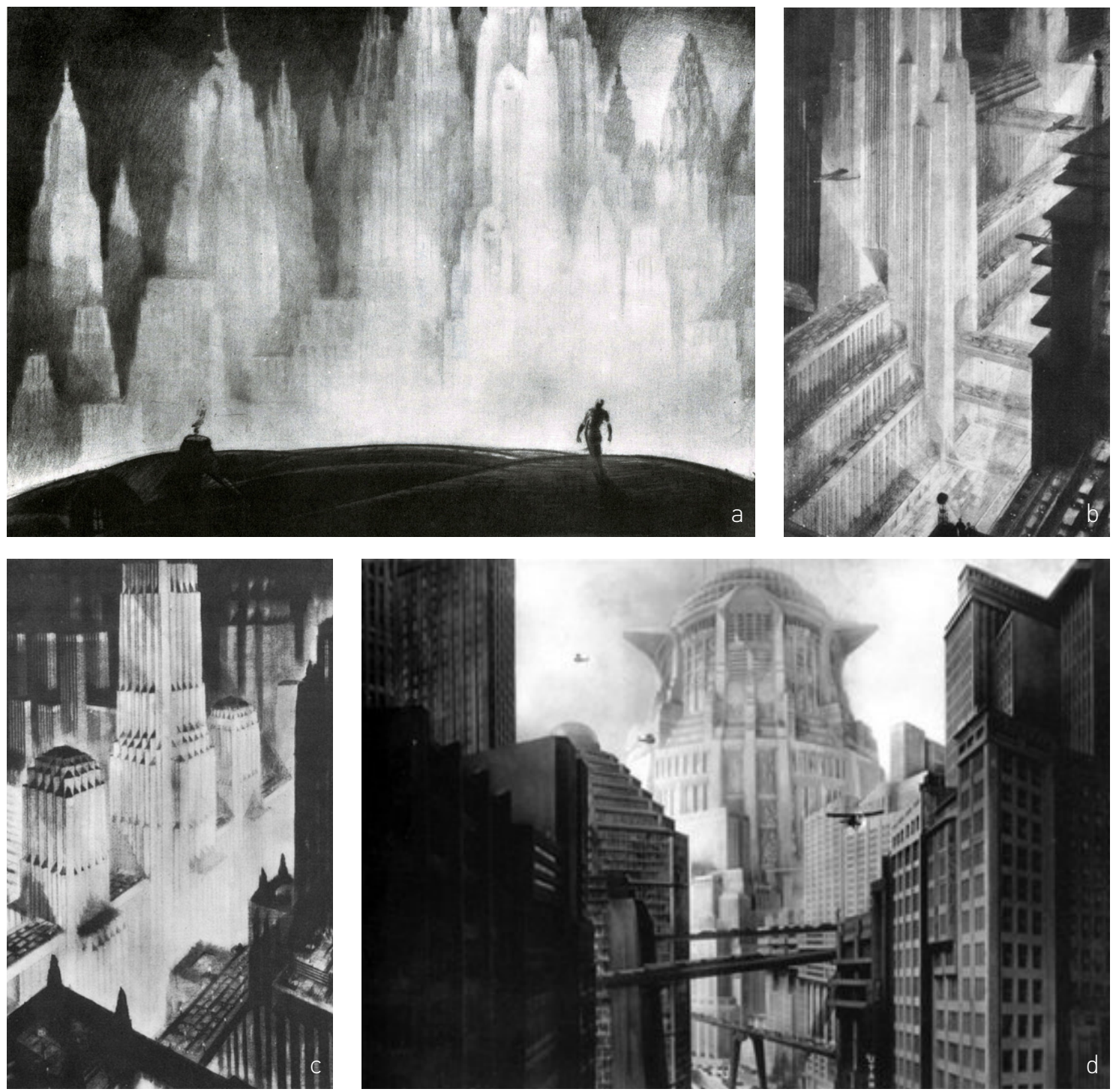

Fig. 4

Carbon Pencil Delineations by Hugh Ferris, 1910's-1920's

Although Brunelleschi played a major role in the discovery of perspectival drawing and construction, he was not the first to write it down in theory. Leon Alberti was the first to put the theory of perspective drawings into written form in his treatise on painting of 1435 . Alberti was a theorist and writer about the arts, and was never con- 
sidered an architect by profession. Nevertheless, he was an influential man in Italy due to his outward humanitarian and philosophical methods of learning. Alberti started his career in writing and published books regarding the importance of painting as a base for architecture. These provide the basis on which he was able to secure individual commissions for architectural designs, the first of which came in 1450. A few years later, in 1458, he was commissioned to design what would become his most famous work: the façade of the Santa Maria Novella.

Leonardo da Vinci brought a whole new approach to drawing and sketching in architecture around the 1480's. An artist of architectural concepts and ideas, he never built a physical structure in his lifetime. Instead, da Vinci made a great name for himself by approaching architecture from a theoretical standpoint, producing a vast number of sketches and drawings. Through his daily regimen of making notes and sketches, he developed a series of observations regarding anatomy, physical laws, machinery designs, mathematics, artistic proportions, light and shadow, and urban form. As Ludwid H. Heydenreich states in Architecture in Italy, 1400 to 1500:

It is not easy to do historical justice to Leonardo's phenomenal status in architecture. The extreme sobriety of his feeling for architecture as an art, the almost mathematical abstractness of his variations on architectural types, the total neglect of the classical repertory of form set him apart from the important practical architect of his generation. ${ }^{11}$

It was through the medium of drawing that da Vinci was able to convey his knowledge and experimental thoughts. Da Vinci drew both what he was able to visually see and what he imagined, and expressed it in the form of a daily journal of depictions through drawings and script. He captured his thoughts visually through drawings, as that was the quickest and best way to capture a thought as it presented itself to him at a given moment. Da Vinci left a great imprint in the history of drawing and art production within the discipline of architecture. He brought a different approach to architectural ideas and theories. 

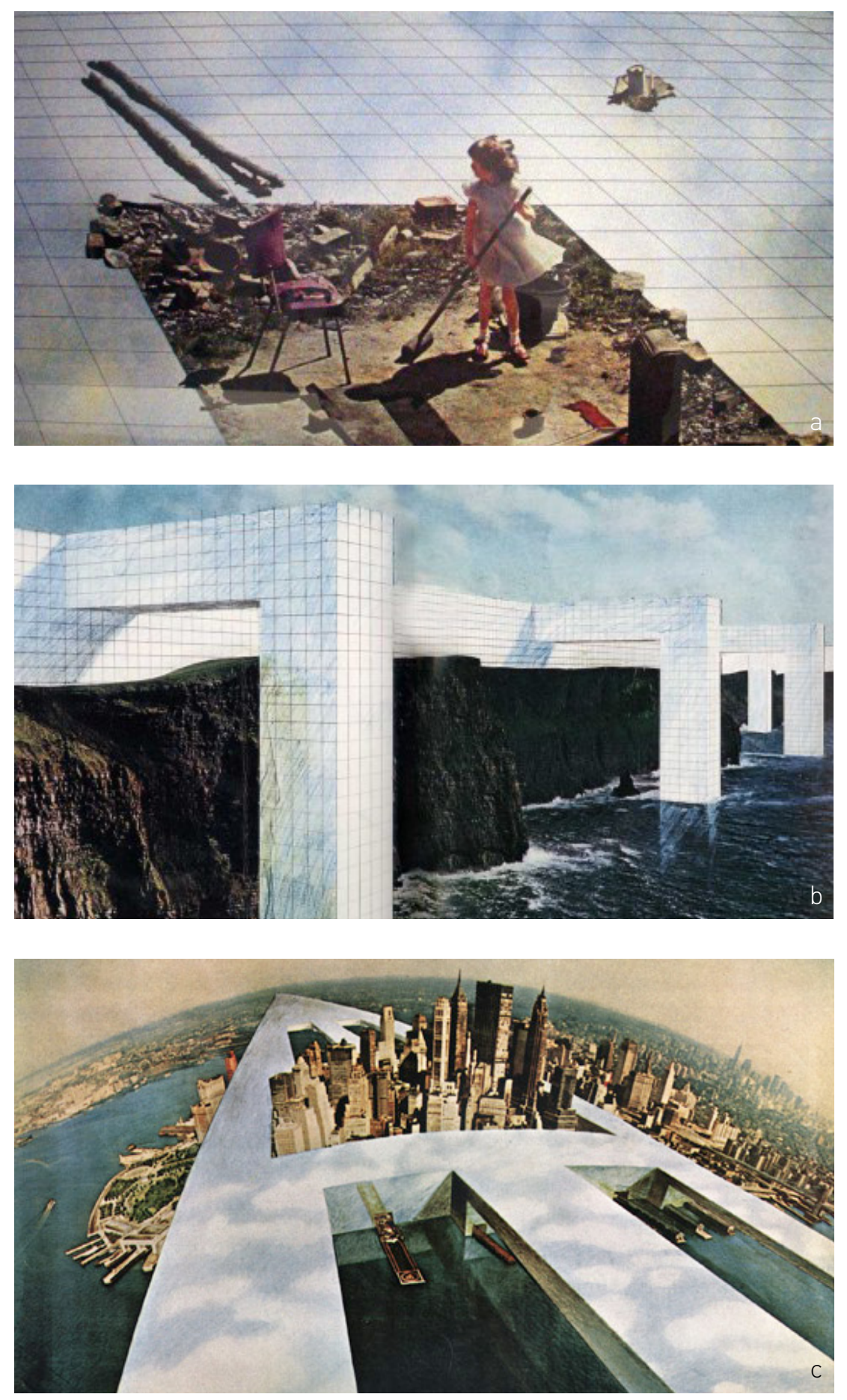

Fig. 5

Continuous Monument by Superstudio, 1969 


\subsubsection{Drawing in the $20^{\text {th }}$ Century}

As with the $15^{\text {th }}$ century, the $20^{\text {th }}$ century also brought forth a new theoretical and scientific approach to architecture, as well as the development of a more technologically advanced design approach. Hugh Ferris, an architect of the early $20^{\text {th }}$ century, became well known for his drawings and delineation of utopian realities. He expressed a new sense of place within an urban vision. Through his drawings and use of carbon pencil to create exaggerated forms, Ferris was able to produce an architectural vision through his drawing. With his focus on skyscraper designs, he anticipated future trends, and proposed a vision of an urban utopia. He became an established architect, serving as a delineator and design consultant. As stated by Carol Willis in "Ferris, Hugh": "Although he was a licensed architect, Ferris elected to 'build' only on paper. Yet like other great architectural delineators he created a compelling and influential two-dimensional reality." 12

In the mid $20^{\text {th }}$ century, a new form of radical architecture emerged; one that concentrated on critically formulated projects that did not culminate in buildings. Superstudio, a group of architects, developed architectural renderings of extreme settings and dreamlike environments. They wanted to showcase architectural ideas through philosophical and theoretical activities that would provoke a new sense of consciousness. ${ }^{13}$

Similar to Superstudio, Archizoom also experimented with radical architecture by looking at consumerism and modernism in 1960. No Stop City was amongst Archizoom's most significant projects. It conveyed an image of an idealistic and fictional world where humans live as campers, combining natural features with artificial settings. Their method of conveying ideas was through drawings and mediums specifically chosen for their ability to express their conception of this utopian world. ${ }^{14}$ 


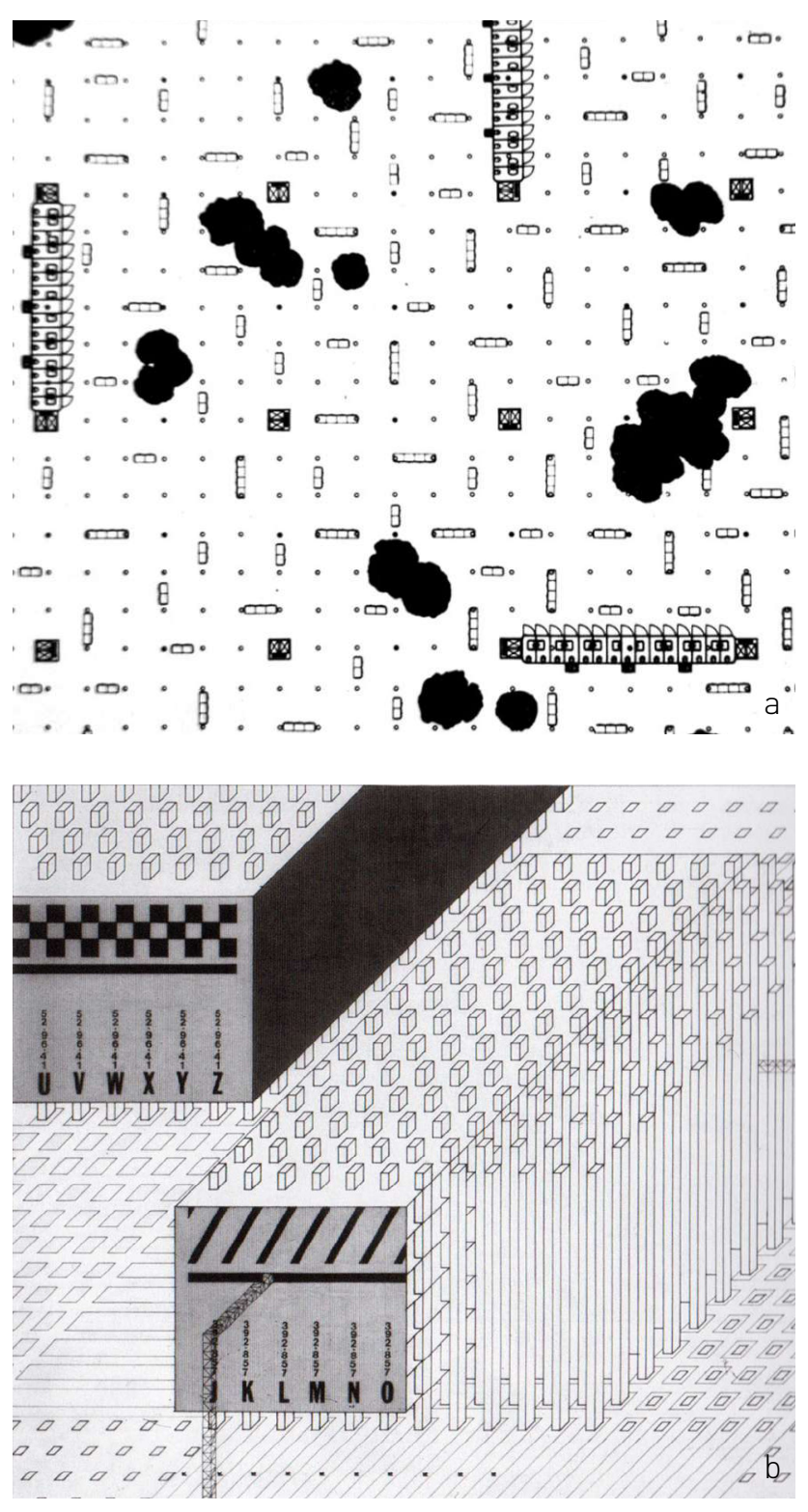

Fig. 6

No Stop City by Archizoom, 1969 


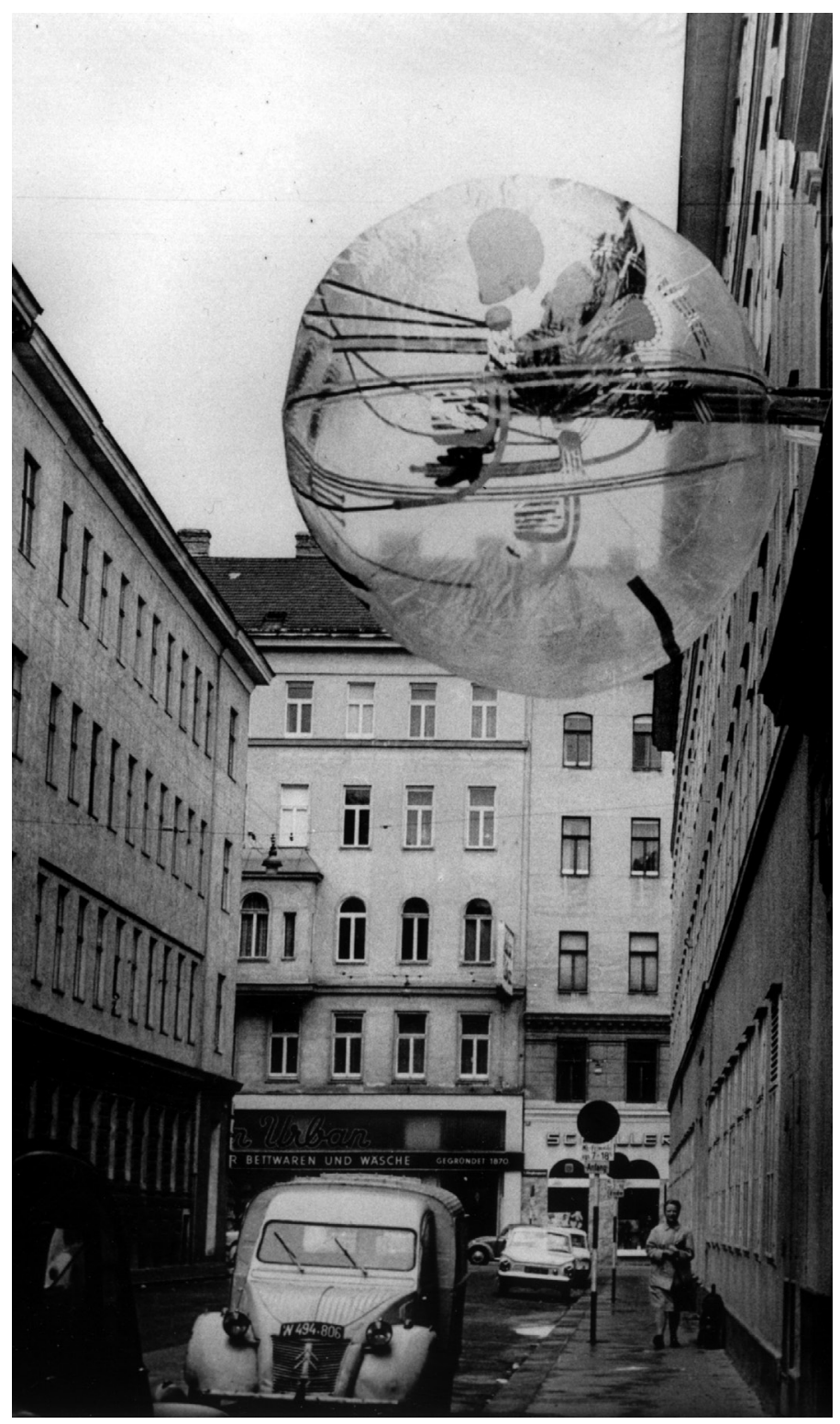

Fig. 7

Balloon for Two by Haus-Rucker-Co, 1967 
Haus-Rucker-Co was another such group, which, gained popularity when they set out to develop a new concept of architecture'15 in the 1970's. The aim behind Haus-Rucker-Co's work was to establish interactive exhibitions and visionary architectural ideas. From 1967-1977 their main focus was the theme 'Architectural Utopia Reloaded.' Over this period they produced a number of successful pieces that gained popularity and public attention, including Balloon for Two, Oasis \#7, and Environment Transformed Vienna. ${ }^{16}$

In the 1960s and 1970s the term 'paper architecture' entered the lexicon. The term refers to architectural ideas that were experimental and designed as a form of inquiry and theory rather than as drawings intended to be finalized in the form of a built structure. Paper architecture played an important role in establishing a new formal architectural approach in the mid to late $20^{\text {th }}$ century. By exploring issues concerning utopia, radicalization, the monumental, and Pop art, the depictions of paper architecture aimed to define a new postmodern practice and evaluation of architecture.

\subsubsection{Drawing the Visually Seen}

Amongst the most common drawing types is the act of drawing what can be visually seen. When one draws what one sees, emphasis is placed on visual perception, and in order to draw what one sees, one must first get a good understanding of the setting they are in. A part of visual perception is the ability to interpret the environment by processing the information contained in visible light. ${ }^{17}$ Drawing what is seen gives the artist a unique understanding and appreciation of their surroundings. When one draws a subject, one engraves a better mental image of the physical space in one's mind, due to the amount of attention that must be given to the smallest details while drawing. The act of drawing therefore gives the artist a different form of awareness of the object than the act of merely looking does. Through the act of drawing what can visually be seen, fine detail of the subject matter is given more attention. A place or an event may also be 
captured through photos, but neither the drawing nor the photo will bring back that exact past moment or spatial experience again. They are both means of depiction that capture a portion of the whole.

An object can never be represented, as visually seen, in all of its totality. There is a distance between the object and how it is represented. In other words, a representation or a depiction of an object can never be the object itself. Therefore a representation will showcase an object or information about an object in different forms. As Casey argues in Representing Place, "In the most general sense, 'representation' signifies a circumstance in which one thing is a surrogate for something else. The first item substitutes for the second and is therefore its proxy, its 'representative'." 18 Representing something derives from creative expression and the need to communicate thoughts. As David Scheer observes in The Death of Drawing:

By exploring the ambiguity of representation we discover ways of representing aspects of our experience we have not been able to express before. That these representations are themselves often obscure and ambiguous is a token of the inability of any representation to fully describe our experience. ${ }^{19}$

In Figure 8, a collection of drawings were developed that showcase the method of drawing the visually seen. The drawings explore not just simply the representations of varying subject matters and differently shaped objects. They also represent methods of drawing. These methods include blind contour drawings, shaded drawings, and depth of perception drawings. Each method allows the pencil to encounter the surface of the paper differently, depending on the intent or purpose of the drawing, whether it is to look directly at the subject matter alone, or to study the effects of light on the object, or to represent the object's proximity to the artist. Each of these types of drawing presents a form of drawing the visually seen, and each communicates a different understanding of the subject matter according to how it is perceived. 


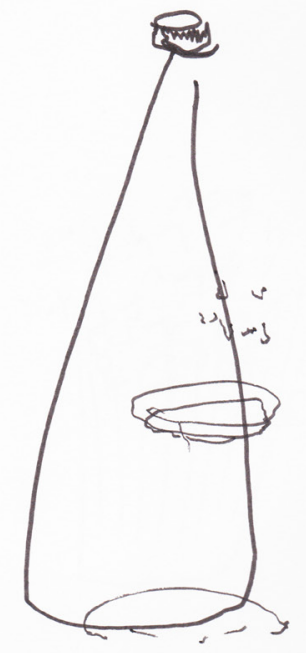

a
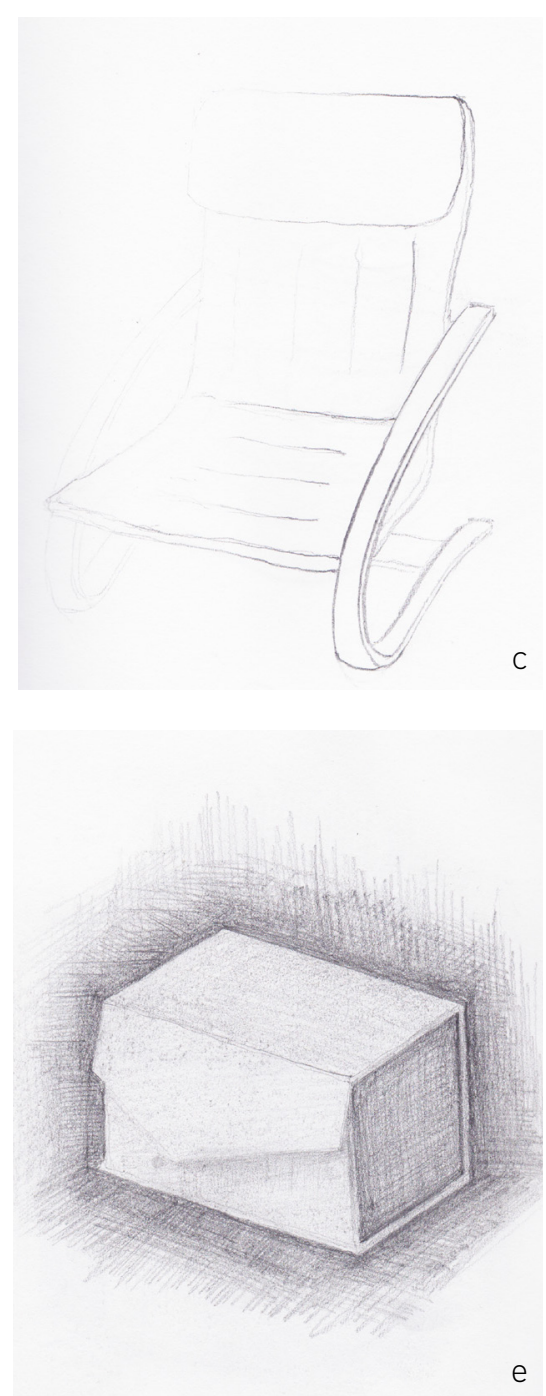

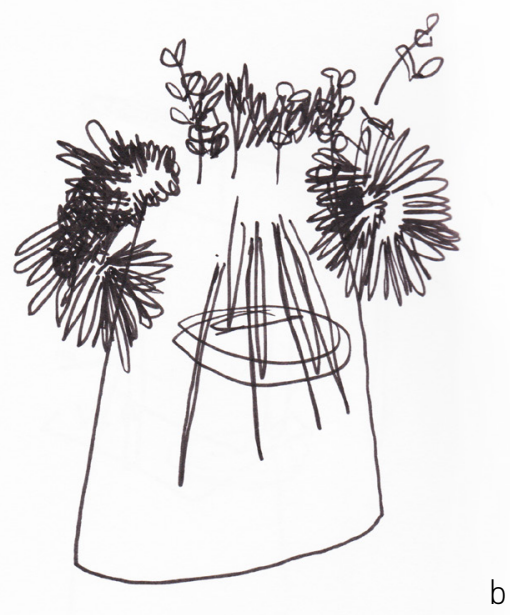

d

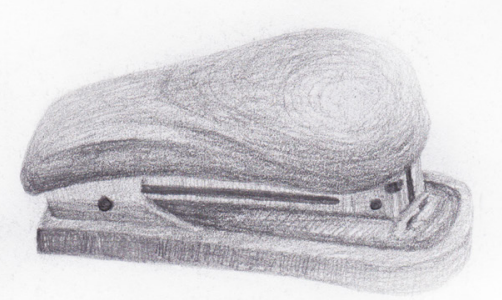

f

Fig. 8

Drawing the Visually Seen 

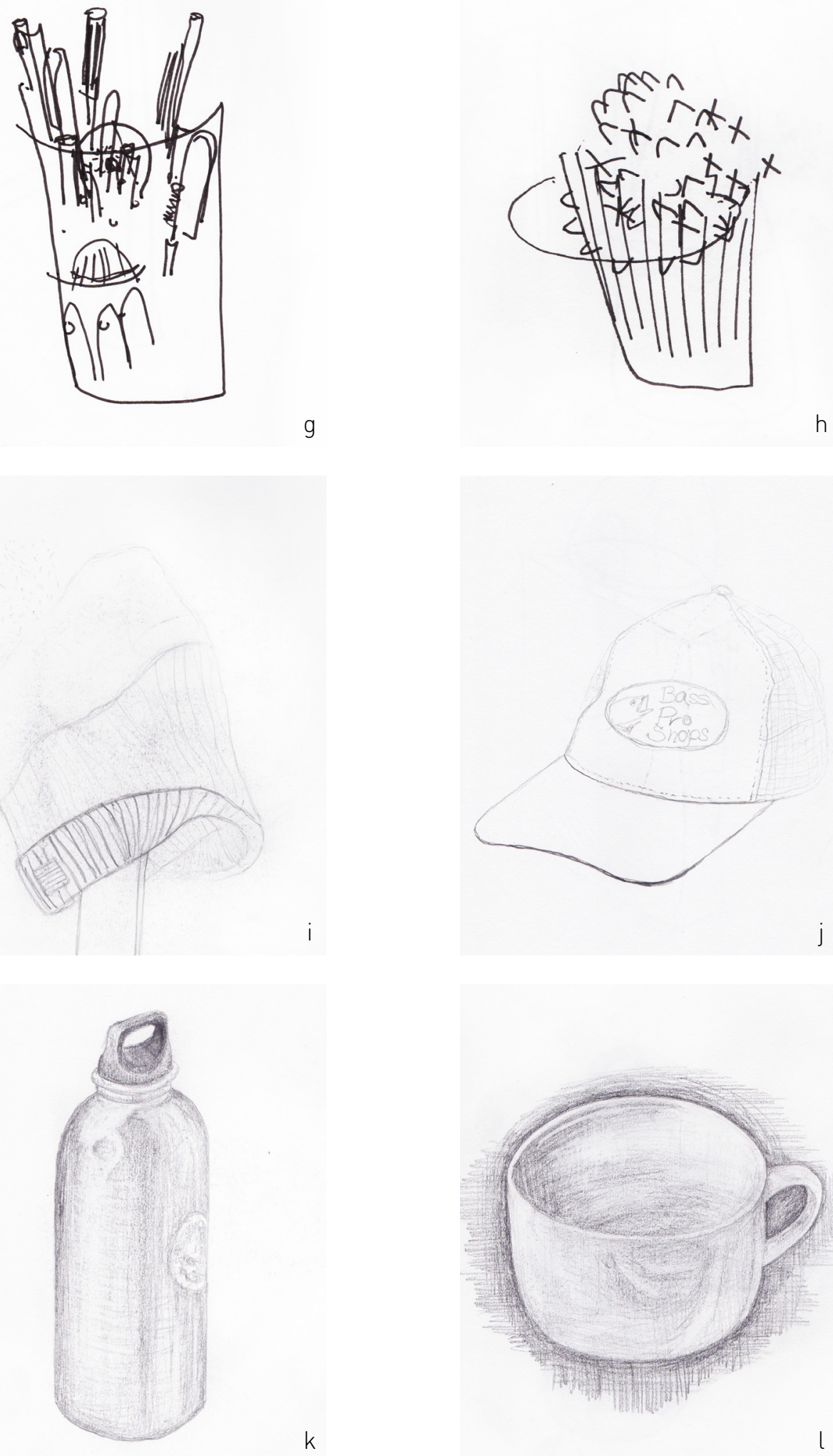

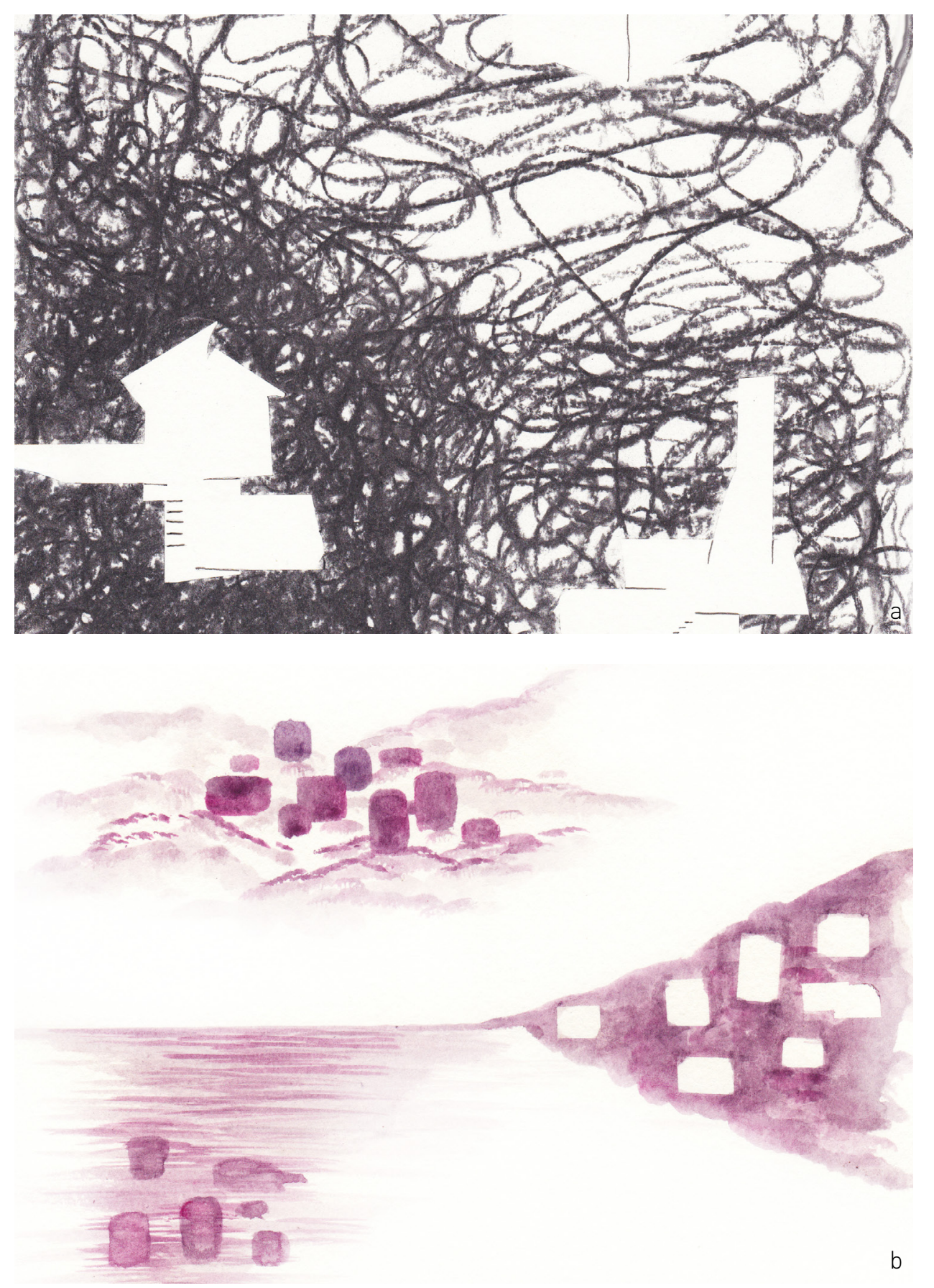

Fig. 9

Drawing the Imagined 


\subsubsection{Drawing the Imagined}

Within architectural discourse, drawing has become an influential design thinking method, a form of design that is not restricted to building design or construction. This opens up the discussion to understandings of architectural drawing as not merely a medium of communication, but a form of thinking as well. The process of drawing the imagined is derived from our need to express our thoughts and ideas in physical form. There are many methods of communicating a creative thought process, such as through speech or written text, but drawing is an important means of laying out an idea that crosses the mind. It acts as a means of giving physical form to passing, intangible thoughts. As fluid and changing entities, architectural ideas are given form in drawing. In the preliminary stages of design the act of drawing enhances the process because it captures thought. The following narrative, taken from Why Architects Still Draw, captures this nicely:

The place was empty. I suddenly remembered something, so I took my notebook out of my pocket, because I knew very well, after many years spent writing, a story can suddenly come to you, and if you don't have the tool to catch it, at least sketch it, it might go away as easily as it came. ${ }^{20}$

Drawings that represent architectural designs are considered architectural drawings, or, drawings that exist in relation to an architectural idea. Prior to the drawing process, mental images are but obscure visions presented abstractly in our minds as ideas. Drawing the imagined is a process that strives to depict ideas that are constructed by the imagination rather than the eye. Designers are driven to express their ideas through visual means such as line, shading, and colour rather than through text. The process of drawing is consistently developing and trying to catch up with the rapidly shifting creative process of the mind; drawing is not a linear process that can be followed through and guided in step-by-step increments. It is a process that begins with rough sketches and initial trials that attempt to present a thought. Drawing is a process that must continue to produce successive ideas in physical form in order to reach a more satisfactory and mature final result. As Scheer writes, "[t]he roughest sketch collapses the practically infinite possibilities suggested by a mental 
image into a restricted range defined by the general shape of the sketch." ${ }^{21}$ Every stage of the drawing process is as important as the final finished product. The designer must draw in repeated attempts, until a more refined depiction of an idea is formulated. Through this exploratory mode of production, the results of each drawing stage are important to the next. As the drawings accumulate, it becomes a trial and error procedure through which the designer finds the best depiction of a given idea.

Drawing is therefore not just a tool for the communication of architectural ideas. It is a pedagogical practice, one from which the designer can learn and study. Drawing is a form of activity that produces a body of knowledge about architecture and a type of expression that is individualized according to each designer. How one might draw or depict architectural ideas in physical form depends to a large extent on the individual's own thought process as well as whatever external factors have influenced their individual intellectual and imaginative landscape. Drawing can be described as a method of presenting diachronic experiences (changing over time) in synchronic delineations (present at a point in time) in order to give architecture its forms. ${ }^{22}$ Drawing activates an authentic connection between the brain and the hand, allowing the latter to be used as a tool of expression. Through drawing, the potential for unique creations is nearly infinite, given the array of opportunities for inscribing images through varying mediums.

\subsection{Methods, Mediums, and Techniques}

Architectural depictions are a form of design expression that comes in varying mediums, methods and techniques. The significance that depictions hold within an architectural process depends on the form of depiction. Depictions can take a variety of forms, the choice of which influences methods of design and expression. With today's 

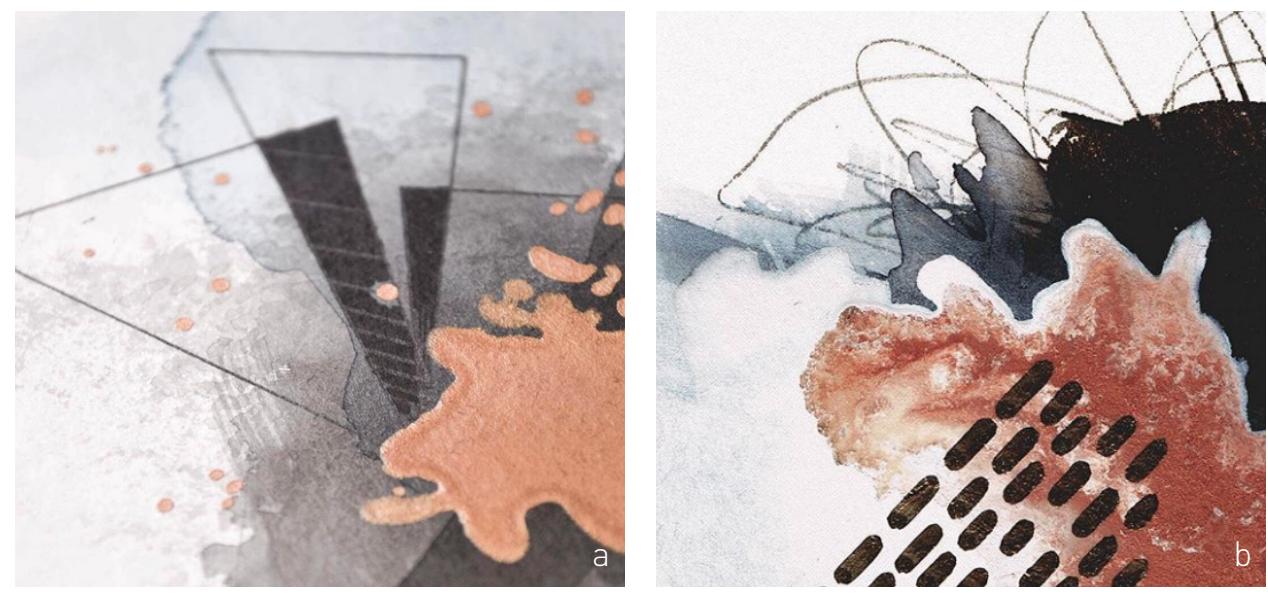

Fig. 10

Watercolour and Ink drawings by Eloise Bound, 2017

technological advancements, the methods and mediums of depiction are constantly evolving and proliferating. Architecture lies in the process of creating and experimenting with different artistic mediums to express concepts and ideas. The architectural design process is formulated through the use of speculative and unrestrictive design approaches which make use of the mediums that are best suited to inscribe a given thought process. The designer aims to choose the best among the available, tangible tools in order to capture and express the immediacy of thought and the intangible architectural ideas contained therein.

The architectural design process does not end at drawing. It advances through additional stages and modes of expression. Painting, sculpting, and digital media are examples of other mediums of depiction within architectural discourse. In addition to pushing the design process further these mediums allow greater space for experimenting with different concepts. Depictions are not limited to specific forms, mediums, or techniques. They are always changing, alternating, and advancing forward according to the discipline's trends. 


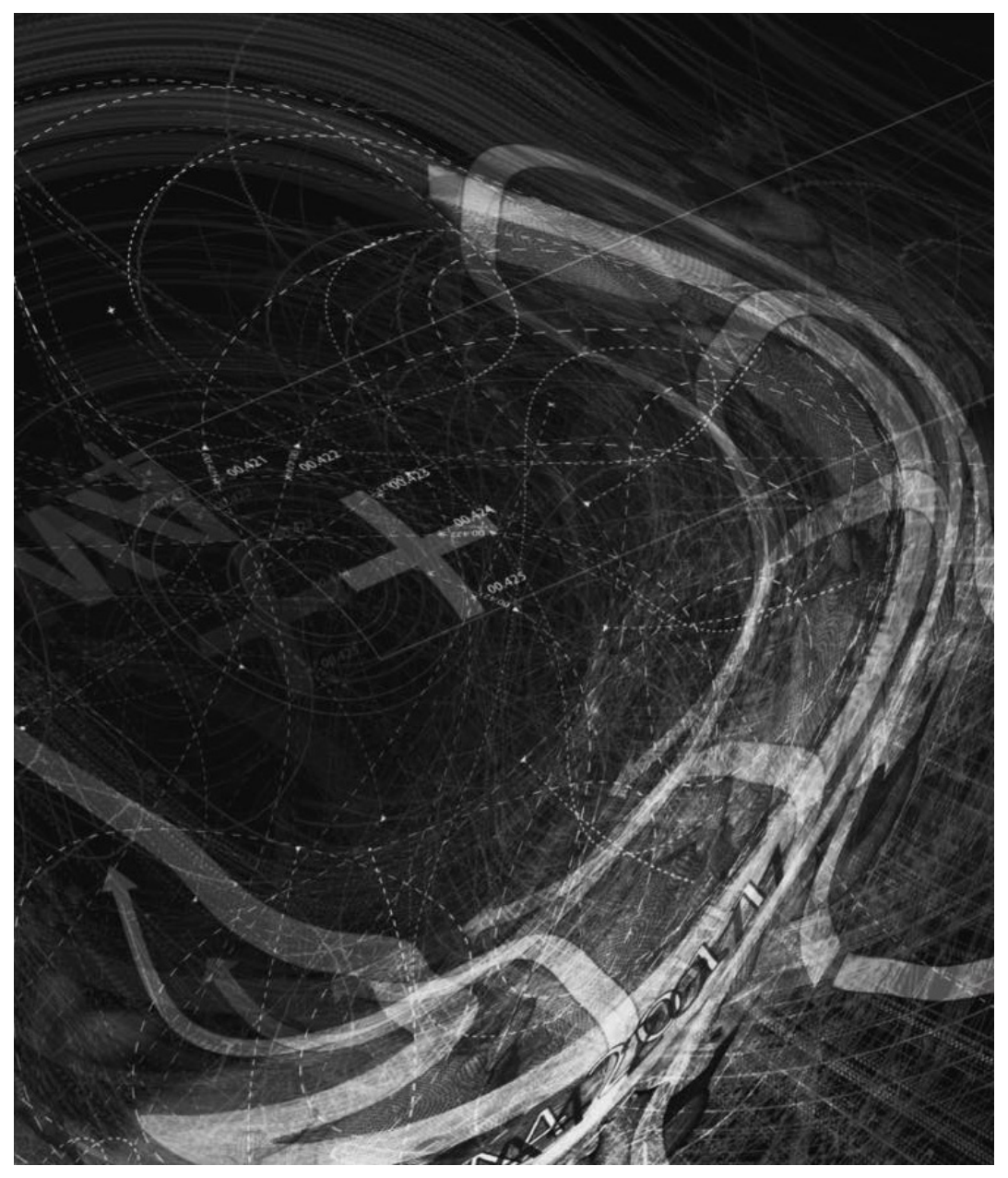

Fig. 11

Portal Shifting by Bryan Cantley, 2016 


\subsection{Depictions in the Digital Age}

Depictions in architecture have come to be present in many forms and methods of expression today; they are not limited to one particular type of media, technique, or tool. Depictions are constructed with any utensil or tool an architect or designer can use to express thoughts visually and to conceptually experiment with ideas. As Alberto Pérez-Gómez and Angeliki Sioli argue, "[e]very tool at our disposal should be used towards a meaningful architecture." ${ }^{23}$ Modes of expression are expanding beyond the traditional hand drawing; they are extending to computer programs, digital media, and other technologies and methods that are on the rise. ${ }^{24}$ With each new method of depiction, a new innovative tool is introduced to architectural design and a new way of communicating ideas emerges. While it is important to experiment with alternative methods of depiction, one must realize the value that every original and new method holds within a design process. With today's rapid expansion in the digital realm, it is important to maintain an appreciation of the value of manual techniques of depiction, as a foundational and a well-established technique.

Digital tools are not tools that replace manual methods. They are new technological innovations that are used as alternative methods of design. Digital tools develop ideas through technological software rather than through the hand forming depictions directly. The role that digital tools have played in influencing architectural design within the past few decades is undeniable. It has impacted the ways that architecture is visualized, the ways that ideas and projects are represented, and the ways that designs are built. ${ }^{25}$ Digital design tools have eased production and advanced drawing in the direction of more precise outcomes, making it easier to approach design ideas as practical formulations. As Pérez-Gómez and Sioli observe, "[e]xploring the way the majority of architects use the software shows that for them it is basically a drafting method more efficient and more productive than the hand-drawn orthographical drawings that have been the norm in architecture." 26 
Notwithstanding all of the advantages and possibilities digital design software programs bring to architecture, it is important to note that more exploratory uses of this technology are comparatively lacking. The accessibility of digital design platforms have encouraged designers to use them more as drafting tools. However, digital tools and computer programs that are viable for use in experimental and investigative manners do exist. ${ }^{27}$ These same tools could be widely deployed in the service of the production of experimental and speculative architectural forms. Designs have become more driven by the capabilities of digital programs and how these programs formulate a technical understanding of the design problem.

Over the last decades, this strikingly powerful tool has captured all our attention, making us think less critically as we engage less and less with the physical world around us (trusting solely Google Earth for all the information we need to know a placel and in fact allowing the imagination to intervene less and less in the design process. ${ }^{28}$

This thesis argues for greater use of these digital methods of depiction to be made, in ways that are more critically and experimentally generated. It argues that the act of depiction itself is generative of architectural forms. It is important to maintain the conventional use of digital design, while at the same time mobilizing it within a more theoretical and poetic form of architectural production. "Digital or not, the architect must be able to decide which media to use and how, taking advantage of what they can offer and acknowledging at the same time their inherent limitations." 29 
Notes

1 Edward Warder Rannells, "The Study Of Architecture As Art", College Art Journal 8, no. 3, (1949), 204.

2 Iman Ansary, "Eisenman's Evolution: Architecture, Syntax, And New Subjectivity”, Archdaily, 2013, http://www.archdaily.com/429925/eisenman-s-evolution-architecture-syntax-and-new-subjectivity.

3 “Drawing - Definition of Drawing In English | Oxford Dictionaries", Oxford Dictionaries | English, 2017, https://en.oxforddictionaries.com/definition/drawing.

4 "The Definition of Drawing", Dictionary.Com, 2017, http://www.dictionary.com/browse/drawing.

5 Alberto Pérez-Gómez and Angeliki Sioli, “Drawing With/In And Drawing Out : A Redefinition Of Architectural Drawing Through Edward S. Casey's Meditations On Mapping", in Exploring The Work Of Edward S. Casey : Giving Voice To Place, Memory, And Imagination, 1st ed. (Bloomsbury Publishing PLC, 2013), 153.

$6 \quad$ Ibid., 157

7 Ibid., 159

8 Ludwig H. Heydenreich, "Architecture In Italy, 1400-1500". (New Haven: Yale University Press, 1996), 14.

9 Ibid

10 Ibid.

11 Ibid., 149

12 Carol Willis, "Ferriss, Hugh", 2012, http://www.oxfordartonline.com.ezproxy.lib.ryerson.ca/subscriber/ article/grove/art/T028059

13 Stephen Wallis, "A 60S Architecture Collective That Made History (But No Buildings)", Design \& Interiors, 2016, http://www.nytimes.com/2016/04/04/t-magazine/design/superstudio-design-architecturegroup-italy.html?_r=0.

14 AJ Artemel, "Retrospective: Archizoom And No-Stop City", 2013, http://architizer.com/blog/archizoomretrospective/.

15 "Haus-Rucker-Co: Architectural Utopia Reloaded", Archdaily, 2014, http://www.archdaily.com/582842/haus-rucker-co-architectural-utopia-reloaded.

16 Jochen Stöckmann, "Top-Drawer Time Bombs", 2014, https:/www.stylepark.com/en/news/top-drawertime-bombs.

17 Advanced Vision, "Visual Perceptual Processing Impacts The Ability To Learn.", Advancedvisiontherapy center.Com, 2017, http://www.advancedvisiontherapycenter.com/services/assessments/binocu lar vision assessment/visual perception/.

18 Edward S Casey, "Representing Place", 1st ed. (Minneapolis: University of Minnesota Press, 2002), 16.

19 David Scheer, "The Death Of Drawing: Architecture In The Age Of Simulation".

(London, United Kingdom: Routledge, 2014), 24

20 Paolo Belardi, "Why Architects Still Draw: Two Lectures On Architectural Drawing" trans. Zachary Nowak. (Cambridge, MA, United States: MIT Press, 2014). 26.

21 Sheer, 53.

22 Ibid., 58.

23 Pérez-Gómez, Sioli, 160

24 Neil Spiller, ed. “Drawing Architecture”, Architectural Design 83, no. 5, (2013), 30.

25 Pérez-Gómez, Sioli, 153

26 Ibid., 154.

27 Ibid., 159.

28 Ibid.

29 Ibid. 


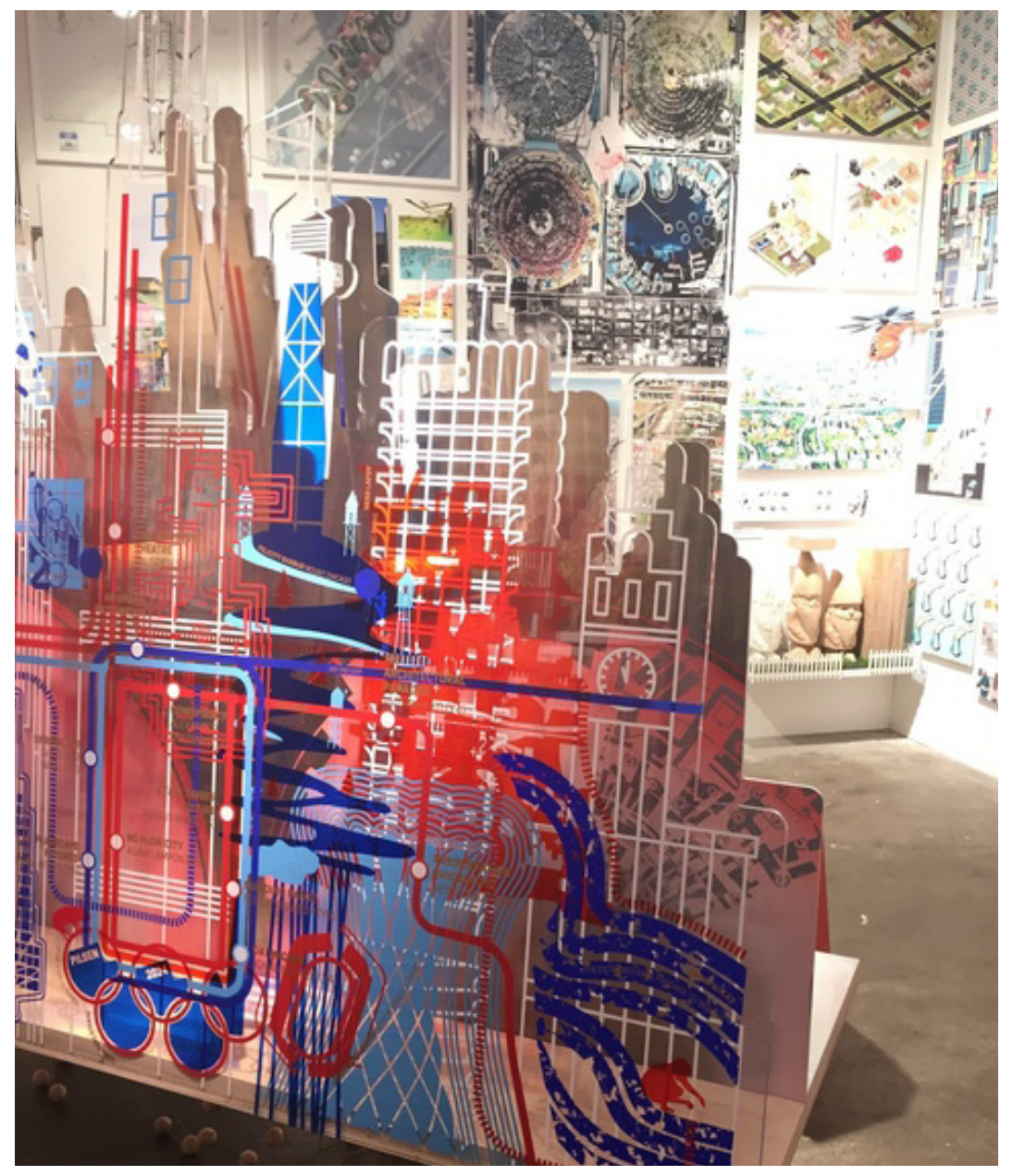

Fig. 12

Incubator by Smout Allen at Bartlett School of Architecture, 2016 


\section{3 | Experimental Design}

\subsection{Speculative Depiction}

Depictions have the potential to be significant forms of production that yield new forms and figures in a given architectural design process. Among the possible applications of depiction is speculation. Speculative depiction is a design approach that generates depiction as architecture. They are a type of architectural work that is generated through experimental modes of design. To speculate is to approach an idea from an analytical and critical perspective. As stated by Anthony Dunne \& Fiona Raby in Speculative Everything, "[t]his form of design thrives on imagination and aims to open up new perspectives on what are sometimes called wicked problems, to create spaces for discussion and debate about alternative ways of being, and to inspire and encourage people's imaginations to flow freely." "Speculating through alternative forms of depiction yields a continuous learning process in which each work informs the next. Architectural forms are generated through this experimental design process and are conceived slowly through each step of the process. In this approach, depictions are not mere representations of simple ideas, nor are they secondary productions within the architectural design process. Rather, architecture is given form through each depiction. Depictions of a speculative nature generate a different approach within design by challenging standard methods of architectural production in the profession. Speculative depictions are non-standard modes of production whose significance lies in the act of exploring and expanding topics that are otherwise not frequently discussed or expressed. The significance of this kind of depiction is not found in its ability to resolve design decisions or technical issues, where the ultimate aim is to construct a building. Instead, their significance lies in the exploration of ideas that may or may not end in built form. Speculation depicts things for the purpose of analyzing and examining ideas. The intention of speculation is to express architectural ideas in varying forms in order to raise a critical discussion and topics for analysis. This more theoretically driven 

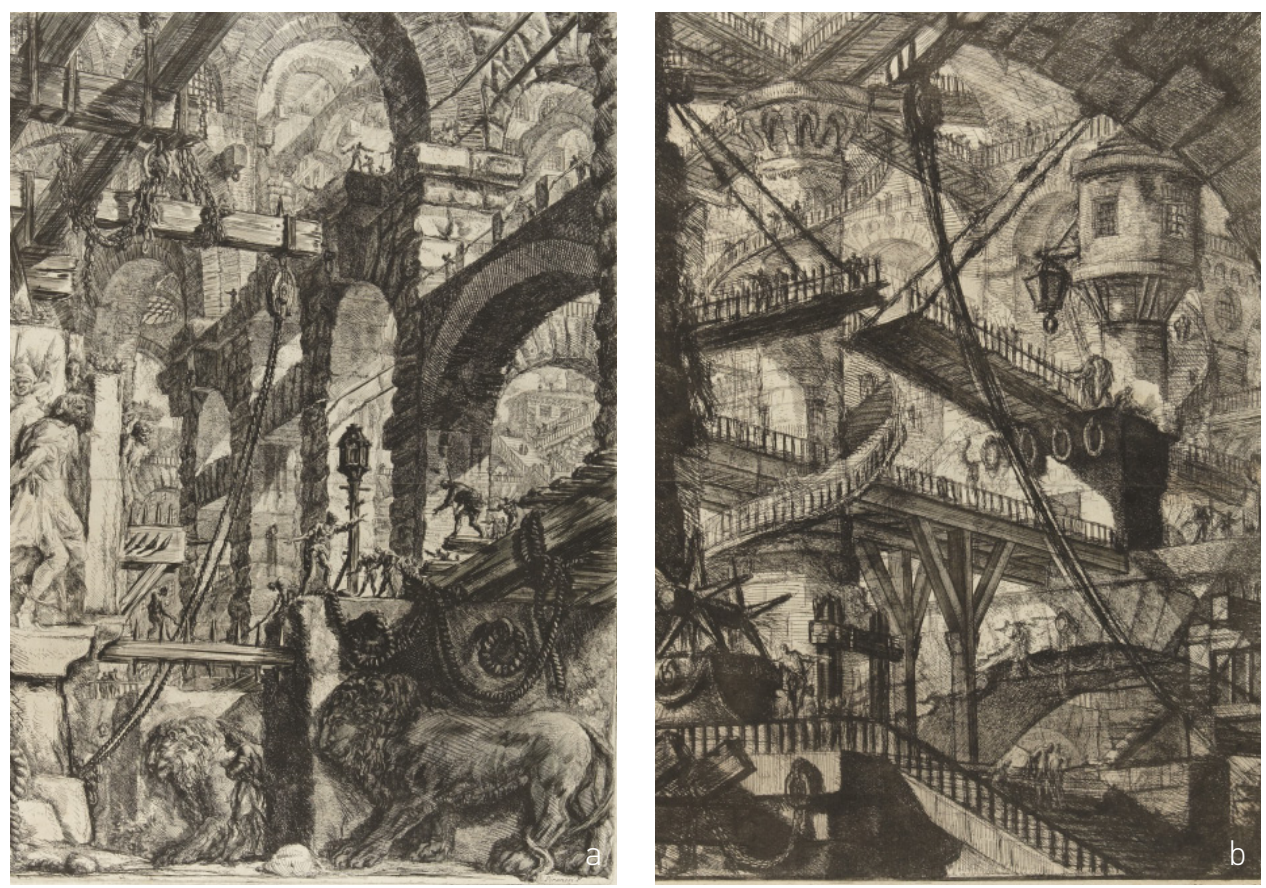

Fig. 13

Imaginary Prisons by Giovanni Battista Piranesi, 1750

design process does not have to be validated through a building, since each drawing or depiction holds its own significance within the design process. Depictions are in and of themselves architecture that can be both a product that informs a subsequent stage of design, or an end in itself. As Will Hunter explains, in the AR journal,

does that mean that every idea has to be built to be validated? Not at all. The richness of ideas presented here, the value of describing radical visions of the future, of speculating about an architecture that may never exist, and pursuing notions that may go nowhere at all: these are an essential part of architecture as a risk-taking discipline. It is these endeavors that keep the culture of architecture alive, and ultimately push built reality to greater heights. ${ }^{2}$

Speculative architecture through depiction can be traced back to at least the mid $-18^{\text {th }}$ century in the work of Giovanni Battista Piranesi.

Piranesi produced unique architectural drawings, which he had no intention of ever building. In these depictions he created fictional 


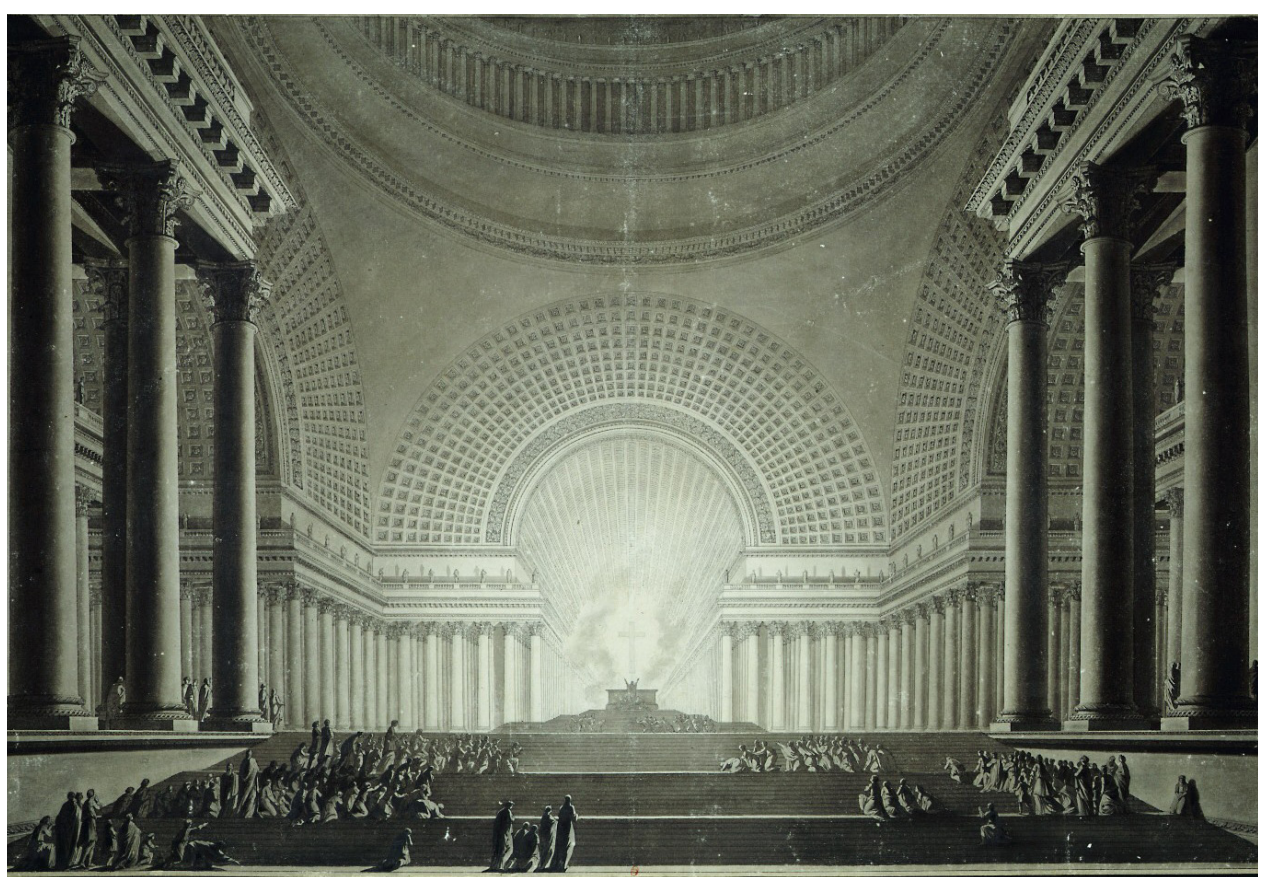

Fig. 14

Metropolitan Basilica by Étienne-Louis Boullée, 1778-1788

settings through the manipulation of scale and architectural space. Amongst his most successful collections is Imaginary Prisons from 1750, a series of drawings that visually communicated places of nonexistence and created architecture of fantasy. ${ }^{3}$ Piranesi's theoretical design approach played an important role in the establishment of speculative architecture and influenced many architects and movements that came after him.

Amongst the architects that were influenced by Piranesi's work is Étienne-Louis Boullée. Boullée was an architect who also brought a unique approach to speculative architecture in the late $18^{\text {th }}$ century. His work challenged standard architectural forms by mimicking natural forms through his architecture. His depictions presented imaginative settings and forms at unbuildable scales. Amongst his best-known projects was the Cenotaph to Newton of 1784, a large spherical form that mimicked the Nature of the Great Divine through its massive scale and perfected form. ${ }^{4}$ 

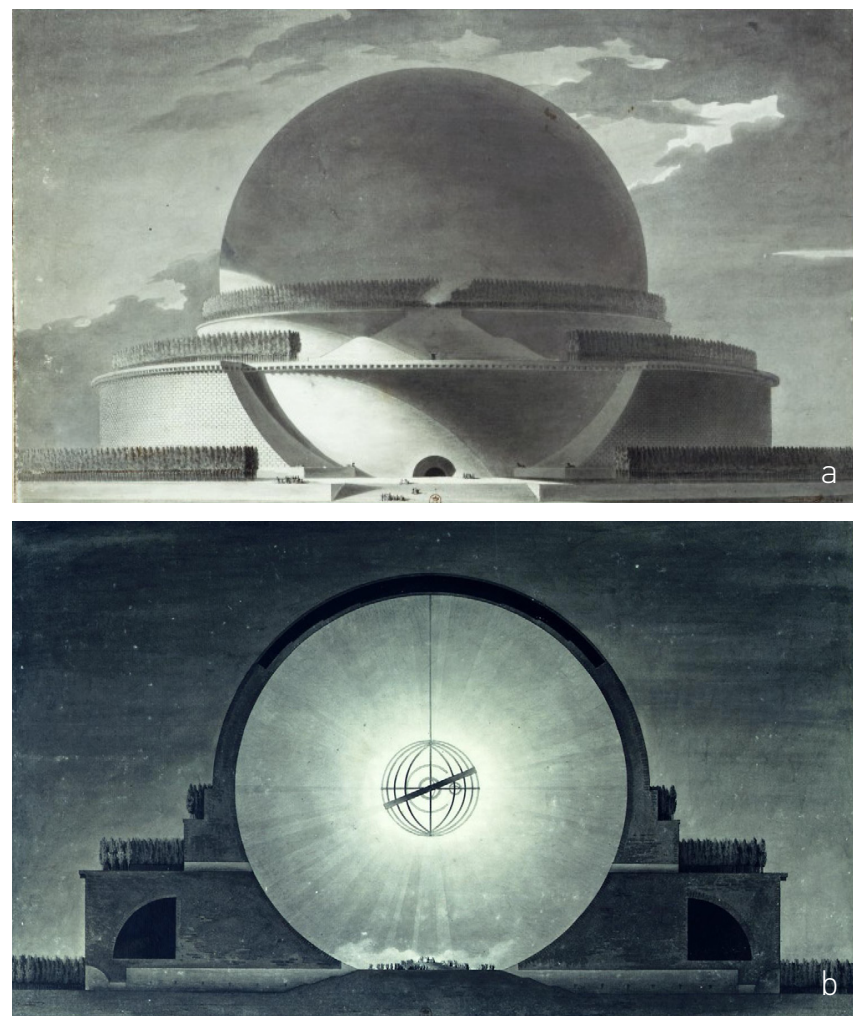

Fig. 15

Cenotaph to Newton by Étienne-Louis Boullée, 1784

\subsection{Imagination}

Imagination is the capacity to form new ideas, images, or concepts of external objects that are not immediately present to the senses. ${ }^{5}$ Imagination is a state that builds on experience, factual evidence, perception, but also has purely fictional aspects. It can be categorized in a number of ways, each describing a state of imagination. These include: spontaneousness, controlledness, self-containedness, self-evidence, indeterminacy and pure possibility. ${ }^{6}$

Given the term's varied interpretations, it is useful to divide the concept of imagination into an act phase and an object phase. ${ }^{7}$ The former phase of imagination can be understood as an activity that is 
mentally perceived but remains abstract, whereas the latter refers to the product or outcome, produced in the physical realm. In other words, the object phase of imagination is the outcome or process of making thoughts and ideas tangible using tools of depiction. Through this duality of its meanings, imagination can be understood to take on various shapes and forms.

Imagination is a complex process that drives architectural thinking forward. It is a primary agent in any form of architectural design. Pushing limits and boundaries with its capabilities, it allows for the exploration of alternative scenarios through experimentation. Drawing and other forms of depictive techniques allow for the translation of the imagination through their architectural productions, in the use of a range of mediums and methods to communicate abstract thought. Through these speculative procedures, depiction affords the opportunity to make architectural forms real by constructing them from the basis of imagination. Anthony Dunne and Fiona Raby explain that the "believable series of events that led to the new situation is necessary, even if entirely fictional. This allows viewers to relate the scenario to their own world and to use it as an aid for critical reflection. This is the space of speculative culture-writing, cinema, science fiction, social fiction, and so on." ${ }^{8}$ Depictions make possible architectural forms and scenarios that raise critical discussions and rigorous insights into social, economical, and political issues. Because they are not mere reflections or representations of a possible future, these depictions allow for opportunities for discussion, debate, and learning, toward the aim of collectively defining and shaping the built world in order to be able to define preferable futures. ${ }^{9}$

Experimentally driven depictions are capable of expressing architectural ideas more freely and translating the imagination into tangible forms. "Design can give experts permission to let their imaginations flow freely, give material expression to the insights generated, ground these imaginings in everyday situations, and provide platforms for further collaborative speculation." 10 The aim behind this form of production is to drive new and different possibilities for de- 

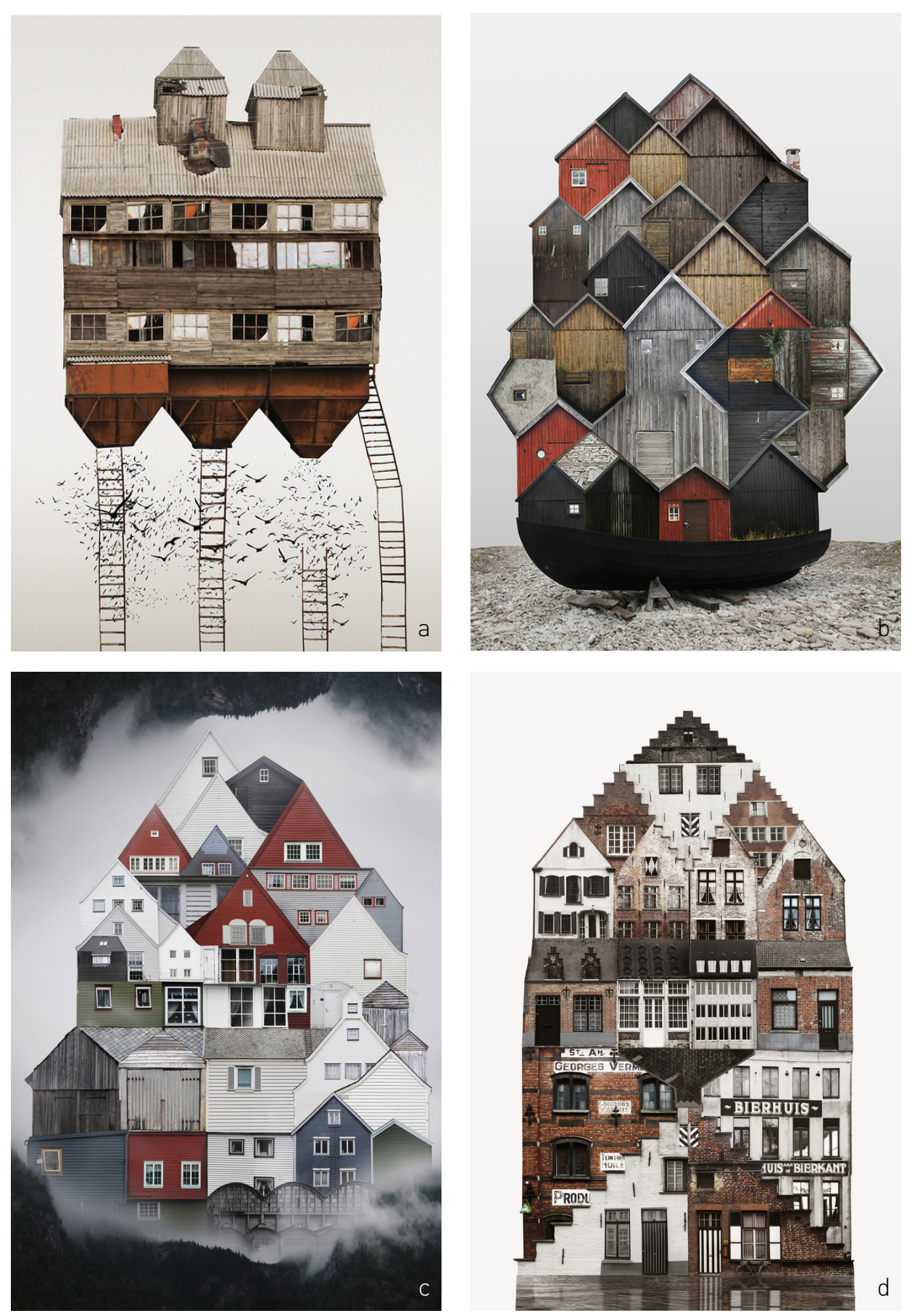

Fig. 16

Genius Loci by Anastasia Savinova , 2016 
sign, to experiment freely with ideas, regardless of their level of practicality, and to explore as yet unexplored territories. Experimentally driven depictions are fueled by imagination, by a state of mind that is restless and pushes design research to greater depths. This is a form of design that allows itself to speculate about alternative settings and architectural forms, unhinged from the necessity of making something better. The objective is to learn from, and to inform architectural thinking.

The imagination is capable of formulating the most exceptional forms and settings. But it is not until these forms and settings are communicated through depiction that they can be perceived by other people. The vast realm of the imagination is driven by ideas that are constantly shifting, influenced by direct and indirect factors within the design process. As noted by Paolo Belardi in Why Architects Still Draw, "[i]deas arise from fortuitous circumstances... from observations that are outside of their specific field... at any moment... [they arise from] oversight... from habit... from dreams... Ideas are in the air, viral elements ready to be assimilated by the most sensitive souls." 11 Alternating thoughts constitute the imagination, through influences from past events, or the act of reading a piece of text, or in recalling clustered pieces of dreams, for example. Similarly alternating ideas are generated through a continuous speculative design process. Each piece of the process communicates a portion of the whole, serving a greater collective idea and communicating alternative and imaginative possibilities through it.

In the text Marco Frascari's Dream House: A Theory of Imagination. Marco Frascari discusses the importance and significance of dreaming in architecture. To dream in architecture, he argues, is to "make visible the invisible within the constructed world,"12 and this is only made real through the drawings. "Architectural dreams are expressed in drawings... These drawings become magic tools. They translate dreams into a constructed world." ${ }^{13}$ Dreaming in architecture introduces the potential of alternative possibilities, making them exist through drawings. Best stated in his quote, 

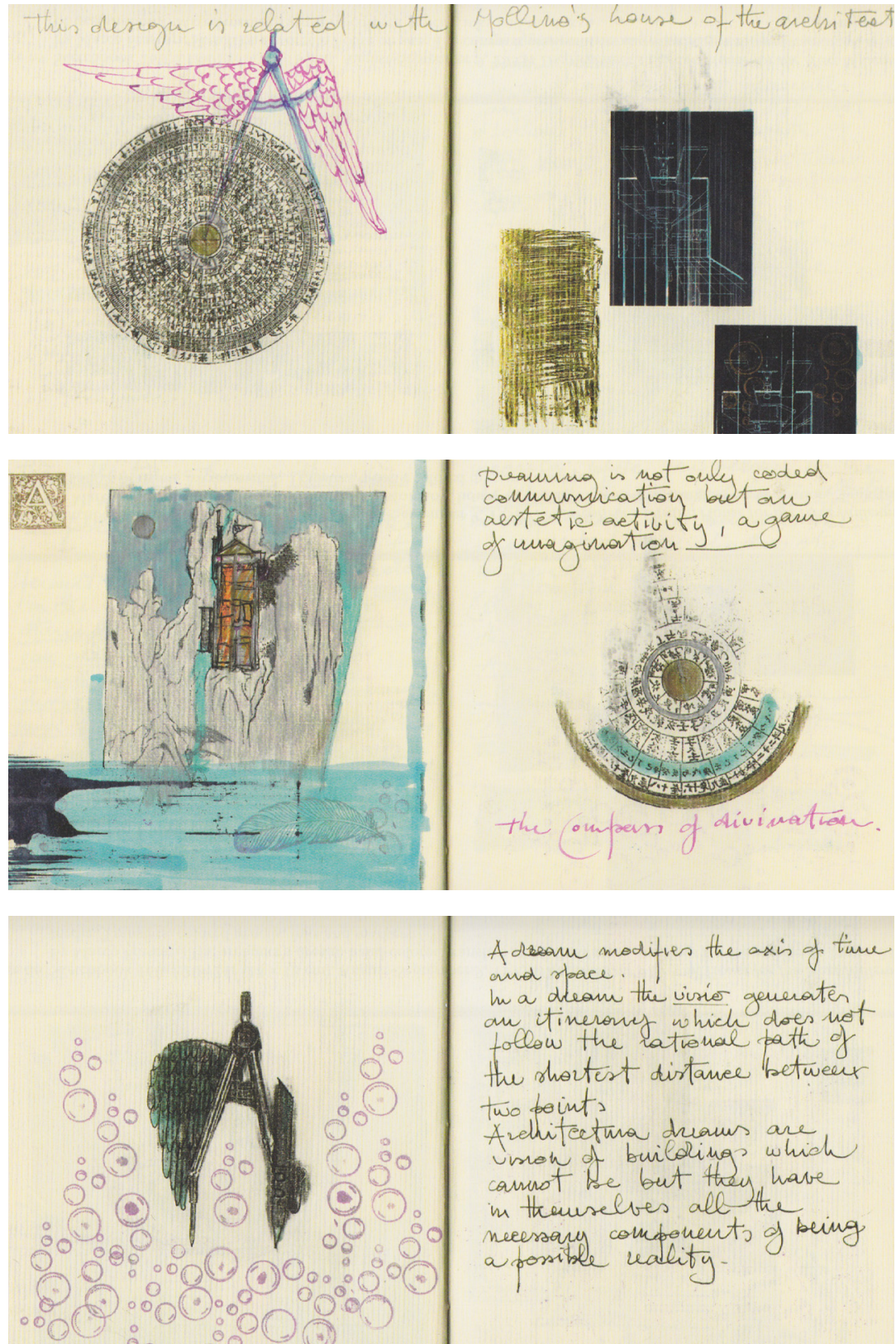

A drearu modities the axis of time and rpace. I

In a deam the visies generates an itinerony which does not tollow the vatronal path of the rhoutest distamee between two boints Arehitectura druans are carret the but they have in thenselves all the necessany components of being. a possible rallity.

Fig. 17

Sketches of the Dream House by Marco Frascari, 1993 
Architectural dreams are meaningful and useful demonstrations to architects... The importance of dreaming for architects is embodied in this description of a dreamscape. The dream is a demonstration and a hypothetical design of the unknown; thus, it is a substantial tool for acquiring knowledge. The dream is a logos, a rhetorical procedure, for wondering within the labyrinth, where the dialogue between real and hypothetical possibilities takes place. ${ }^{14}$

Marco Frascari demonstrates his understanding and thoughts through his design of the Dream House for the Next Millennium. His drawings and sketches intend to communicate abstract architectural thoughts, or dreams, to carry out a professional duty and evoke future buildings. ${ }^{15}$ Frascari believes that true architecture is hidden and lies in propitious visions and dreams. ${ }^{16}$

Italo Calvino's Invisible Cities is a good example of a text that emphasizes the power of the imagination and its potential impact on the design process. Calvino uses text as a form of depiction to speculate on settings and the possibilities of different city forms. He allows the reader to build abstract settings and imaginative visions through his text, and precise descriptions of singular, non-existing cities. Calvino is capable of building alternative possibilities collectively through descriptions of imaginary cities in Kublai Khan's empire. "[Marco] Polo's cities resembled one another, as if the passage from one to another involved not a journey but a change of elements. With cities, it is as with dreams: everything imaginable can be dreamed." 17 From depictions describing cities of memory, desire, signs, and many others, Calvino describes a collective place of imagined cities we might hope to inhabit. He builds his depictions in text, relying on the reader's ability to imagine and visualize alternative possibilities. Describing invisible cities, Calvino is able to generate architectural depictions that are built entirely of words and imagination. 


\subsection{Depicting Place}

Depictions can produce significant outcomes, since they are modes of production that formulate architectural form, make place, and communicate atmosphere. Whether through pencil, paint, ink, or models, depictions are generated in ways that speak a language of their own. They express and build on emotions, experiences, thoughts, and visions of new forms and new places. Through depictions, viewers are introduced to imaginative realms, ones that are purely potential and reveal the spirit and atmosphere of a place through its architectural forms. Place is defined as "a particular position, point, or area in space," ${ }^{18}$ but does not necessarily associate with a specific location. A place is given a setting, with a given set of physical characteristics. Space, by contrast, is a continuous area that is free and unoccupied, a dimension of height, width, and length where all things exist and move. ${ }^{19}$ Depictions are therefore platforms that reveal alternative possibilities, ones that are capable of existing on paper, through paint, and within sculptures. They introduce the artist and the viewer to new possibilities, places that exist within the medium and their techniques. As Megan Craig remarks, "There are things that one can only learn through drawing or painting, a secret knowledge... And yet a painter knows things about places that no one else knows, as the blind sense things about colour that the sighted never discern." 20

To depict a place is not to represent it exactly as it is, and, indeed it is impossible to do so. A representation can't be the subject or the object itself. Rather, it is a tool that aims to translate the subject and the place, using varying mediums: "an artistic representation is never a transparent window onto its own subject. Standing before even the most realistic painting... we are still not led to believe that by viewing it we are simply present to the scene it represents. Instead, the painting stands before us in place of this scene as the self-announced surrogate of it." ${ }^{21}$ Similarly, depictions are not reducible to their representation functions. Depictions are products that stand on their own, as 
individual entities that create place, or, rather, they are re-placed. To capture this irreducibility, Edward Casey describes the depiction of a place as a re-implacement. Re-implacement can be classified in one of three categories: place-at, place-of, and place-for. ${ }^{22}$ The first, place-at, aims at depicting an existing place as precisely as possible, in concordance with its true physicality, and associated with an exact location. The second, place-of, alters the physicality of a place, but not so much that a viewer could not recognize the place. These two forms of place depictions are a kind of topographic re-implacement, a re-implacement "that serves above all to locate, situate, and explain a place." ${ }^{3}$ The third form of re-implacement, place-for, is amongst the least representational forms of depiction, as the truth is attached to its drawn product in a poetic manner. This form of depiction is referred to as topopoetic, and it is "forward-looking: looking forward, for example, toward the sublime of contemplation." ${ }^{4}$ It is a form of depiction "that brings the viewer into the work itself, inviting her to contemplate, participate, and identify with this place." 25

A major role that is played in determining the spirit of a place is through the media and the techniques that are most viable for a given depiction. How a drawing or painting is formulated gives a piece its defining qualities and its ability to showcase the subject matter from an alternative perspective. Varying forms of depiction and the way they unfold within a piece determines how the piece communicates its atmosphere. As Casey explains, "A landscape representation - whether a drawing, painting, photograph, or any other form of representation - can present to us varying commixtures of place-at, place-of, and place-for." ${ }^{26}$ The tools that are used, the mediums chosen, and the techniques at play are what bring architectural forms and ideas into existence as poetic entities. A drawing's conceptual significance is evident in how it communicates the spirit of a place, the atmospheric feel of a subject or form. Again, Casey explains, "To move to the topopoetry is to move to a deeply psychical dimension of the painterly field; it is to move to a place from which the world 
is viewed not only with one's physical eyes but with "the eye of the soul." 27 Depictions are generators of architectural form, and as such they are also generators of place. Through them, alternative realities and possibilities are presented and made possible to the viewer. Depictions formulate architectural forms and places of their own, through their mediums and techniques, offering sensory impressions and experiences to those who view them.

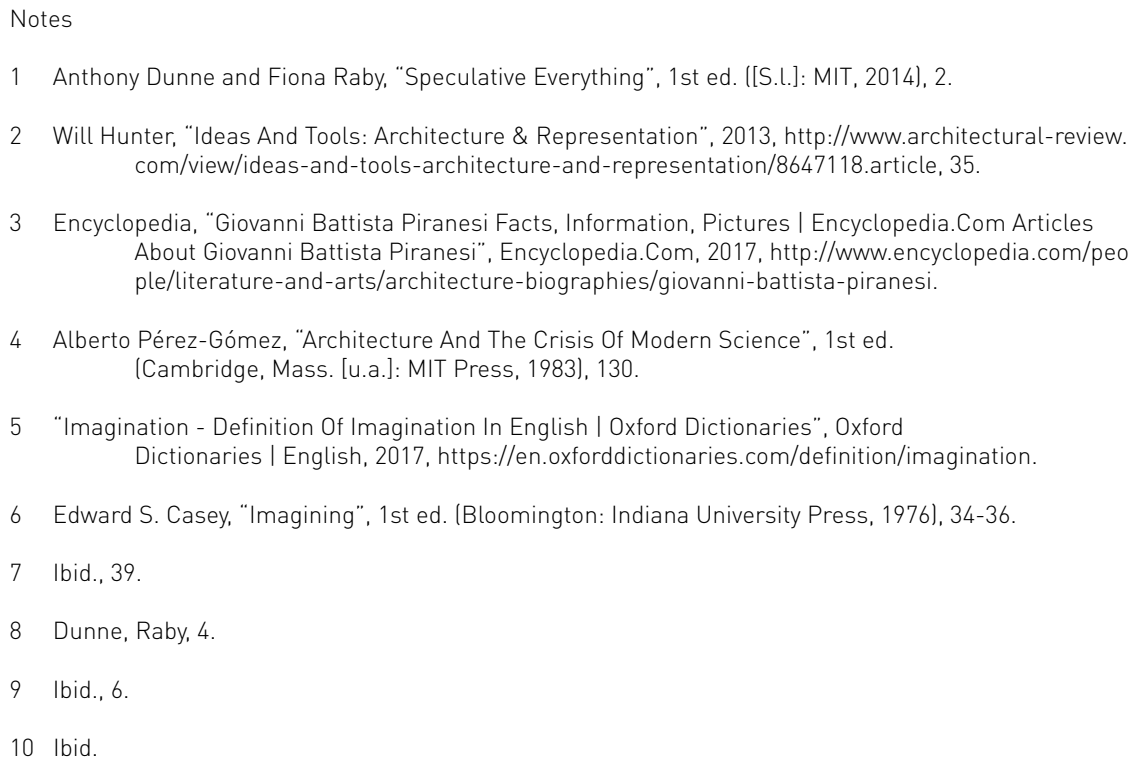


11 Paolo Belardi, "Why Architects Still Draw: Two Lectures On Architectural Drawing”. trans. Zachary Nowak (Cambridge, MA, United States: MIT Press, 2014), 15-16.

12 Marco Frascari and Federica Goffi, ed., "Marco Frascari's Dream House: A Theory of Imagination", 1st ed. (New York: Routledge, 2017), 38.

13 Ibid., 39

14 Ibid., 95

15 Ibid., 97

16 Ibid., 101.

17 Italo Calvino, "Invisible Cities". trans. by William Weaver. (Harcourt Brace Jovanovich, 1974), 43

18 "Place - Definition of Place In English | Oxford Dictionaries", Oxford Dictionaries | English, 2017, https://en.oxforddictionaries.com/definition/place.

19 "Space - Definition Of Space In English | Oxford Dictionaries", Oxford Dictionaries English, 2017, https://en.oxforddictionaries.com/definition/space.

20 Megan Craig, "Slipping Glancer: Painting Place With Ed Casey”, in Exploring The Work Of Edward S. Casey: Giving Voice To Place, Memory, And Imagination, 1st ed. (Bloomsbury Publishing PLC, 2013), 150-151.

21 Edward S. Casey, "Representing Place", 1st ed. (Minneapolis: University of Minnesota Press, 2002), 17.

22 Ibid., 30

23 Azucena Cruz-Pierre, "Framing The Landscape", in Exploring The Work Of Edward S. Casey : Giving Voice To Place, Memory, And Imagination, 1st ed. (Bloomsbury Publishing PLC, 2013), 123.

24 Casey, "Representing Place”, 30.

25 Cruz-Pierre, "Framing The Landscape" 123

26 Casey, "Representing Place", 31.

27 Ibid., 71 


\section{4 | Precedents \& Design Philosophies}

Depiction makes different contributions to an architectural design process. It has displayed its significance historically and into the present as an expressive and creative tool. Depictions hold great importance for the generation of architectural forms and standing as autonomous architectural pieces. Whether it is through drawing, painting, modeling or any other mode of expression, depictions play a role at both conceptual and technical levels. The process, which generates in-depth experiments through depiction and thereby provides platforms for further exploration, is of great value in formulating more critical final architectural outcomes. While depictions and drawings play a vital role in any architectural process, they are required to be perceived and unfolded to greater depths and in more theoretical fashions. Depiction is a tool that must be approached with less practicality, and more conceptually, appreciated as the art that it is.

This chapter will look at work produced by architects for whom the drawing process was critical and will discuss a selection of exemplary designs that have played a significant role in advancing the architectural discipline. Many of these works have made important contributions to the discipline through un-built critical projects. The depictions produced by these architects are significant architectural end products in and of themselves. They contributed to the discipline both through the topics and ideas they conveyed, as well as through the methods of their production. These critically produced drawings introduced the viewer and the discipline to alternative forms of architectural design, and pushed architecture into new territories. Their projects show the significance of investing in such theoretical and investigative 'paper architecture', as a form of architecture that does not require a built design to qualify them as architecture. Architects such as John Hejduk, Peter Eisenman, and Daniel Liebeskind brought forth new investigative modes, shifting the norms of archi- 


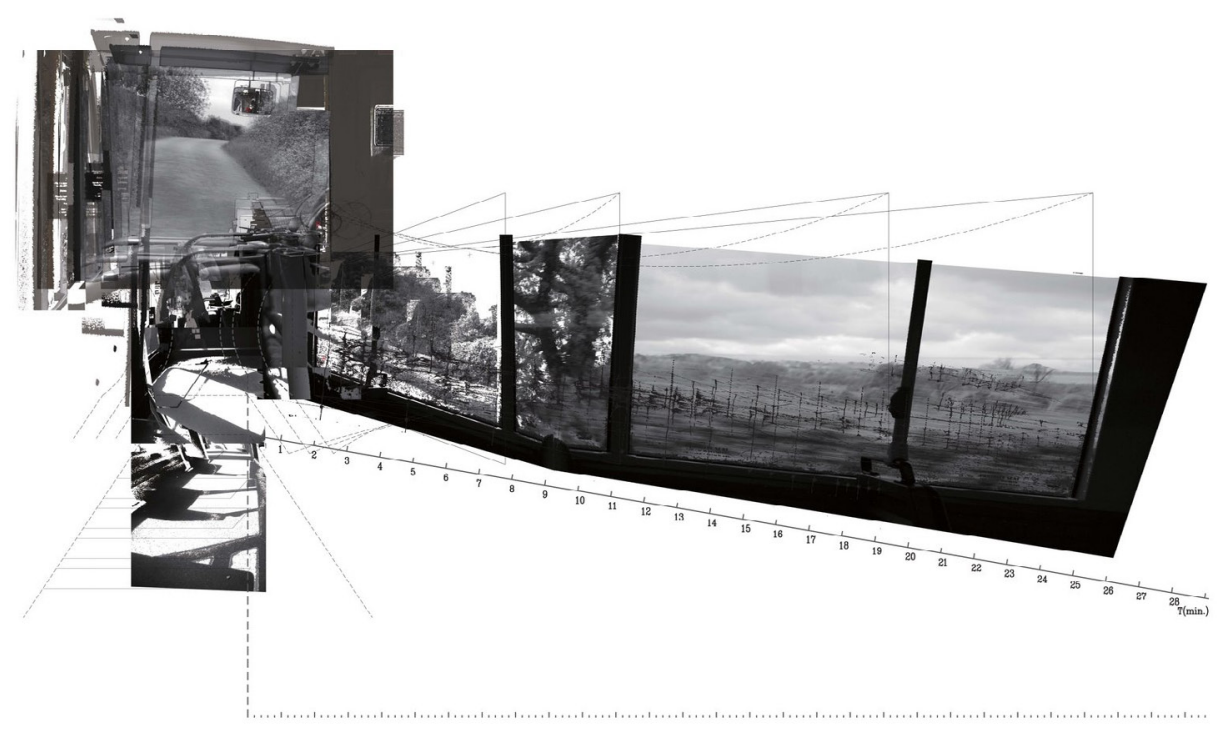

Fig. 18

NASA Surveyor by Diller and Scofidio, 2012

tectural practice. These precedents exemplify the efforts put forth in producing solid, critical pieces that explored architectural ideas by using various forms of depiction. The following examples illustrate the importance of investing time in a speculative process to produce pieces that showcase architectural ideas from alternative perspectives and demonstrate how architectural depictions can be significant products in themselves. More of these depictions in architecture need to be incorporated in the design process in order to push concepts to their furthest limits. 
John Hejduk

John Hejduk was an architect and artist that produced significant theoretical work from the 1960s until his death in 2000. His body of work consists mostly in conceptual projects. ${ }^{1}$ Hejduk began exploring spatial configuration using varying geometric and structural elements. He created spaces using varying geometries of square, diagonal, and curved forms. Hejduk was an artist and architectural theorist who approached design in an experimental manner, trusting the process when formulating architectural forms. The work he produced challenged the status quo of the time and it developed an architectural character that was based on the imagination and that aimed at discovering new realities through drawings. ${ }^{2}$ Amongst the exploratory drawings he produced are Nine-Square series, Texan House, and The Diamond Project. ${ }^{3}$

Hejduk's The Diamond Project explored architectural form and program arrangements using a $45^{\circ}$ rotation in relation to an orthogonal system. The drawings in this series are framed by a $45^{\circ}$ angle boundary, and interiors which correspond to these vertical and horizontal parameters, running parallel to the sides of the drawing. It took Hejduk 5-6 years to develop this critical design exploration project, due to the amount of time he invested in a design-research mode of production. As Martin Soberg writes in John Hejduk's Pursuit of an Architectural Ethos:

Hejduk's methodological approach consistently operated as a search for new forms and programs... Thus architecture was considered more than a mere formal practice as he investigated the possibilities and limits of architectural signification through imaginary projects and thereby the possibilities of arriving at a contemporary architectural ethos. ${ }^{4}$

His diamond shaped houses aimed at "voiding the center and changing the parameter." 5 He was able to achieve architectural form that was beyond vertical and horizontal volumes and regular layouts. Hejduk's work in this project is of significance as a drawn architectural 


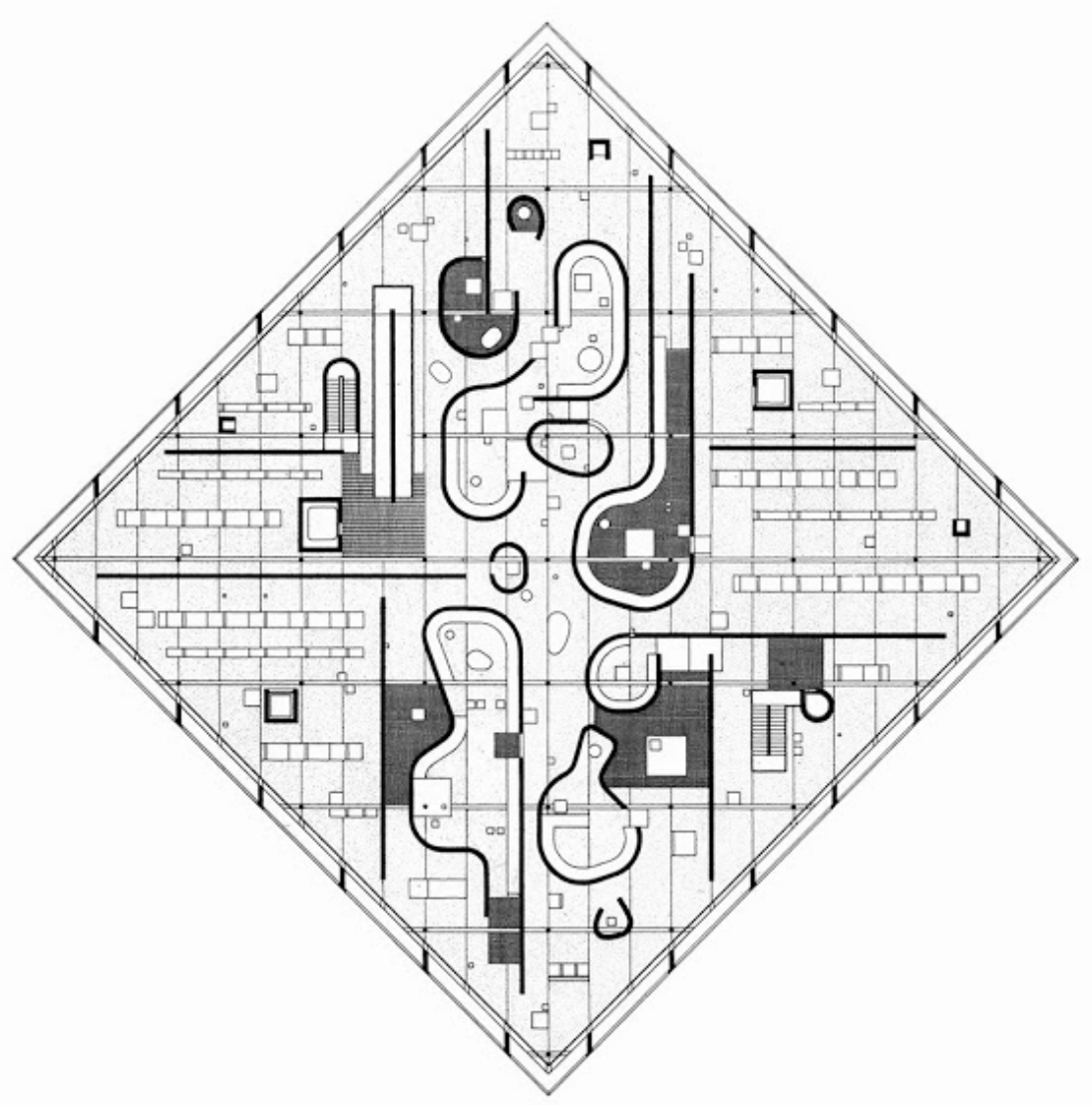

Fig. 19

Diamond Museum C by John Hejduk, 1967

product and stands on its own as an important piece without a built outcome. However, Hejduk himself did not consider his work to be an end in itself, since each piece also helped to influence and impact the design thinking that followed in his later projects. His early experimental drawings influenced a later series called $1 / 4,1 / 2$, and $3 / 4$ House series, which was composed of geometries and dividing grids similar to those that were the hallmark of The Diamond Project. Through Hejduk's house series drawings, the architectural practice was introduced to a new experimental design, one that was theoretically driven in aim of exploring new forms. 

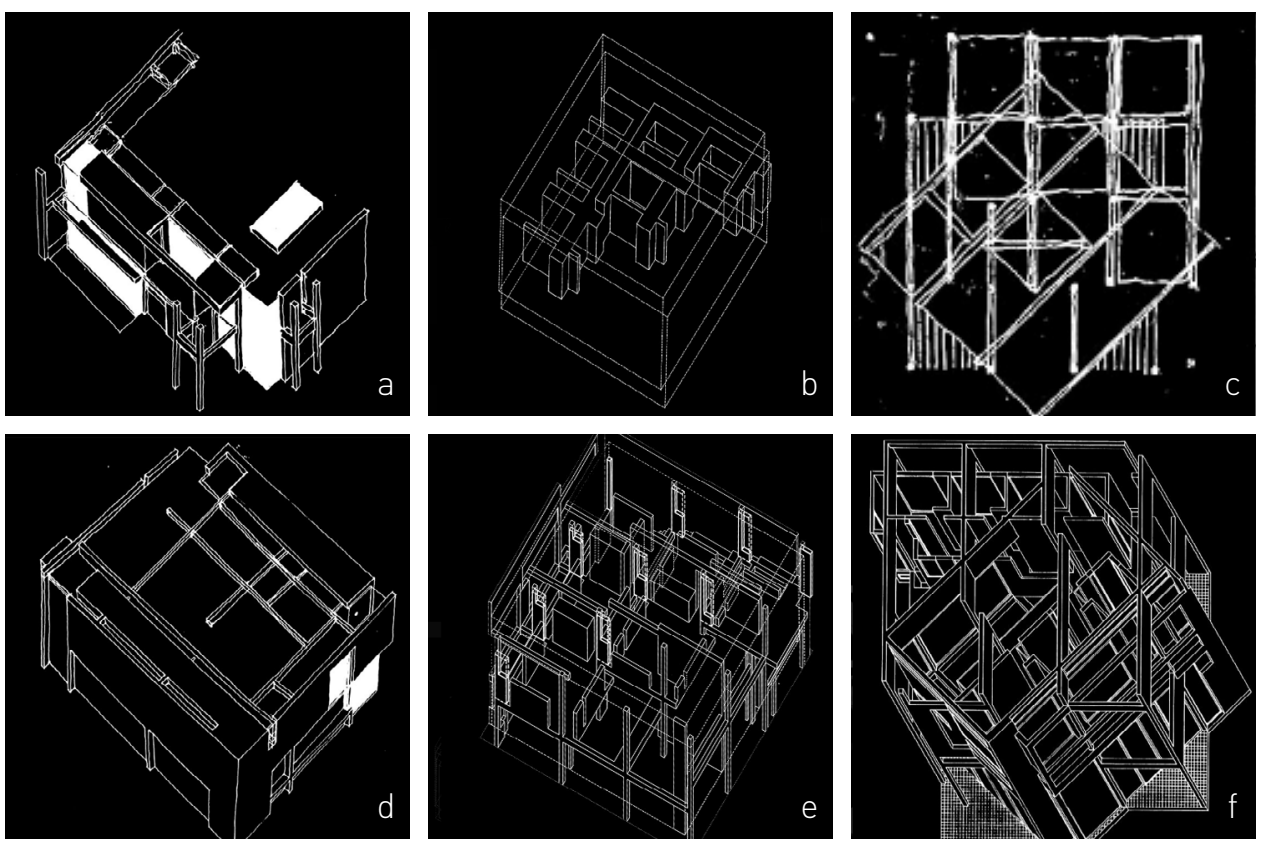

Fig. 20

House I, Housell, House III by Peter Eisenman, 1968-1971

Peter Eisenman

Peter Eisenman is another influential architect, who established himself in the architectural discipline in the late 1960s. Early in his career, Eisenman was interested in exploring pure architectural form, without the restrictions associated with traditional disciplinary conventions such as program, function, and structure. Instead, he concentrated on the role of drawing as means of generating architectural forms. In his drawings he moved away from the practical matters of context, site, and construction, preferring to study architectural figures such as openings, walls, and columns through his axonometric projections. ${ }^{6}$ The design philosophy behind his House series was to draw continuously until he had reached the form of the house most desired and most satisfactory. As Eisenman explained in an interview with The Architectural Review, "I would draw and draw and draw because I never knew what I was looking for. I knew the general parameters of what I was looking for, but I had no formula for setting up how to achieve it." Eisenman became an exemplary figure, showcasing the significant role drawing plays within an architectural design process, as he let the process of drawing slowly determine the forms of his houses. His House series, from House / to House VI, are 

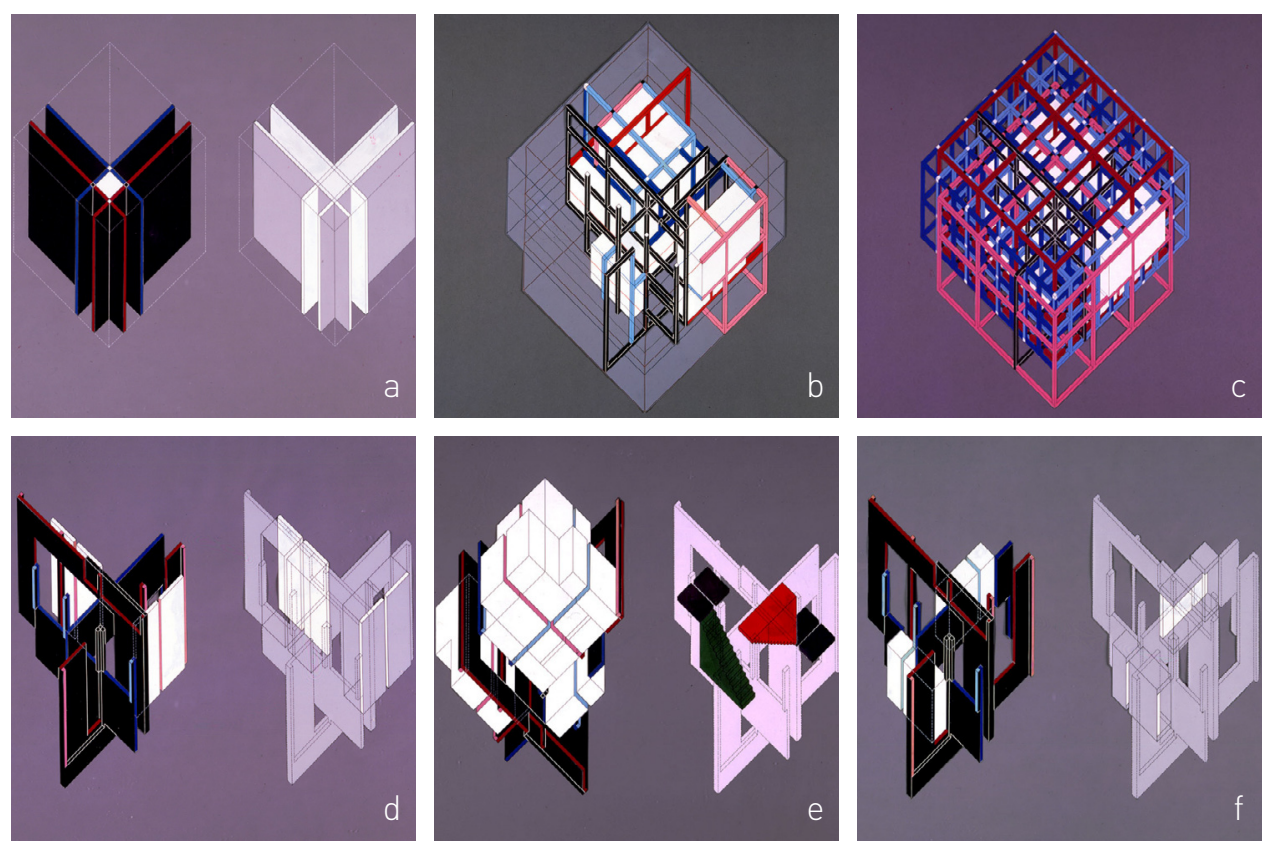

Fig. 21

House VI by Peter Eisenman, 1975

each composed of numerous drawing studies that investigate forms in varying geometrical, gridded configurations. For Eisenman

Drawing is a way of thinking... So to me drawing is a form of writing, and a form of reading what I write. So I don't see any difference. To me drawing is not making pretty things or making representations. It's not representing anything; it is the incarnation of the thing. I'm not trying to represent something; I'm trying to make it real. And the only way it can be real is through my drawings. ${ }^{8}$

Notwithstanding his focus on drawing and the role it plays in generating form, some of Eisenman's house designs did go on to be built. However, one does not complete the other. Each one has its own role to play, and each communicates architectural form differently. As Eisenman describes it, "[t]he 'real architecture' only exists in the drawings. The 'real building' exists outside the drawings. The difference here is that 'architecture' and 'building' are not the same." 9 Nevertheless, Eisenman still felt the need to build in order to be taken seriously within architectural practice. Without his built work, he believes he would not have reached the point he is at today in his career. 


\section{Aldo Rossi}

In the 1950s and 1960s, Aldo Rossi played a prominent role in the establishment of a post-war architecture. His architectural projects consisted of both built and un-built designs, with each having equal significance in his career. Rossi dedicated a significant amount of time to theoretical and artistically infused architectural pieces. ${ }^{10}$ The process of drawing for him was a process of translating his imagined designs onto paper. He used drawing as an instrumental tool to visually depict any design he envisioned. For Rossi, drawing was a method of visually communicating thoughts and a way of rendering ideas. Rossi drew to make real his imagined forms, classifying them as documents that visually recorded his architectural designs. ${ }^{11}$ To Rossi drawing was a form of exploring different possibilities, ones that were impossible in their construction, and possible only through the imagination and drawing. With an interest in and a focus on urban structures and the vision of cities, he concentrated on artifacts, monuments, and the urban fabric in his drawings. Rossi communicated those artifacts using varying graphic techniques to pursue aesthetic and atmospheric qualities appropriate to his designs. His techniques included pencil, pen, and tonal wash drawing, to give his designs a sense of texture and lighting composition. It is perhaps Morris Adjmi who best describes his design approach

Rossi perceives the city as a work of art, as a collective memory, and as an agglomeration of artifacts. The constant superposition of urban contexts, buildings and fragments continue to preoccupy him and to inform his architecture. Through his drawings and paintings, he is able to realize his visions, both real and fantastic, and imbue his designs with timeless spirit. ${ }^{12}$ 

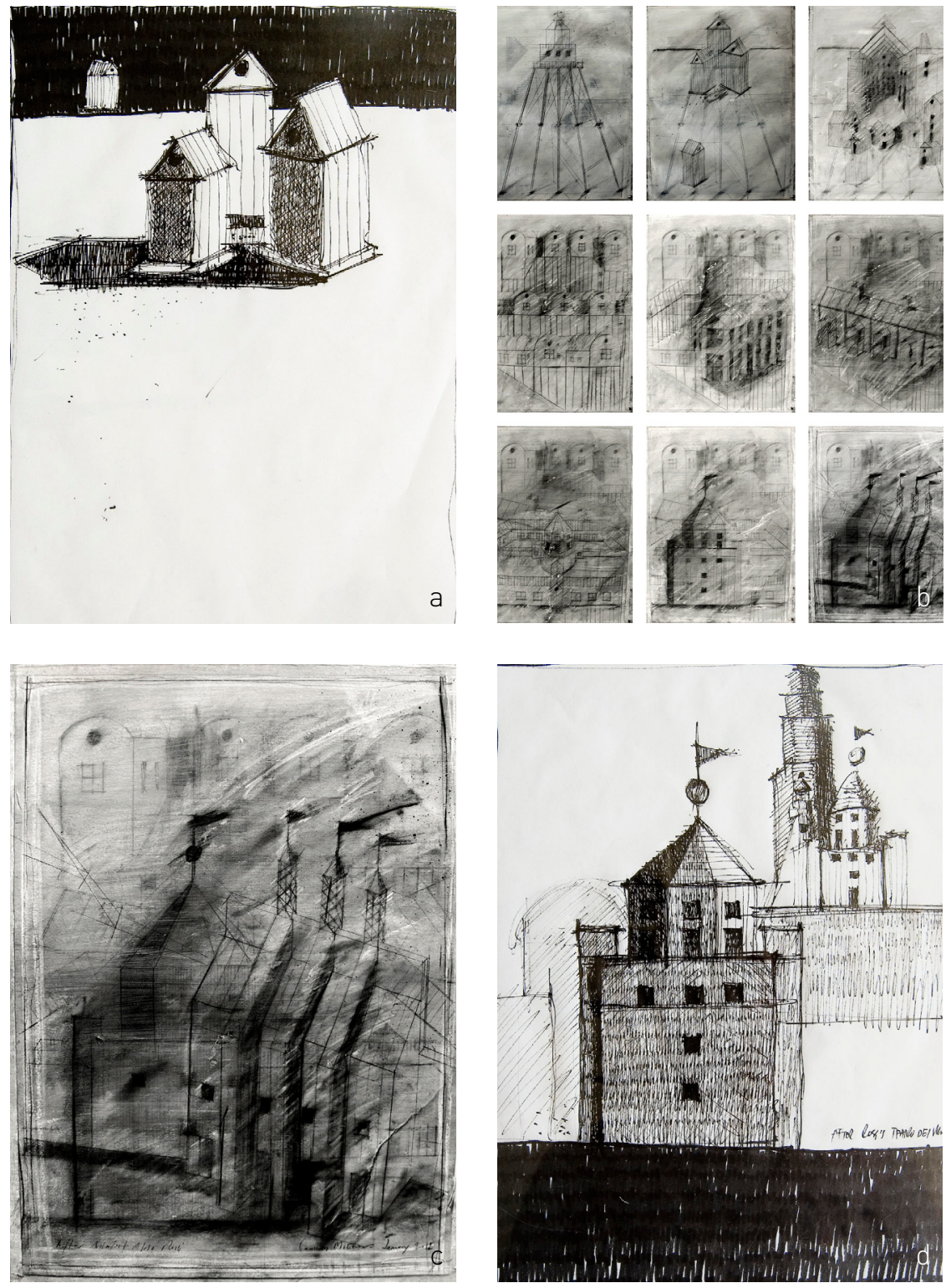

Fig. 22

Sketches by Also Rossi, 1980's 
Daniel Liebeskind

A student of John Hejduk's at the Cooper Union, Daniel Liebeskind began his career in architecture in the late 1970s. He was a musician and an artist before he became a world-renowned architect. Liebeskind argues that drawing is an essential part of architectural design as it is a form of communicating abstract thoughts into physical realities. Drawing is a main ingredient in the design process because it is what makes ideas real, by translating them visually. ${ }^{13}$ Before launching a career as an architect, Liebeskind dedicated a period of his early career exclusively to drawing. He produced a number of drawing series that were considered artworks as well as architectural drawings in terms of the themes and topics they conveyed. The drawing series include Micromegas and Chamberworks. This process informed his first built project, The Jewish Museum Berlin. It is as important to incorporate materiality, light, and proportionality in a drawing as it is in a built form. In Liebeskind's portfolio, Micromegas marks the beginning of building on paper. This project presented a series of pencil drawings that later served as studies for 12 prints. ${ }^{14}$ Micromegas portrayed more than drawings of abstract architectural figures: it also conveyed a concept of time. The forms generated in this series depict fragments of architectural elements at different times, liberating form from a single moment, and implying that architecture has a past and a future. Liebeskind writes "[i]n any case, a drawing is more than a shadow of an object, more than a pile of lines, more than a resignation to the inertia of convention." ${ }^{15}$ He makes real an imaginative reality within the architectural pieces, allowing the viewer to develop their individual understanding of it according to what their imagination permits. ${ }^{16}$ 

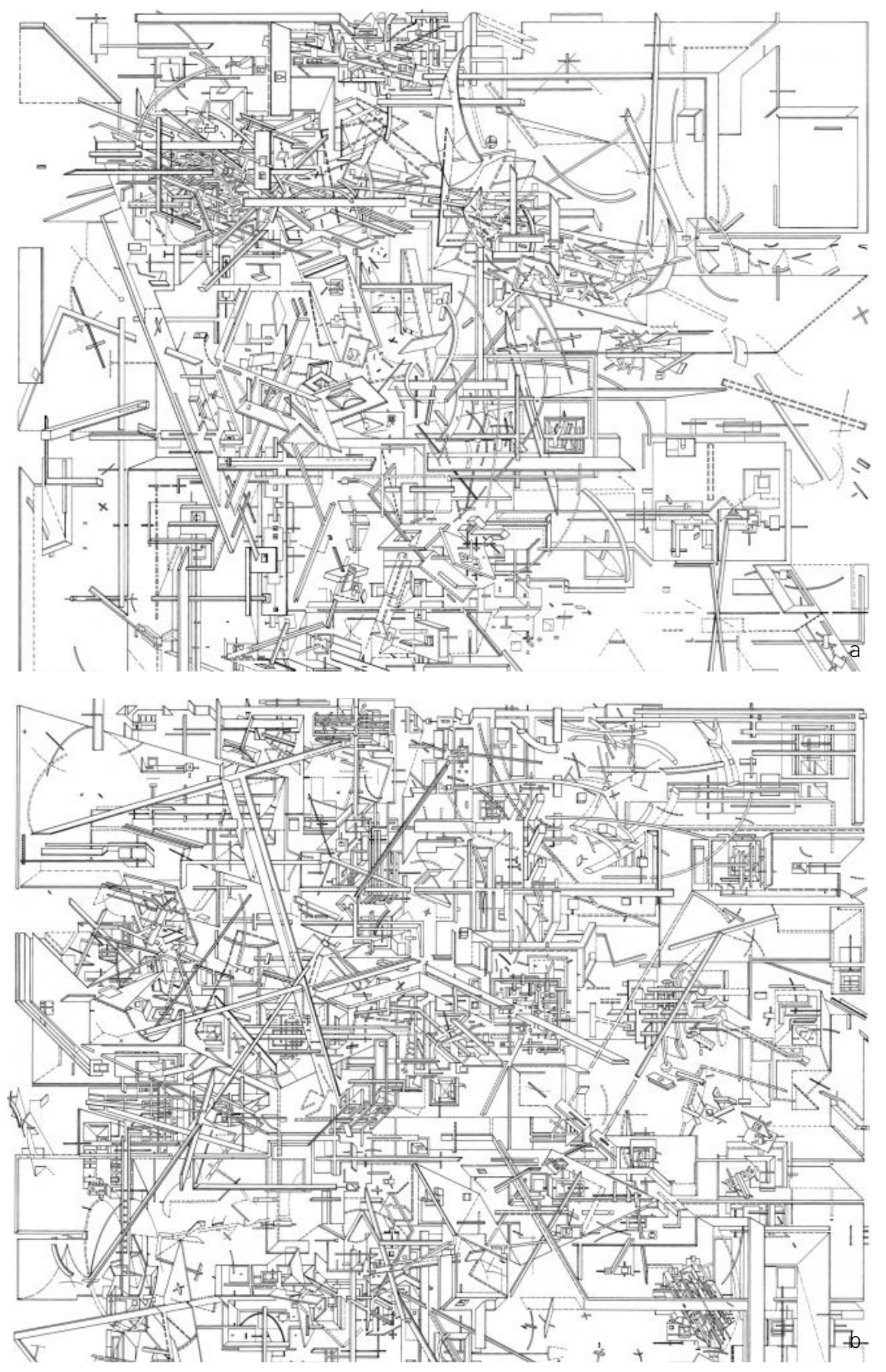

Fig. 23

Micromegas by Daniel Libeskind, 1979 

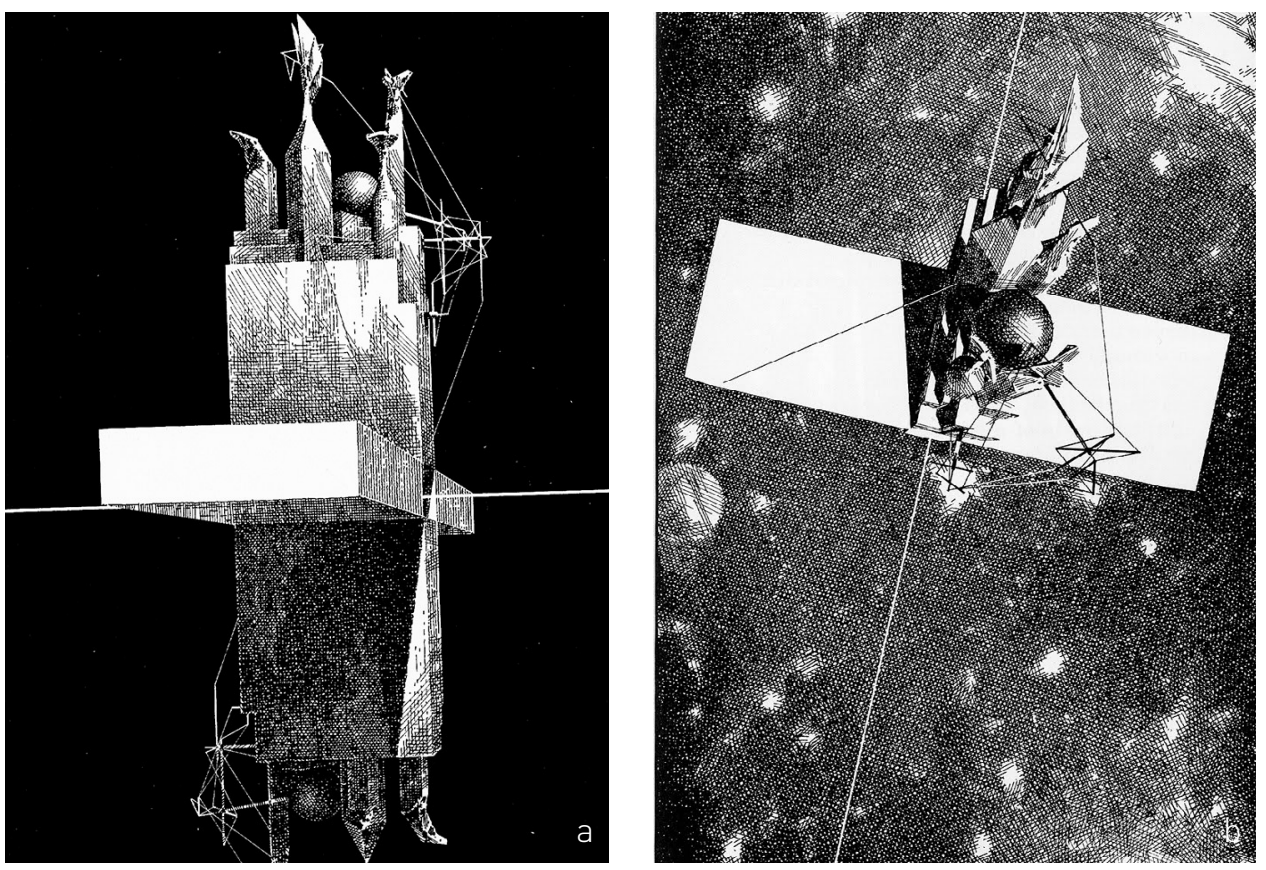

Fig. 24

Einstein's Tomb by Lebbeus Woods, 1984

Lebbeus Woods

Lebbeus Woods was an architect that 'built' only on paper. He never abided to a client's needs nor to the construction of his architecture. His work was primarily conceived and made real through drawings, and he dedicated his career to drawing forms that challenged norms and widely held perspectives. ${ }^{17}$ Woods drew forms that challenged physical forces. He used distortion to draw forms that were partially familiar and partially alien. ${ }^{18}$ His drawings allowed the viewer to complete the design in their mind. ${ }^{19}$ His architectural forms were contorted, presenting new forms through his drawings. They introduced forms that challenged gravitational forces and normal liv- 

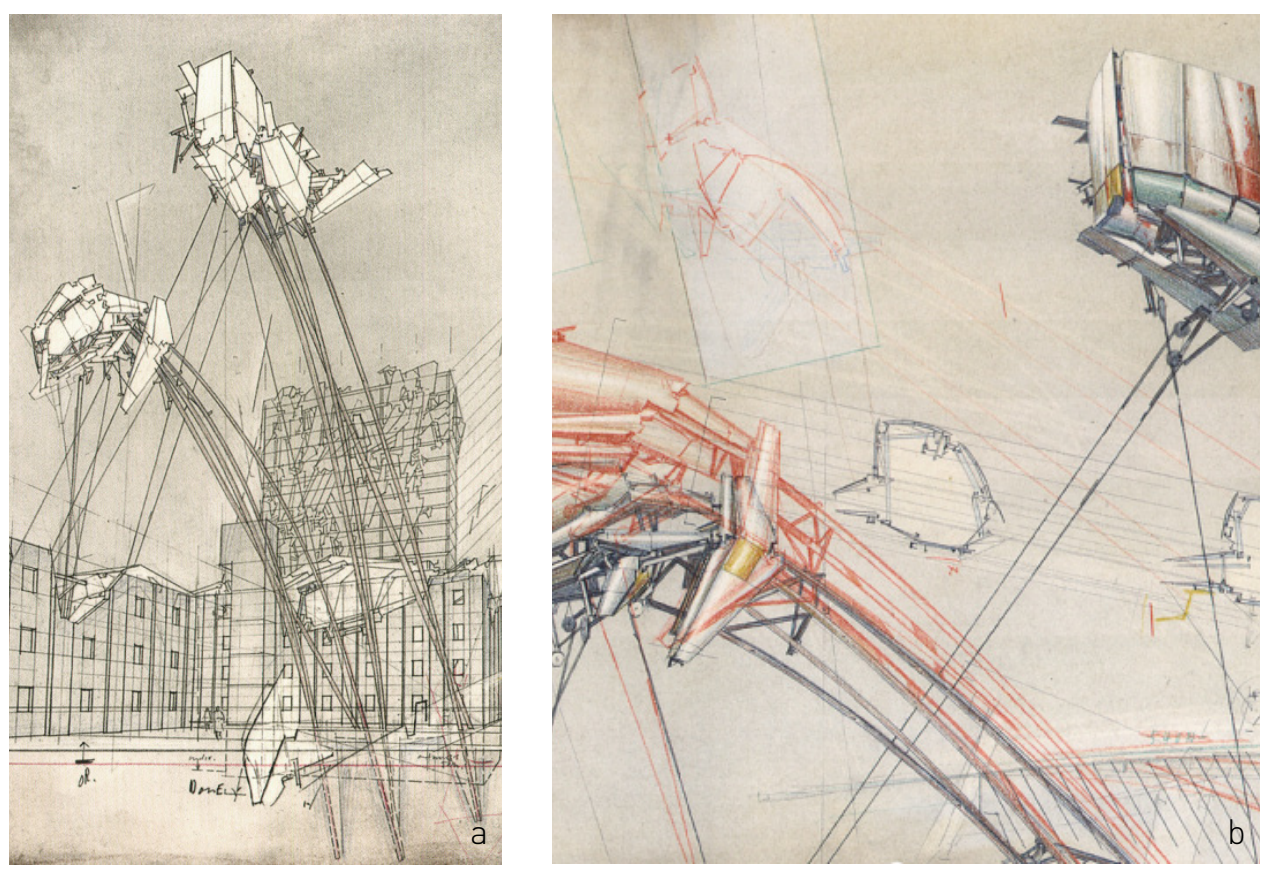

Fig. 25

High House by Lebbeus Woods, 1994

ing conditions: forms that floated, stood on stilts, dug underground, or hovered way out in space. Woods created worlds that did not exist in reality, but were made real through drawing and as such his work introduced society to an architecture that could exist in cities that could have been built. ${ }^{20}$ Amongst his works are The High House, Einstein's Tomb and Injection Parasite. As described by Woods, the houses of The High House series "[r]espond to people's powerful need to achieve freedom of movement in space through a fuller plasticity of experience, and to exist in the full dimensionality of space - to fly and yet, paradoxically, to be rooted, to belong to a particular place and time." ${ }^{21}$ In sum, Lebbeus Woods' work, with its forms and its existence exclusively on paper, always fought convention. 


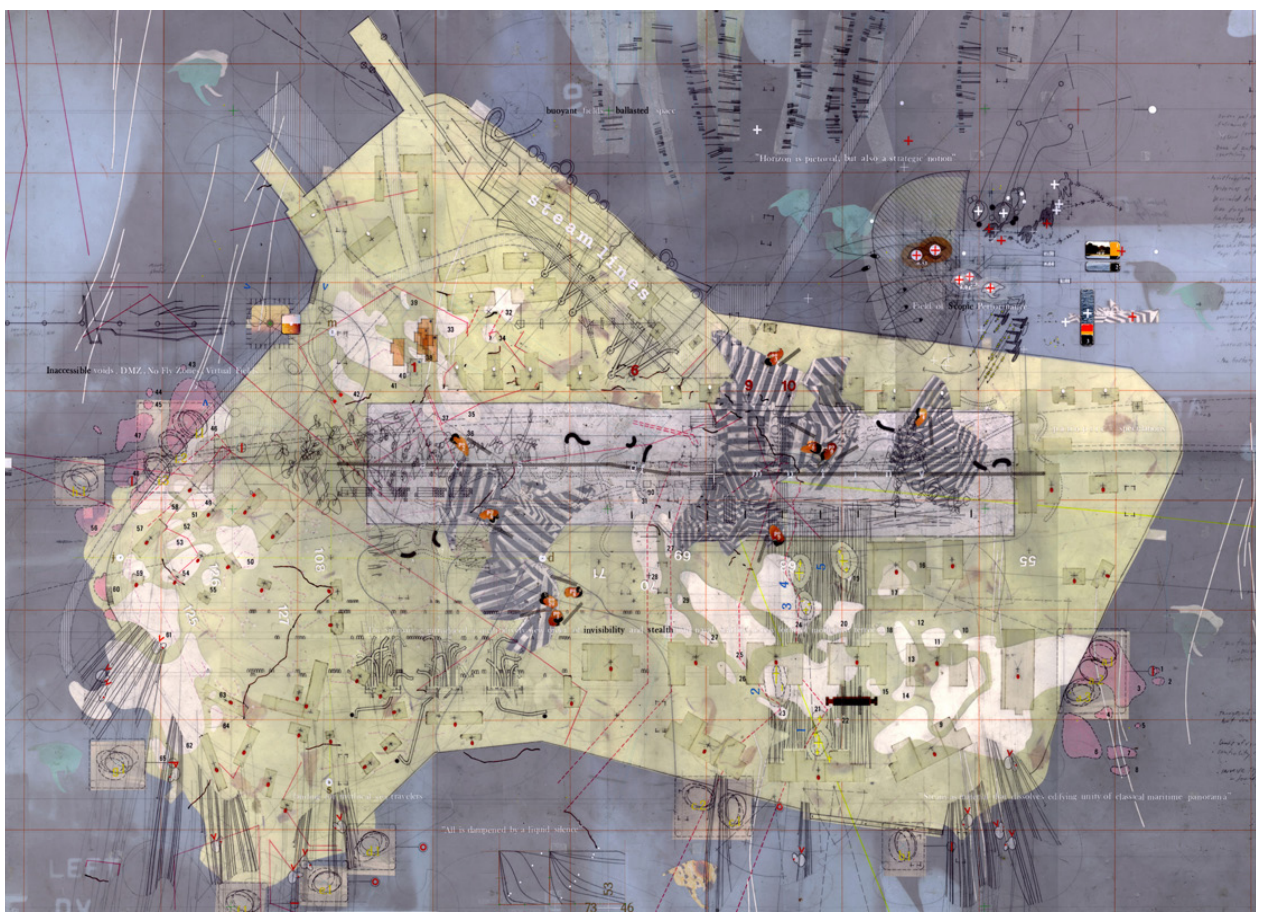

Fig. 26

Strategic Plot by Perry Kulper, 1997

Perry Kulper

Perry Kulper is an architect and educator skilled in various forms of drawing and representation. In his work Kulper concentrates on an unconventional set of drawing modalities that visually communicate alternative possibilities. Kulper does not approach drawing as a problem-solving activity, but rather as a tool to uncover an emerging visual field through the act of drawing: "[d]esign opportunities can be discovered, exposed and realized through the medium of the drawing, a key disciplinary ally for architecture." ${ }^{22}$ Kulper's drawings are forms of visualization of thoughts, both intentional and unintentional, 


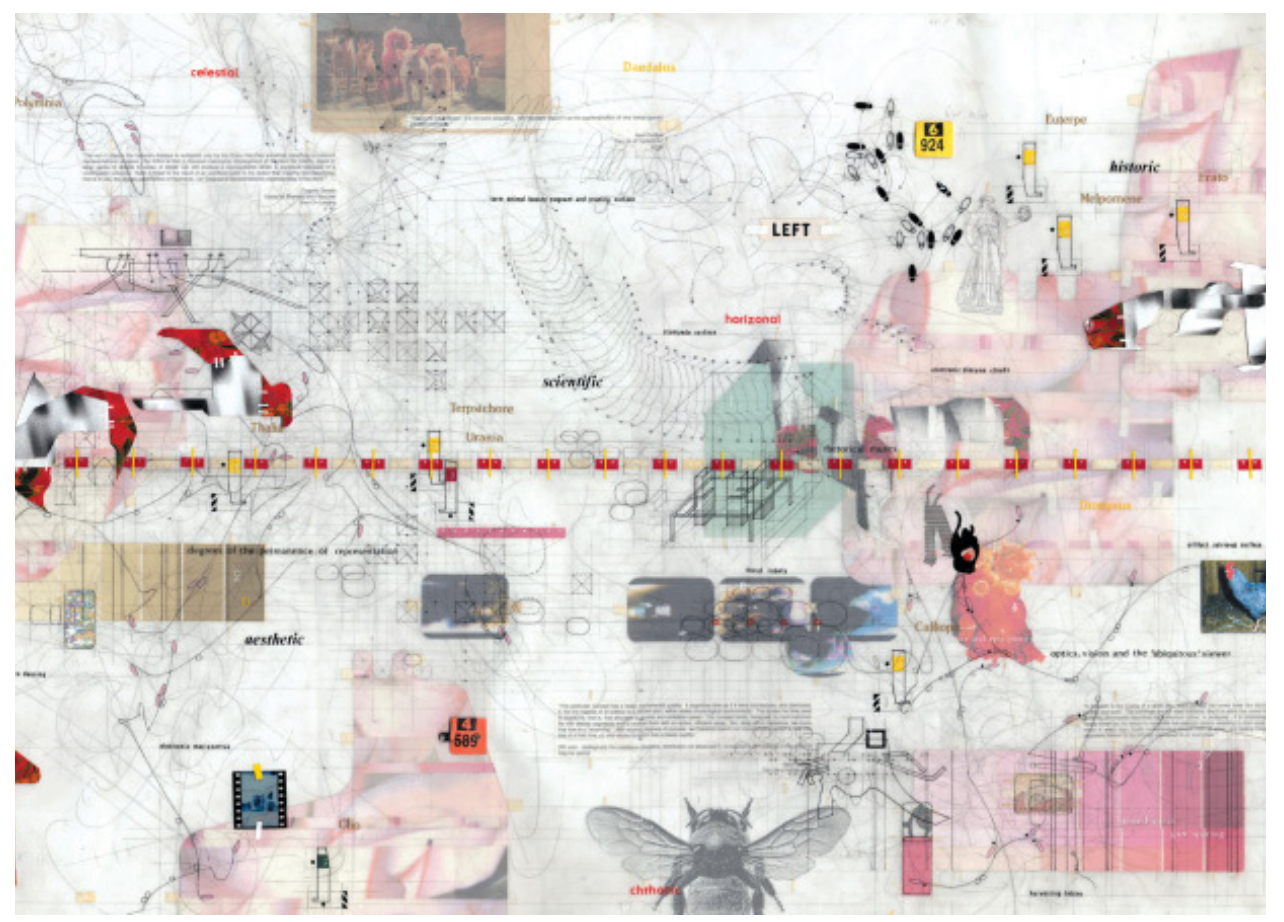

Fig. 27

Thematic Drawing by Perry Kulper, 2001

which vary their final outcomes accordingly. With his thematic drawings, he works off of a given subject and draws with no set scale, figures, or configurations. ${ }^{23}$ Kulper's work makes use of different techniques including orthographic drawing, mixed media techniques, and digital modeling and rendering. The drawings, in any of their forms, become sites that unfold architectural forms and new possibilities. ${ }^{24}$ His drawings are usually abstracted figures that depict conceptual frameworks, territories, notions, indexes, durations, and spatial configurations. Kulper explores other territories with his conceptual line work, use of color, and form. This is most evident in his early work, in Strategic Plot (1997) and Thematic Drawing (2001). ${ }^{25}$ 


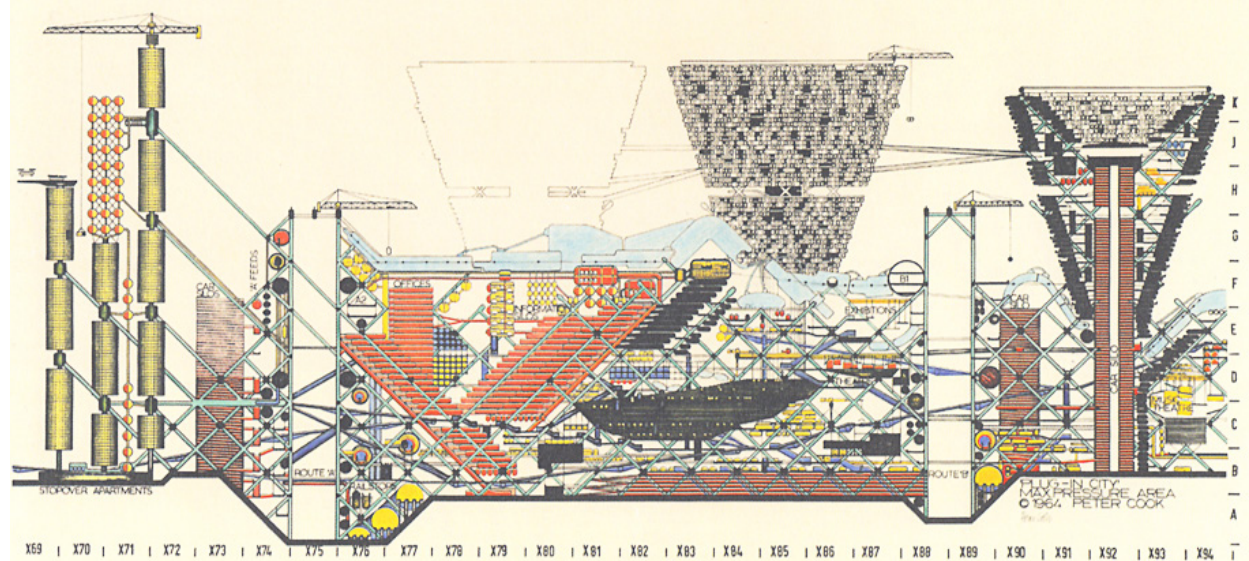

Fig.28

Plug in City by Peter Cook,1962-64

\section{Peter Cook}

Plug in City is a drawing of a visionary urban structure consisting of residences, services, and routes for its inhabitants. Building nodes would plug into a 'craneway' to create flexible and ever-changing living styles. The mediums that were used to create this drawing are ink and graphite on tracing paper. ${ }^{26}$ 


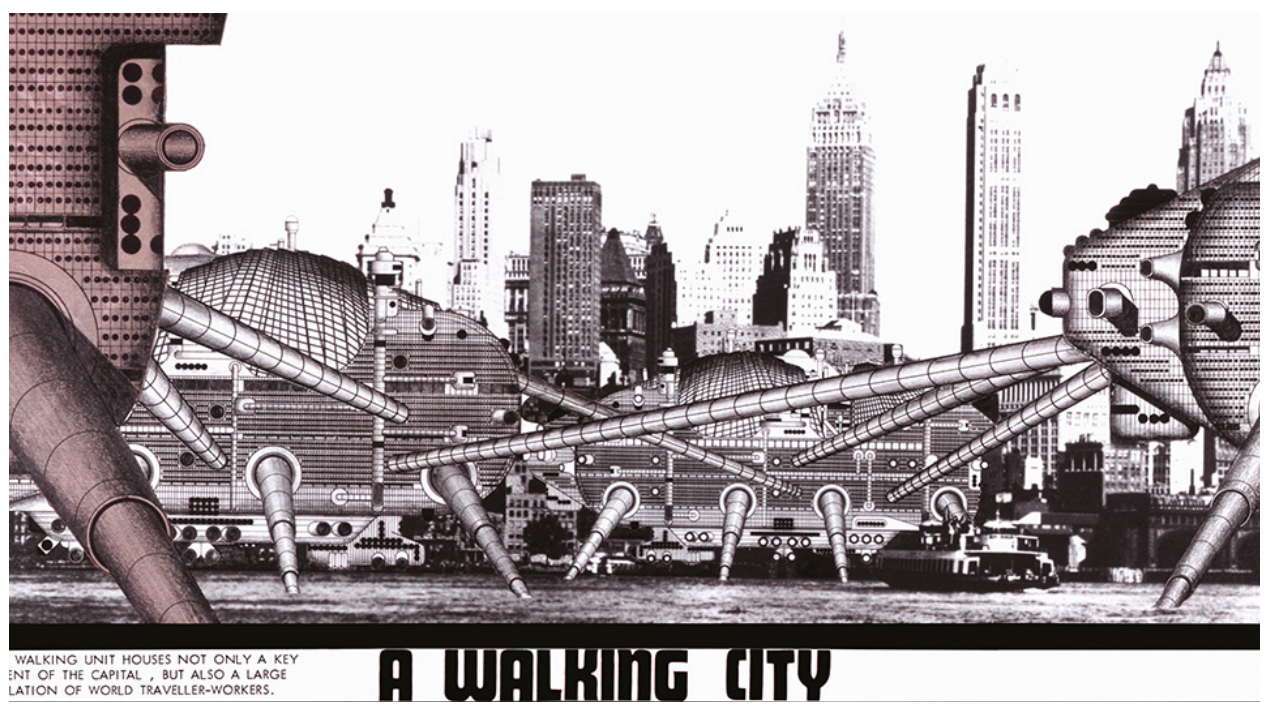

Fig. 29

Cities Moving by Ron Herron, 1964

Ron Herron

Cities Moving is a drawing that showcases moving buildings that are located within a body of water in front of the New York skyline. The building's large legs suggest that they are capable of walking the planet. With the use of ink, pencil, and photo collaging techniques, this "unimaginable" setting is composed amidst one of the world's most populated cities. ${ }^{27}$ 

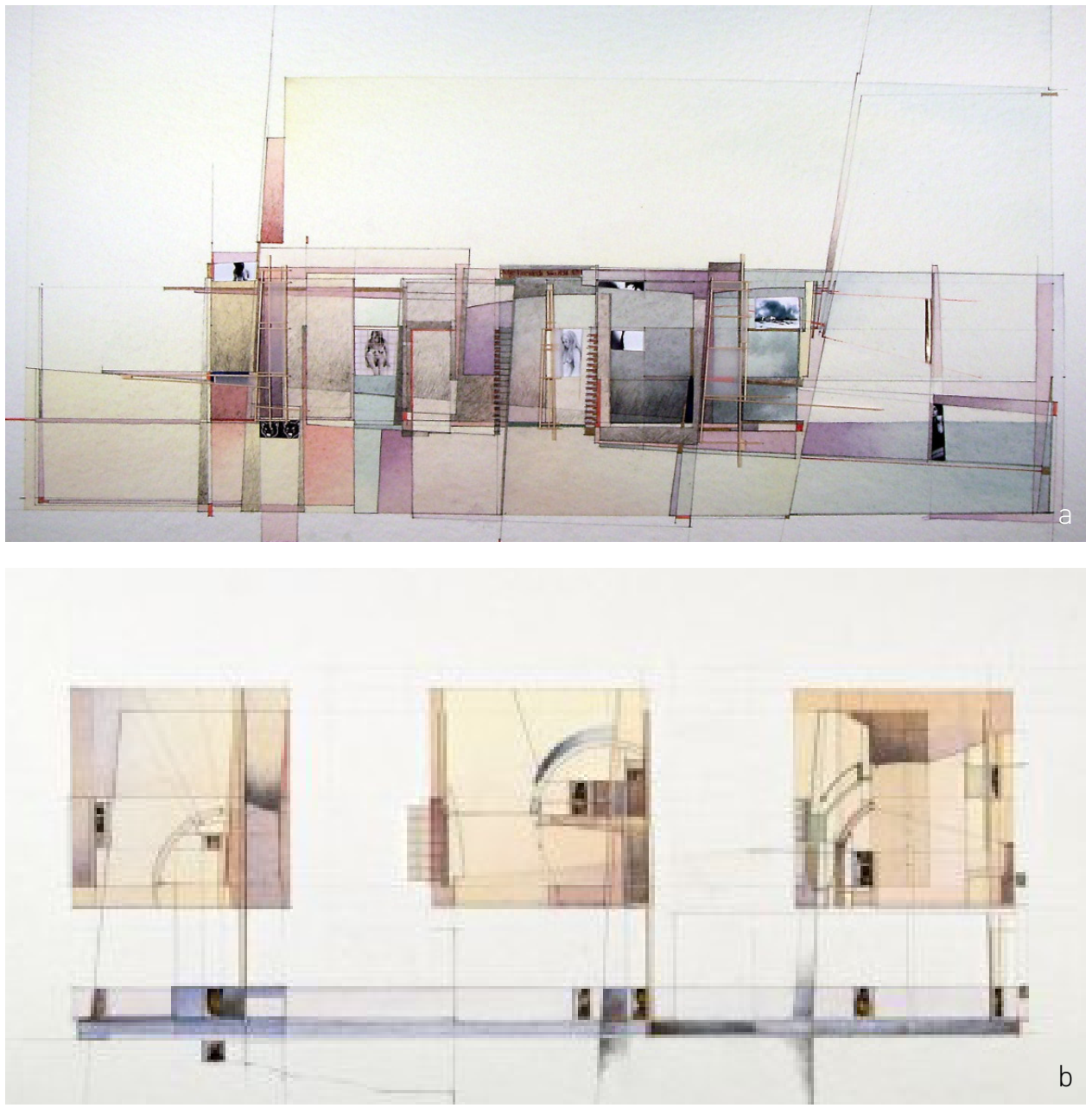

Fig.30

Window and Fragments by Richard Ferrier, 1994

\section{Richard Ferrier}

The Window and Fragments series by Richard Ferrier showcases the varying narratives and themes in a set of compositional layers, with human figures creating scale and emotions. His depictions are formulated through sketching, watercolors, and collaging techniques. Each sketch in the series has its own theme, and each is depicted and presented in its own organized way. ${ }^{28}$ 

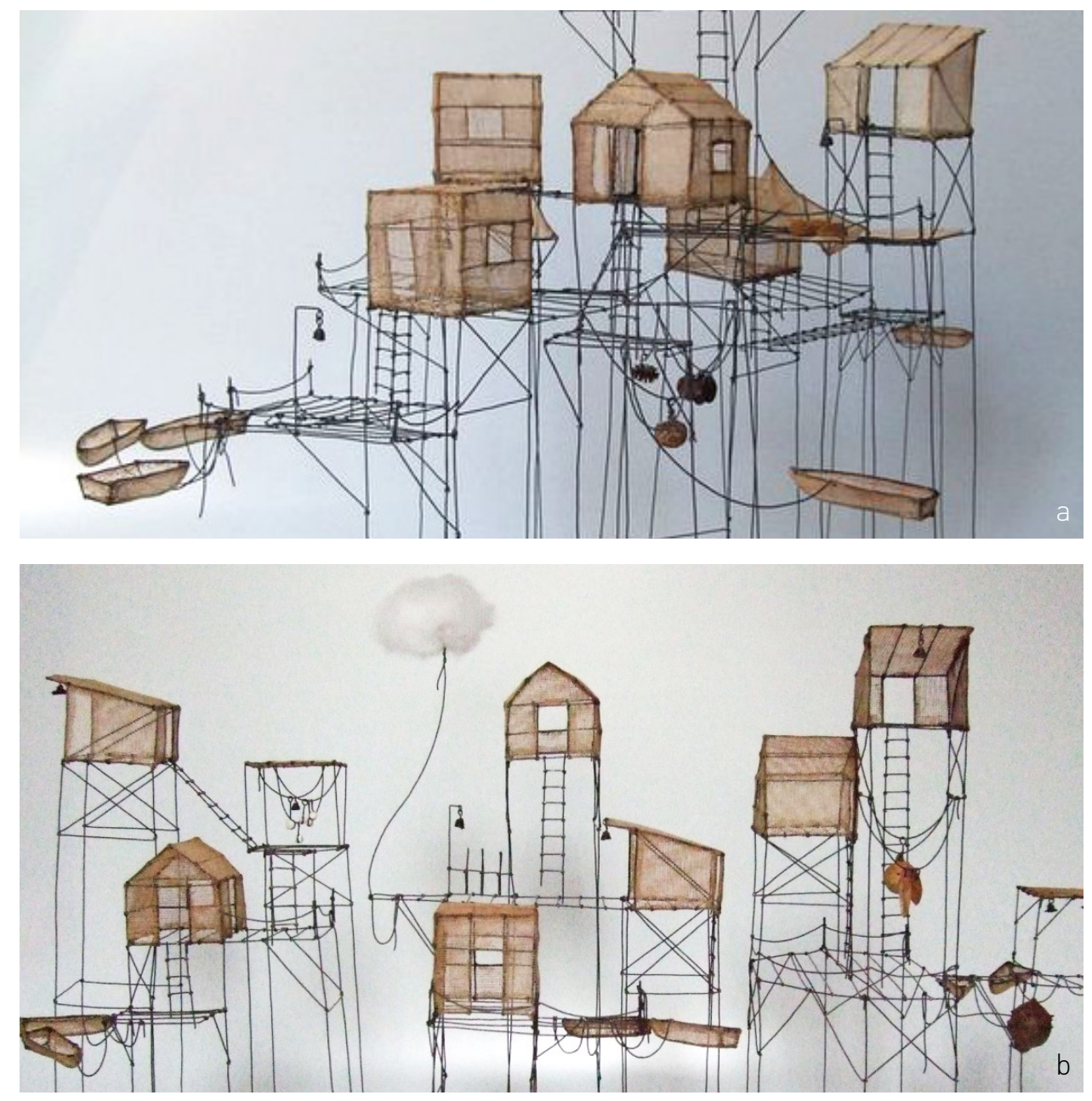

Fig. 31

Iron Wire Models by Isabelle Bonte, 2017

\section{Isabelle Bonte}

The models developed by Isabel Bonte exhibit a great deal of detail and emphasis on creating architecture within a setting of water, earth, and air. Using metal wire and rough burlap to create translucent surfaces, structures and models are developed that are capable of depicting a form of an architecture that exists in these materials. ${ }^{29}$ 

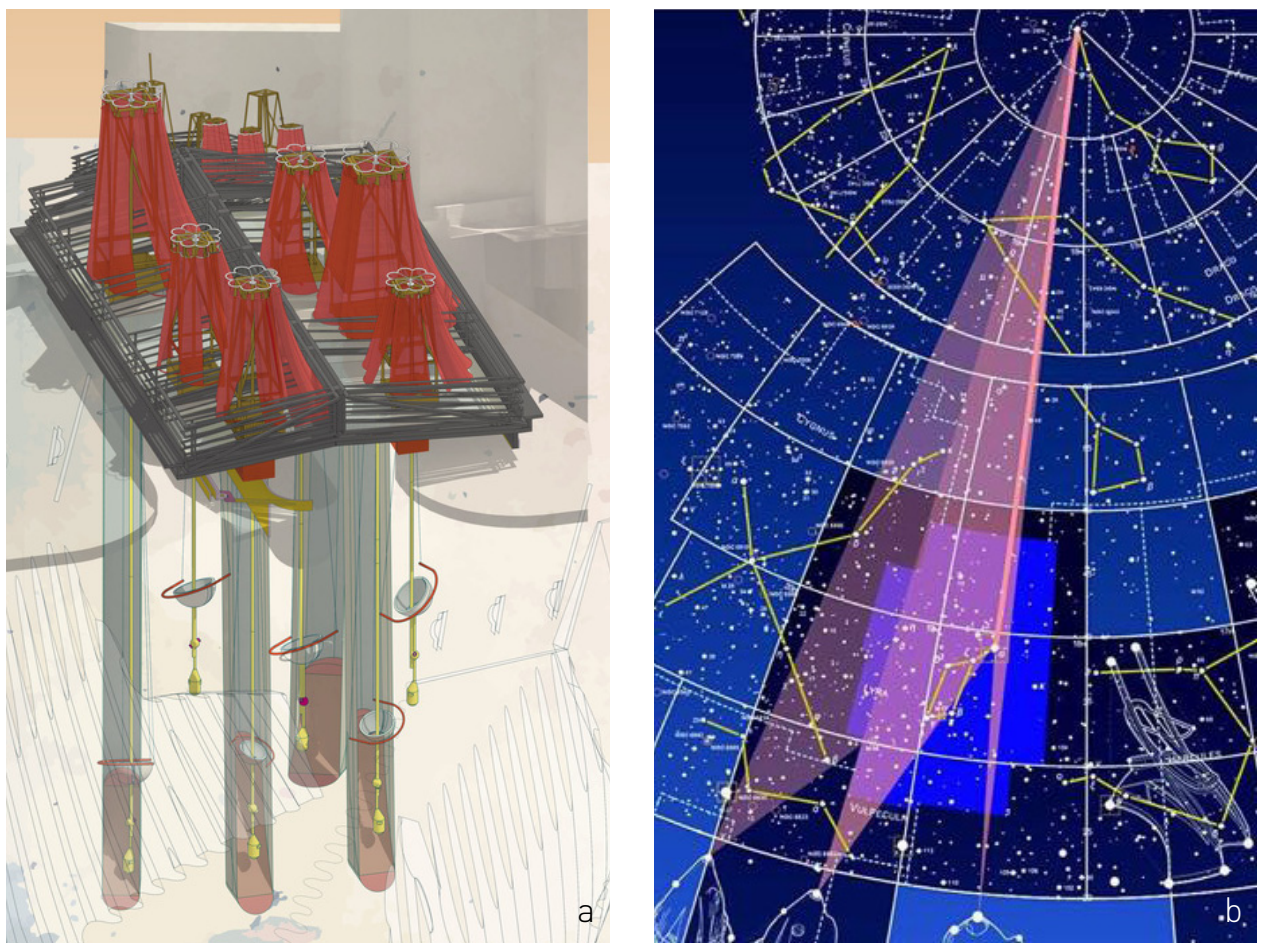

Fig. 32

L.A. Recalculated by Smout Allen, 2015

Smout Allen

Through digital mapping and cartographic drawings Smout Allen depict a system that speculates about Los Angeles' catastrophic earthquake regions in the project, L.A. Recalculated, that builds conceptual architectural structures to tackle the area's ecological fragility. With intense research and scientific data, Smout Allen produces architectural depictions as a means of experimenting with digital software and processes. As such, "[a]rchitecture becomes a means for giving shape to these existential investigations." ${ }^{30}$ 
Notes

1 Martin Søberg, "John Hejduk's Pursuit Of An Architectural Ethos", in Architecture Culture And The Question Of Knowledge: Doctoral Research Today, 1st ed. (FOOTPRINT, 2012), http://footprint.tudelft.nl/index.php/footprint/article/view/753, 114.

2 Ibid.

3 Michael Jasper, "Working It Out: On John Hejduk's Diamond Configurations", 2014, https://journal.eahn.org/articles/10.5334/ah.cb/.

4 Søberg, "John Hejduk's Pursuit Of An Architectural Ethos", 126.

5 Jasper, "Working It Out: On John Hejduk's Diamond Configurations".

6 Stefano Corbo, "Peter Eisenman”, Drawingmatter.Org, 2017 https://www.drawingmatter.org/sets/drawing-week/corbo-peter-eisenman/.

7 Iman Ansary, "Eisenman's Evolution: Architecture, Syntax, And New Subjectivity”, Archdaily, 2013, http://www.archdaily.com/429925/eisenman-s-evolution-architec ture-syntax-and-new-subjectivity.

8 Ibid.

9 Ibid.

10 Germano Celant, "Aldo Rossi”, 1st ed. (Milano: Skira, 2008), 18.

11 Aldo Rossi and Morris Adjmi,ed., "Aldo Rossi: Drawings And Paintings", 1st ed. (New York: Princeton Architectural Press, 1993), 51.

12 Ibid.

13 Ian Volner, "Daniel Libeskind: Drawing A New Architecture.", NUVO, 2014. http://nuvomagazine.com/magazine/autumn-2014/daniel-libeskind.

14 Daniel Libeskind, "Daniel Libeskind. Micromegas Project, Time Sections. 1979 | Moma”. The Museum Of Modern Art, 2013, https://www.moma.org/collection/works/295.

15 Ibid.

16 Ibid.

17 Lewis Wallace, "Lebbeus Woods: The Architect Who Dared To Ask 'What If?'”, WIRED 2013, https://www.wired.com/2013/02/lebbeus-woods-conceptual-architect/.

18 Neil Spiller, "Visionary Architecture: Blueprints Of The Modern Imagination": With Over 450 Illustrations (New York: Thames \& Hudson, 2008), 170

19 Wallace, "Lebbeus Woods: The Architect Who Dared To Ask 'What If?"”

20 Spiller, "Visionary Architecture", 172.

21 Ibid., 110

22 Neil Spiller, ed. "Drawing Architecture”, Architectural Design 83, no. 5 (2013), 59

23 Ibid.

24 Sophia Banou, "Perry Kulper - 'Spatial Blooms' And Digital Expectations", Drawingmatter.Org, 2017, https:/www.drawingmatter.org/sets/drawing-week/perry-kulper/.

25 Spiller, “Drawing Architecture", 58.

26 Victoria Patricia, “Plug-In City (1964). Archigram.”, PROYECTOS 7 / PROYECTOS 8, 2013, https://proyectos4etsa.wordpress.com/2013/01/16/plug-in-city-1964-archigram/.

27 Karl Fabricius, "Archigram's Walking City: A 60'S Architectural Vision Of The Future", Scribol.Com, 2009,http://scribol.com/art-and-design/architecture-art-and-design/archigrams-walkingcity-a-60s-architectural-vision-of-the-future/.

28 “Design Museum Holon - Magazine - Post 4”, Dmh.Org.Il, accessed 29 July 2017. http://www.dmh.org.il/pages/default.aspx?Pageld=401\& catid=-1.

29 Isabelle Bonte, “De Fer Est Mon Fil”, Deferestmonfil.Com, 2017, http://www.deferestmonfil.com/.

30 Laura Allen and Mark Smout, “LA Recalculated”, Smout Allen, 2015, http://www.smoutallen.com/larecalculated. 


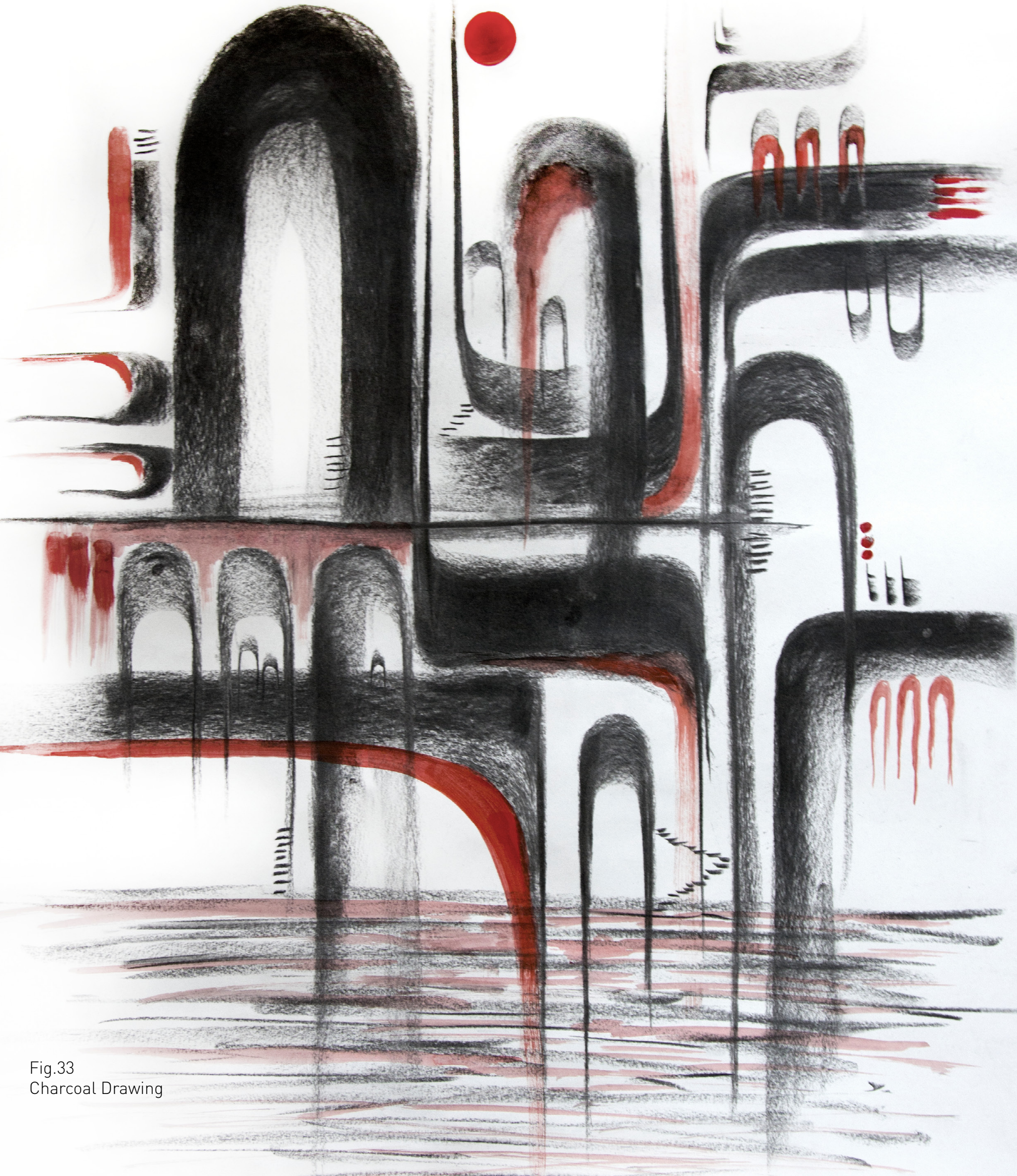




\section{I Houses of the Imagination}

\subsection{Home and The House}

Building on the preceding discussion of the role depictions play in architectural design processes and the way they serve the discipline in its totality, this chapter explores houses of the imagination as design vehicles and as intricate and critical forms of depiction. Using speculative architectural production of conceptual and practical nature, depictions pertaining to home and the house are generated in order to reflect on this condition. The idea of a house of the imagination is proposed as a way to inform architectural depictions to this end. The aim is to generate architectural forms through depictions by exploring alternative possibilities and scenarios for these houses in fictitious settings. This will slowly inform a larger collective architectural project and communicate through an architectural idea as a whole.

The house is a form of home; it is a dwelling place where one lives and is typically considered to foster important emotional connections. ${ }^{1}$ Home is where one finds peace and comfort, reflecting a deep and intimate connection between the dweller and the space. Houses are homes where man takes shelter, and is set at peace. Houses are built forms that are made precisely for mankind to live, work, and be nurtured in; it is a dwelling place where comfort and protection are found. A house is a place that fosters us in all of our activities and forms of living; it provides comfort and shelter in a safe space. A house gives form to a home, which then becomes a place of comfort, freedom, and deep attachment.

Houses come in varying shapes, forms, and sizes. They do not consist of one typology, but rather in numerous types and styles that vary according to different settings. While a dwelling's main purpose is to shelter and provide peace and comfort, it is not limited to specific shapes and settings. It can take any form or location, as long as 
it serves and maintains its function. As Bill Bryson notes, "Houses are really quite odd things. They have almost no universally defining qualities: they can be of practically any shape, incorporate virtually any material, be of almost any size." ${ }^{2}$ With that in mind, this becomes the driving force to give form to different houses using an exploratory design method of varying techniques of depiction and drawing. Through speculative experimentation with forms of depiction houses of the imagination will begin to emerge in accordance with each step of the process.

As there is no limit to what the mind can create through different forms of depiction, these houses reflect the depths of the imagination as it responds to different settings, scales, and scenarios. The approach to this design project mimics the abstract and intangible characteristics of the imagination by making use of non-existent settings and altering situations. By referencing the conceptual definition of home and dwelling, a better understanding can be established, one that aids in the formulation and depiction of altering forms of houses of the imagination, erected in idealized settings. Houses of the imagination are designed and generated through depictions that are critically and speculatively generated, in order to give shape and form to what can not be imagined at a specific location, but must instead unfold through altering scenarios. 
In this design-research form of production, the aim is to explore new forms of architectural house designs generated through depictions that will encounter a visual and critical definition of houses made possible in imaginable settings. This form of speculative design production will allow for the exploration and the examination of scenarios made real through depictions. Having memory play a vital role in what one imaginatively constructs and refers to as home or dwelling, the aim is to create altered dwelling typologies that are a combination of what people are accustomed to and what the imagination can mentally submerge them within. By distorting standardized forms of dwellings and generating non-standardized modes of depiction, a critical design approach to dwellings will emerge in helping push built realities to further extents.

As Gaston Bachelard is quoted in The Architectural Uncanny: Essays in the Modern Unhomely, "This house is far away, it is lost, we inhabit it no more; we are certain of inhabiting it never again. It is, however, more than a memory. It is a house of dreams, our oneiric house. ${ }^{3}$ It is through depiction that these houses are made possible. It is through the act of drawing out an idea and translating it into physical mediums, that these alternative realities are formulated and can impact our thinking. 


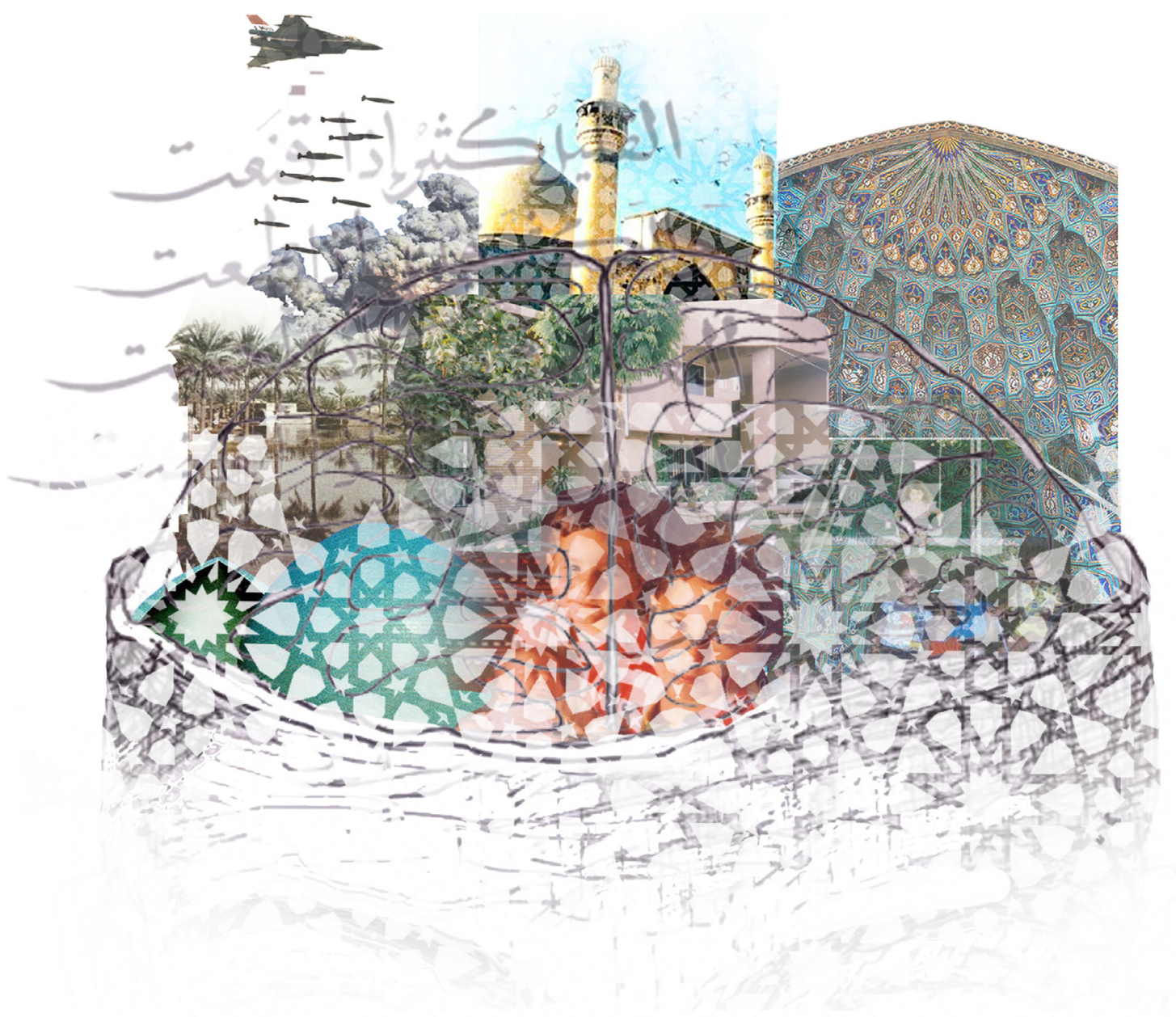

Fig. 34

Early Drawing Study of Home, 2015 


\subsection{Houses: Air, Ground, Water}

The architectural proposition in this thesis approaches houses of the imagination from an exploratory perspective using depictions to guide the design and generate architectural form. This project focuses on the establishment of a few settings that help guide the design process. The initial stage of depicting houses of the imagination began from three elemental settings: air, ground, and water. The characteristics of these three settings, representative of the three states of solid, liquid, and gas, are entities that help generate architectural ideas that can slowly be transformed into depictions. As C.J. Lim observes in Realms of Impossibility: Air, "Air, ground, and water form the building blocks of the man-made environment, making them fit themes for architectural investigation. ${ }^{4}$ In the design process of this thesis, these three states were first viewed as separate entities, each informing and influencing a separate architectural form, which is situated in, on, or around the three respective elements. Each of the states has its own challenges, and defines different aspects of the house according to its particular constraints.

Air, ground, and water are three states that helped in defining a setting with no particular location, a generic setting along mountains, oceans, and the sky. Their undelineated character assists the imagination in perceiving alternative realities, alternative possibilities, and builds it off a continuous process of depicting ideas. Challenging standardized physical concepts and allowing for the mind to think freely in artistic fluidity through drawing and model forms, a different form of architecture can begin to be expressed.

The intention is to create spatial configurations rather than physical buildings in the chosen settings. The process of depiction begins with trials: attempts at initial thoughts and ideas, attempts at both rough and refined qualities. Drawing was the initial form of communication in this design process, used to establish a starting point in the process by depicting the first forms that came to mind when conceptualizing floating, standing, or submerged houses. The first set of drawings consisted of architectural forms of houses. The 

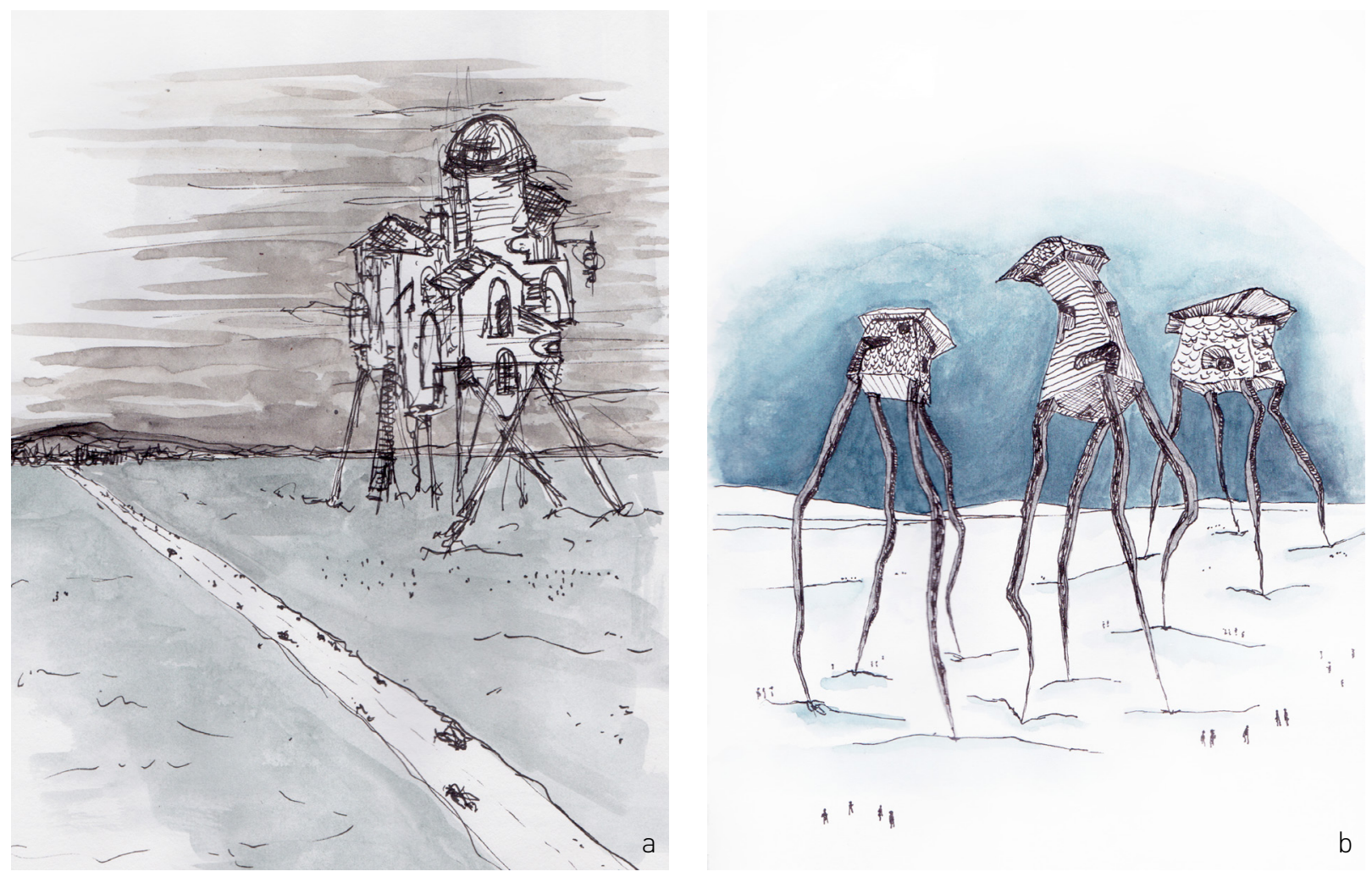

Fig. 35

Figurative Sketches of Houses of Air, Ground, Water

drawings were made with ink on paper, and later enhanced through watercolour. Each drawing was distinct from the other, each roughly depicting a house of the imagination. These figurative houses, despite their rough, sketched appearance, depicted precise qualities within the three settings. I was able to derive specific features from each one, whether it was its structure, its daring physicality, or its bold and unfamiliar forms. With this non-restricted form of design, I had the freedom to explore with varying drawing methods, shifting the mode of design from figurative architectural forms to conceptual drawings that represent an architectural idea. This fluidity in the process also allowed me to thoroughly analyze the forms and the compositions I was generating in the process. By simply depicting, it enables me to analyze an idea and determine whether a certain form or configuration would carry through within the design process or not. 

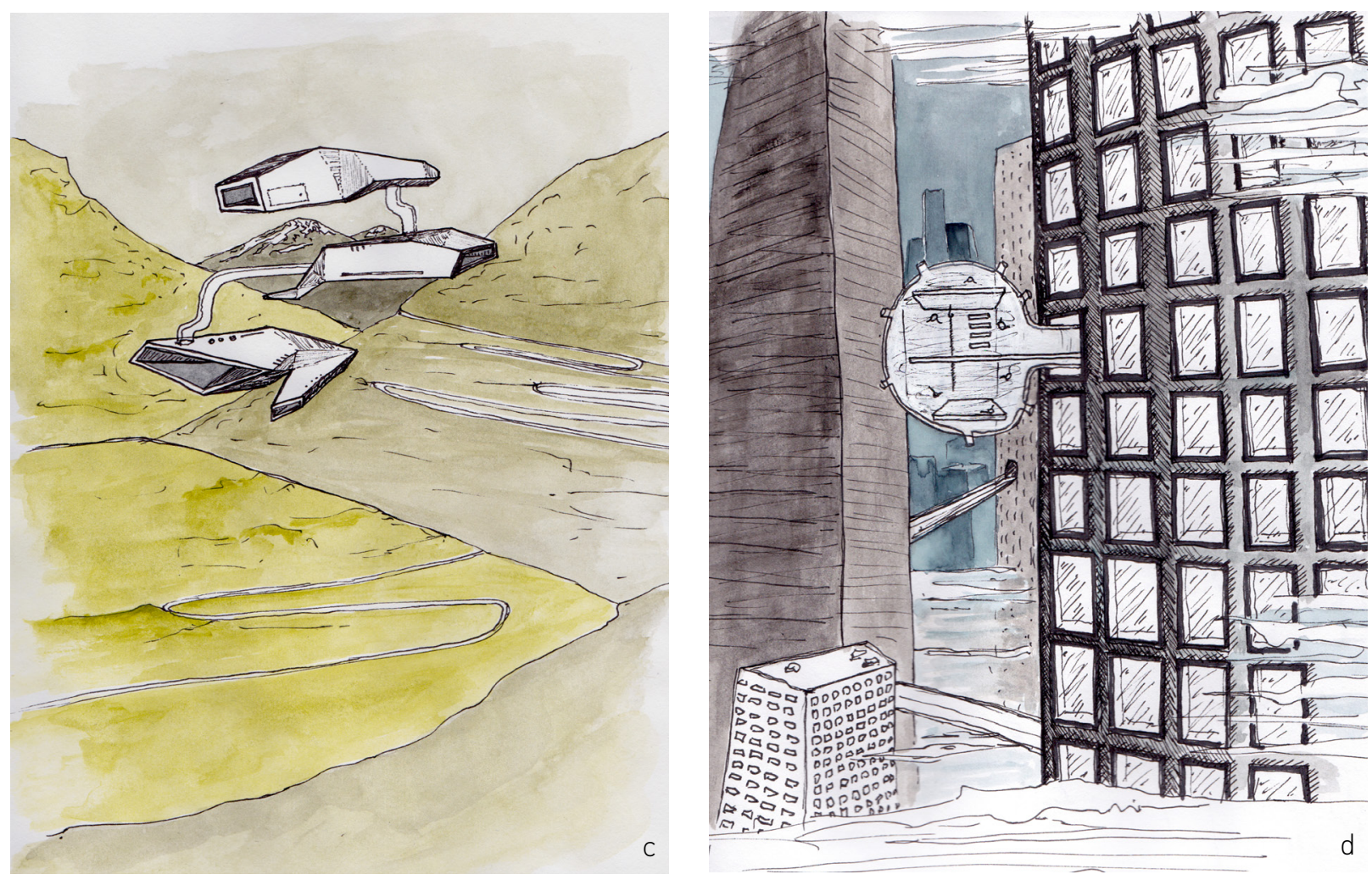

The second aspect of my design approach presented architectural concepts through a process of intuitive sketching, with the objective of seeing what forms could be generated through the process. These conceptual drawings were created through a process of layering pencil strokes. Each stroke represented a memory of the house, with different strokes of varying intensities. This intuitive method of rough sketching with pencil contributed to the procedure by pushing forth a design that was not based on images in the mind, but instead by slowly developing an assembly of arbitrary strokes. Architectural pieces such as these strengthen a form of trust between the designer and the medium used, a trust in how the medium will respond.

In the method of drawing the visually seen, discussed in chapter two, blind contour drawing requires the artist to refrain from 


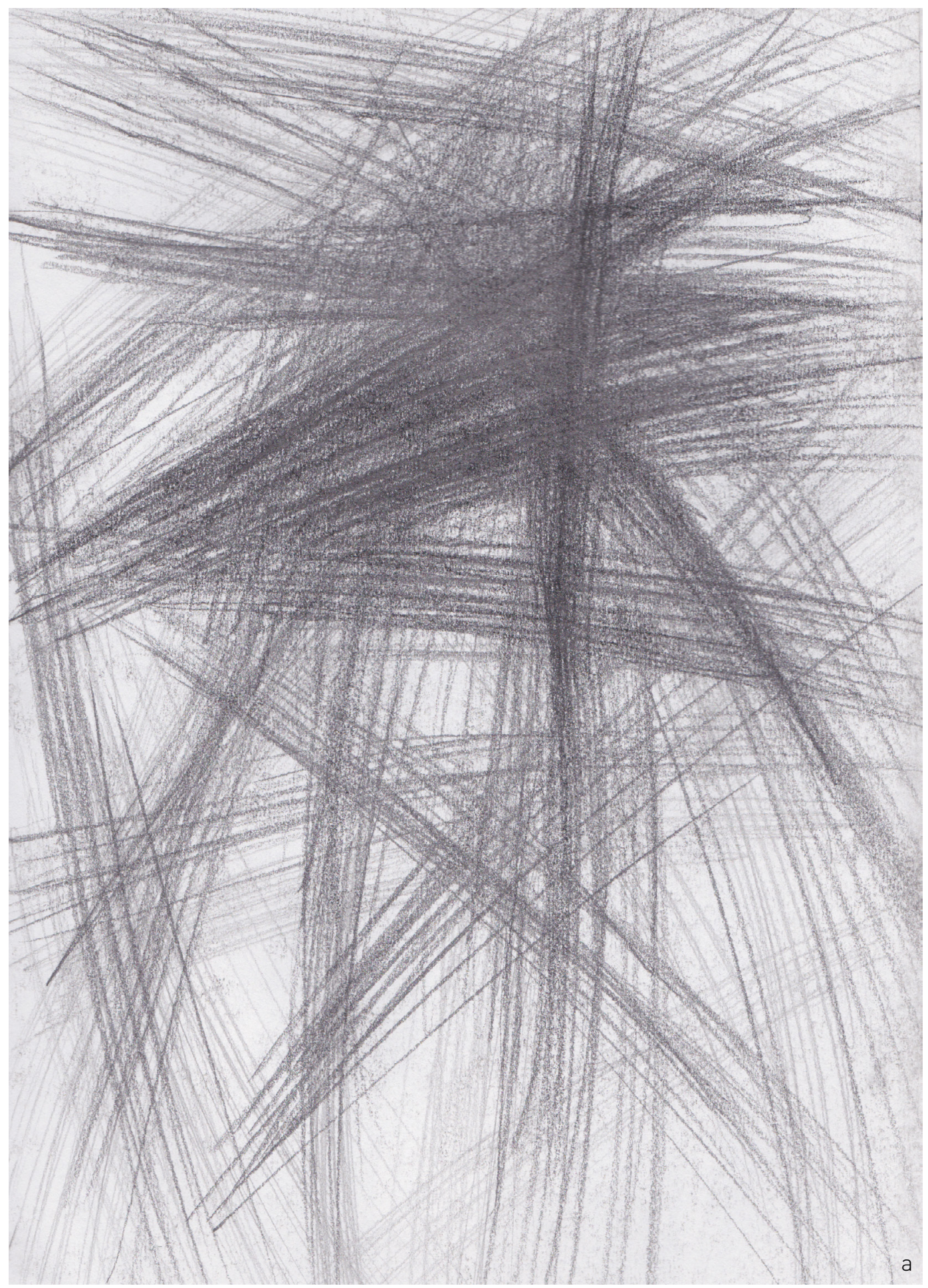

Fig. 36

Conceptual Pencil Sketches 


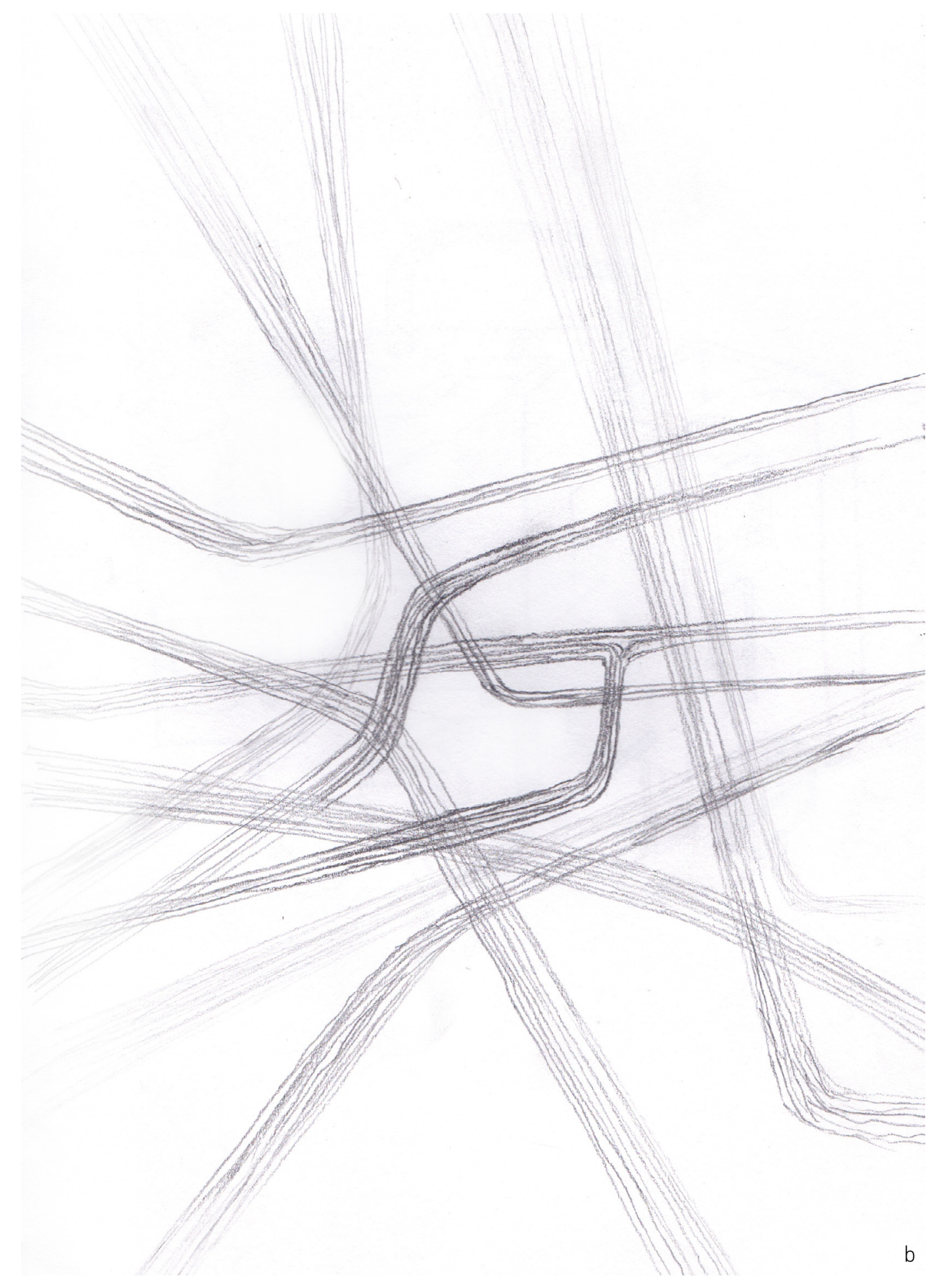



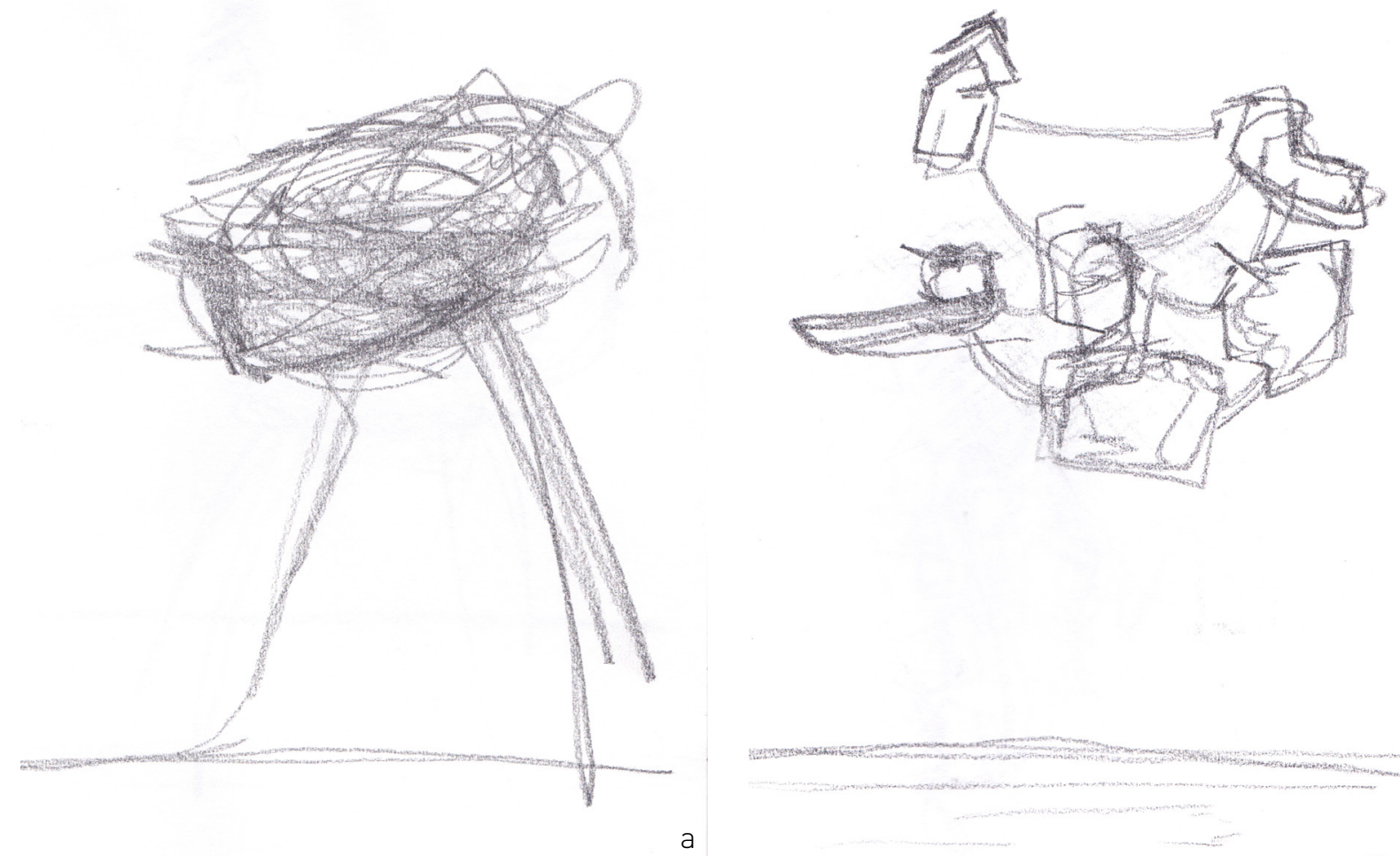

a

Fig. 37

Blind Contour Drawings of Houses

glancing down at the drawing and to keep their eyes on the subject being drawn. This method contributes to a spontaneous and imprecise depiction. Similar to blind contouring, I attempted to draw individual houses in each of the three settings, by closing my eyes and drawing. In this way, I was not able to see the depiction as it was unfolding, or to rely on a physical subject or object to represent. I had to rely on my imagination alone, all the while wondering how my thoughts would compare to the drawing. The spontaneity of the method accounts for imperfections in the line work, and it is these imperfections that give these depictions their value. Their significance is in their ability to express house figures in arbitrary style.

In the third design phase, I approached my house drawings with a similarly spontaneous design method, continuous contour 

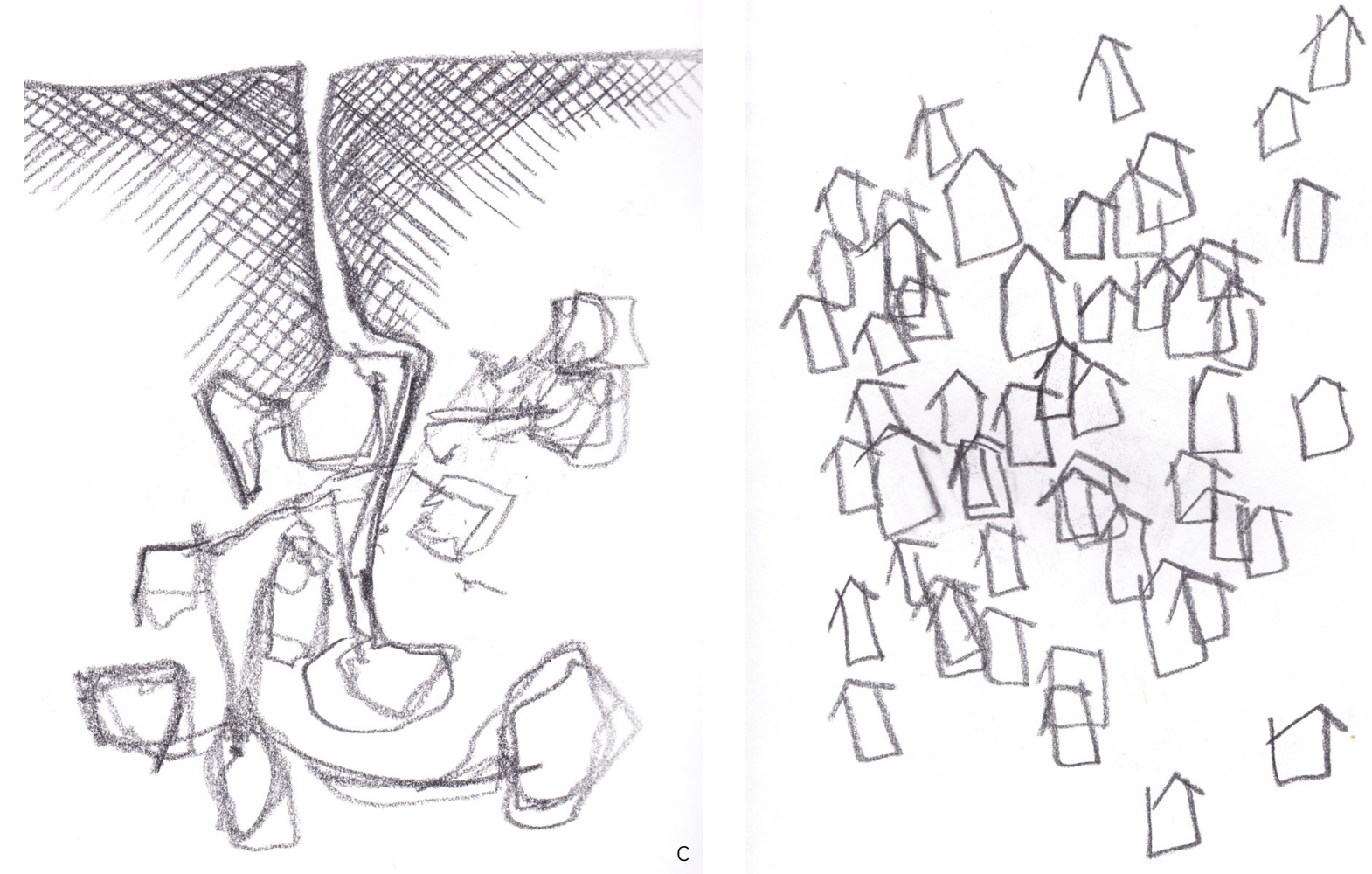

d

drawing. This method requires the designer to keep the drawing tool in continuous contact with the drawing surface, forcing the depiction to emerge quickly through line works and leaving very little time for thinking. The contour lines guide the design of the house as the line work forms irregular shapes with the pen's twists and turns in arbitrary motions and directions. Given the settings of air, ground, and water, I established a rough layout of where each house would go, but the continuous contour drawings were what gave form to the abstract houses in all three settings. It was through this design phase and through this drawing method that I began to think of all three of the house typologies as connected to one another in some way. This contour drawing method was not restricted to a specific geometric layout, or specific form, and so it was able to convey irregular figures, with nooks, curves and spirals that gave shape to smaller details of 


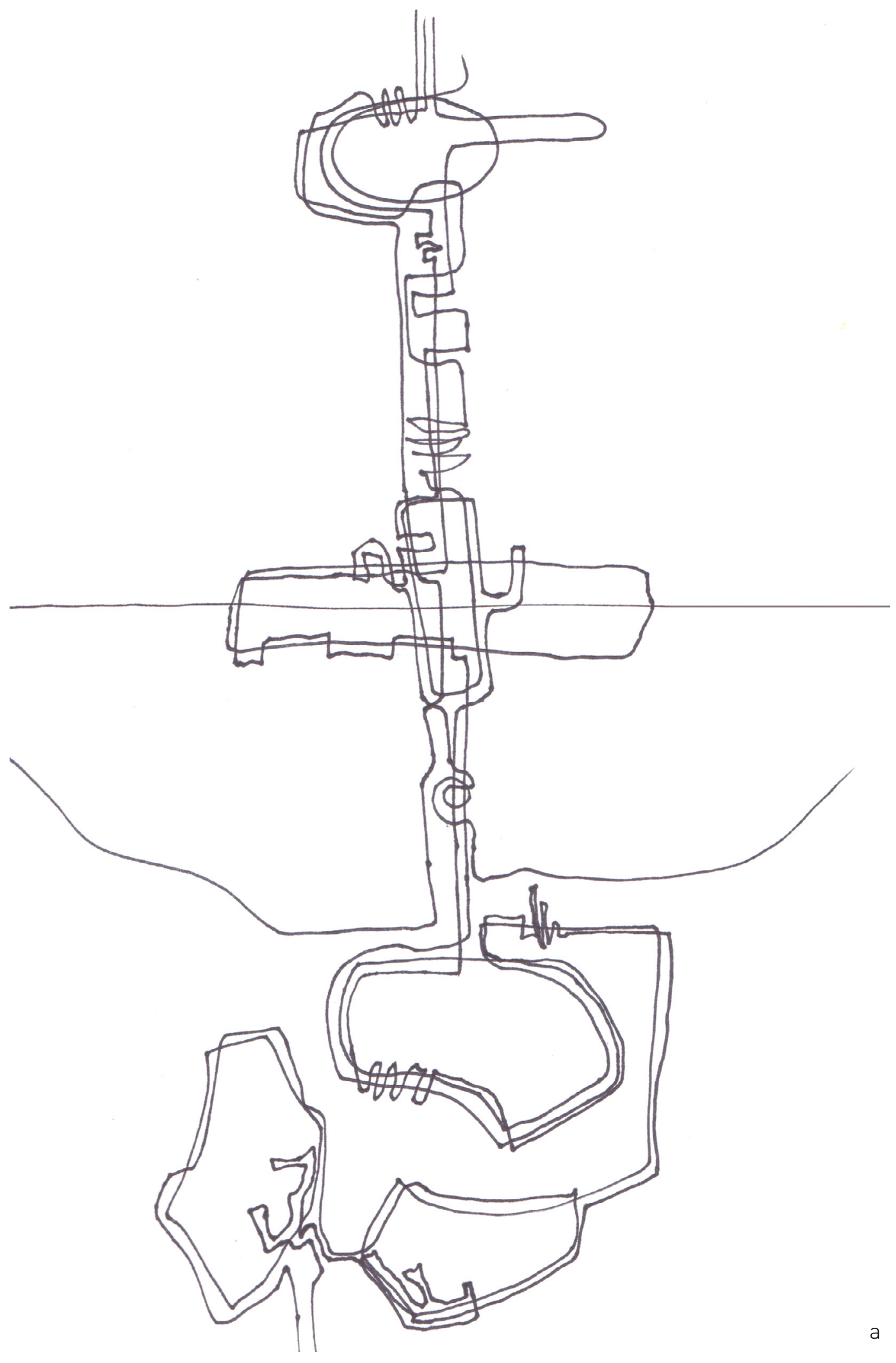

Fig. 38

Sectional Continuous Contour Drawings of Houses 


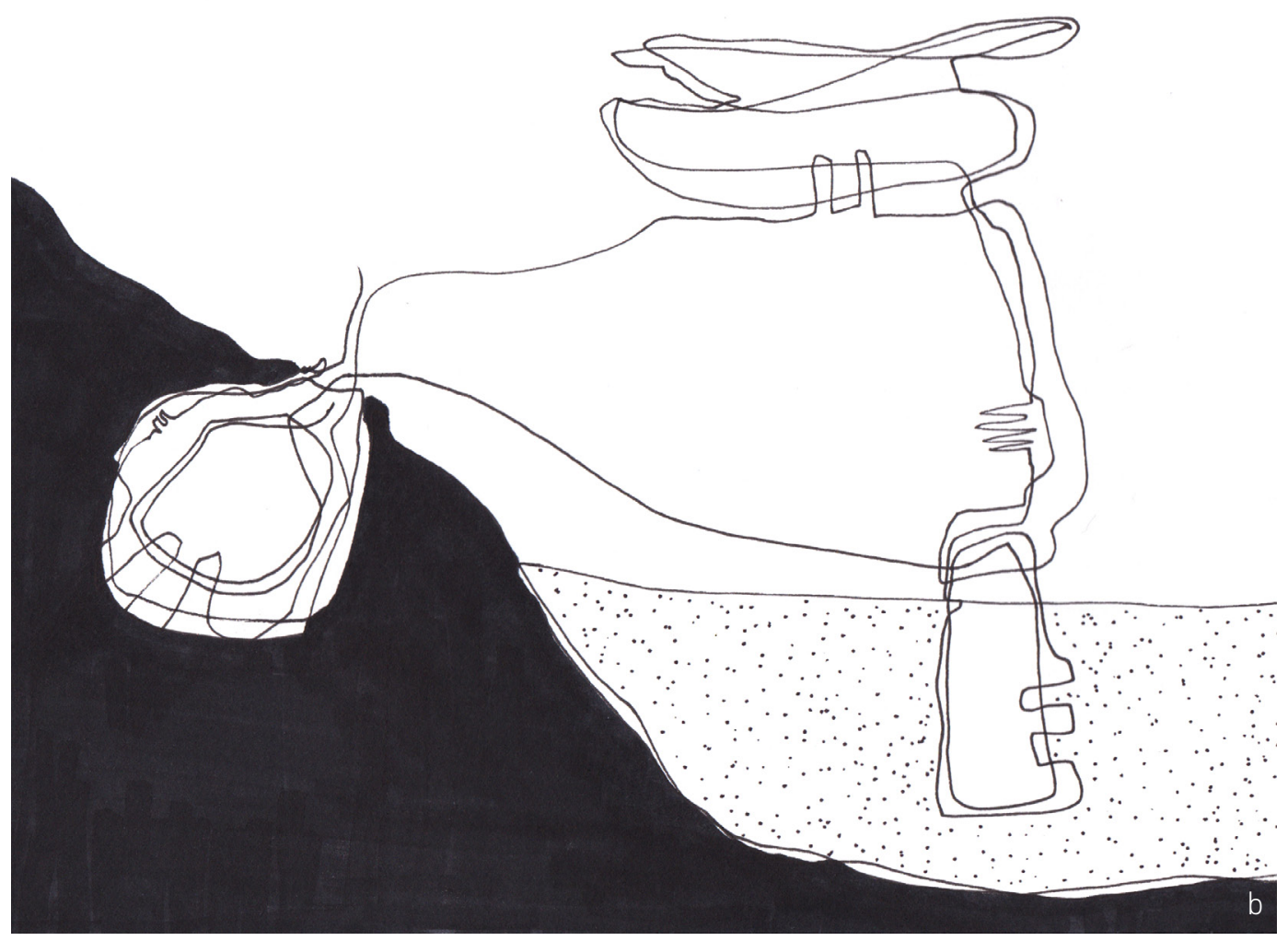


Fig. 39

Watercolour Drawings of Houses

the house. These depictions, in turn, contributed to the production that followed, setting out new boundaries for the design to be analyzed and developed further.

My following work, the fourth stage of design with air, ground and water, was built off the preceding house layouts, with each house established in its own setting, but now having a means of connection to the other houses as well. Through the application of watercolour brush strokes using precise techniques, architectural forms were constructed using strong geometric compositions. Each brushstroke depicted a volumetric arrangement of a house, a spatial configuration around it, or an interlaced circulation connection from one configuration to the other. Further to these watercolour depictions I developed additional paintings using the same brush techniques, but altered them further through the addition of fine ink sketching. The ink ad- 
ditions refine the depiction of the houses in further detail by using the watercolour strokes as a design guide. These depicted watercolours expand the imagination. They expand on what each volumetric shape can be, finalizing it with details such as doorways, windows, stairways, and structural supports. Despite the lack of practical detail within this form of watercolour depiction, these paintings are still able to convey an architectural idea, an idea that is strong and stands both as a singular piece and contributes to a larger whole. In this process, every small piece of depiction has value, notwithstanding its imperfect nature. What matters is that it played an important role at a point in time in the design process.

Given that each of the previous depictions in the process were able to generate their own forms and compositions through drawing, my next design phase aimed to translate certain forms from these 


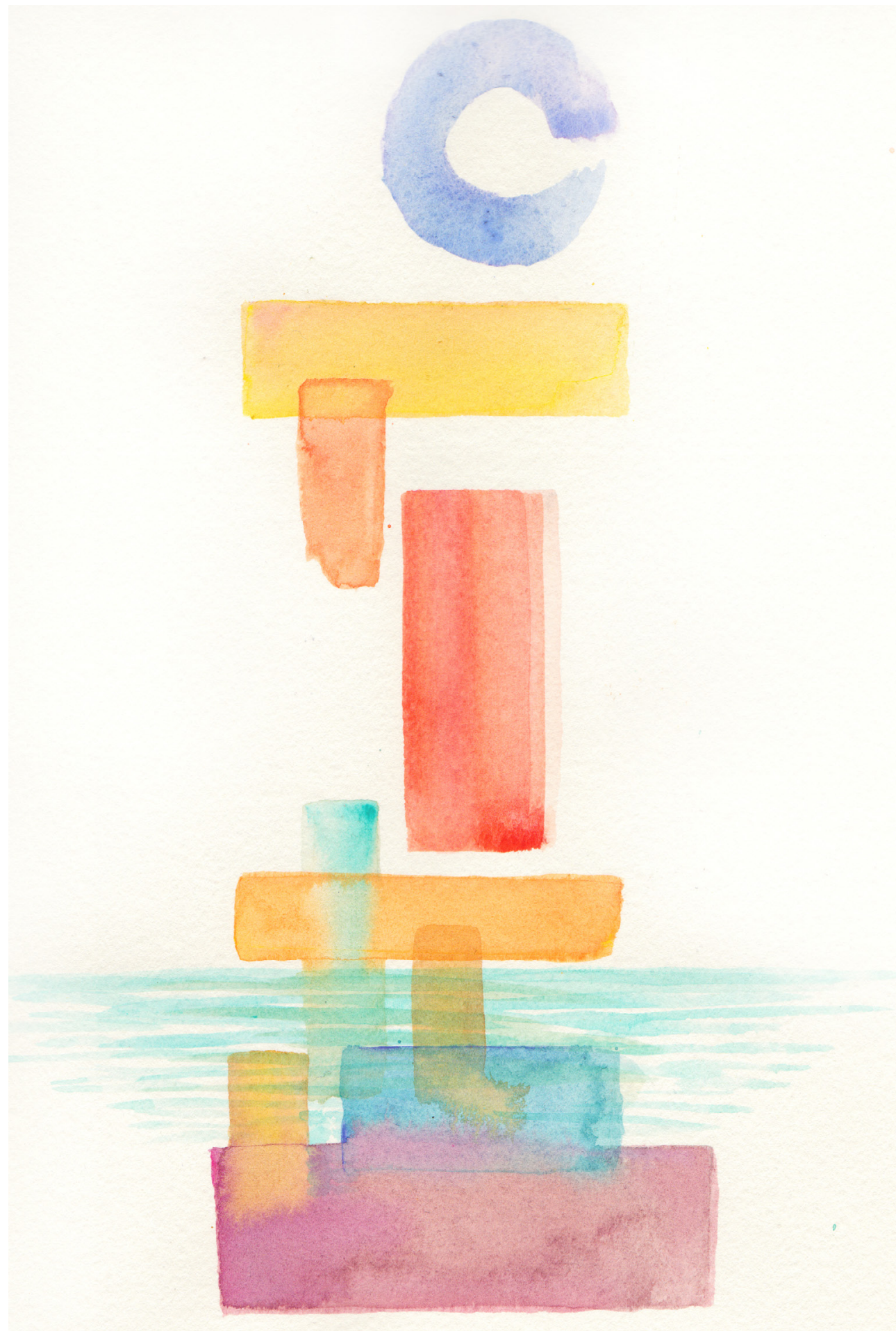

Fig. 40 Watercolour Drawings of Houses 


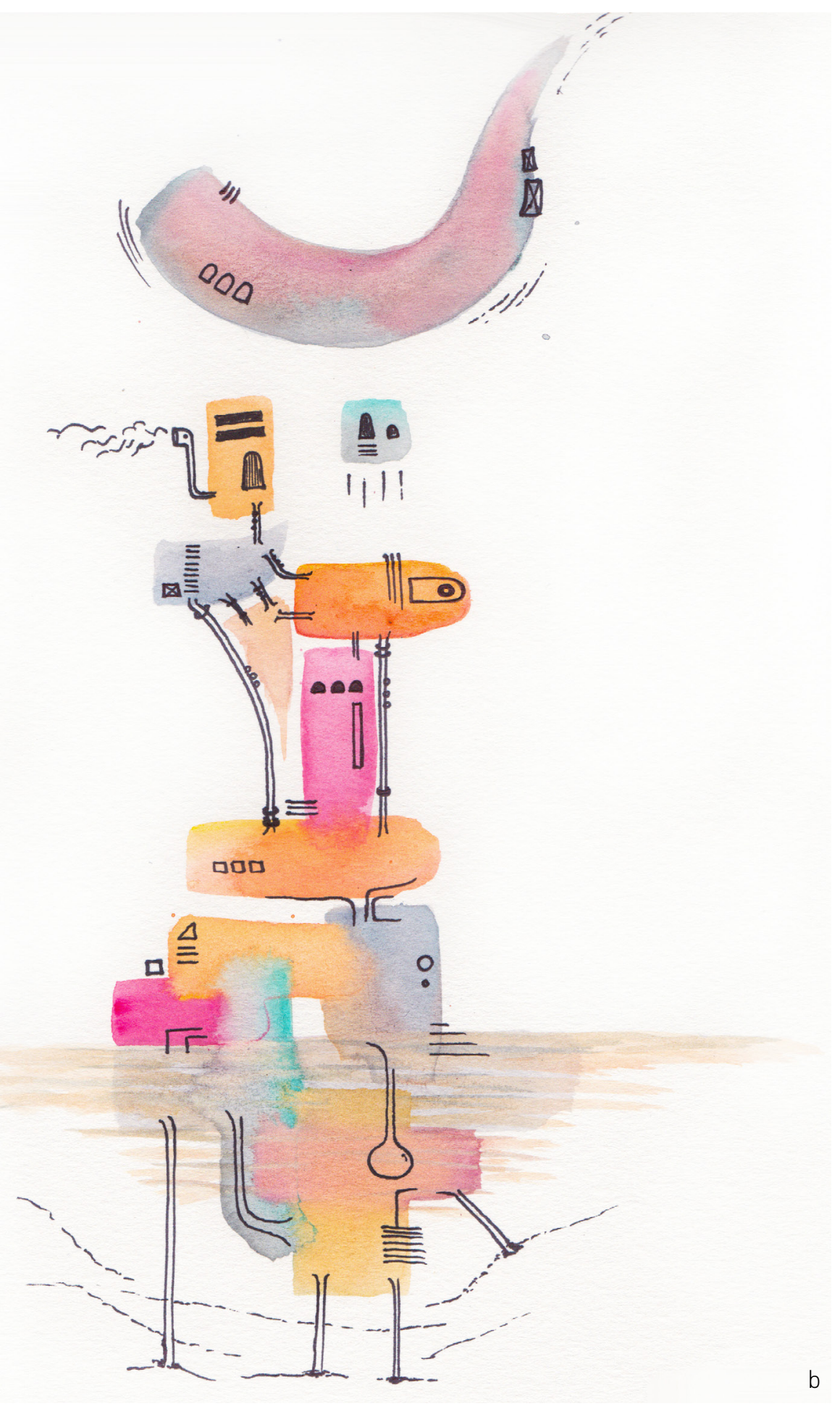



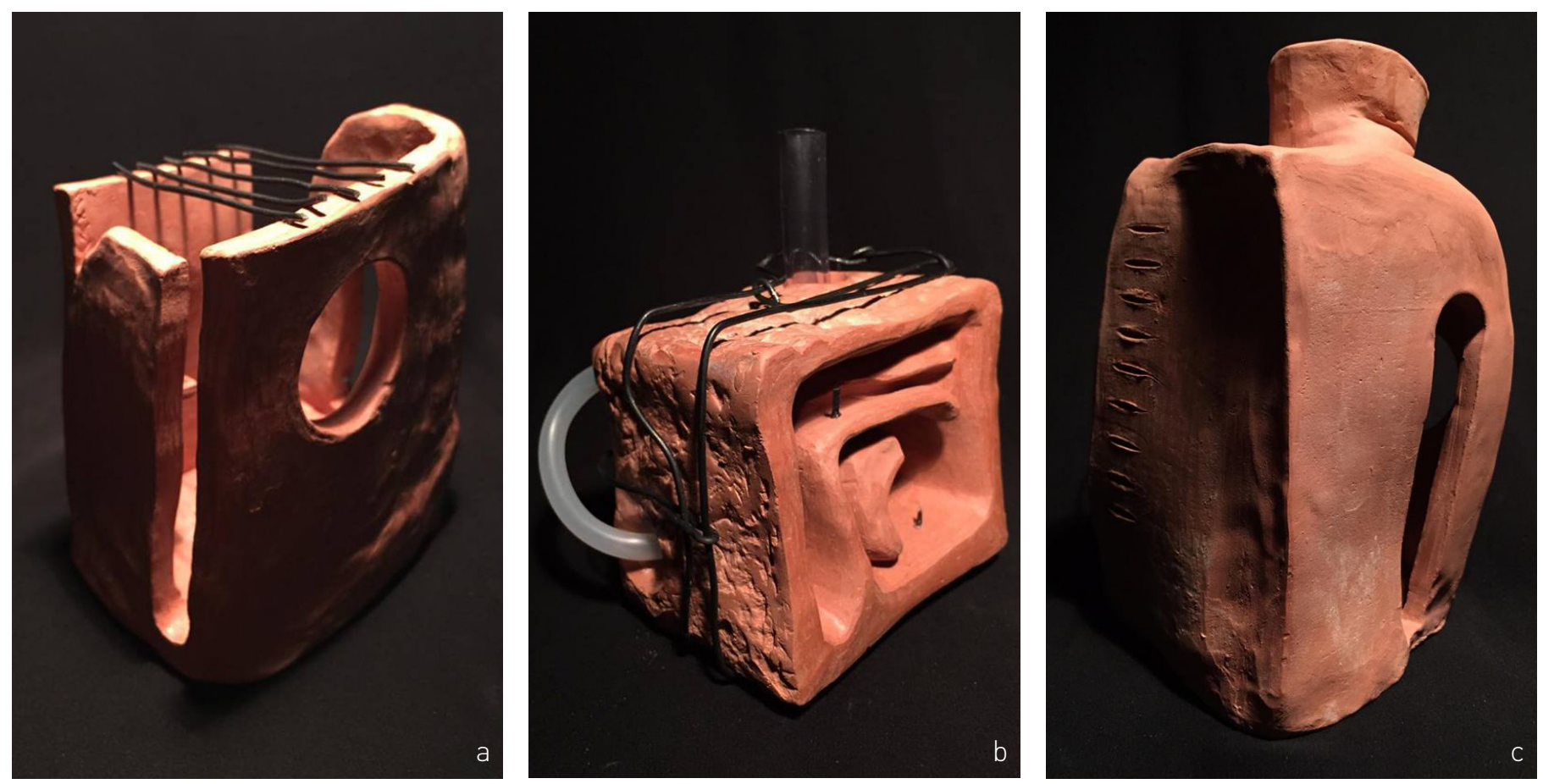

Fig. 41

Clay Houses

drawings to three-dimensional depictions. Working with varying mediums such as metal wire, paper-mâché, and pottery clay, I began to give physical shape to houses in air, ground, and water. Having no specific final form in mind, I approached the molding process as a speculative one, going along with where the medium leads me. Mixing different mediums together gave the design less of a monochromatic appearance; each medium dictated a different feature of the house.

The design of houses of the imagination shifted into one unified form in the next phase, in which all of the three settings were brought together as one entity rather than treated as separate ones. The impetuous for this shift came from the place of each depiction as a part of a larger whole. Each depiction represented a portion of a house, a house that is made real when these depictions of air, ground, and water settings are merged. 

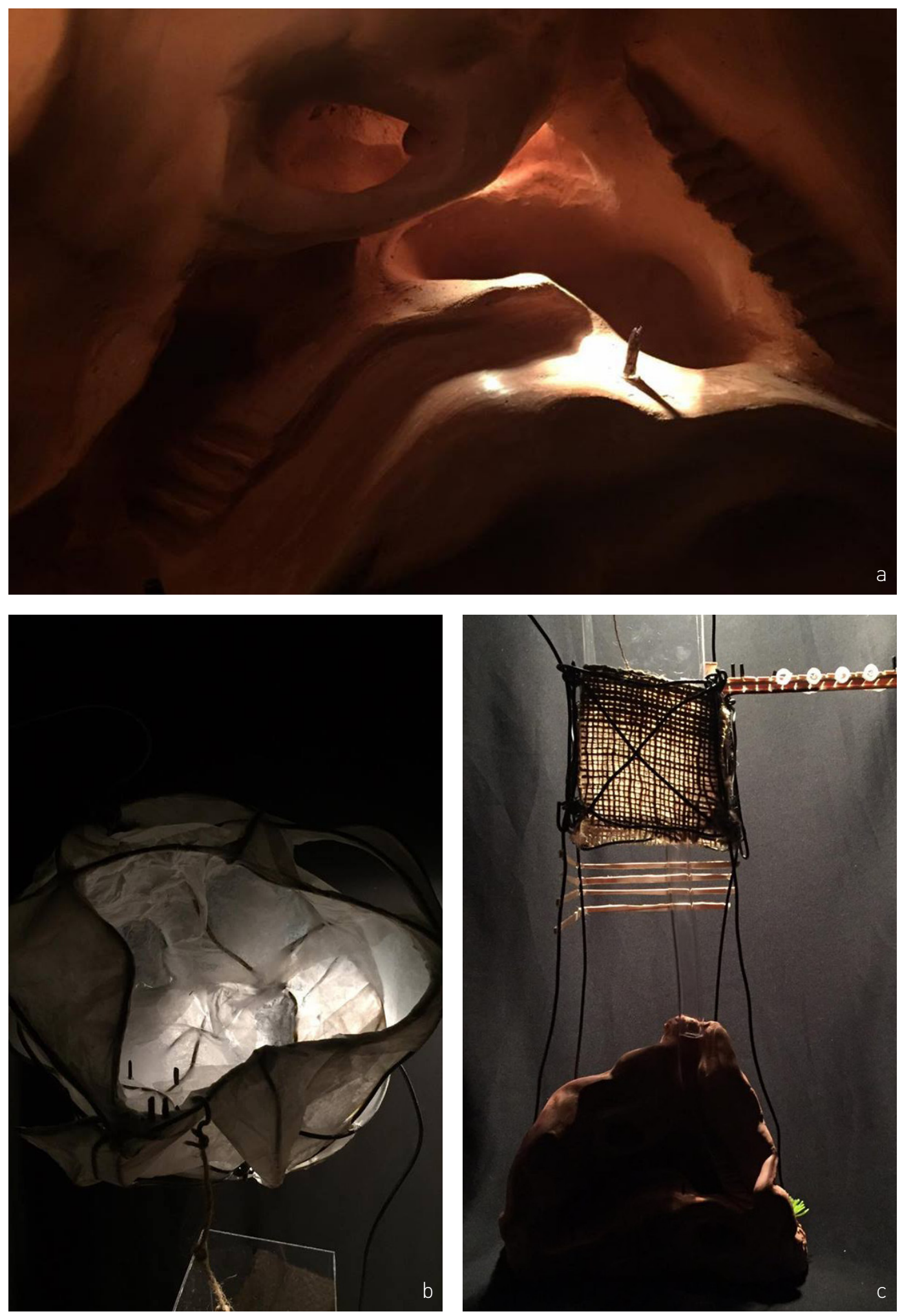

Fig. 42

Mixed Media Houses 


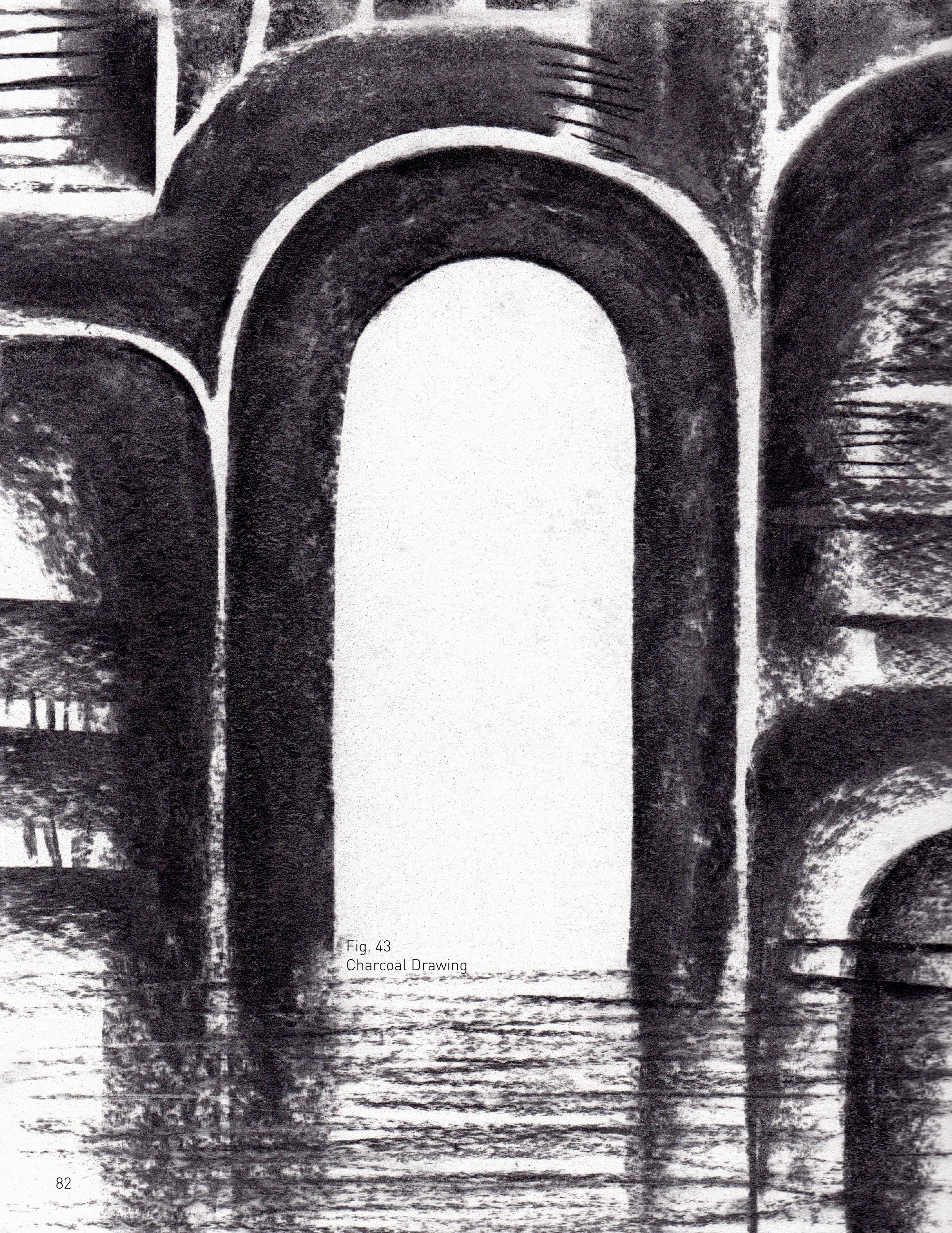




\subsection{Modest Mansion: Mountain Shoreline}

The architectural project for this thesis develops a Modest Mansion, situated along a mountain shoreline in a fictional setting. With the freedom of scale and size afforded by imaginary houses, it felt most appropriate to design the house as a mansion. And due to its simplistic character, it was named 'Modest Mansion'. A mountain shoreline was chosen as a setting that combines the three states of air, ground and water of the earlier design investigations together in one. This Modest Mansion is a merger of all the previous depictions and an extension of them to a form of house designed in a distant, secluded and idealized place. The design of the mansion shifts within this phase, alternating between more unified designs and more fragmented portions of the mansion. There are three main categories within this phase. The first approaches the design as a unified whole with multiple depicted iterations. The second concentrates on the fragments of the mansion, and formulates isolated, stand-alone parts to analyze and study their architectural forms. And finally, the third category consists of a cohesive design of the mansion, which was reached after extensive experimentation with various forms of depiction and drawing techniques. In this final stage, the design slowly starts to shift into a mansion that is made real through these design explorations and speculations in different mediums. Drawing out forms and building experimental models in the chosen settings introduces architectural forms that can be critically analyzed, and that can impact other built realities. The intention here is to create forms concerning architectural topics that have not been given sufficient attention in the architectural discipline due to their non-standard characteristics. These depictions are significant architectural works that portray a deeper study and analysis of houses of the imagination. 


\subsubsection{Unified}

The Modest Mansion steadily began to take a more refined form with every depiction, whether it was drawn, painted, sculpted, photographed, or digitally produced. Building off of the previous design explorations and approaching the design in a unified style, multiple design iterations were developed in this phase using varying mediums and techniques. The first unified design I produced was made by drawing geometric architectural forms using charcoal sticks and the motion of curved hand gestures. The length of the charcoal stick was used as a guide in determining the geometric forms that were produced. These simple charcoal strokes, through their curvatures and linear forms, began to generate arches, doorways, platforms, walls and roofs, on top of a water surface, along a mountainside, and suspended in an infinite sky. The mansion is given its majestic shape through vastly scaled compositions, which combine smaller elements of the house into one unified mansion. These charcoal depictions present an imaginable setting through a black-and-white shading effect. The medium's fragility gives the depictions of the Modest Mansion a dreamlike essence, depicting a place and an architectural form of isolated nature, a place faraway that is not yet discovered. "For the real houses of memory, the houses to which we return in dreams, the houses that are rich in unalterable oneirism, do not readily lend themselves to description. To describe them would be like showing them to visitors. " It is through these silhouette black-and-white depictions that this mansion is made real in its abstract setting.

The next design iteration in this phase was to translate those elementary silhouettes into more elaborate depictions, ones that gradually begin to detail the Modest Mansion. In this phase I began to formulate depictions using a collaging technique through imprinting cut outs of patterned prints in similar geometric forms to those of the charcoal drawings. The process of imprinting images, and its mirrored figure results, adds suspense to the final form of the composition. Once all the images were revealed within the depiction, a unified mansion began to appear as a whole. The depiction was then 

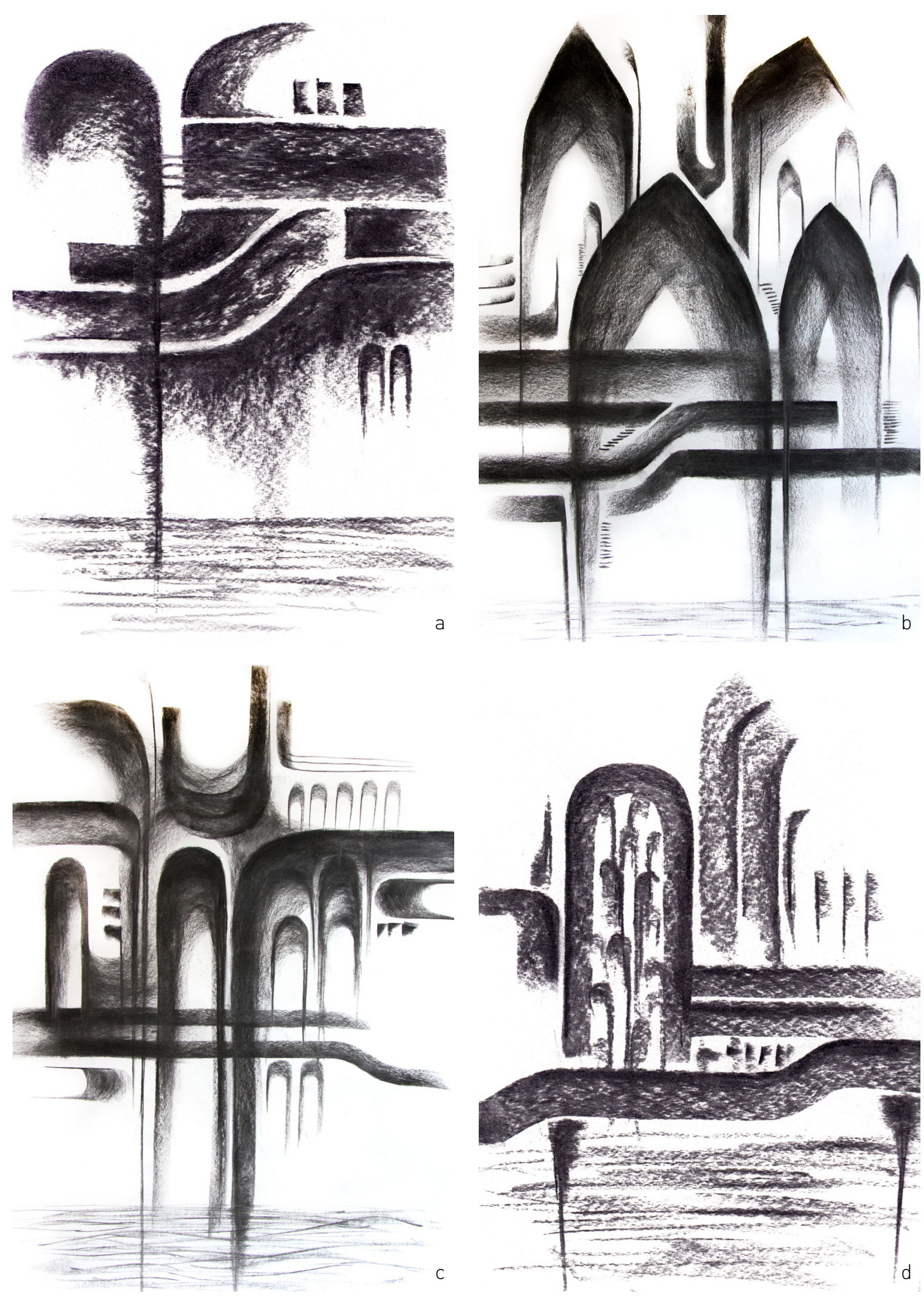

Fig. 44

Charcoal Drawings of Unified Modest Mansions 


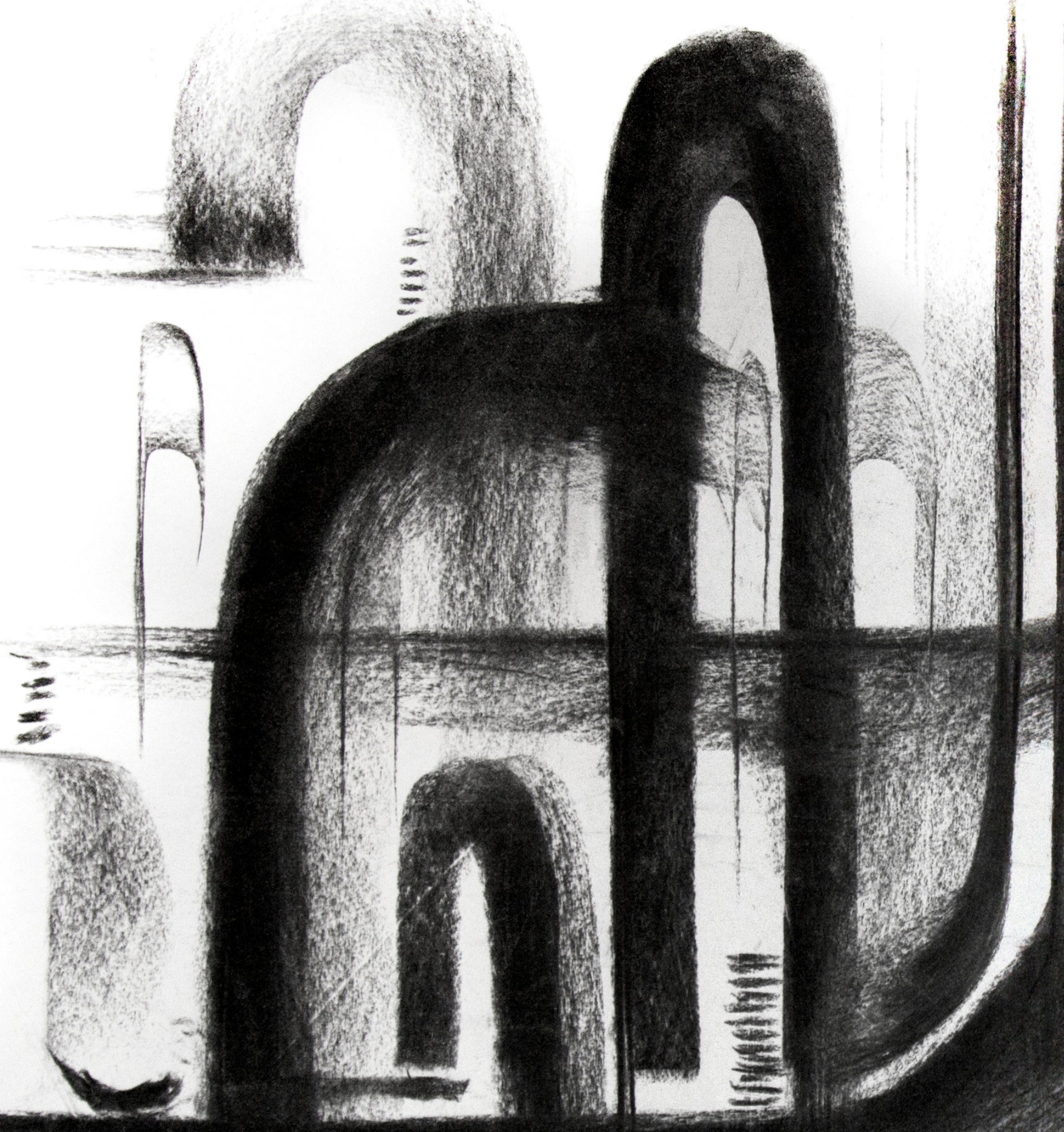





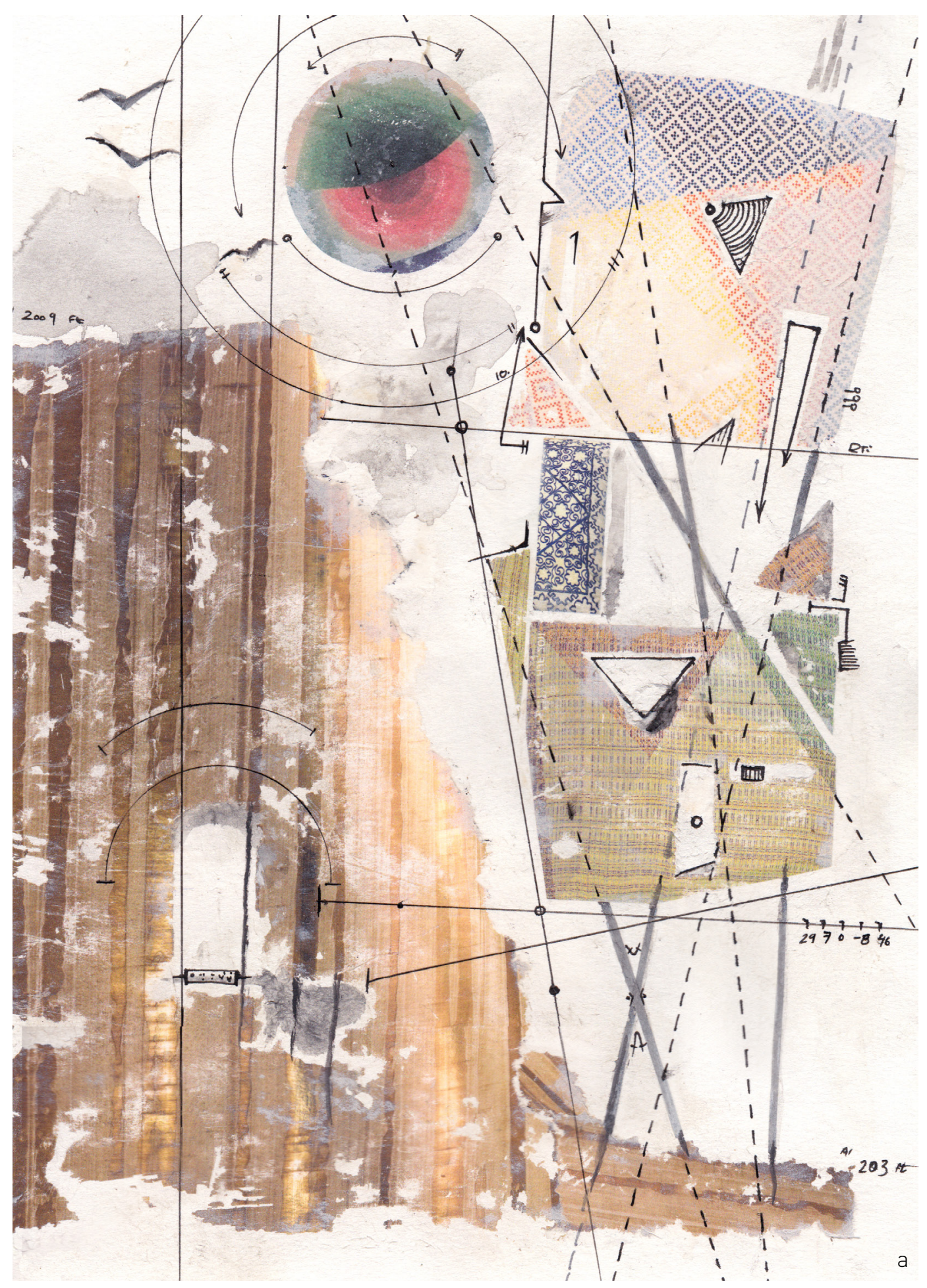

Fig. 46

Collaged Depictions of Unified Modest Mansions 


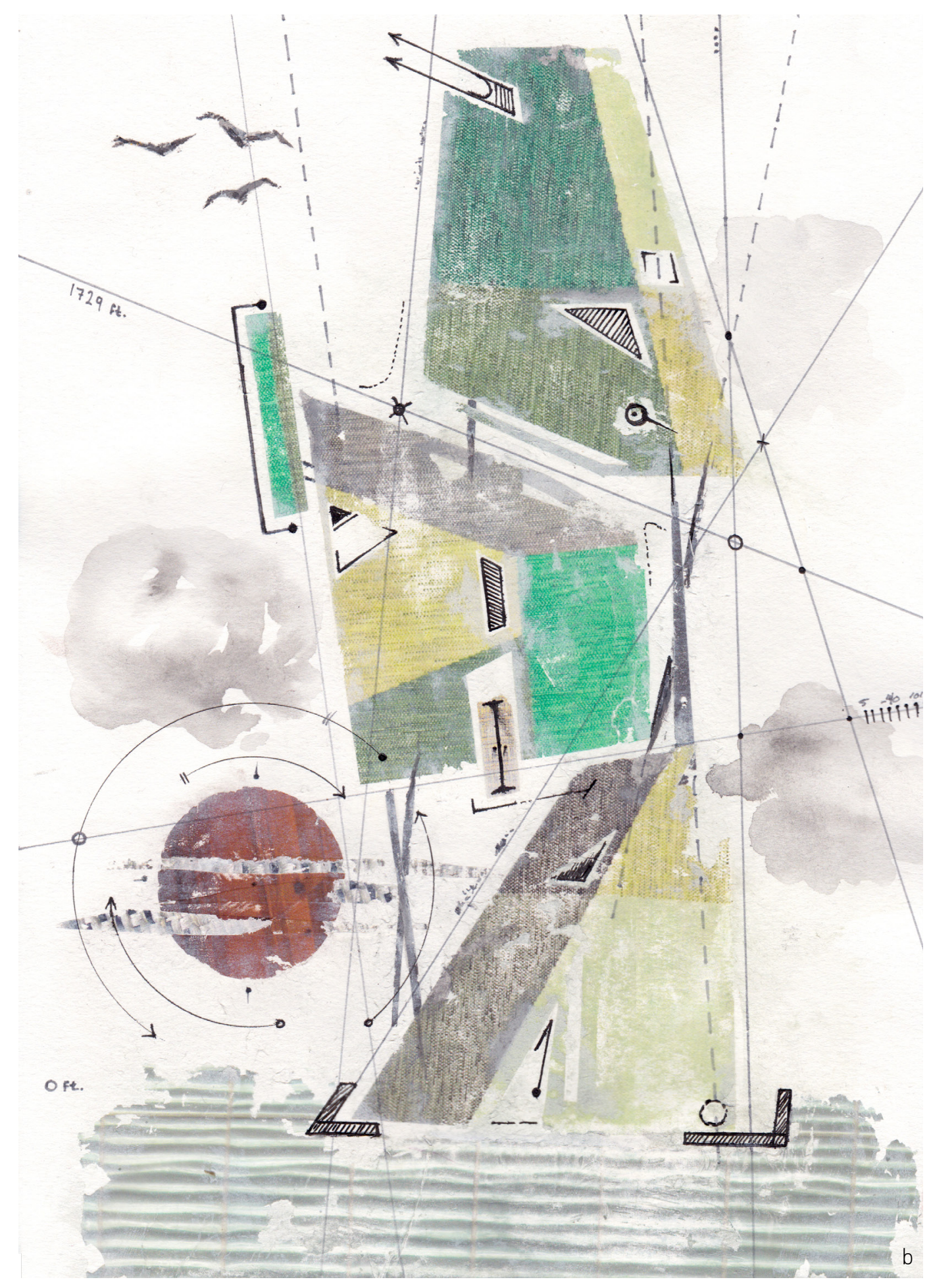




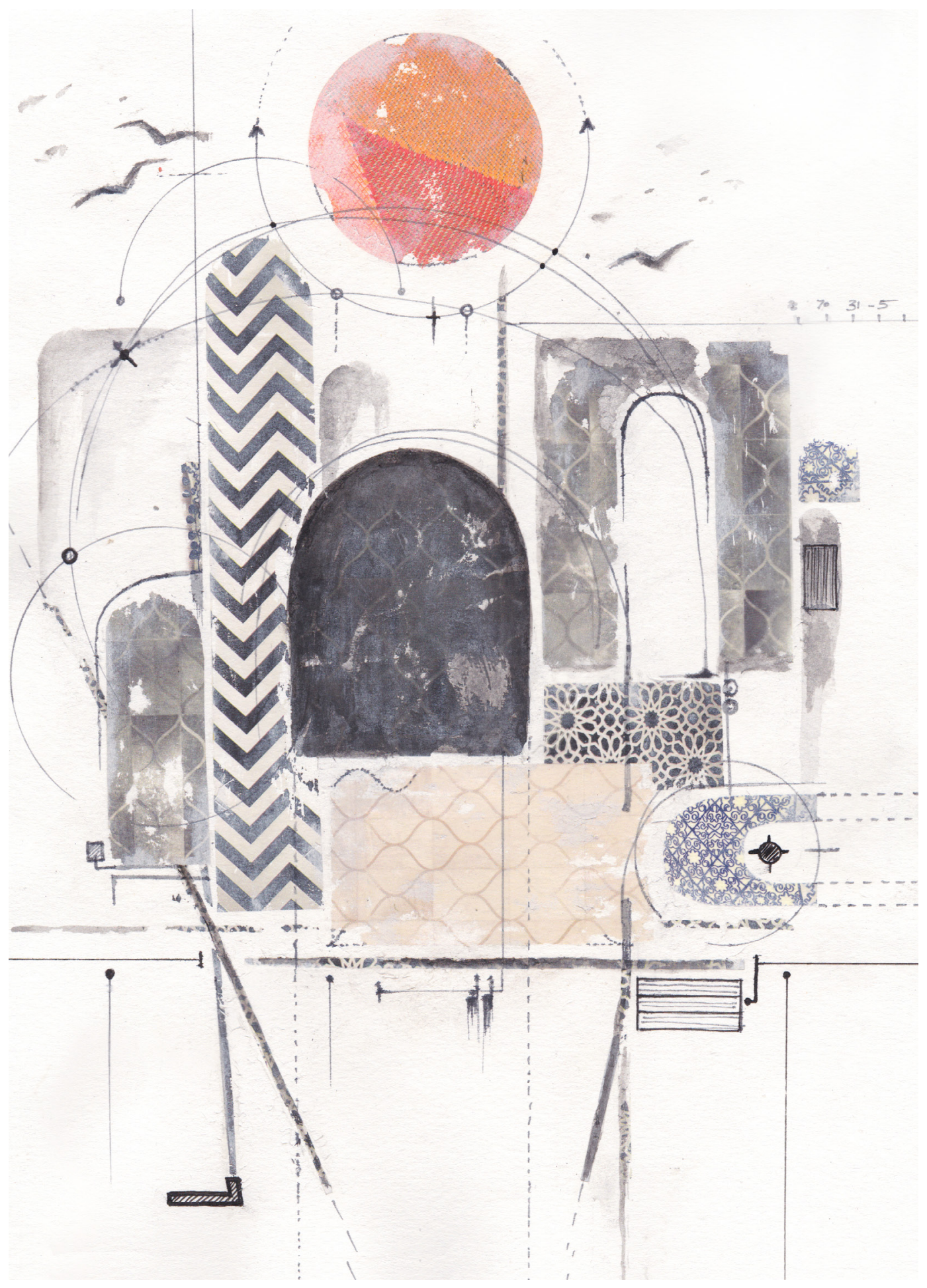

Fig. 47

Collaged Depiction of a Unified Modest Mansion 
enhanced with ink and pen line work. Drawing on the collaged depiction added further detail to the mansion design by emphasizing the linear and structural systems of the drawing and architectural notations that are distorted to represent the imaginative state of the mansion. The imprinted figures in these collaged depictions showcase potential material, texture, and colour configurations of the varying fragments of the mansion. Through these collages, the first set of iterations was explored at a smaller scale, and subsequently explored at a larger scale using more elaborate types of production, imprinting, and drawing techniques. These collages helped to shape a better understanding to the forms that would generate the overall Modest Mansion.

The forms that were developed through these collages were then translated into axonometric drawings. I began to draw out smaller fragments of the mansion that depicted thresholds, corridors, stairways, and halls through these axonometric projections. Through the use of projected hand drawings, digital programs, and physical models, I was beginning to formulate a better three dimensional understanding of the forms generated with the aid of all the previous depictions. By studying the Modest Mansion from a three dimensional perspective, a better understanding of the architectural spatial configuration of the form emerged. This design iteration was a form of transition in formulating an elaborate depiction of the Modest Mansion, one that took on a less conceptual design approach.

The next shift was to move into digital production and to speculate upon what forms of depiction could be generated from this method. This form of drawing and form making was not used to translate the handmade forms of depictions that preceded the digital works. Rather, it was used as an alternative method capable of generating forms of its own with more ease and perfection due to the speed and precision of the techniques. Using a selection of computer programs 


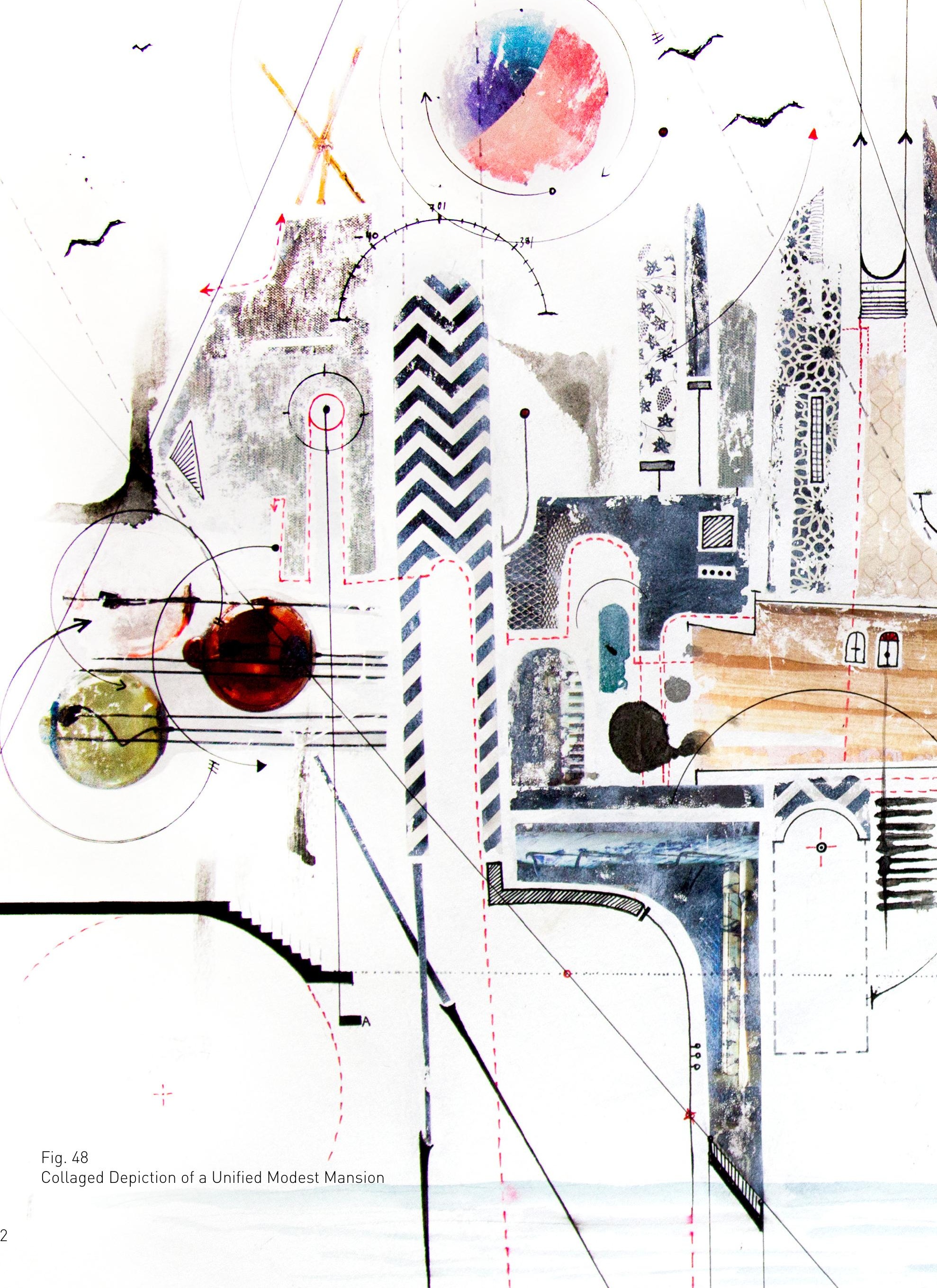




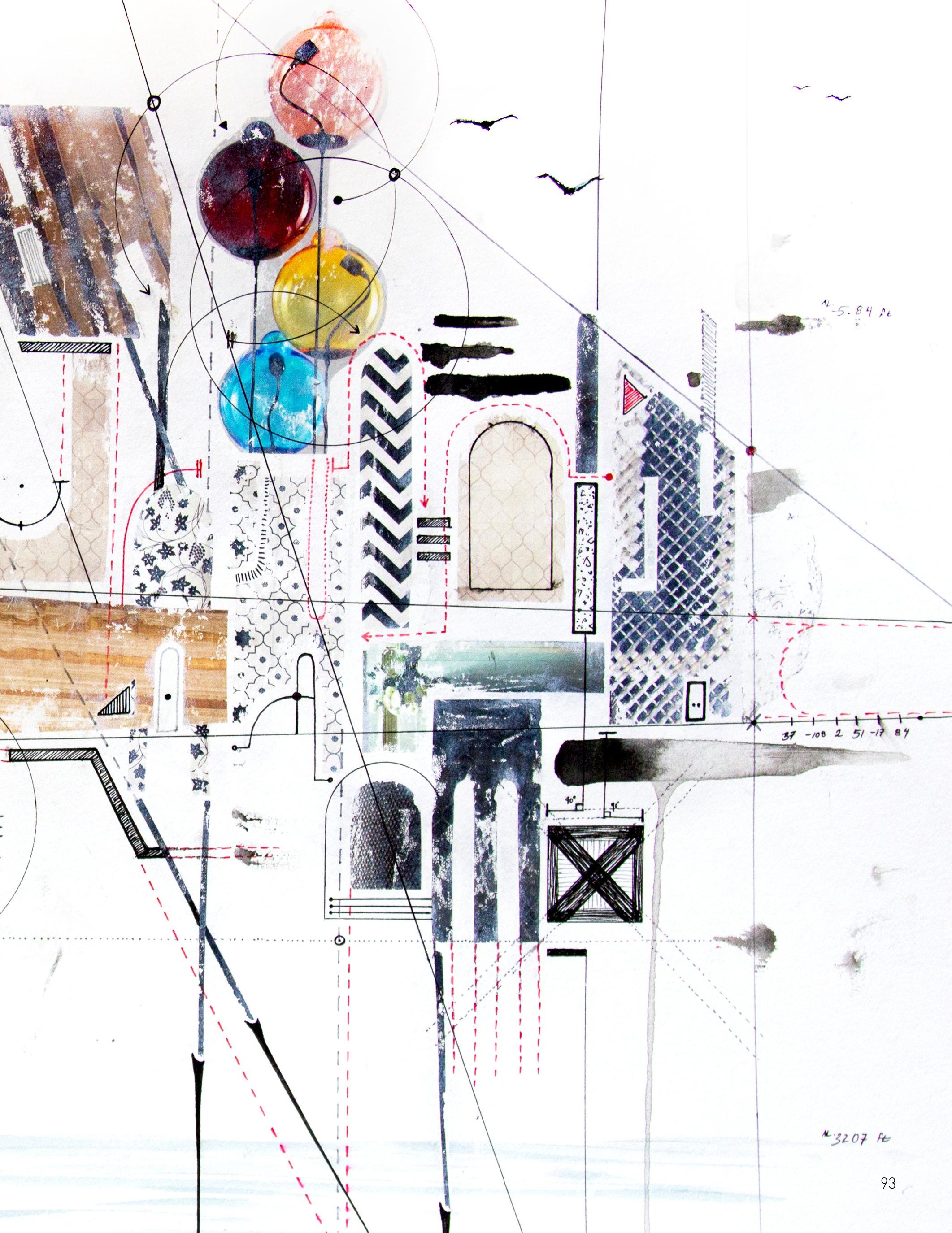




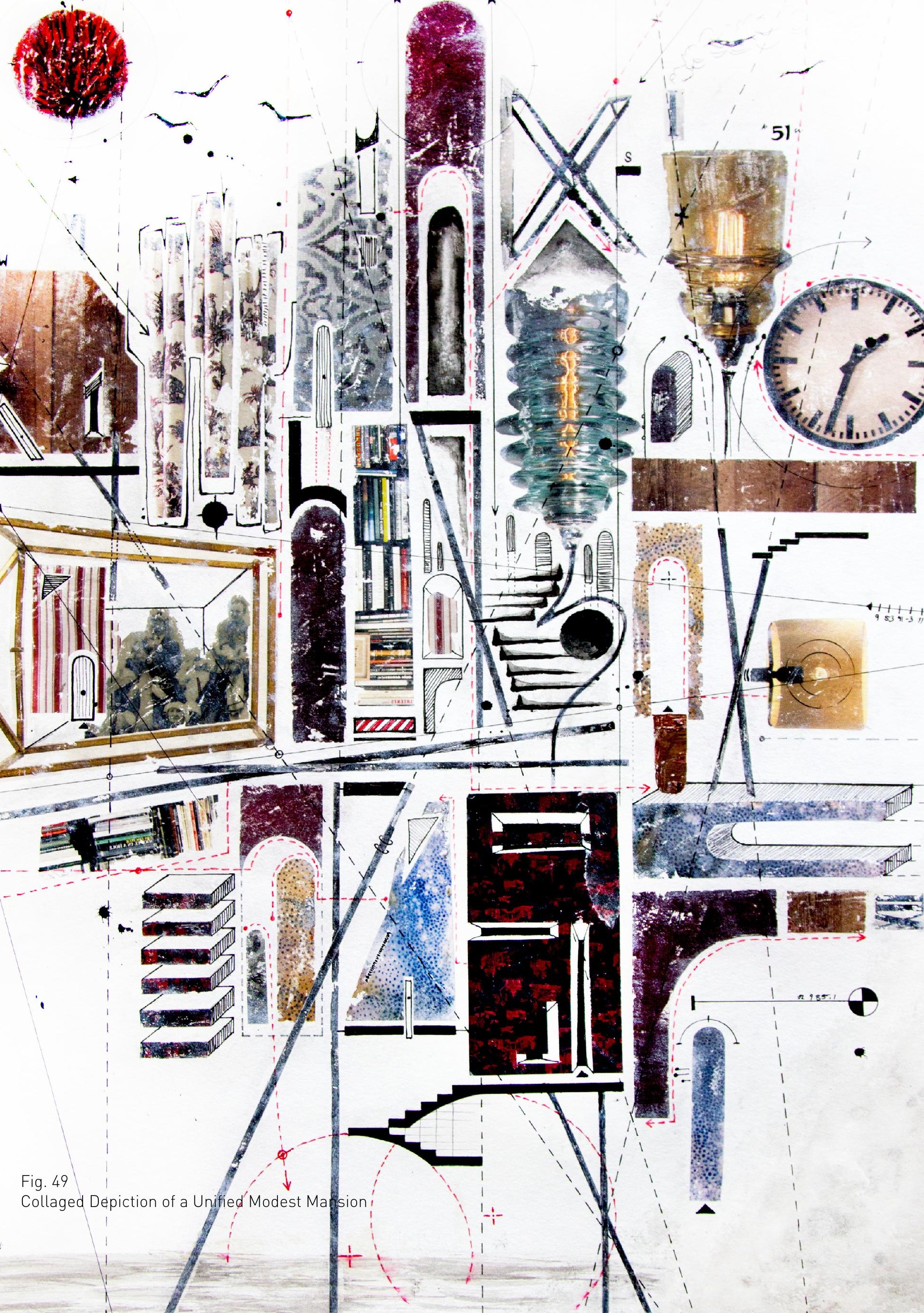



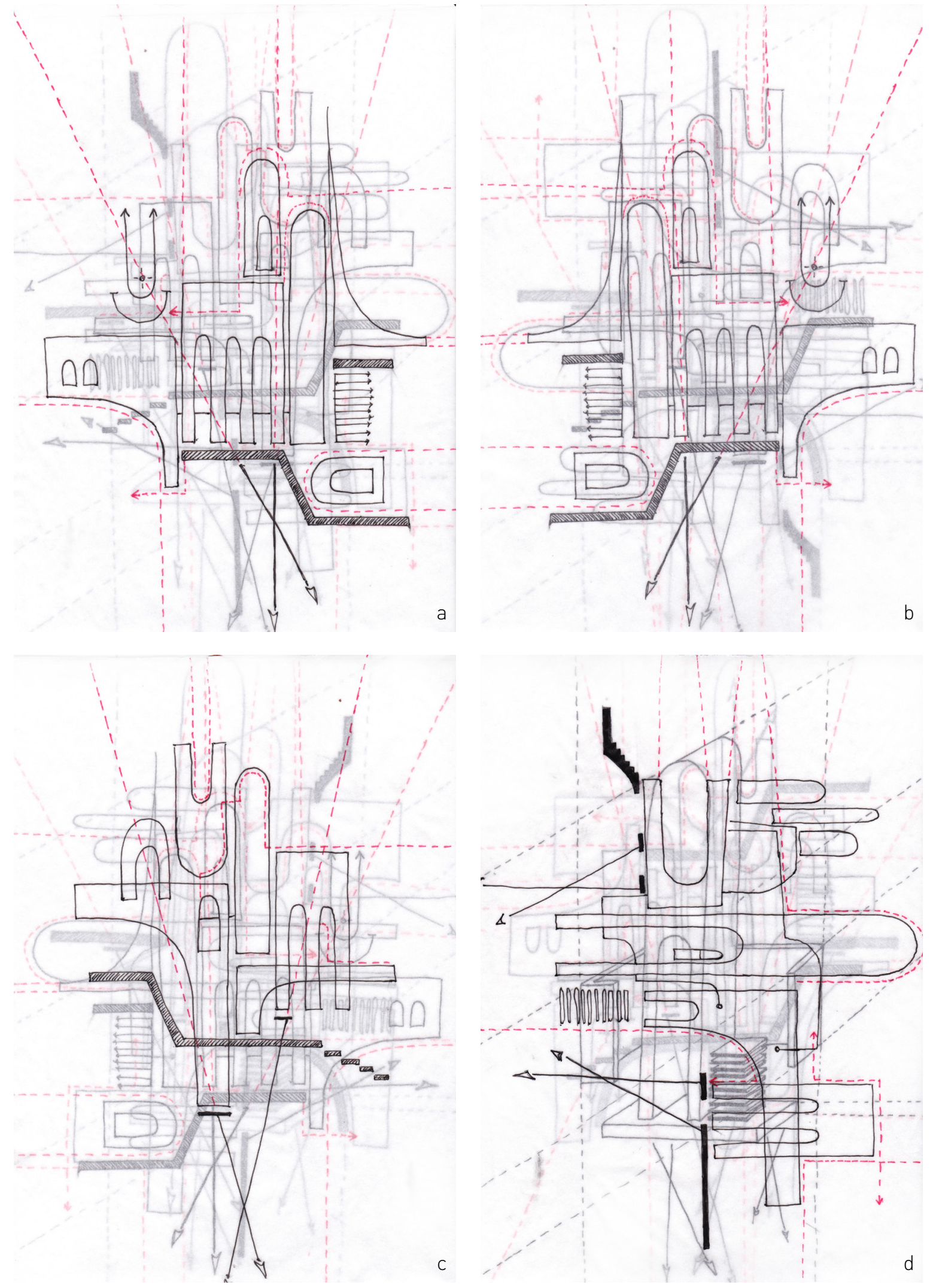

Fig. 50

Layered Drawings of a Unified Modest Mansion 
that are able to coherently work together to produce a digitally formulated design (i.e. Rhino, Revit, CAD, Photoshop and Illustrator) I speculated upon architectural forms for the Modest Mansion.

Each form of depiction has its defining qualities, whether it was handmade or digitally produced. Every depiction within the overall design process was of significance in informing the next proceeding phase. Certain elements of the Modest Mansion would carry through and develop in a new way using other modes of production. The underlying architectural idea is carried through with every depiction, even though the mediums and methods used when depicting an architectural idea differed. Every method of depiction imprints its unique qualities into the design of the unified Modest Mansion; with every speculative depiction, the design pushes the architectural idea further. 


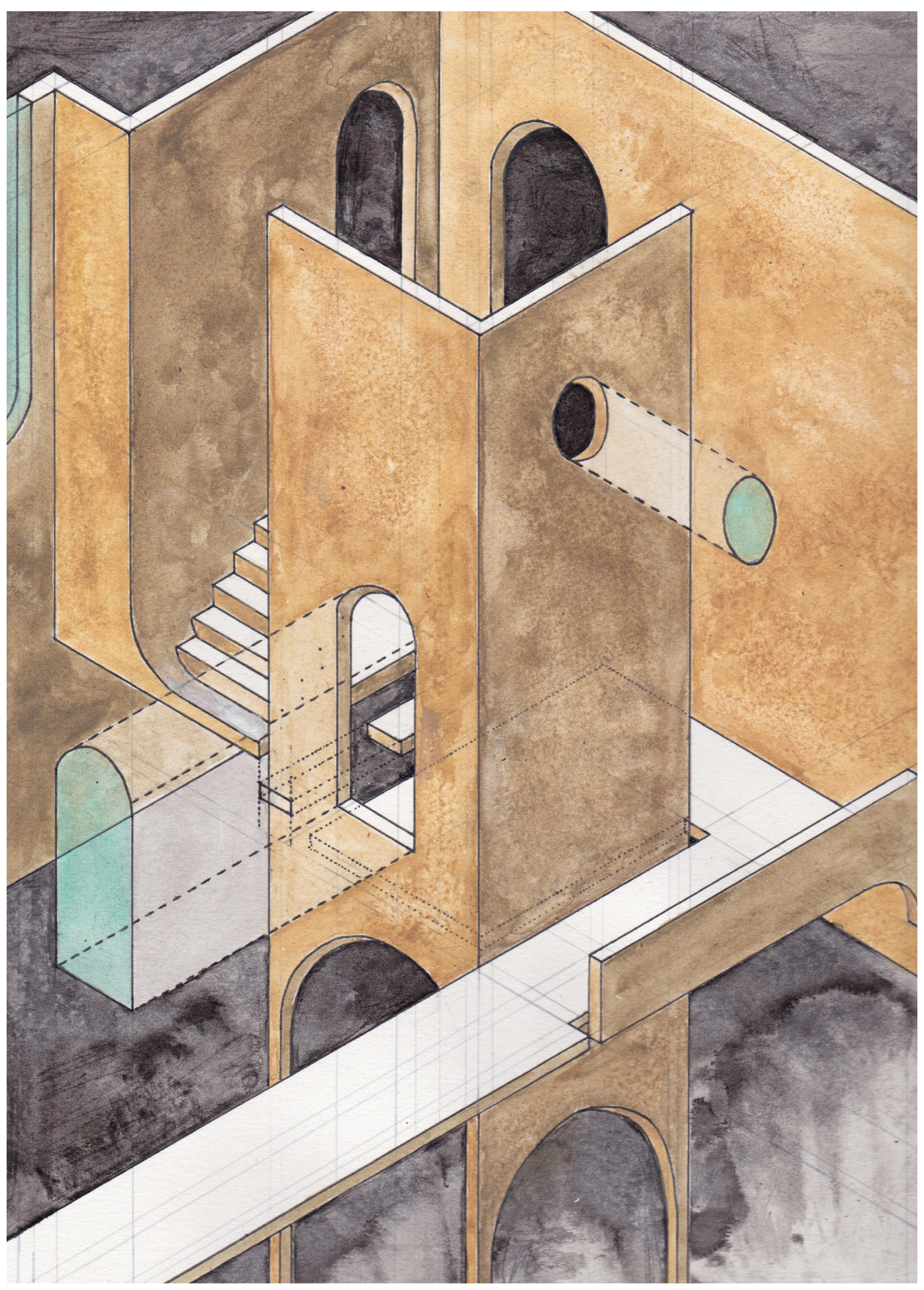

Fig. 51

Axonometric Painting of a Unified Modest Mansion 


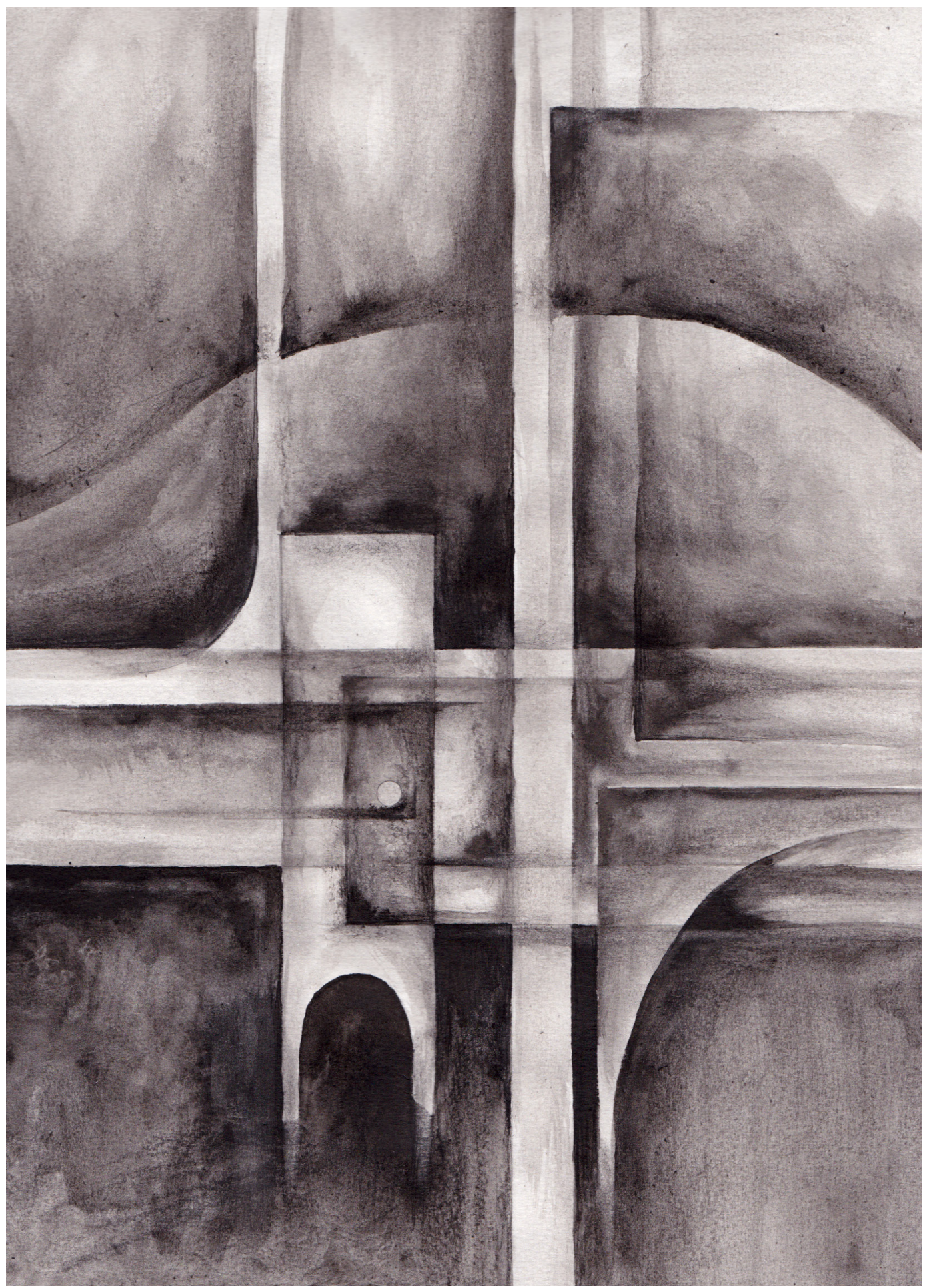

Fig. 52

Painted Plan of a Unified Modest Mansion 


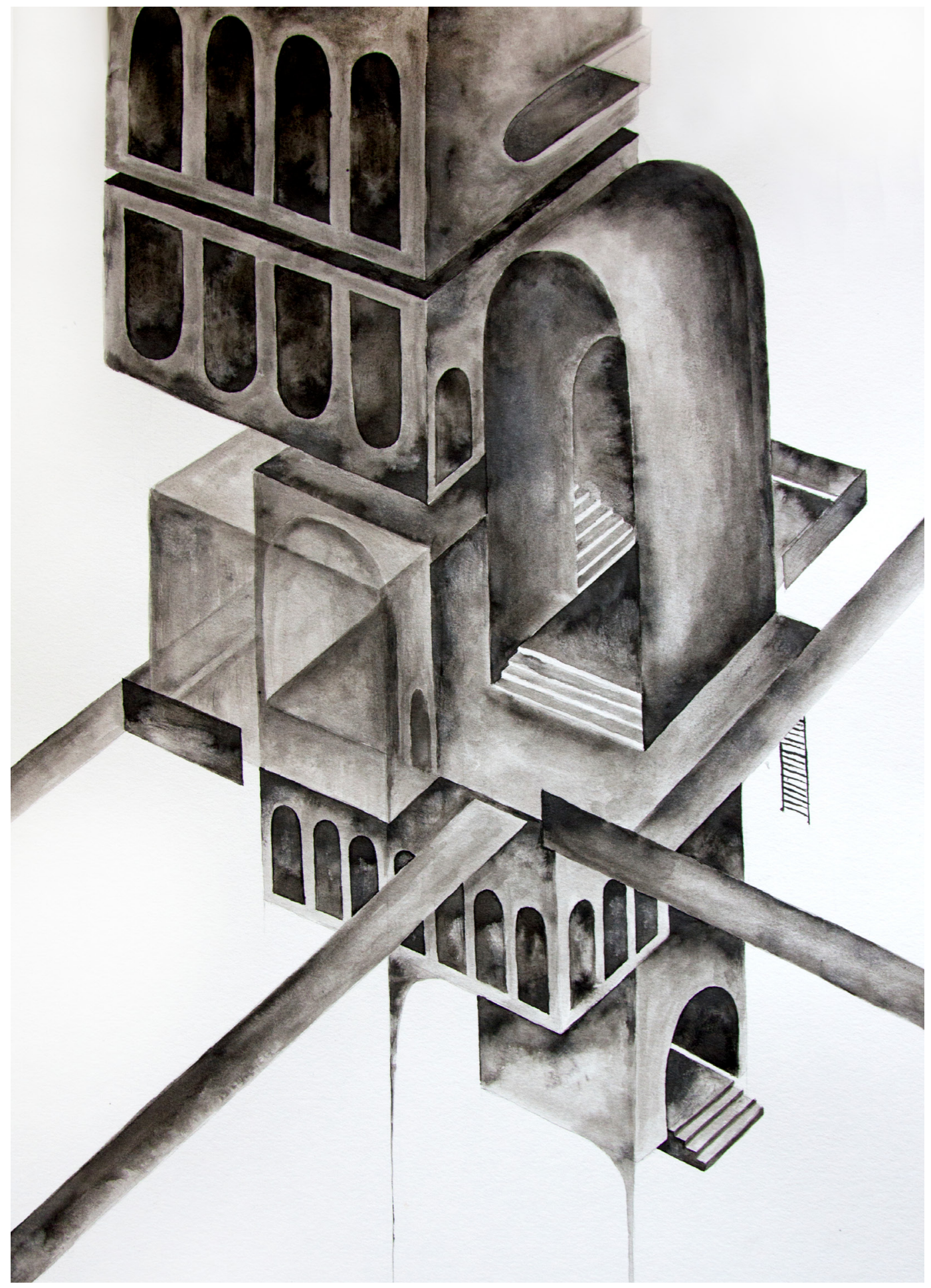

Fig. 53

Axonometric Painting of a Unified Modest Mansion 


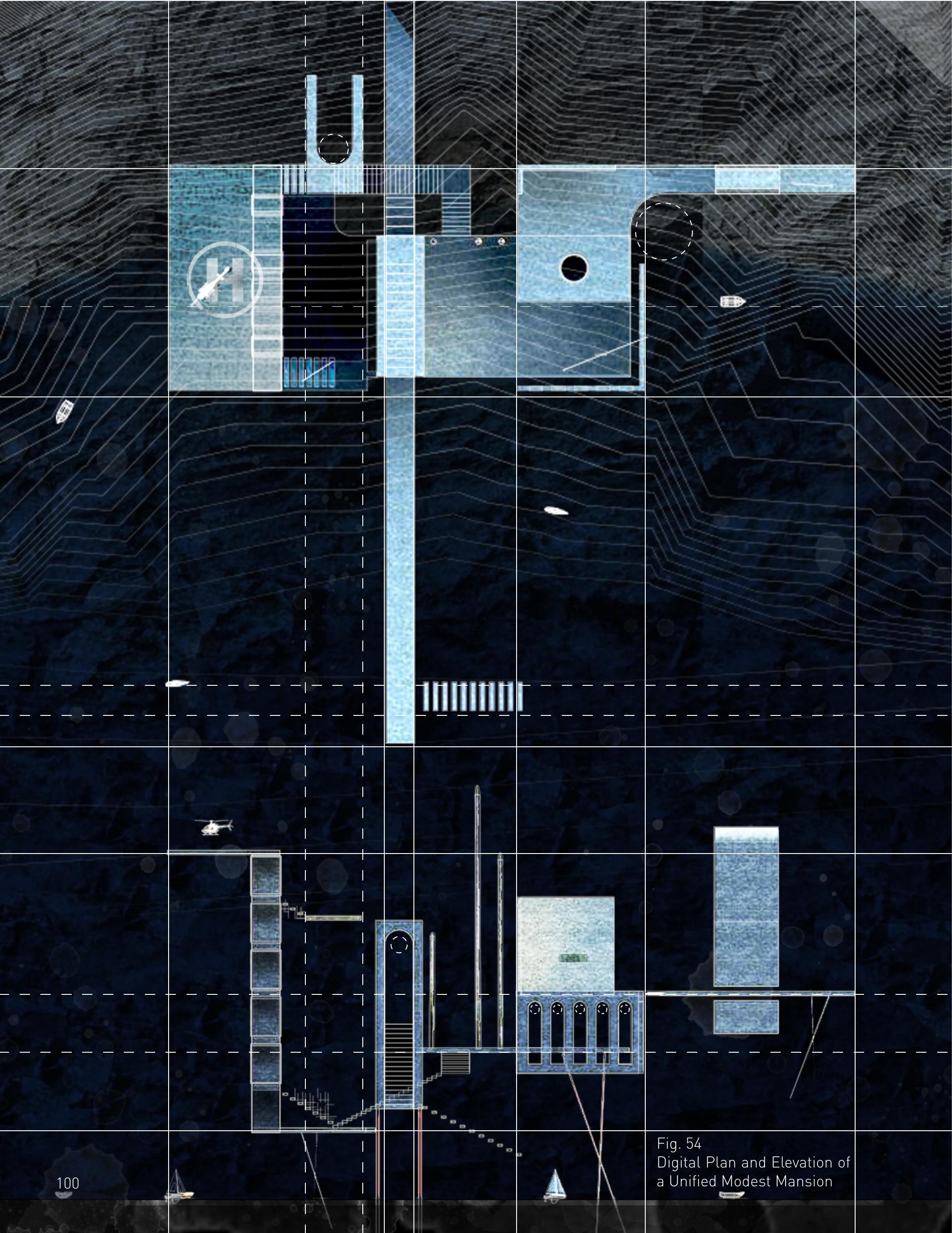




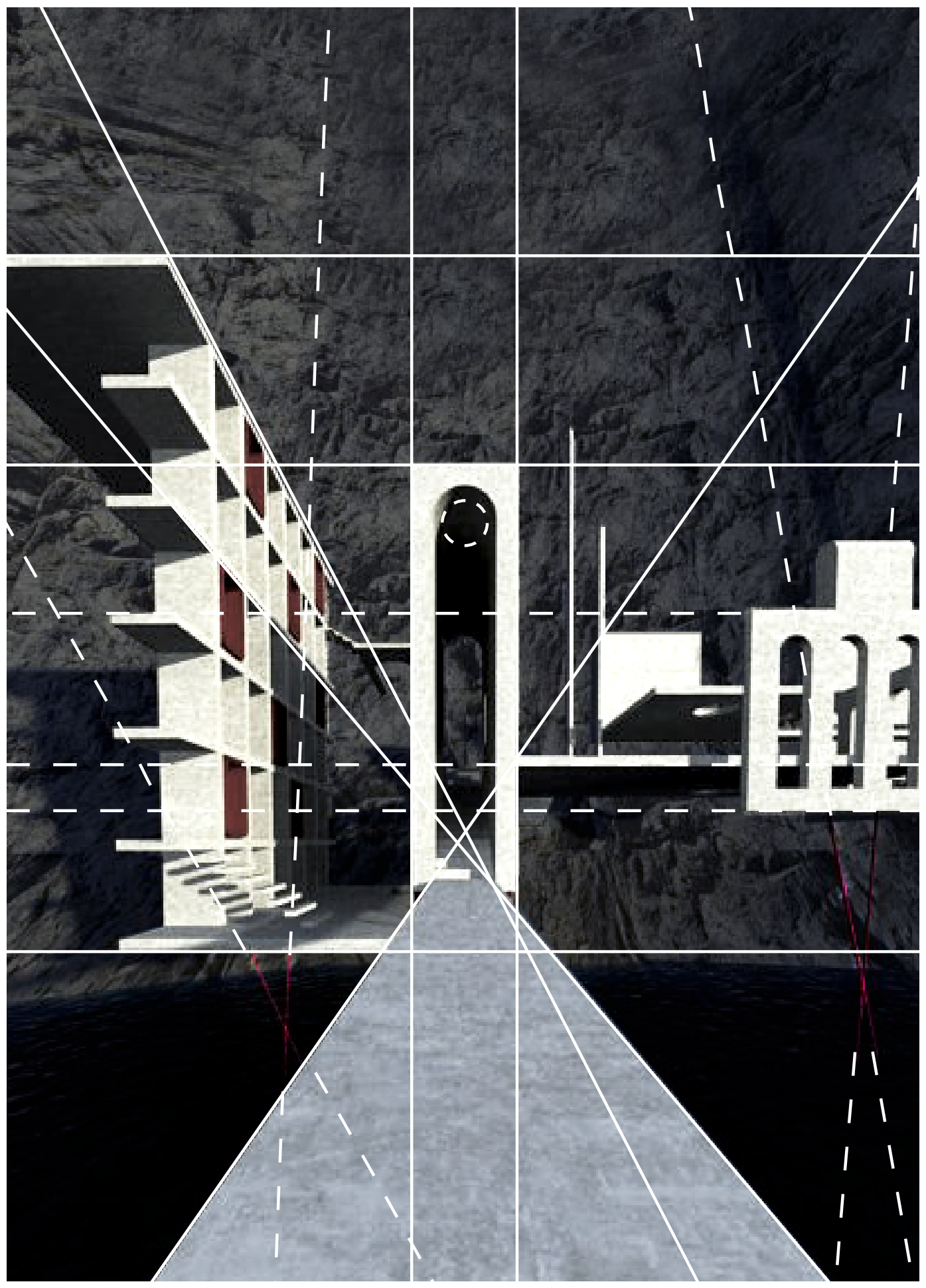

Fig. 55

Digital Render of a Unified Modest Mansion 


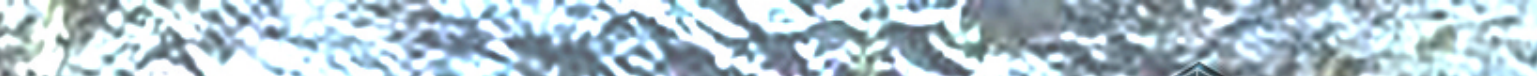

E.

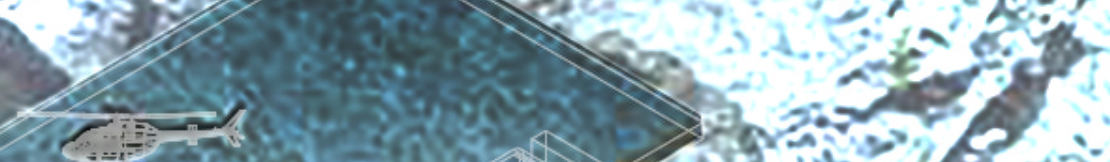

ind

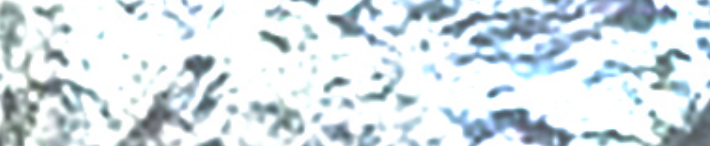

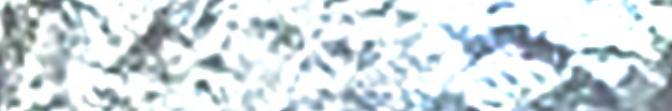

- seption ations

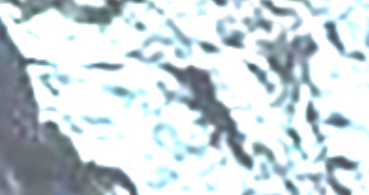

2.

if

$\operatorname{lic}_{2}=2$

s- -3

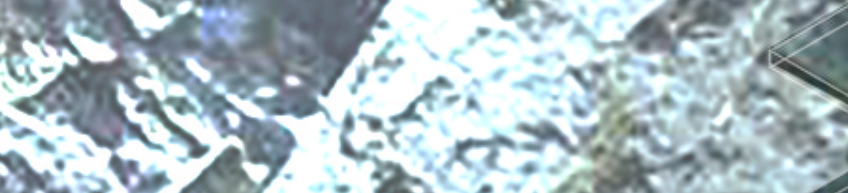

15 $3 \times$ a

(4) 2 s

and wats

$$
\text { orstris us: }
$$

Sid and 0 i. 6 . orot 5 is..
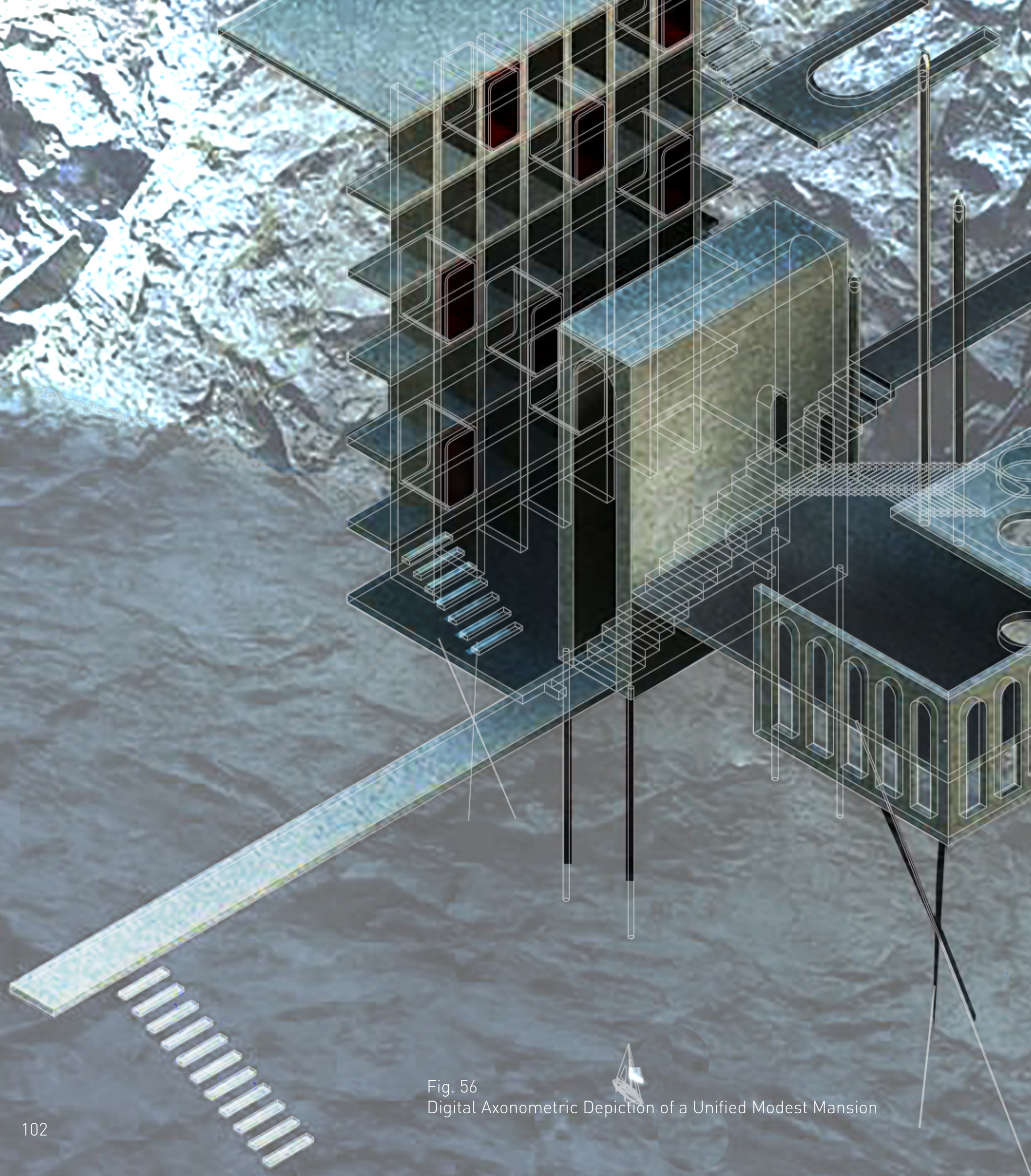


\section{2}

artis.

r.20?
St+

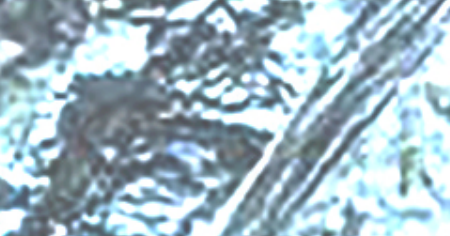

M.

.

tivis

a.

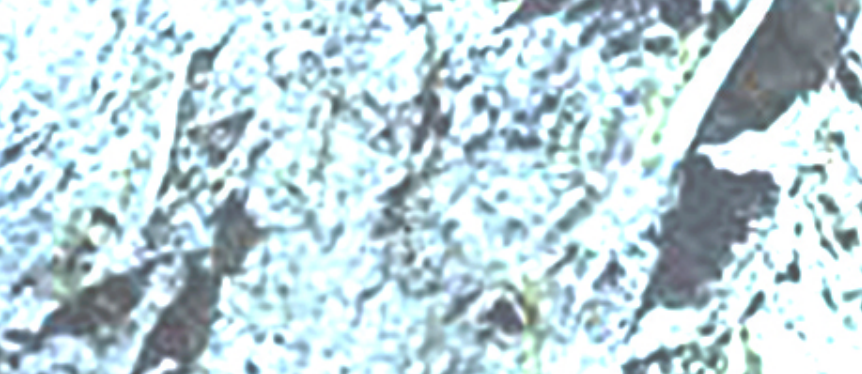

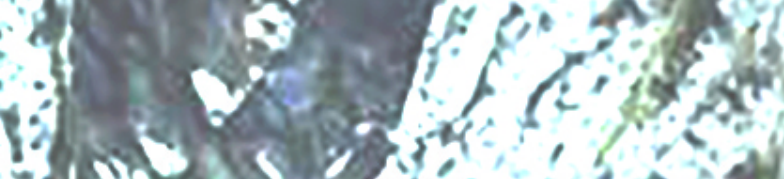

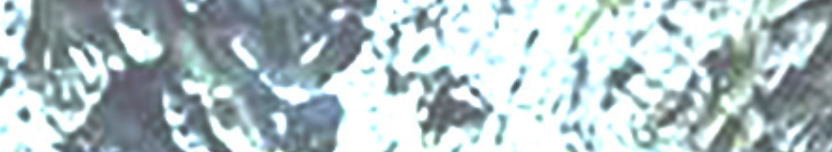

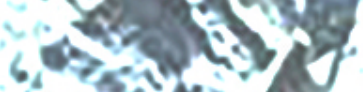

\section{Bation.}

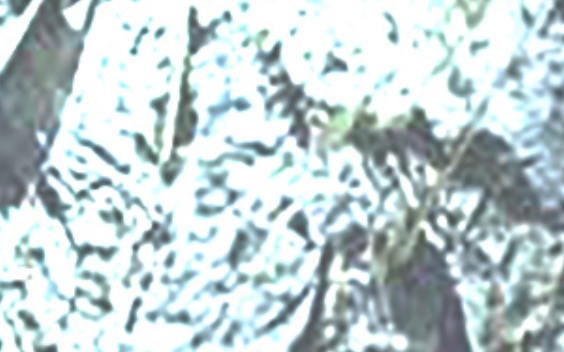

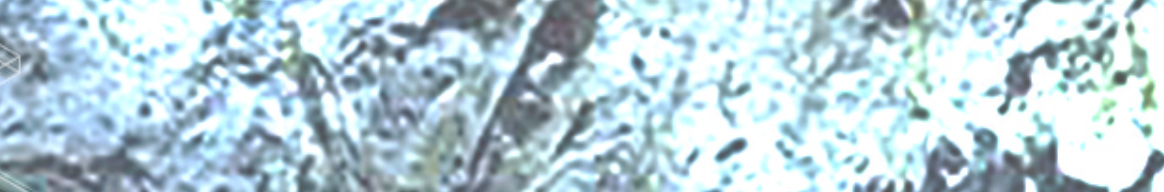

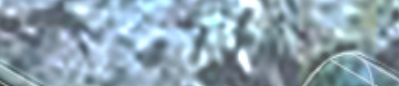

200

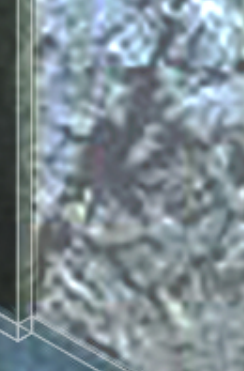

mam

oryar

She Nition.

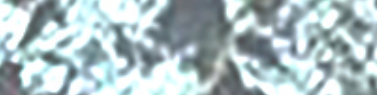

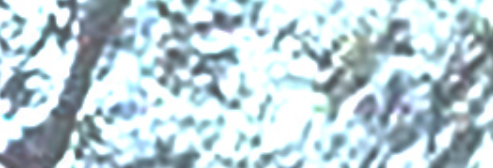

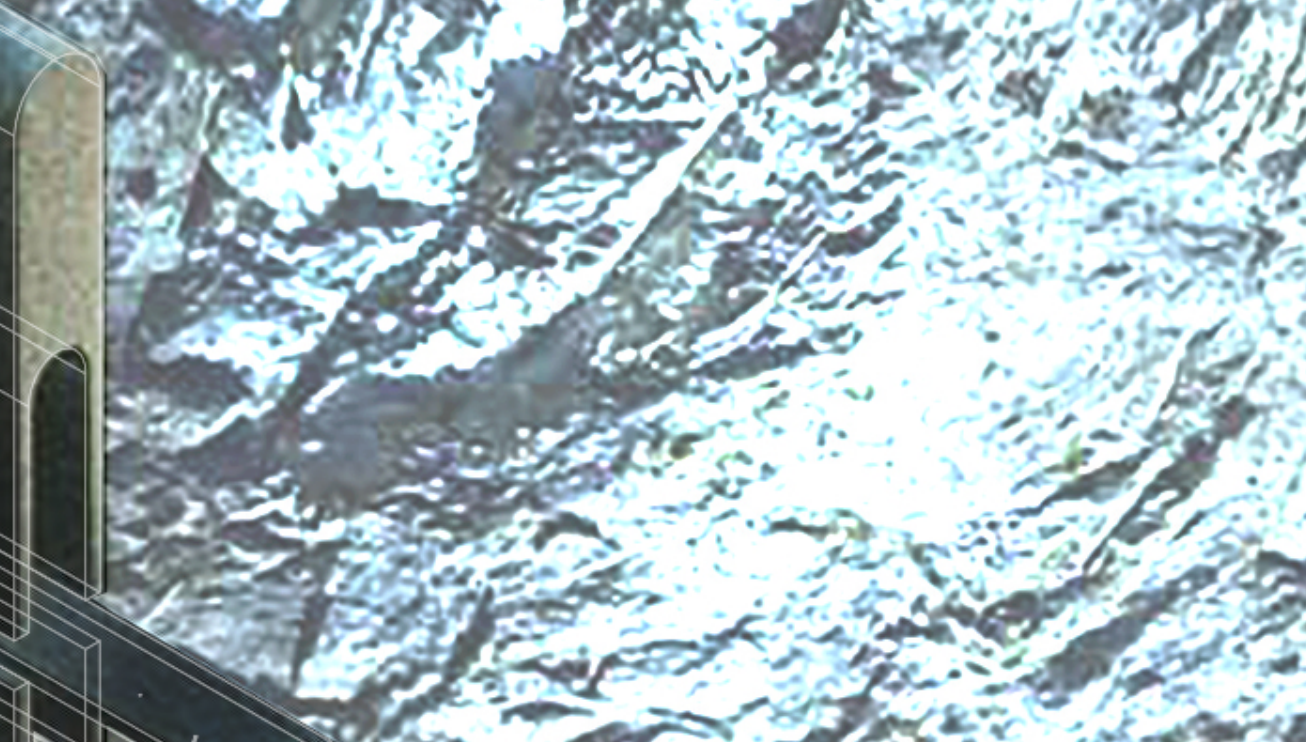

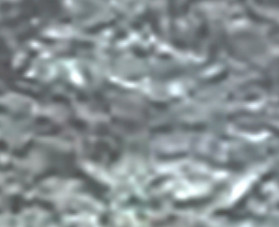

$8 x^{2}=2$

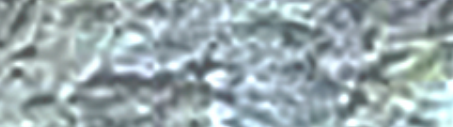

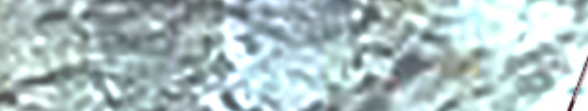

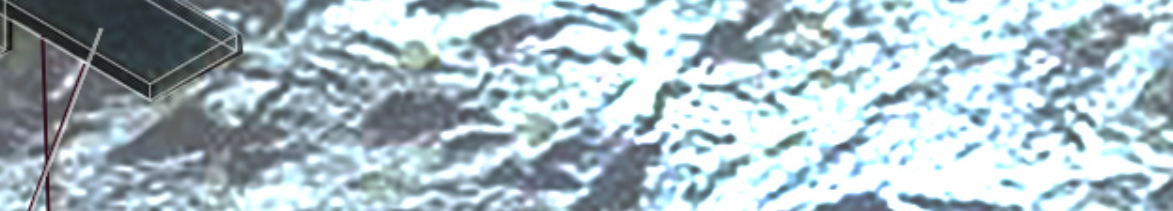

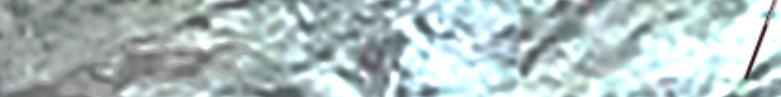

Let.

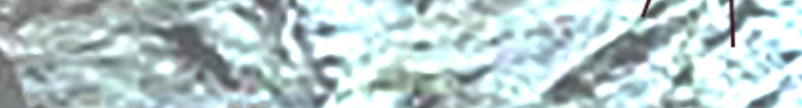

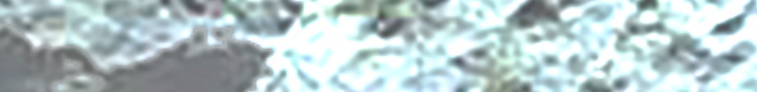

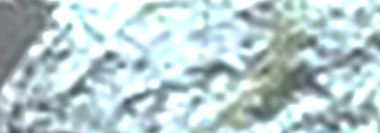

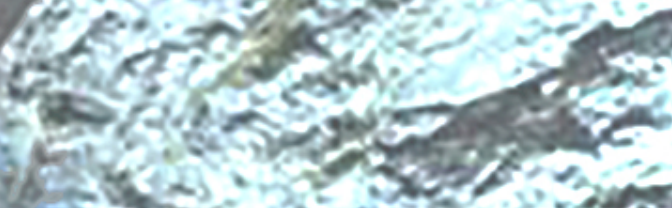

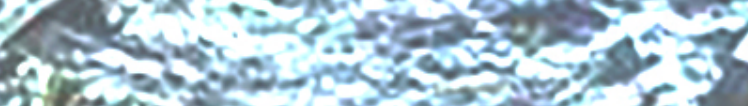

>2

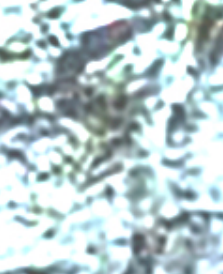

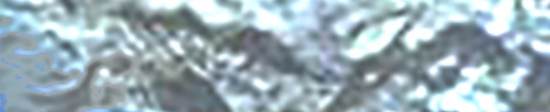

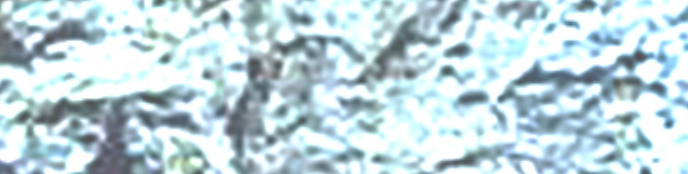

Go

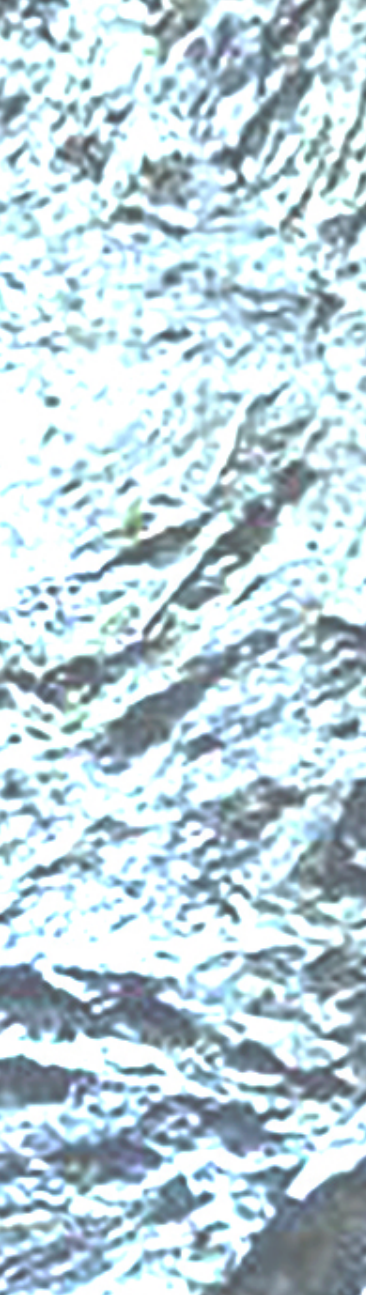

$\operatorname{lom}_{0}$

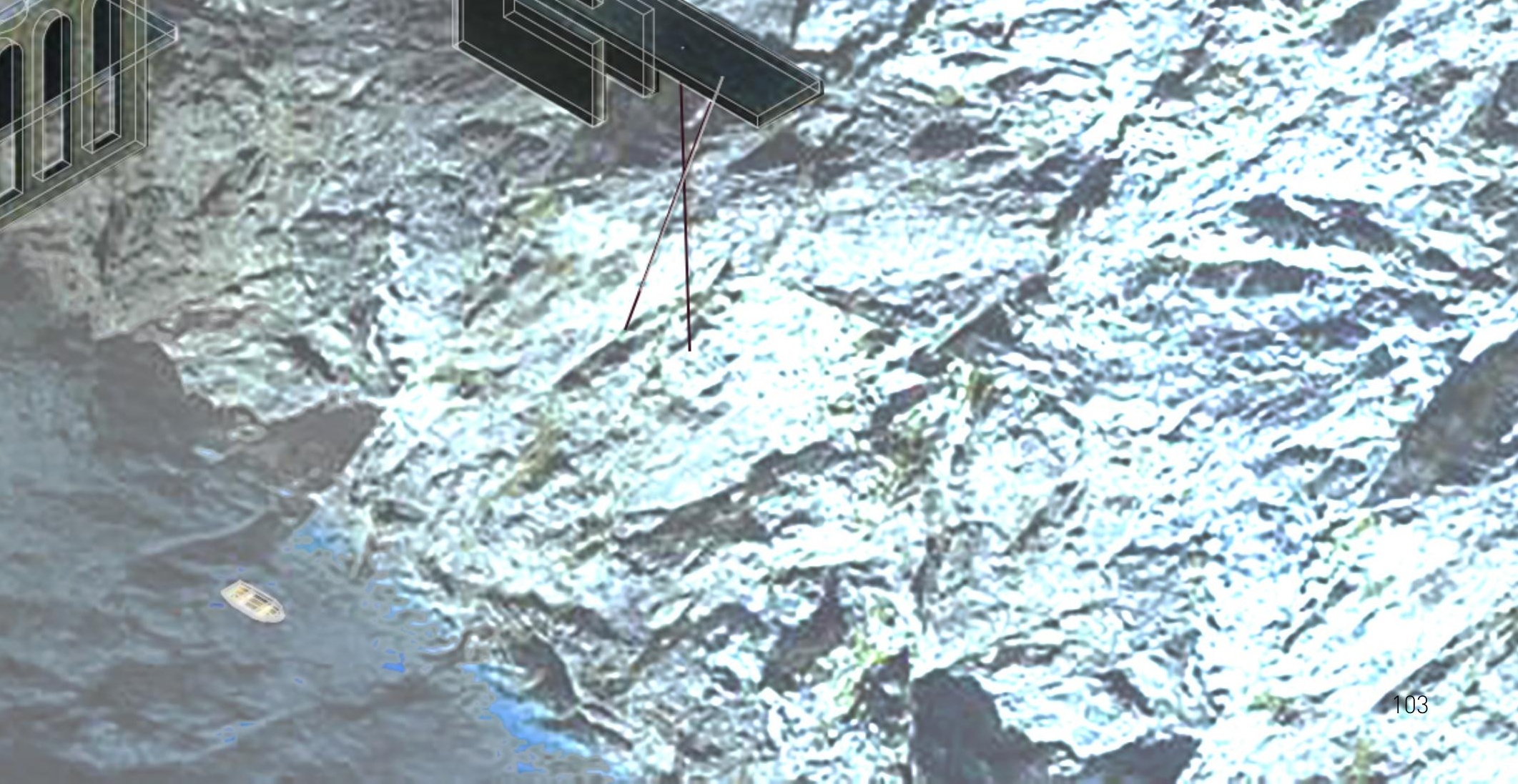




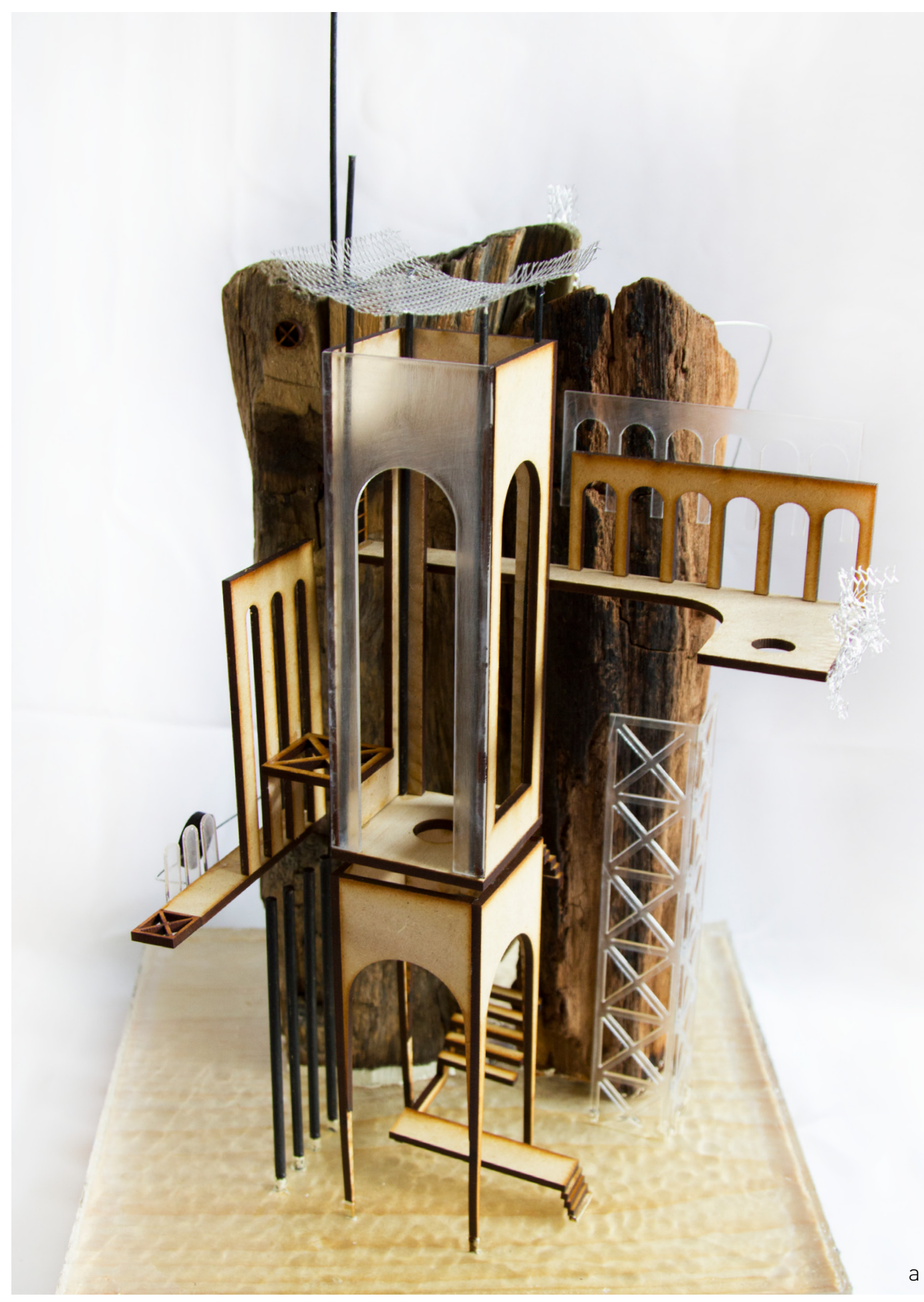

Fig. 57

Physical Modesls of Unified Modest Mansions 


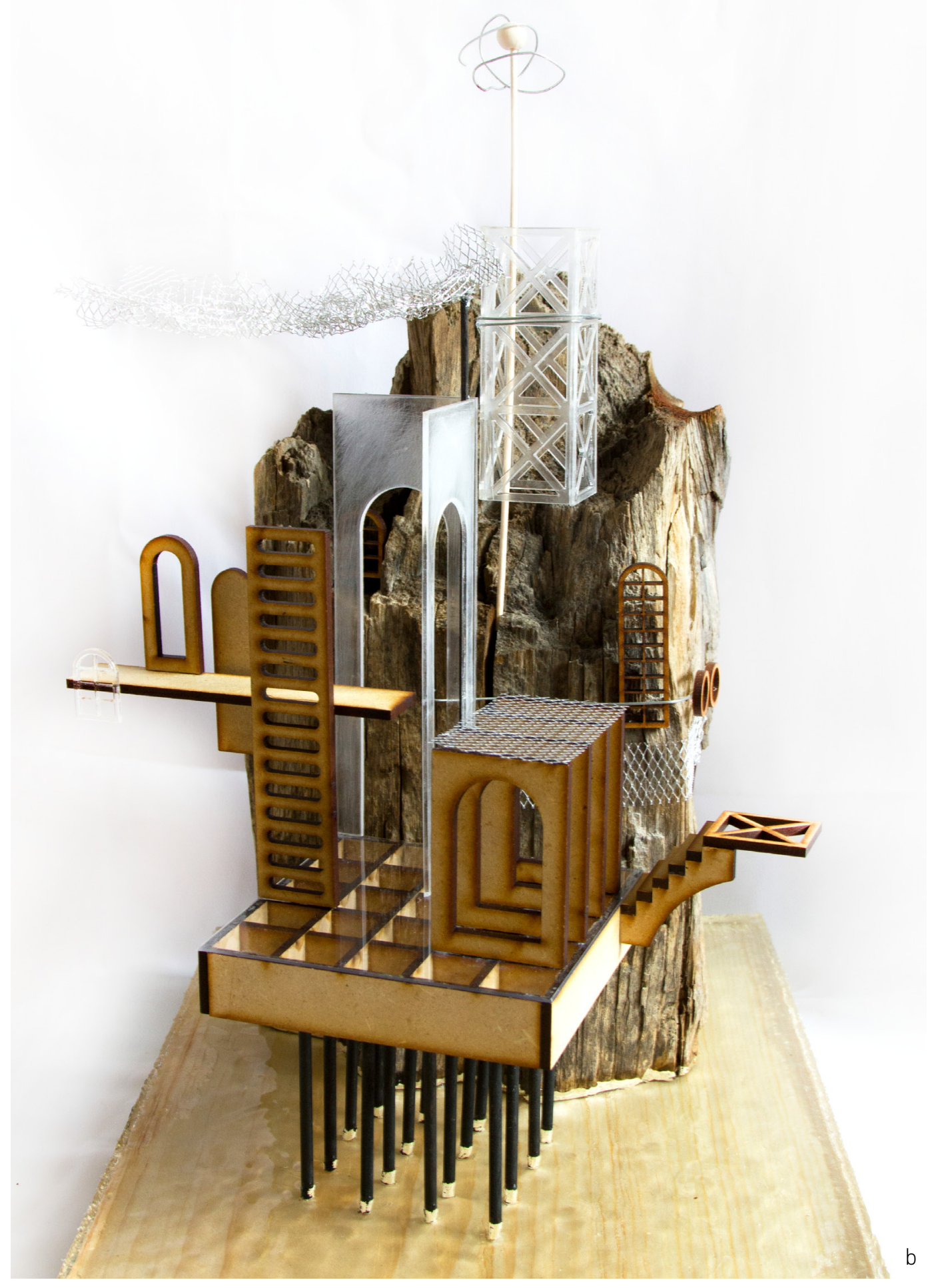




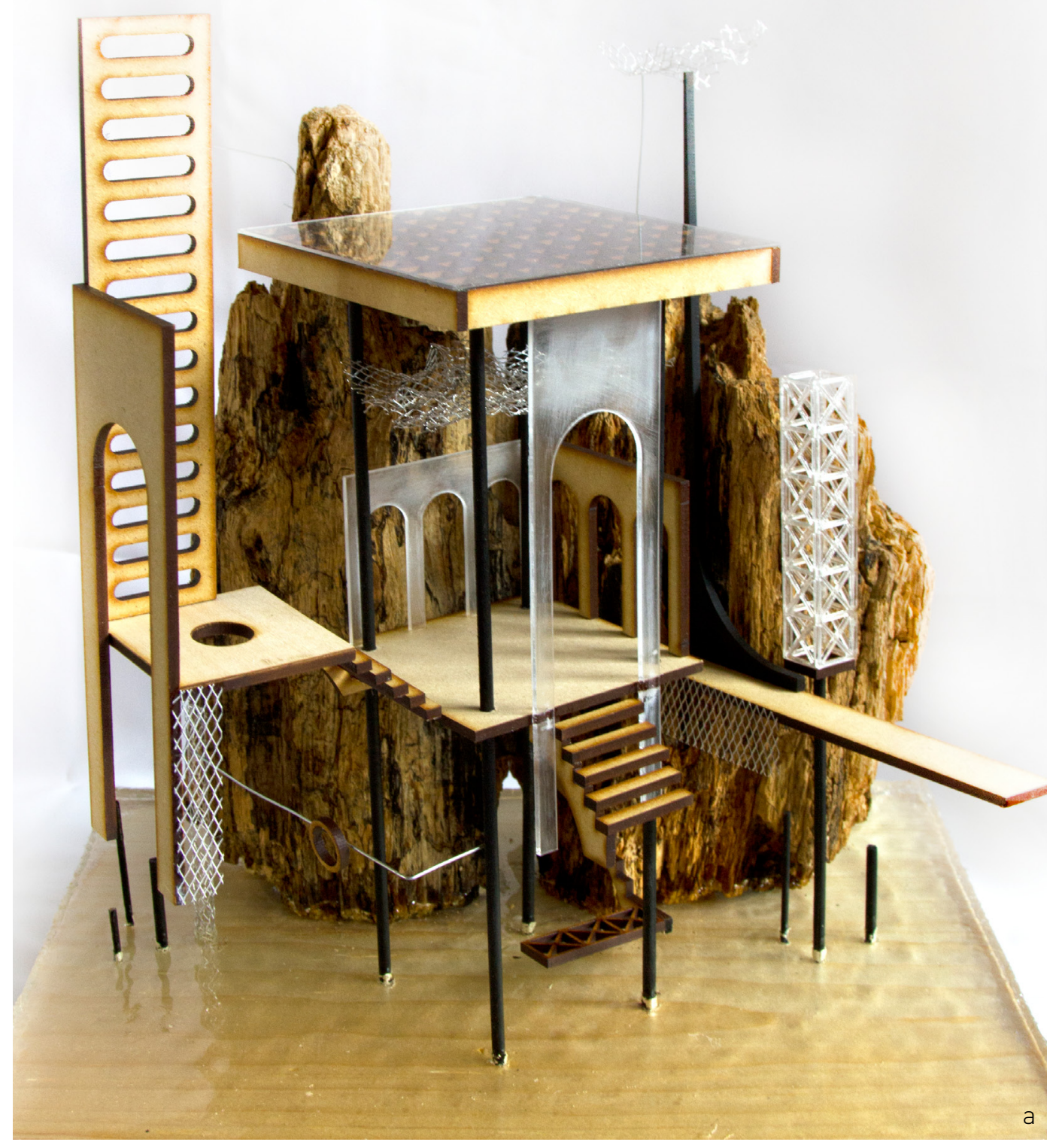

Fig. 58

Physical Modesls of Unified Modest Mansions 


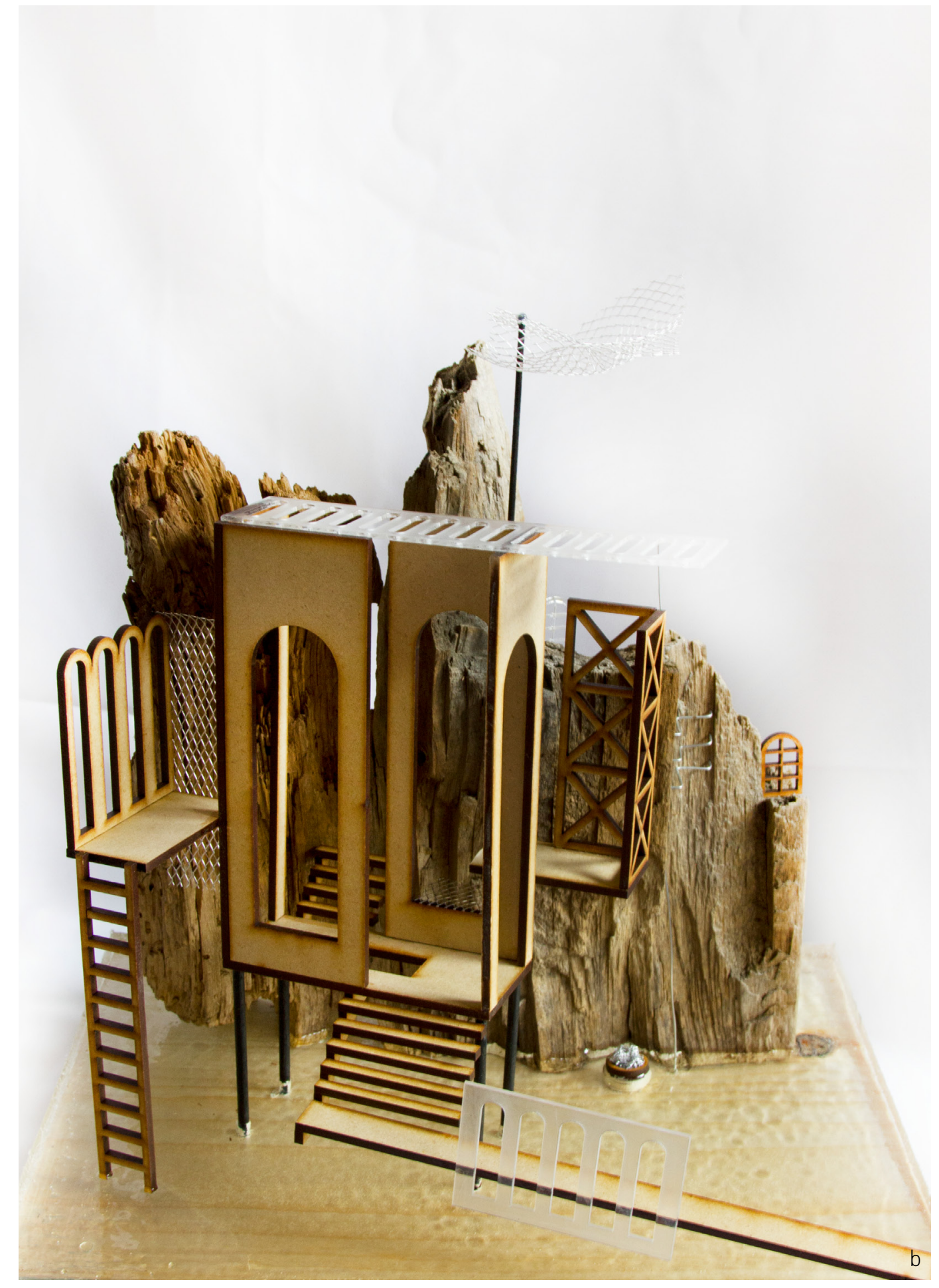




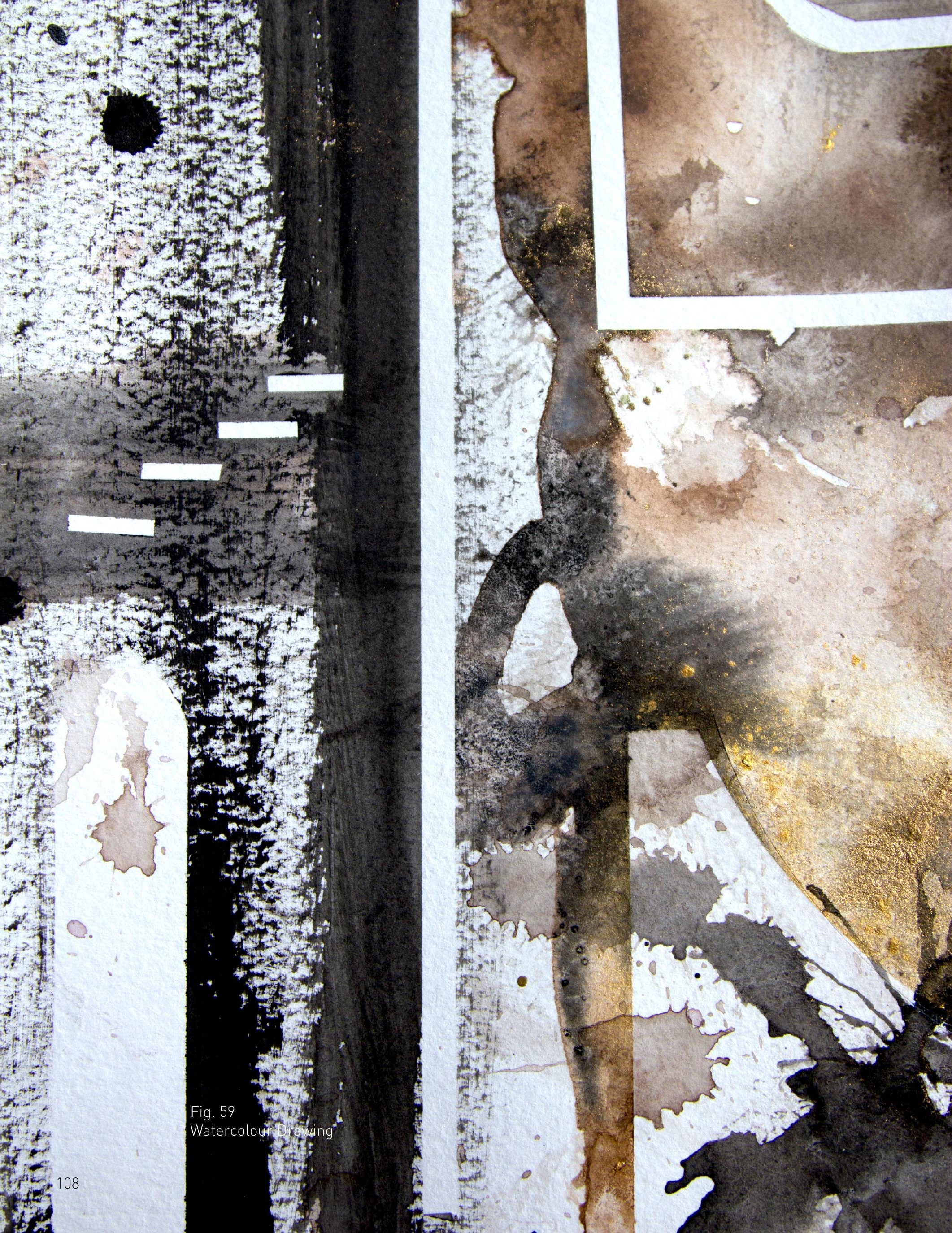




\subsubsection{Fragmented}

The second design phase of the Modest Mansion approaches the design with a different method, altering between a unified mode of design iteration and a more fragmented one. This reversed role concentrated on the production of architectural forms through fragments rather than unified designs. The aim was to use depictions to generate architectural fragments that might be of significance in understanding the Modest Mansion from different perspectives. Its role was to experiment with varying depiction methods, while concentrating on specific elements in the production of fragmented portions that act as design studies for the Modest Mansion. In certain iterations, the fragmented designs were conceptual and aimed at experimenting with techniques and mediums. In other iterations, the fragmented designs were precisely organized. At each stage of the design, the intention was to use depictions as tools to generate form. Through this learning process the Modest Mansion and its fragments, spaces, forms, and architectural configurations were slowly formulated.

I began this design phase by painting and hand drawing, in very rough style, any fragment that came to mind, without imposing any particular order or arrangement to the depiction or the arrangement of the forms produced. Part of the objective here was to develop rough fragments of components: floors, walls, roofs, doorways, and stairs. From there, I experimented with the configurations that could be composed from these rough sketches. Having no unified design to structure them, the fragments begin to formulate architectural forms through the depictions, creating unfamiliar unified compositions of their own. Produced thusly the individual components introduced a different relation between elements. Because they were unconsciously placed without a predetermined order or setting, they formulated architectural compositions out of line techniques, colour effects, and textured patterns. They allowed a new perspective to come into view in more precision, as compositions and fragments of the Modest Mansion hadn't previously been considered. Depictions make these architectural forms real for the purposes of analysis, critique, and assessment of their impact on the designer and the viewer. 


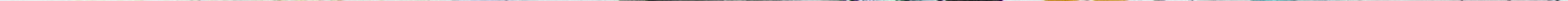




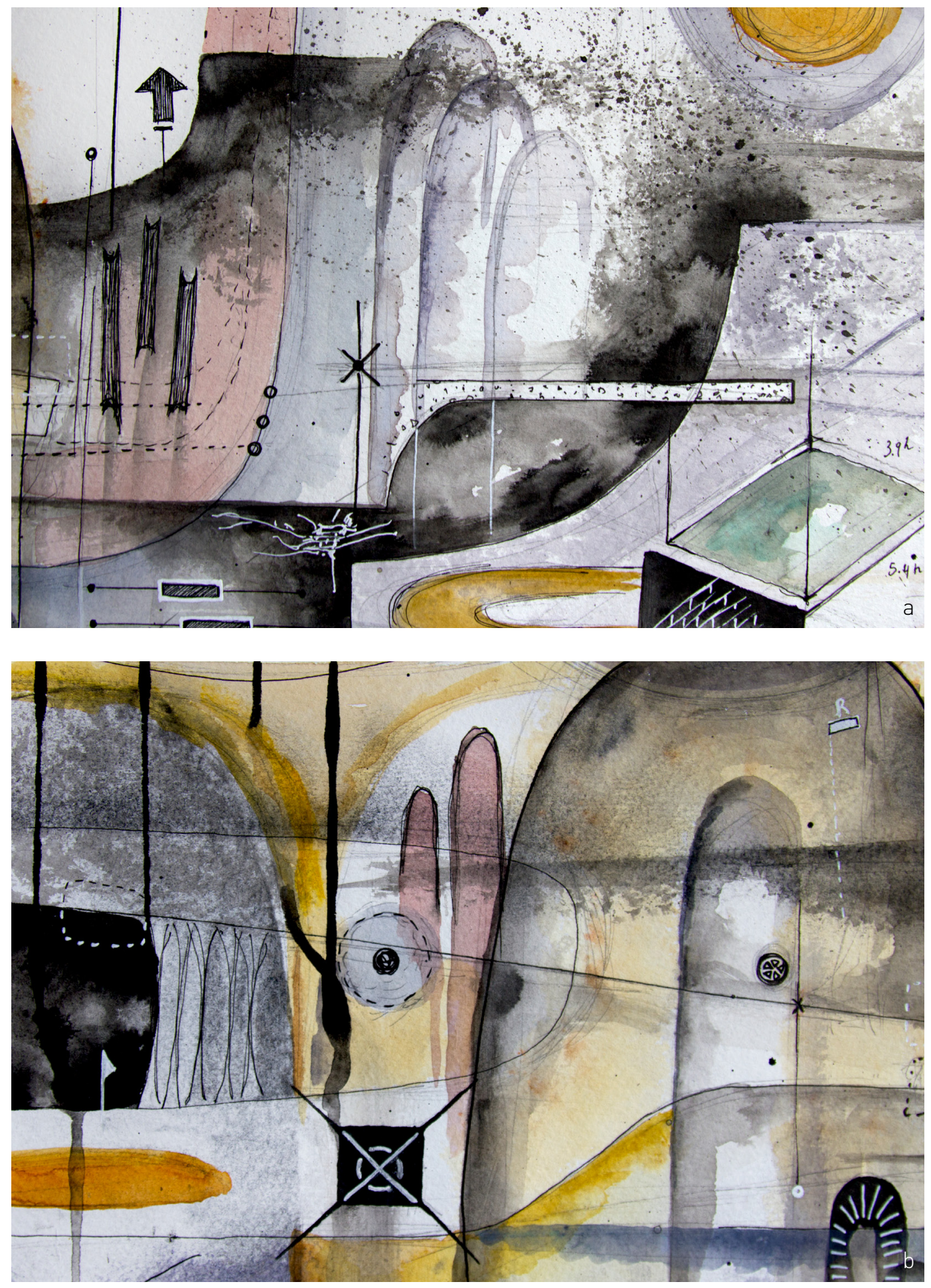

Fig. 61

First Iteration of Mansion Fragments - Fragments 
The second iteration also concentrated on fragmented architectural elements, but this time in an ordered and organized manner. These fragments and their positioning in the piece weren't predetermined nor pre-decided upon. Rather, they were guided by clean line work that was randomly guided by the ruler and placed on the paper. The horizontal, vertical, and the diagonal lines drawn on paper acted as the main guide in formulating the fragments of the Modest Mansion in this piece. Elements, whether visualized in a plan view, elevation view, sectional view, or axonometric view, began formulating accordingly piece-by-piece, fragment-by-fragment. The colours of the depiction were chosen to be faint and simple to complement the clean linear line works of the peace. This painted drawing helped formulate a geometric understanding of the Modest Mansion, one that brought forth the drawing in a clear-cut system, and altered the role of the drawing to one of fragments existing independently of a cohesive whole. 



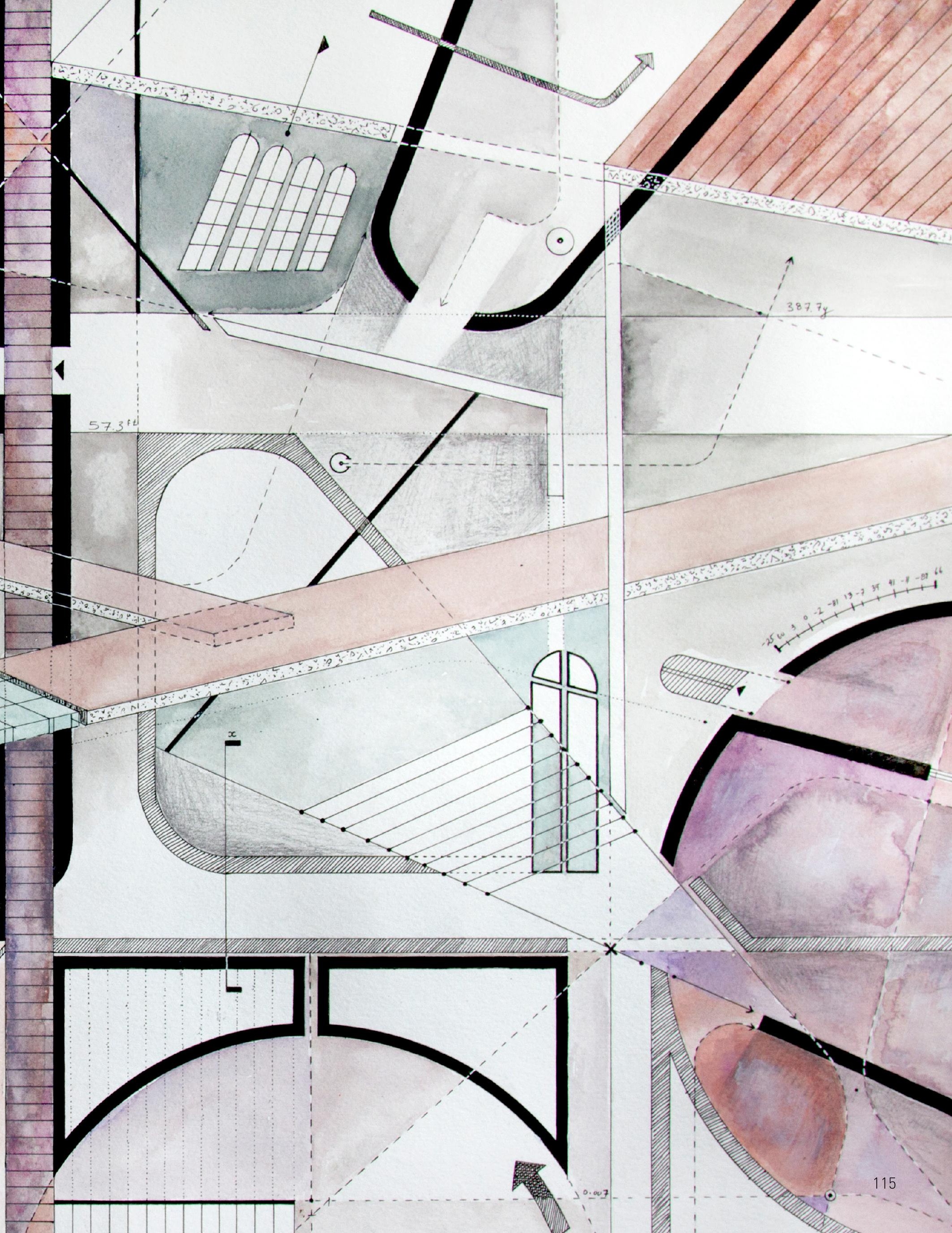



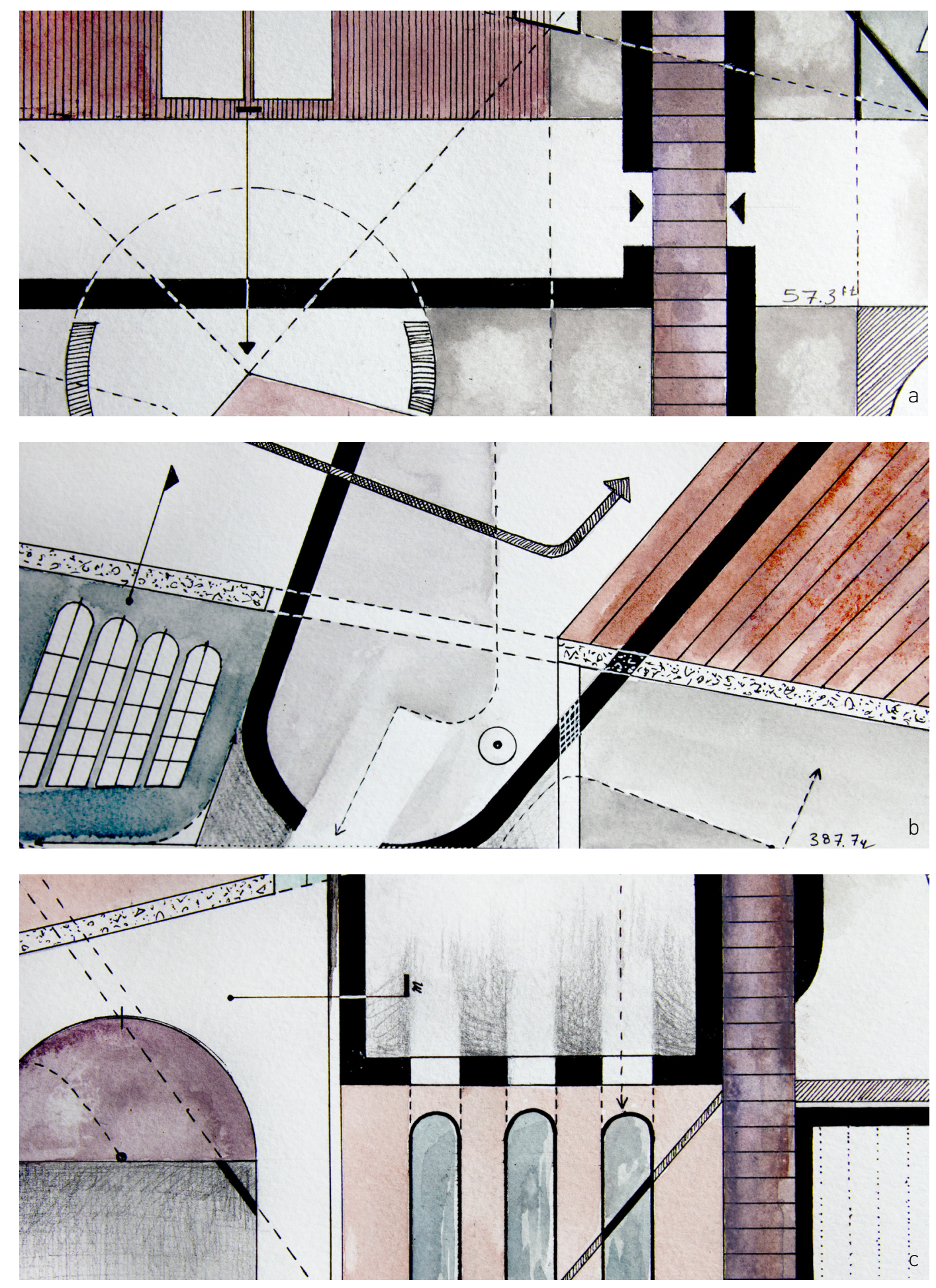

Fig. 63

Second Iteration of the Fragmented Mansion - Fragments 
The next iteration in this phase looks at how architectural forms can be generated through negative and positive painting effects. By varying thickness tapes laid out at different arrangements, layers, and shapes, positive shapes on the depiction are formed. Using dark watercolour tones, I begin to spread paint over the paper and the taped portions. After drying, the tape was removed and the depiction remained with contrasting negative and positive areas that portrayed fragments of the mansion. Forms such as walls, corridors, stairs, and ramps were imagined through these depictions, making real fragments of the house through these mediums, thereby allowing the viewer to build their own interpretation of the depiction. This type of painting generated architectural forms that stand-alone as individual fragments at the same time as it generated a new unified composition. The exact placement of the tape notwithstanding, the uncontrolled bleed of the watercolour gave each painting its specific configuration. Given the chosen setting of a shoreline, the darker tones of the sea, the rocks, and the sky were used to depict where the location of the mansion, blending it and contrasting it using different techniques and mediums at different times. Furthermore, the dark pallet reads as a background contrast to the mountain shoreline on which the mansion is located. 



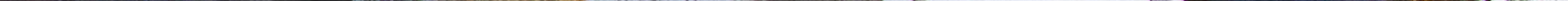



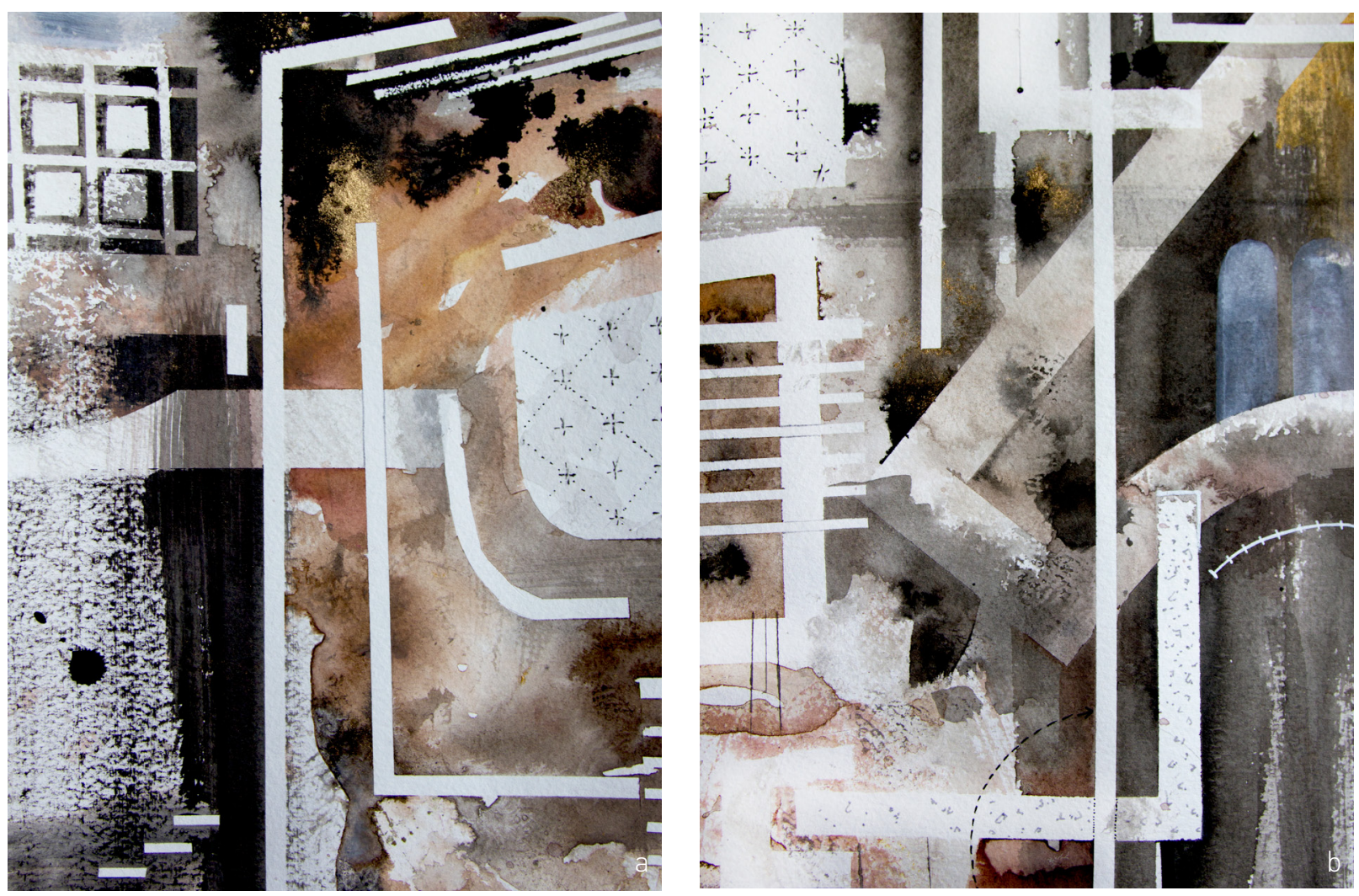

Fig. 65

Third Iteration of the Fragmented Mansion - Fragments

The next set of iterations moved into digital production, formulating digital drawings with the aid of computer programs. Here, the role of the drawing shifted when compared to the start of the experimentation process. In particular this form of digital drawing brought the depictions into more spatially arranged fragments. With the aim of generating architectural form for the Modest Mansion, I experimented using digital programs as a modern form of depiction; one that makes architectural forms using digital drawing techniques. Computer programs aided in generating a better three-dimensional understanding of architectural configurations. They made it easier to interpret an architectural idea through drawing. All the fragments in this iteration were first generated using Revit. Each was individually being drawn and rendered alone, generating features such as walls, 

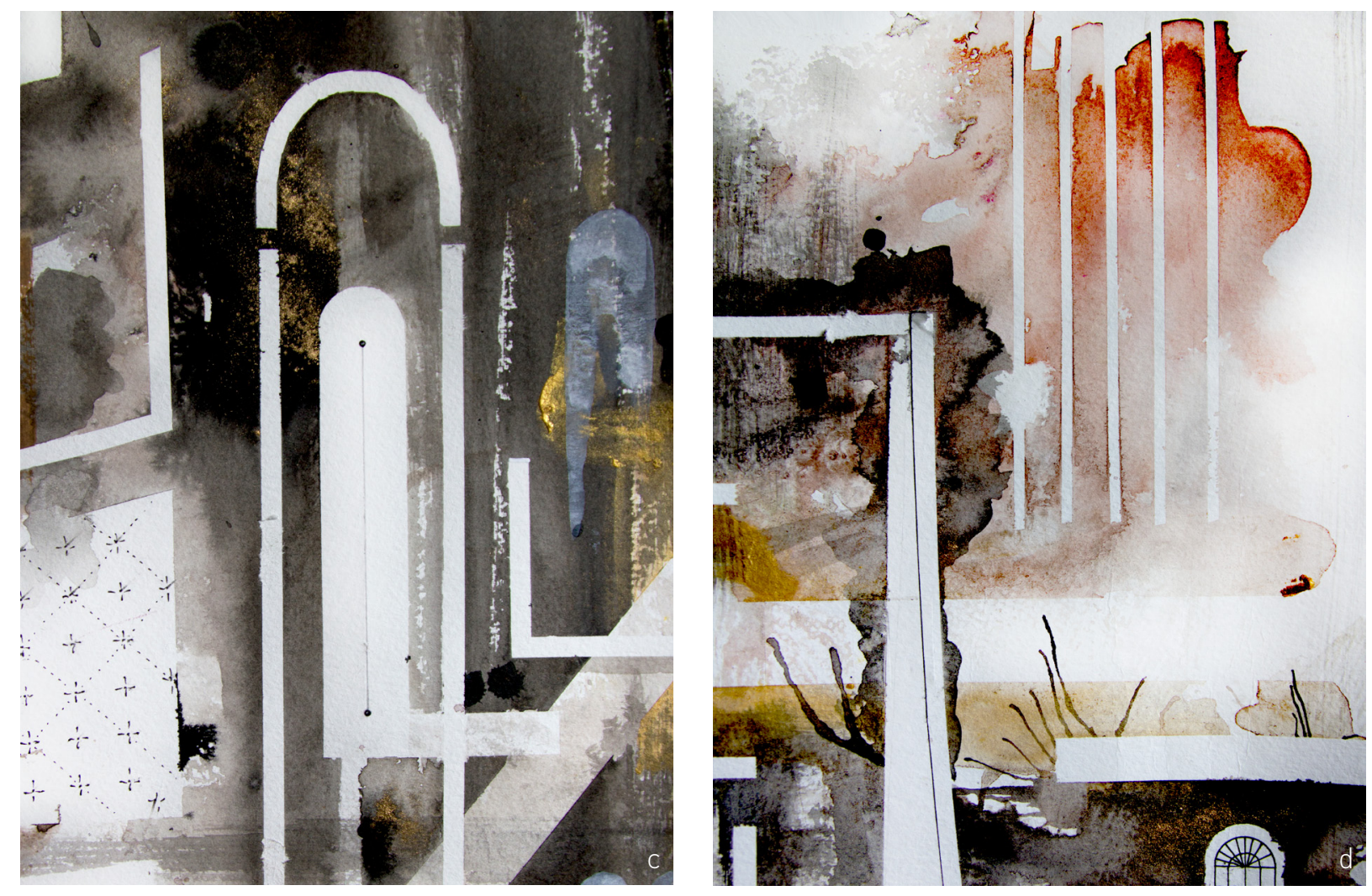

paths, stoned arches, stairways, and windows. These were later combined into architectural compositions using Photoshop. The separate digital fragments were configured in arrangements that experimented with varying entrances, paths, and doorways into the mansion from different heights and levels. These depictions formulated spatial arrangements, generating a unique place identity through each drawing. These depictions are capable of generating a sense of place due to their method of drawing and the medium of representation used. The fragmented iterations in this series were best at depicting a topopoetic sense, which builds on the viewer's interpretation of the piece, and communicates the fragmented spirits of the Modest Mansion?. The depiction and the digital programs were crucial to the realization of these architecturally formulated settings and spatial forms. 

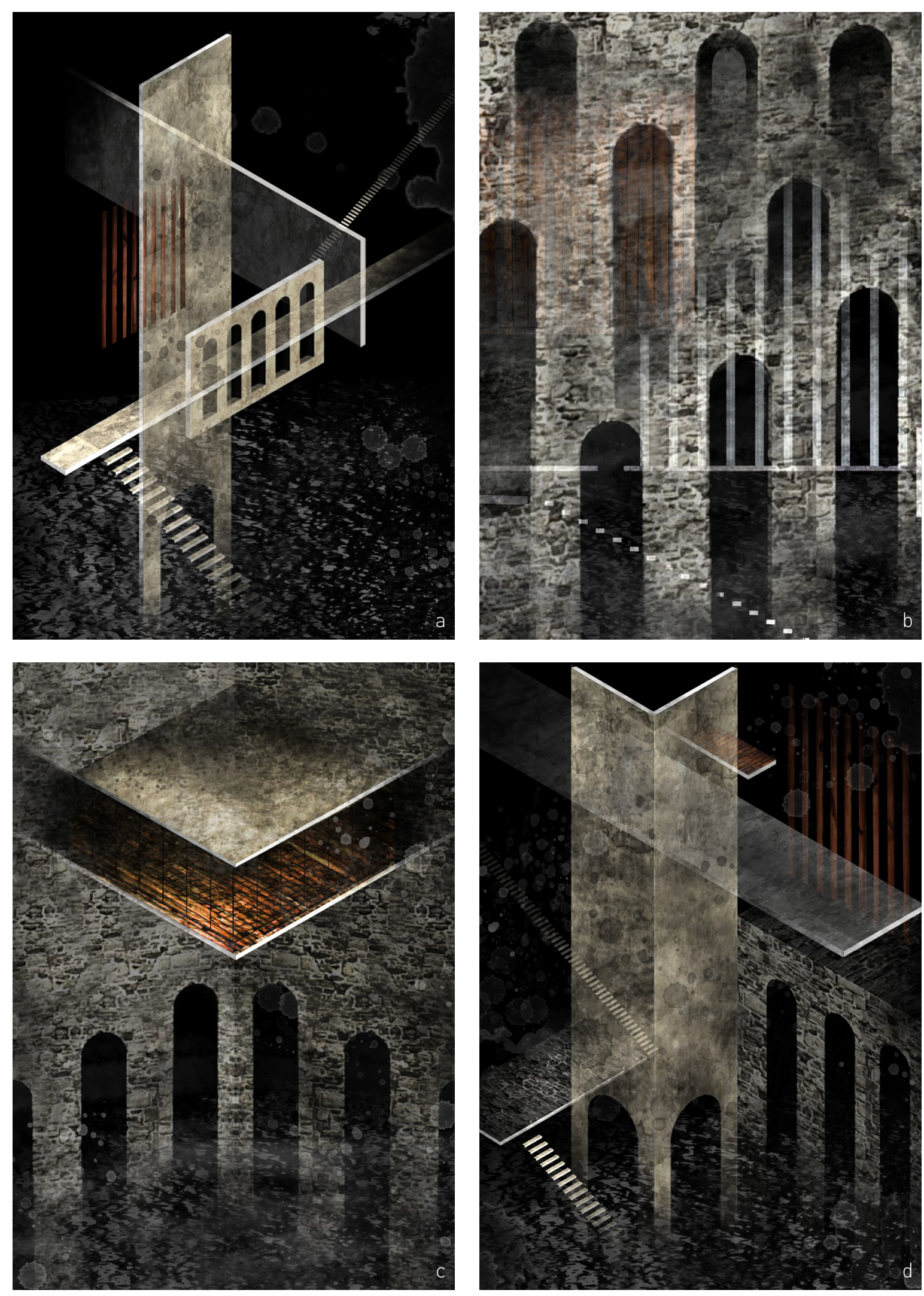

Fig. 66

Digital Series of the Fragmented Mansion 

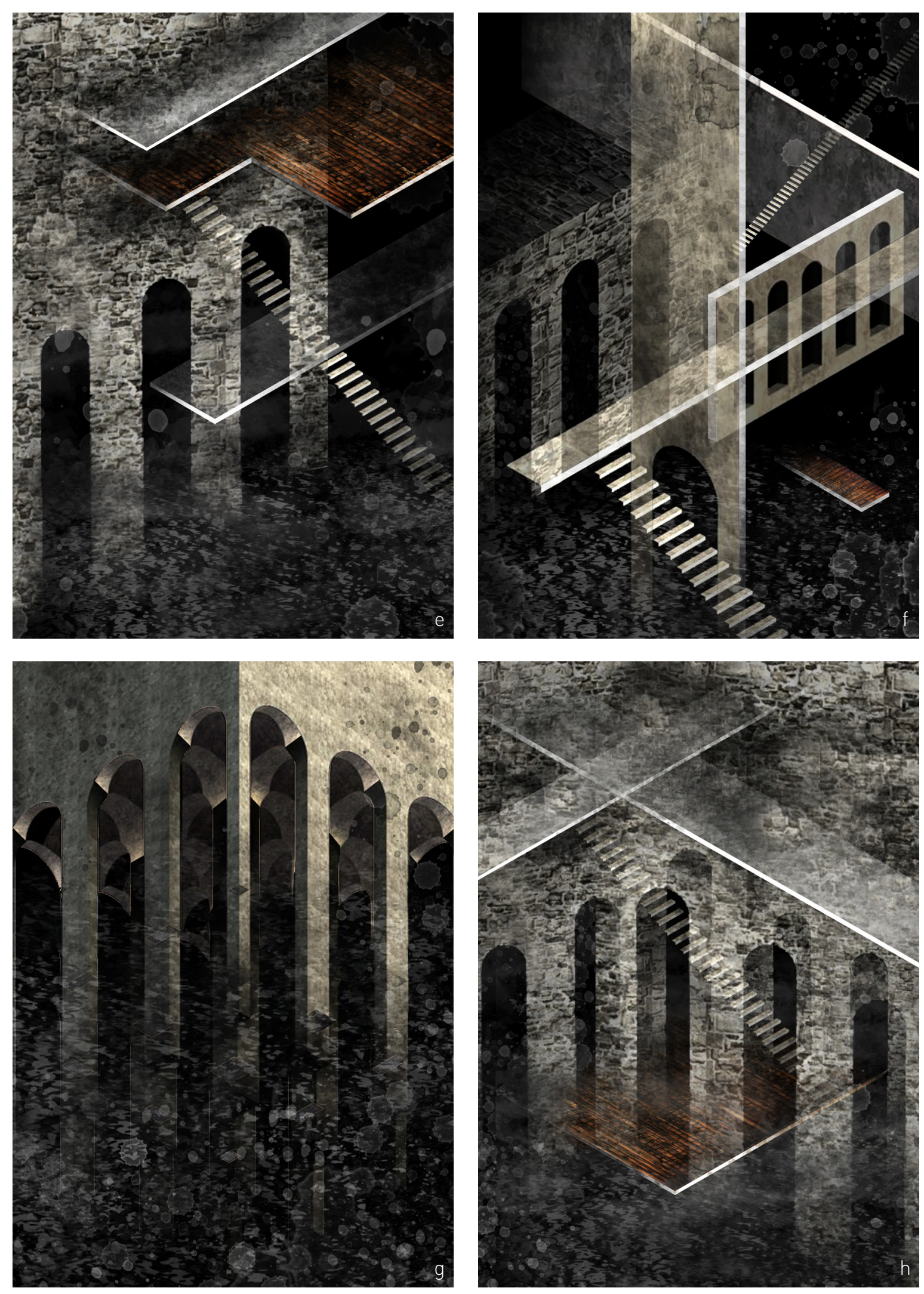


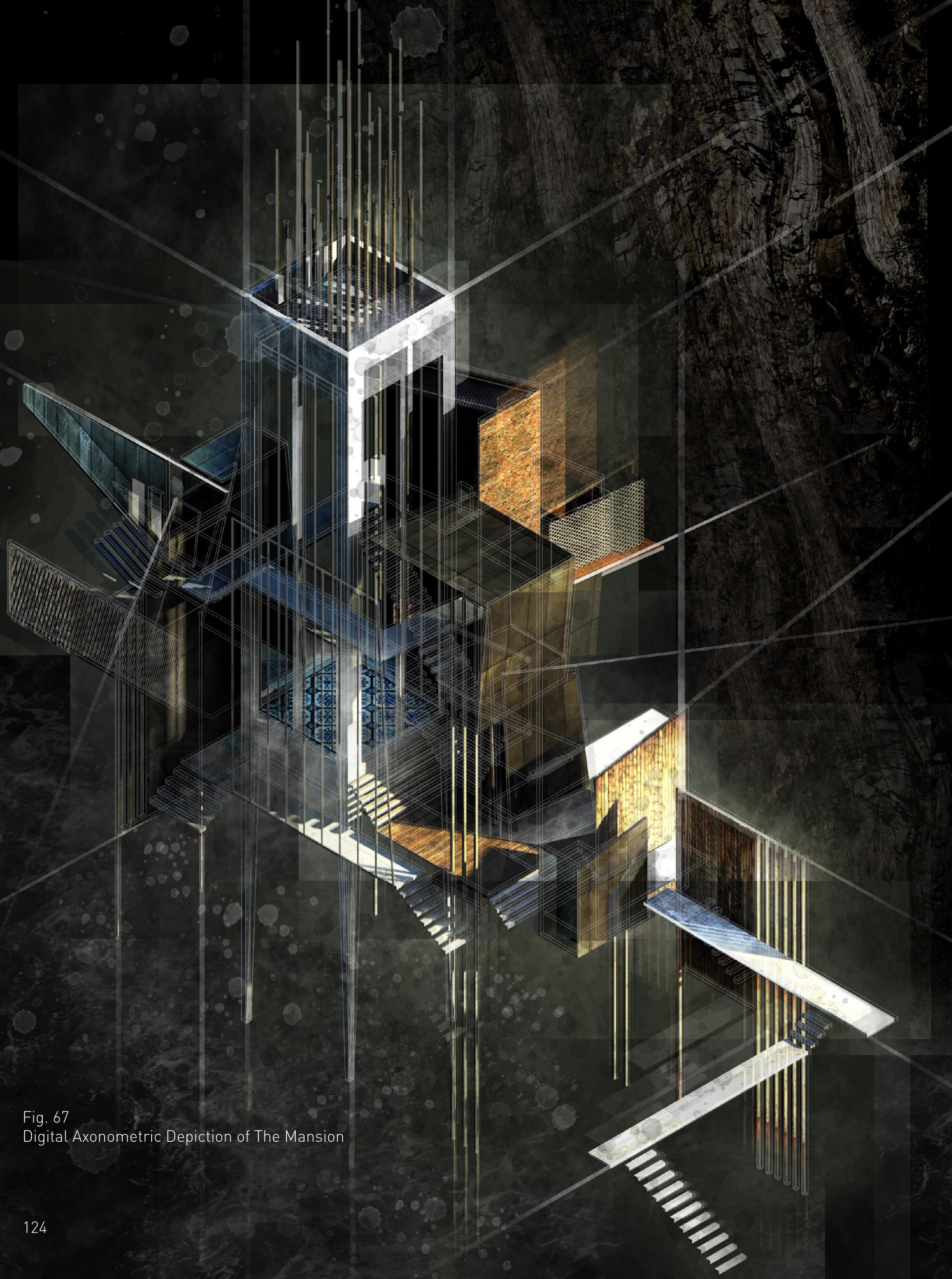




\subsubsection{The Mansion}

The third and final design phase of the Modest Mansion was one that took a different approach with the role of drawing and depiction. The role of drawing in this stage transformed, as the design reached finality. With all the drawings and design explorations developed in the previous phases, depictions were used as a tool of experimentation and speculation about architectural ideas, with the objective of researching critical forms of architecture. Given the prior design explorations pursued in this thesis, each phase assisted in demonstrating the significance of depictions and the role they play in generating architectural form. Each depiction, whether it was drawn, painted, built, or developed through other methods, formulated a learning outcome within the design process.

Building upon this experimental design process and verifying the role of drawing within it, the final phase brings together all of the previous speculations of forms and drawings in one final unified and cohesive design. This phase assembled the puzzle from the pieces generated in all other previous depictions, and thereby formulated a cohesive mansion. The form of this mansion contains the traces of the initial rough pencil sketches, the forms taken from watercolour brushstrokes, the forms produced through collaged imprints, and those developed using digital programs. The Mansion emerges as a unified whole only after this extensive design process is completed. Each drawing played a role in the process, whether or not a specific element was carried forward from one phase of the design to the next, or left behind according to the dictates of the imagined setting. 


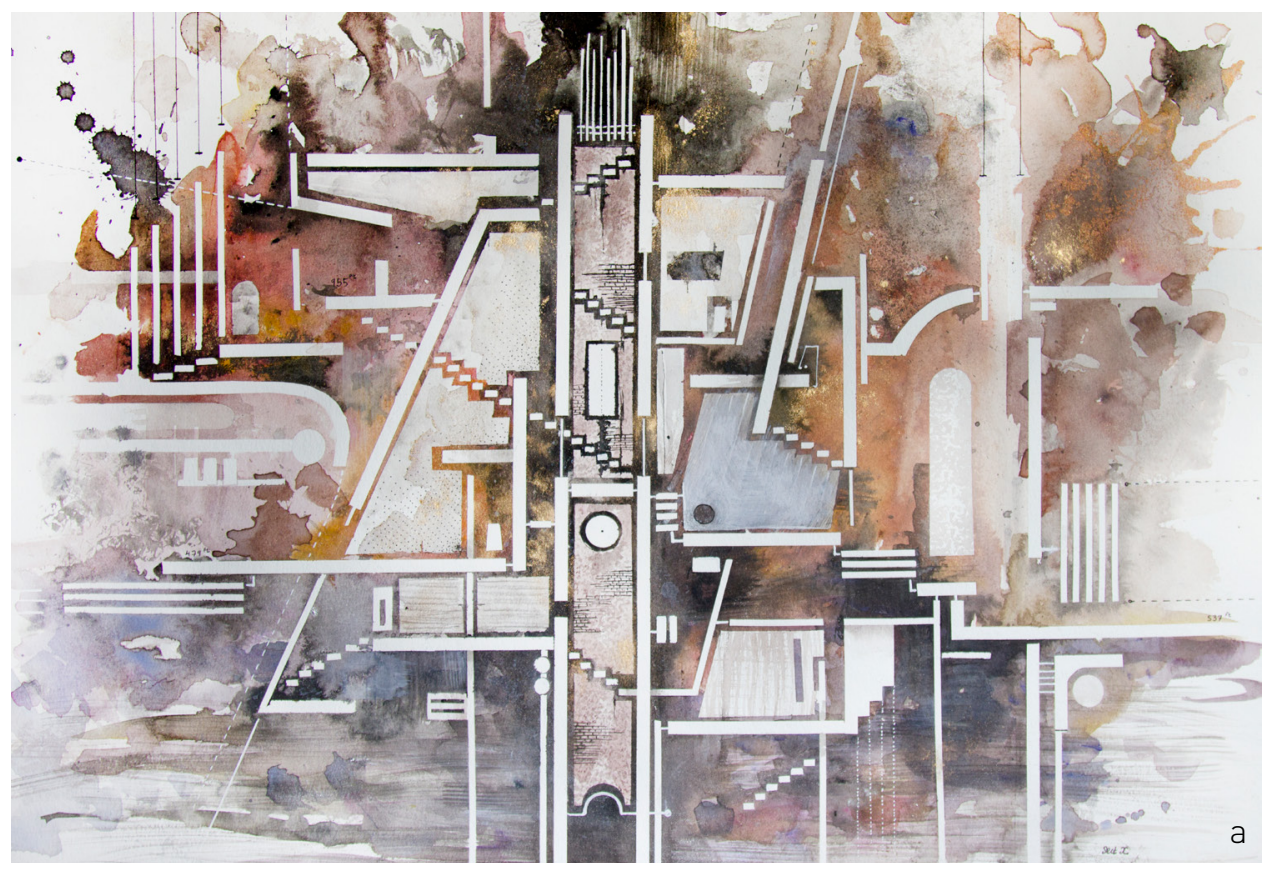

Fig. 68

Watercolour Iterations of The Mansion

The design of The Mansion began with a couple of hand painted sectional views and plan views of potential layouts. Through these the mansion started to take form. Then, using tape and dark tonal techniques similar to the previous phase, I began laying out the spatial configuration of the mansion, taking into consideration the mountain shoreline setting as well as prior depictions, in order to give it a cohesive formation. I tried to formulate a unified mansion design that could represent the design process and the previous drawings as fairly and as best as possible in the final mansion design. The aim was to combine all of my previous learning, findings, and research of architectural form making through depiction into one design, and to communicate the best way possible as one unified form. The first two painted sectional and plan iterations set important points of reference for understanding The Mansion's spatial layout as a whole unit, by indicating where the main spaces would be located. 


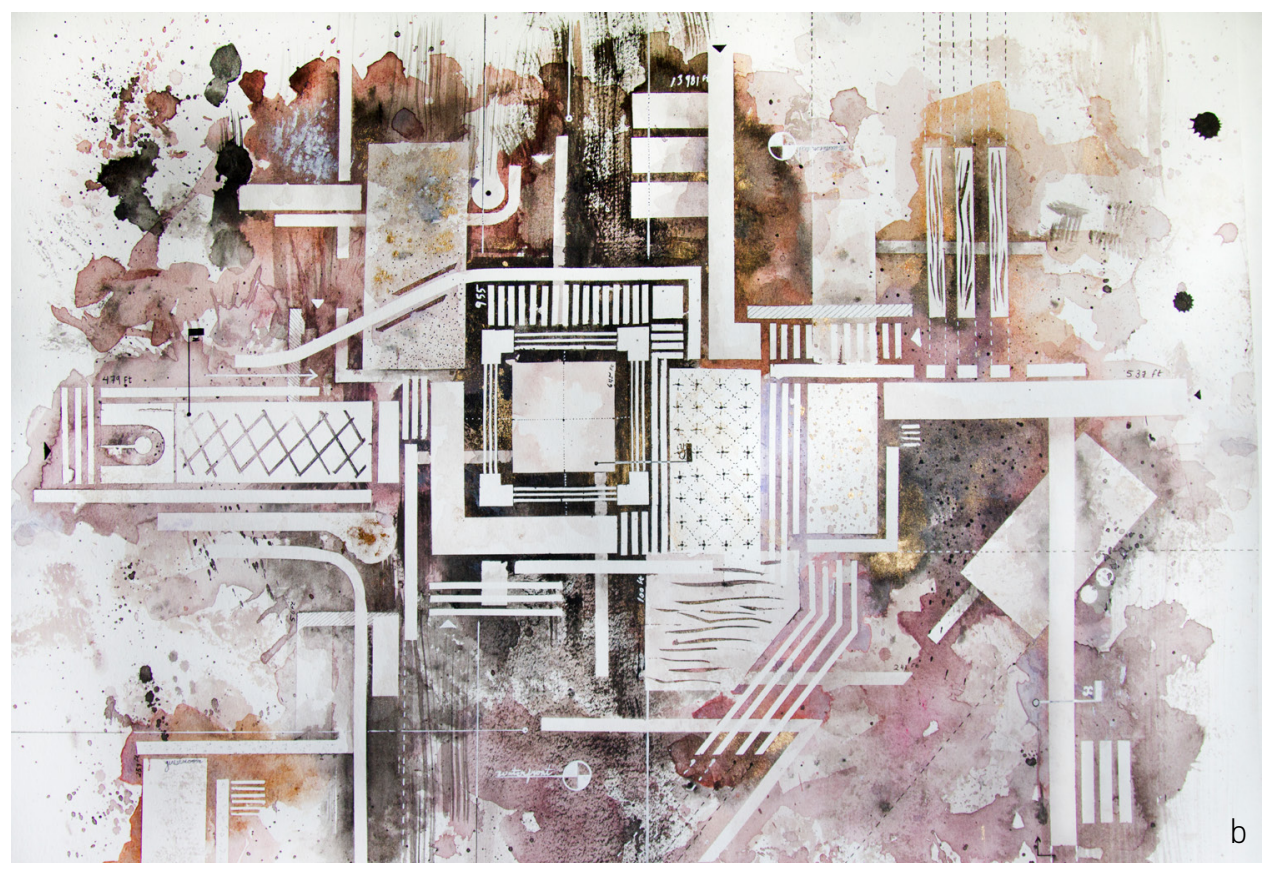

The next and final step was to formulate my understanding of the mansion up to this point into the final digital model, where I could easily draw and manipulate the forms being generated. I began formulating a similar layout to that of the previous two iterations, but this time using digital programs. With computer software, drawing becomes a much easier and faster process to generate architectural forms. Therefore, many iterations are made possible. What became points of reference in generating the platforms and the spatial arrangements are the previous depictions drawn in the design process as well as the ease in experimenting with numerous design options using digital media. Floors, walls, stairs, and roofs can be redrawn many times until the best satisfactory form that depicts the unified mansion is reached. Piece by piece, and portion-by-portion, spatial configurations start to formulate The Mansion, making up one cohesive final design. 


As the model was finalized, and read as a cohesive mansion, the drawings that communicated the design itself could then be used as experimental depictions capable of generating alternative architectural forms in and of themselves. Using digital programs, the act of layering varying plans, sections and elevations of The Mansion to develop alternative architectural forms, is simplified. Therefore other architectural configurations can be achieved through the drawing. An example of this is shown in the plan drawings of the three stories of The Mansion. The plan drawings present the physicality of the unified design while the elevation and section drawings depict the layering of various elevations and sections in individual drawings. This produces different outcomes, each of which produces their own forms.

The Mansion stands as a final unified form. It has a cohesive design with particular spatial configurations (such as entrances, seating area, resting areas, courtyard, and sleeping areas) and it has also become a point of reference as an architectural form generator in itself. The Mansion is a place where the drawings themselves hold significance beyond the act of communicating the physicality of the mansion. The drawings invite further expansion on and experimentation with architectural ideas. They reflect a more topopoetic manner of depiction, one that aims to portray and represent more than a subject or object. They are drawings that can interact with the viewer. ${ }^{7}$ They are forms to be read and interpreted however perceived. The drawings convey more than the final physicality of The Mansion: they convey the spirit of the place through form and line work; they convey feelings through material and colour choices; and they convey architectural composition through their forms and shapes, drawn and made real through depictions. 



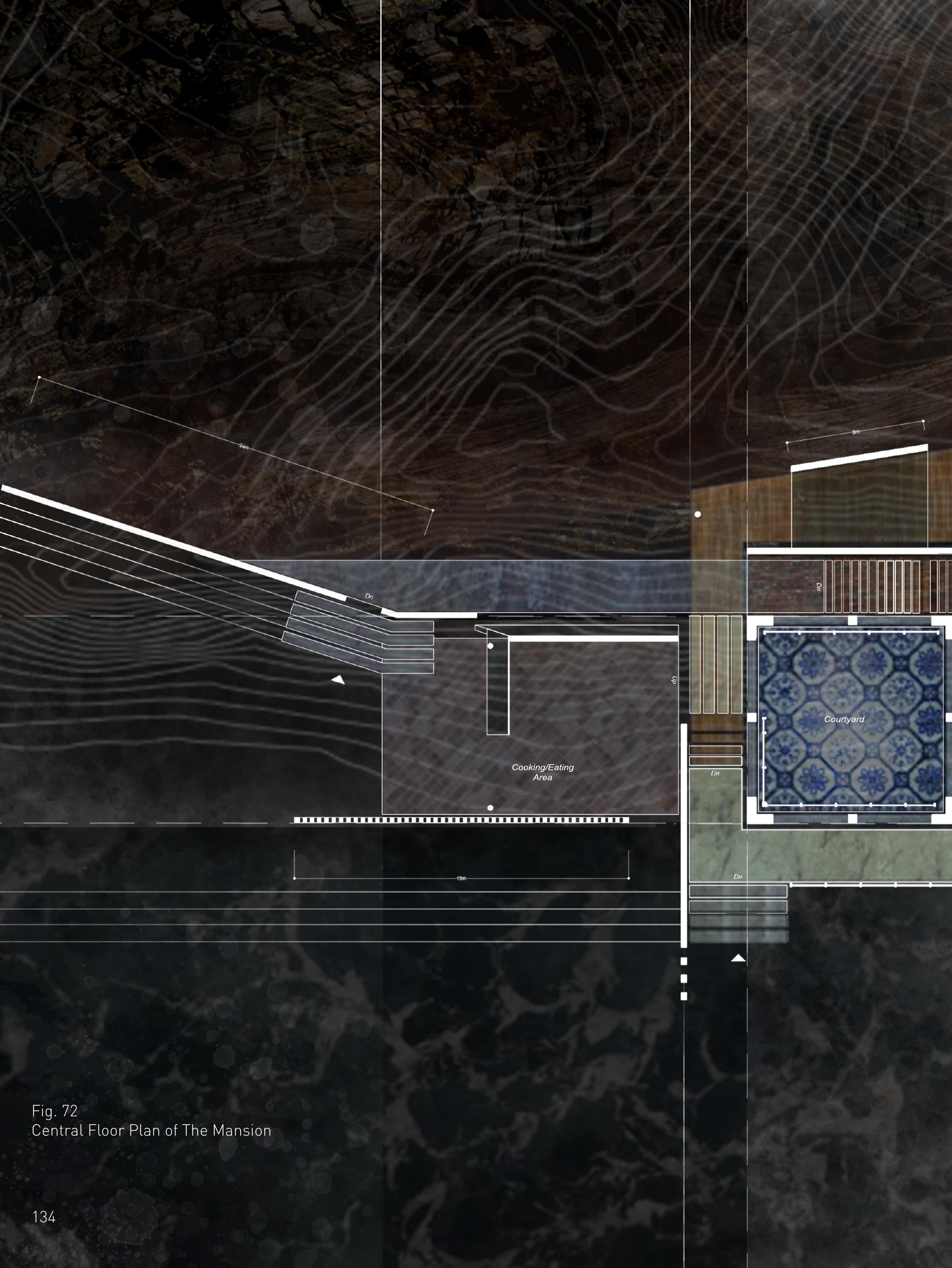





1 Dictionary, "The Definition of Home" (Dictionary.com, 2016).

2 Bill Bryson, "At Home: A Short History Of Private Life".

(New York: Knopf Doubleday Publishing Group, 2010), 28.

3 Anthony Vidler, "The Architectural Uncanny: Essays In The Modern Unhomely", 5th ed. (Cambridge, MA: M.I.T. Press, 1992), 65.

4 C.J. Lim, "Realms Of Impossibility: Air" (United Kingdom: Wiley-Academy, 2002), 7.

5 Gaston Bachelard, "The Poetics Of Space". (New York: Viking Books, 1964), 13.

6 Edward S. Casey, "Representing Place”, 1st ed. (Minneapolis: University of Minnesota Press, 2002), 30

7 Ibid

Fig. 74

Physical Model of The Mansion 


\section{6 | Depicting Architecture}

Drawing and model making are significant forms of production within the design process that generates architectural forms. They are important and central means of production in architecture that yield critical designs. Theoretical depictions, more than technical drawings, play a primary role throughout the design process through extensive explorations. The design process must be regarded as an experimental platform where architectural ideas may be explored and developed, across different mediums and techniques of expression. This experimental method of design exploration is lacking in the discipline for the most part; not enough of an experimental architectural mode of production exists nor is it freely explored within an architectural discourse. Platforms that endorse such experimental design strategies and design methods result in architectural forms that yield alternative perspectives and understandings of architecture through their mediums and freedom of design. Critically formulated drawings hold significance through their process and in their final outcome, serving as a learning procedure that guides the artist/designer in generating critical designs.

Depictions, through the forms they generate, are able to convey alternative architectural configurations and spatial compositions in this exploratory mode of production. The forms generated in turn introduce alternative and new architectural configurations that influence the designer and the viewer's thinking. Speculative depictions are able to widen the perspective of one's understanding with its forms, and build on the creative thinking process of those that are exposed to them through its range of methods of expression. Architectural depictions are generated with the aim of producing forms that 
can be analyzed; they are to influence and to be interpreted by the viewer. They are productions that can benefit both the designer and the viewer by serving as impactful works in the architectural forms they develop. Depictions can communicate more than just form. They inform an architectural atmosphere: feelings, and emotions that allow the viewer to interpret the depictions and formulate their own analyses and understandings.

Depictions, through varying visual, tactile, and material means, produce architectural form, which in turn push design thinking to other territories. Through an experimental and speculative process of designing Houses of the Imagination, the role that drawing, painting, modeling and other forms of depiction played in the architectural process and in the generation of significant architectural forms at all phases is evident. Drawing and model making are central practices that played a central role in developing the architectural project in this thesis through an exploratory mode of production. Every depiction intends to speculate and formulate a learning outcome, and each generates artifacts that are, in and of themselves, architecture.

After an extensive experimental design process, which explored designing with varying mediums, techniques, and methods of expression, a Modest Mansion was formulated from a design study depicting Houses of the Imagination. The project exposed an alternative approach to design, formulating critical designs that influenced my design thinking within every phase of the design process. Whether it was drawn, painted, built, collaged, modeled, or photographed, architectural forms were made real through depiction. Depictions give architecture forms that are of value in expanding the architectural discourse. 
Appendix
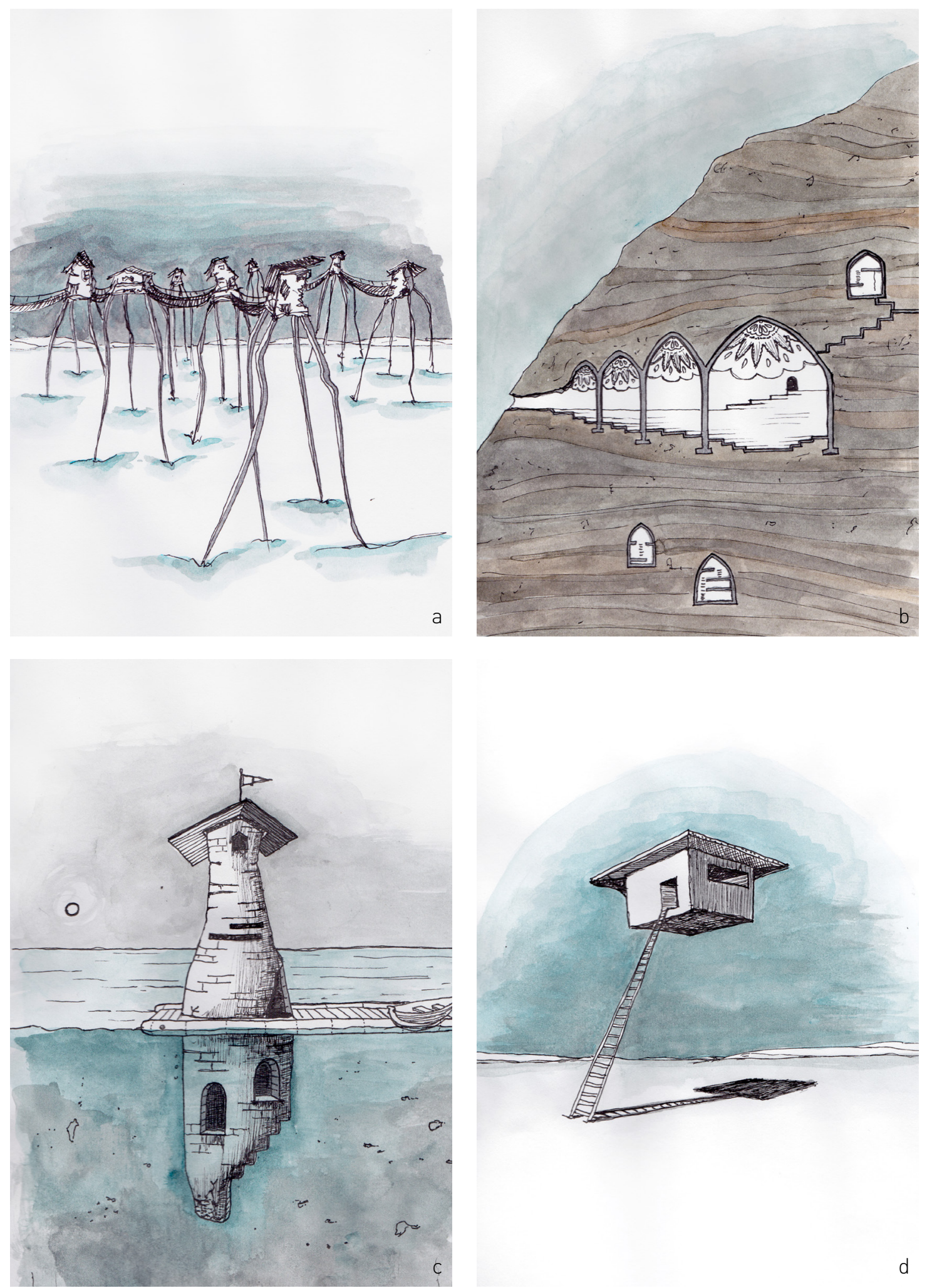

Fig. 75

Figurative Sketches of Houses of Air, Ground, Water 

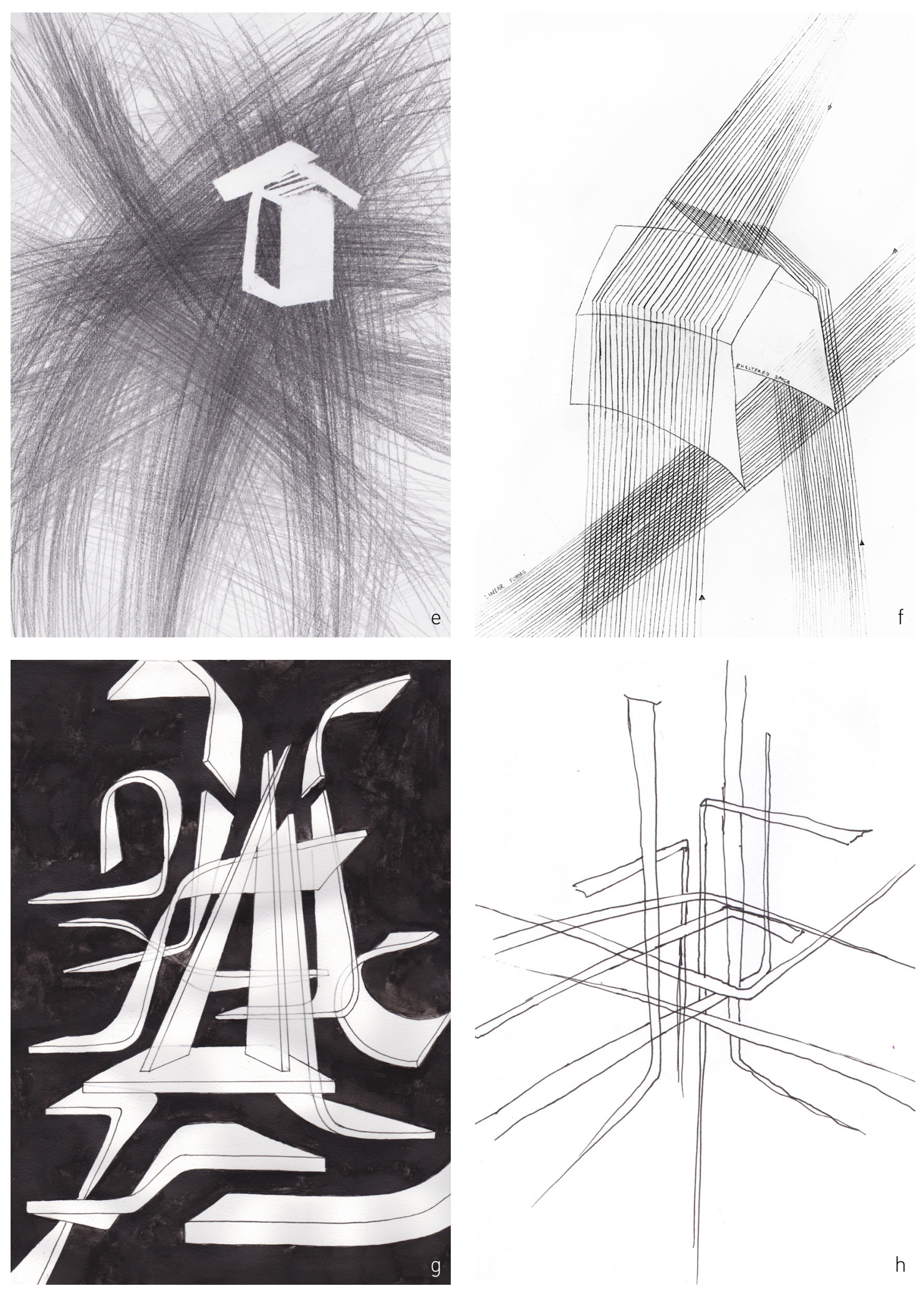


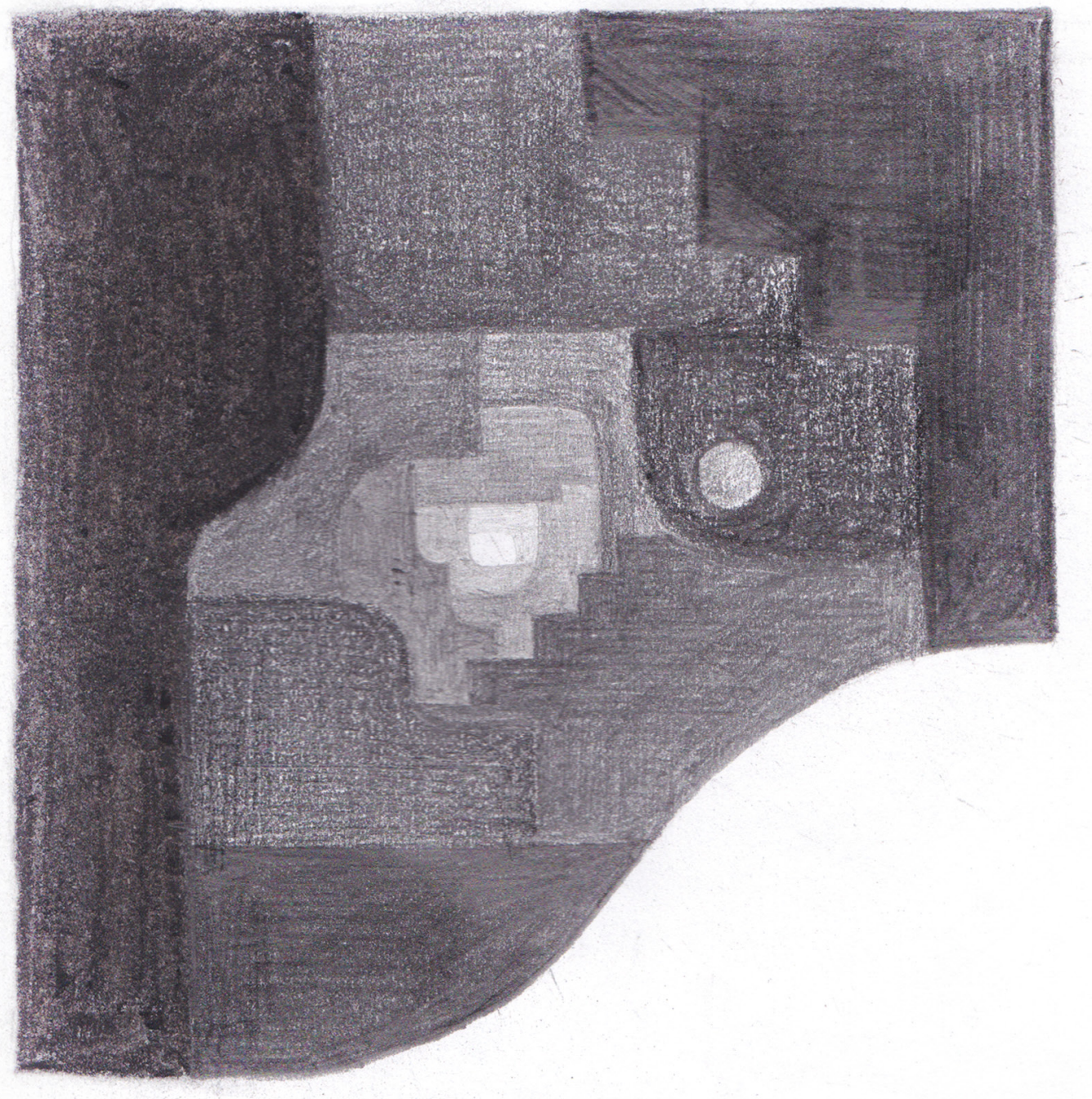

Fig. 76

Conceptual Spatial Layering 

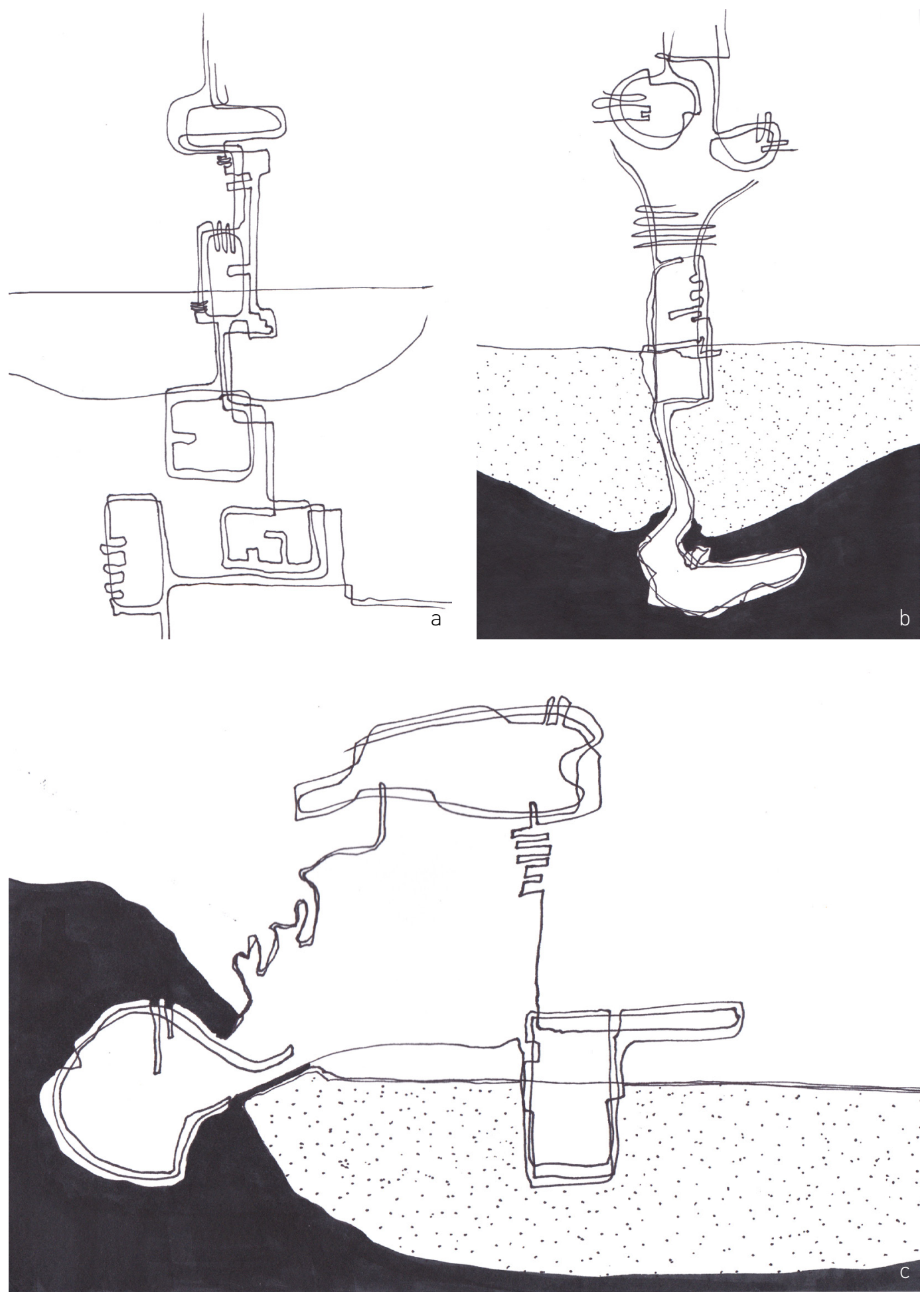

Fig. 77

Sectional Continuous Contour Drawings of Houses 

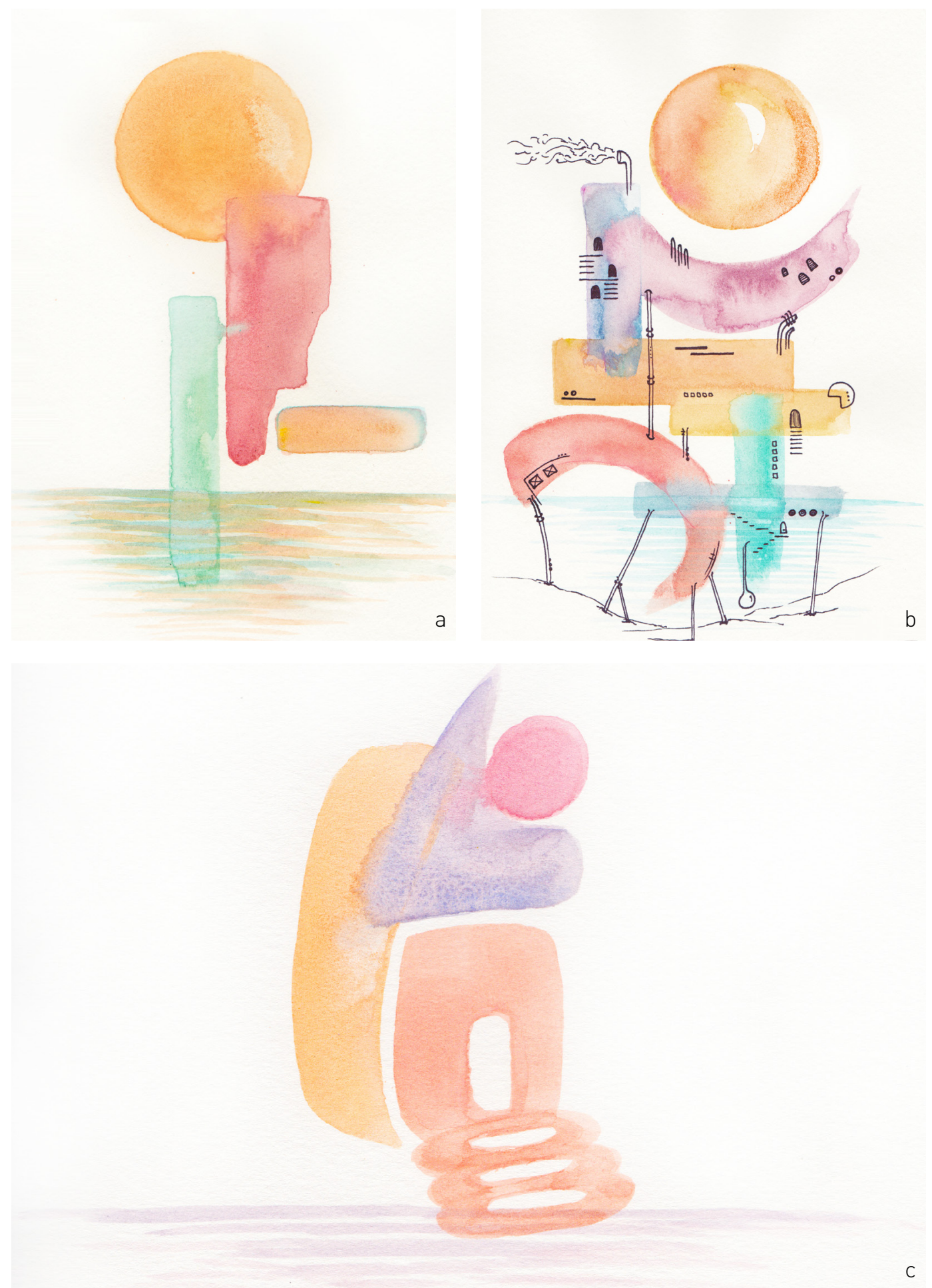

Fig. 78

Watercolour Drawings of Houses 


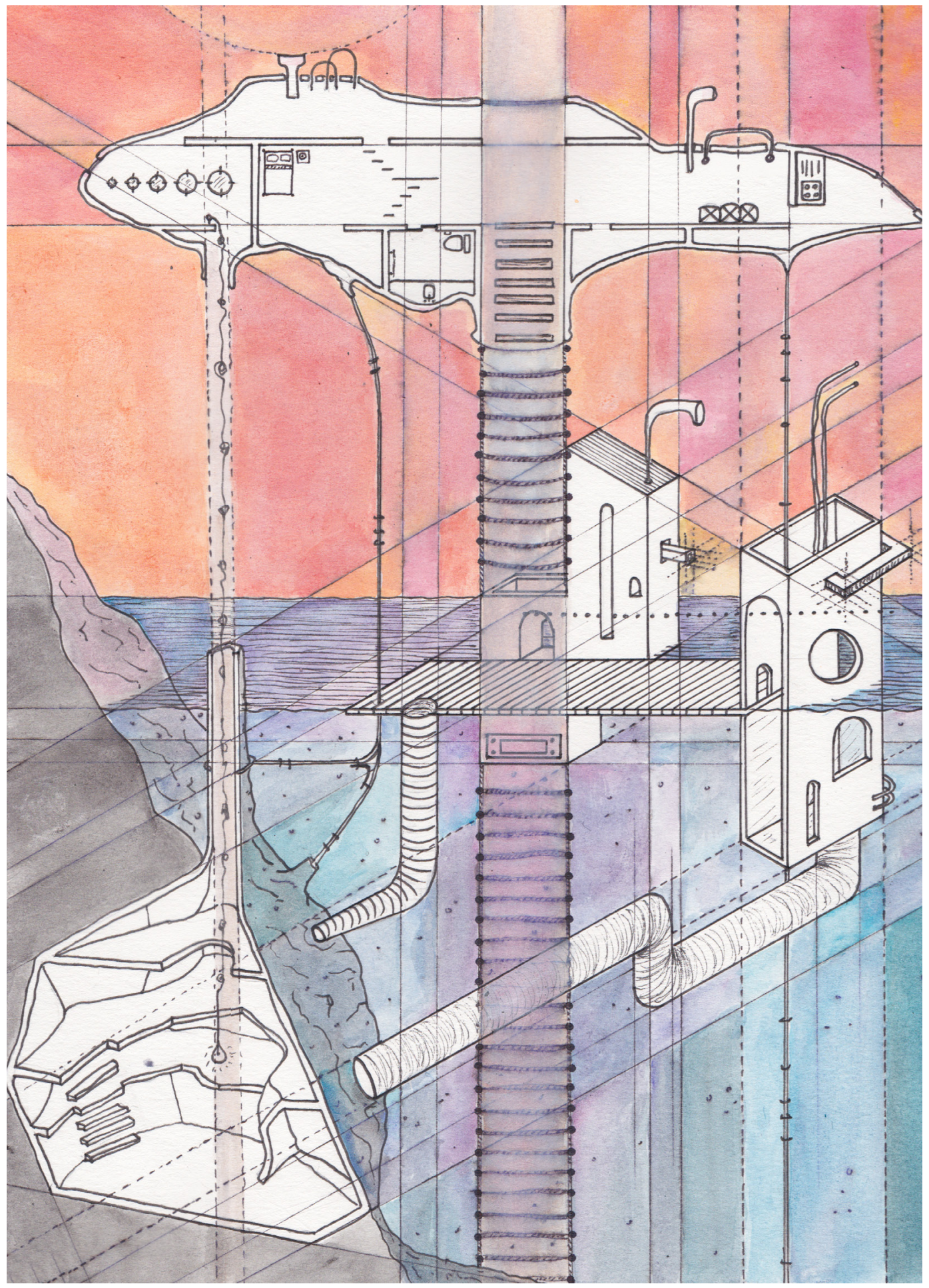

Fig. 79

Figurative Watercolour Drawing of Houses 

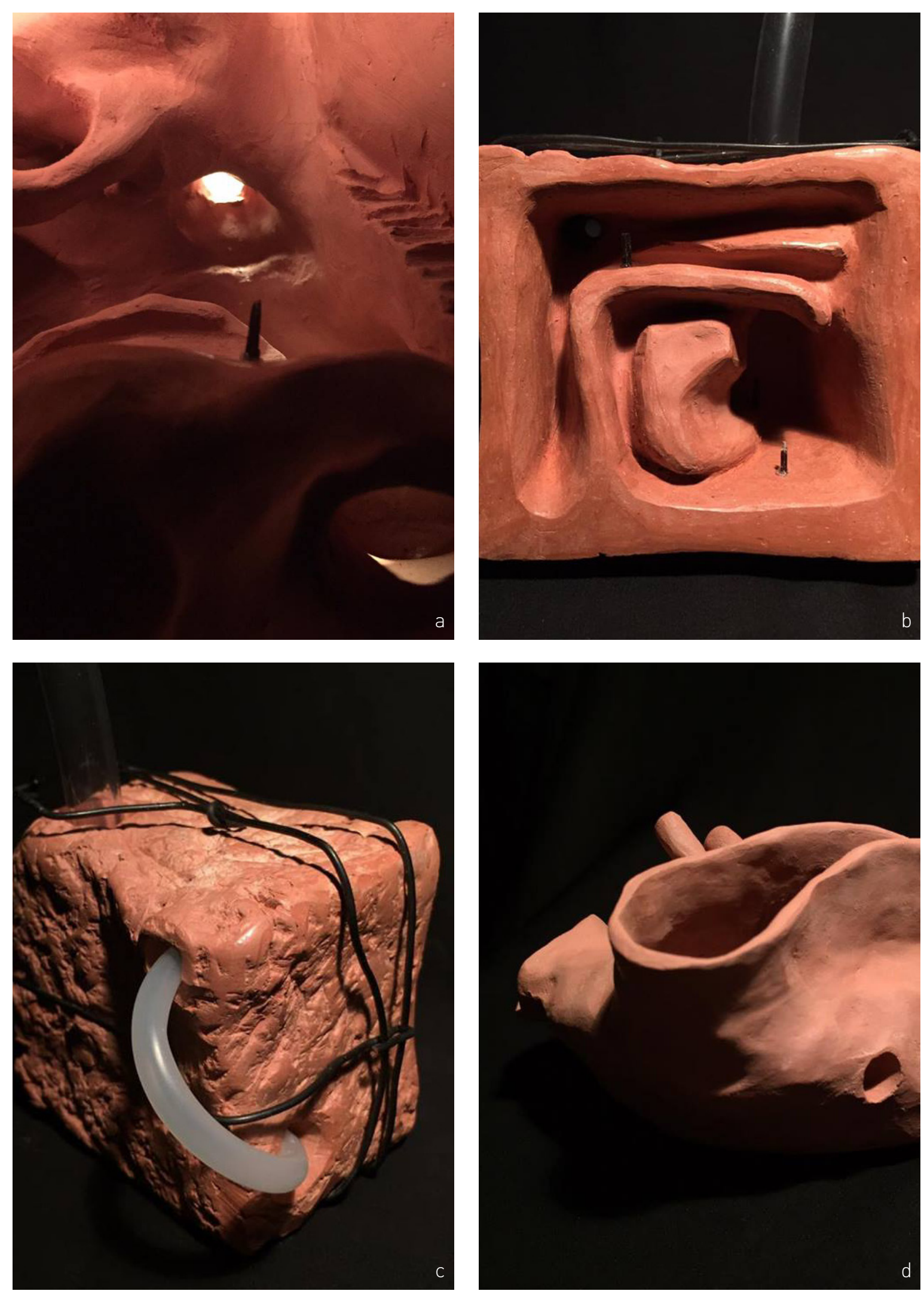

Fig. 80

Clay Houses 

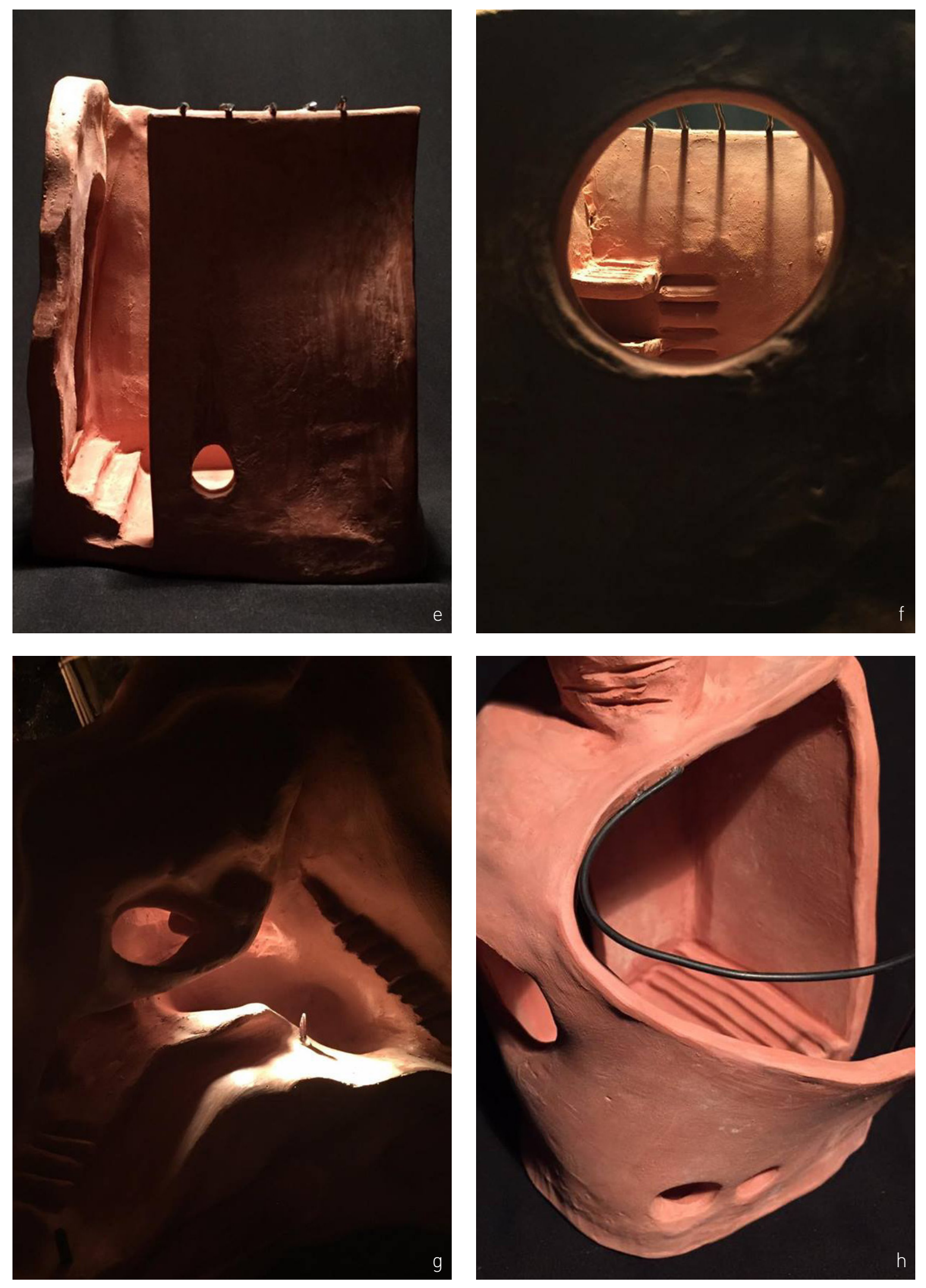


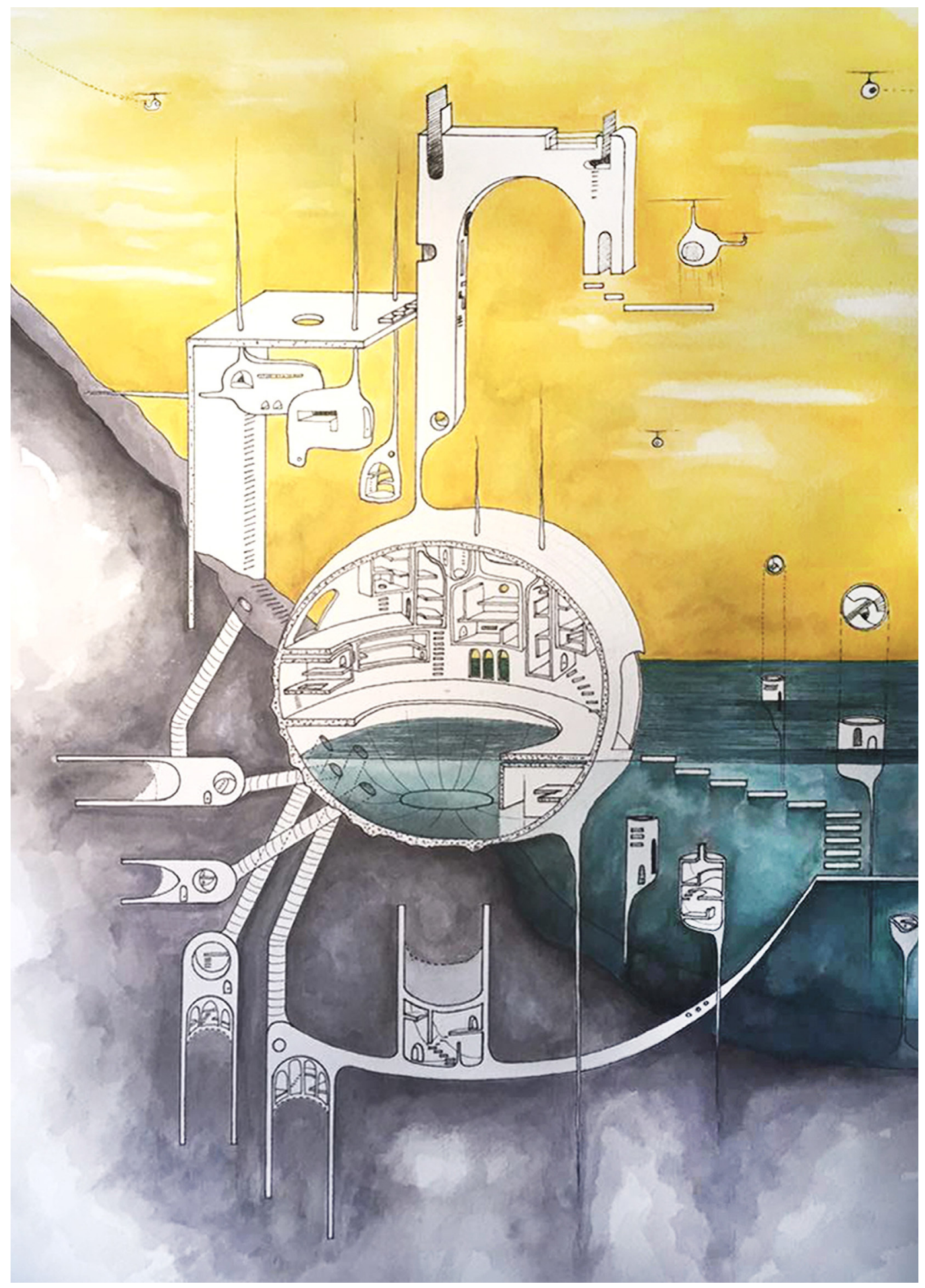

Fig. 81

Figurative Watercolour Drawing of Houses 

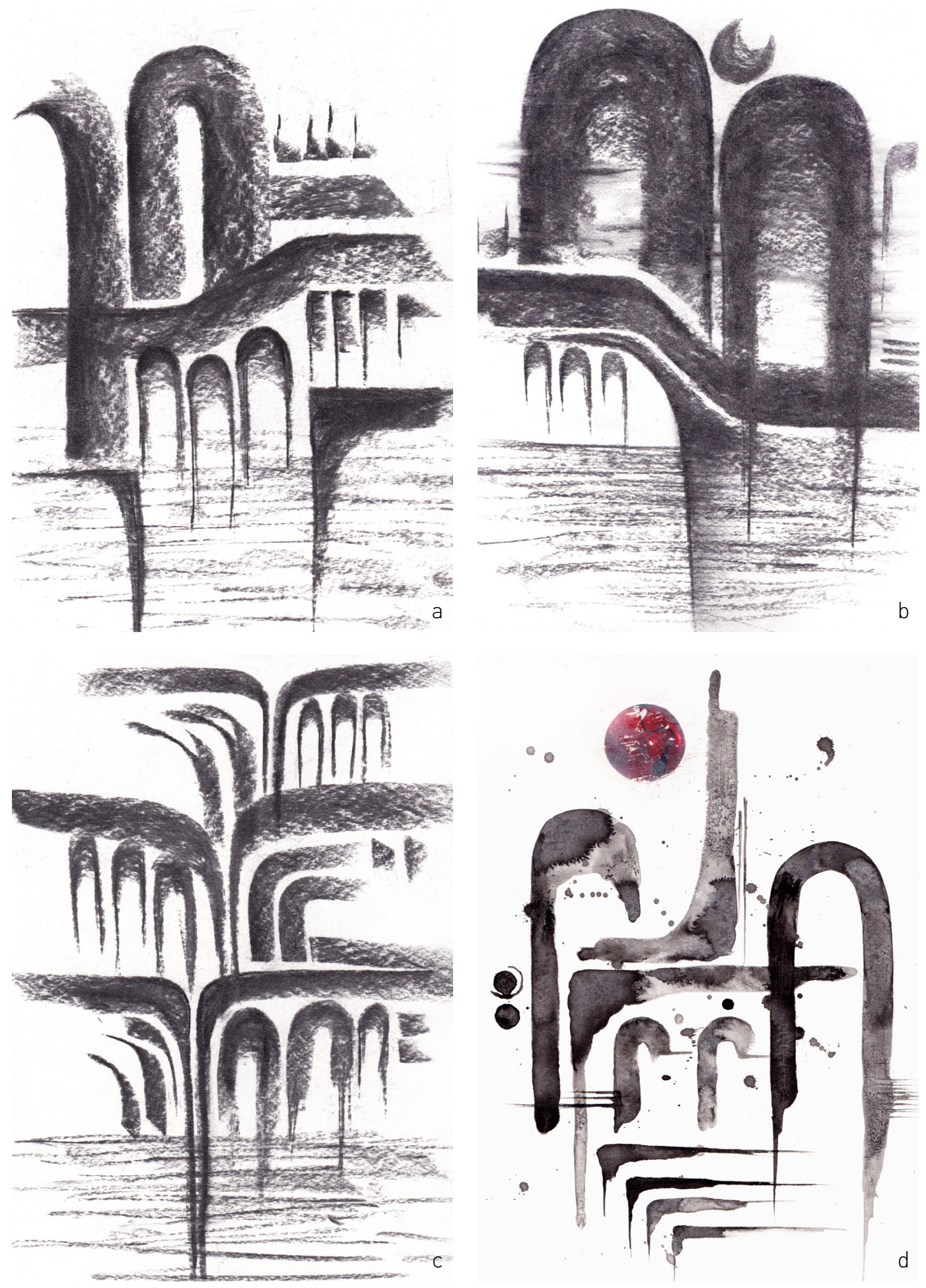

Fig. 82

Black and White Silhouettes of Houses 

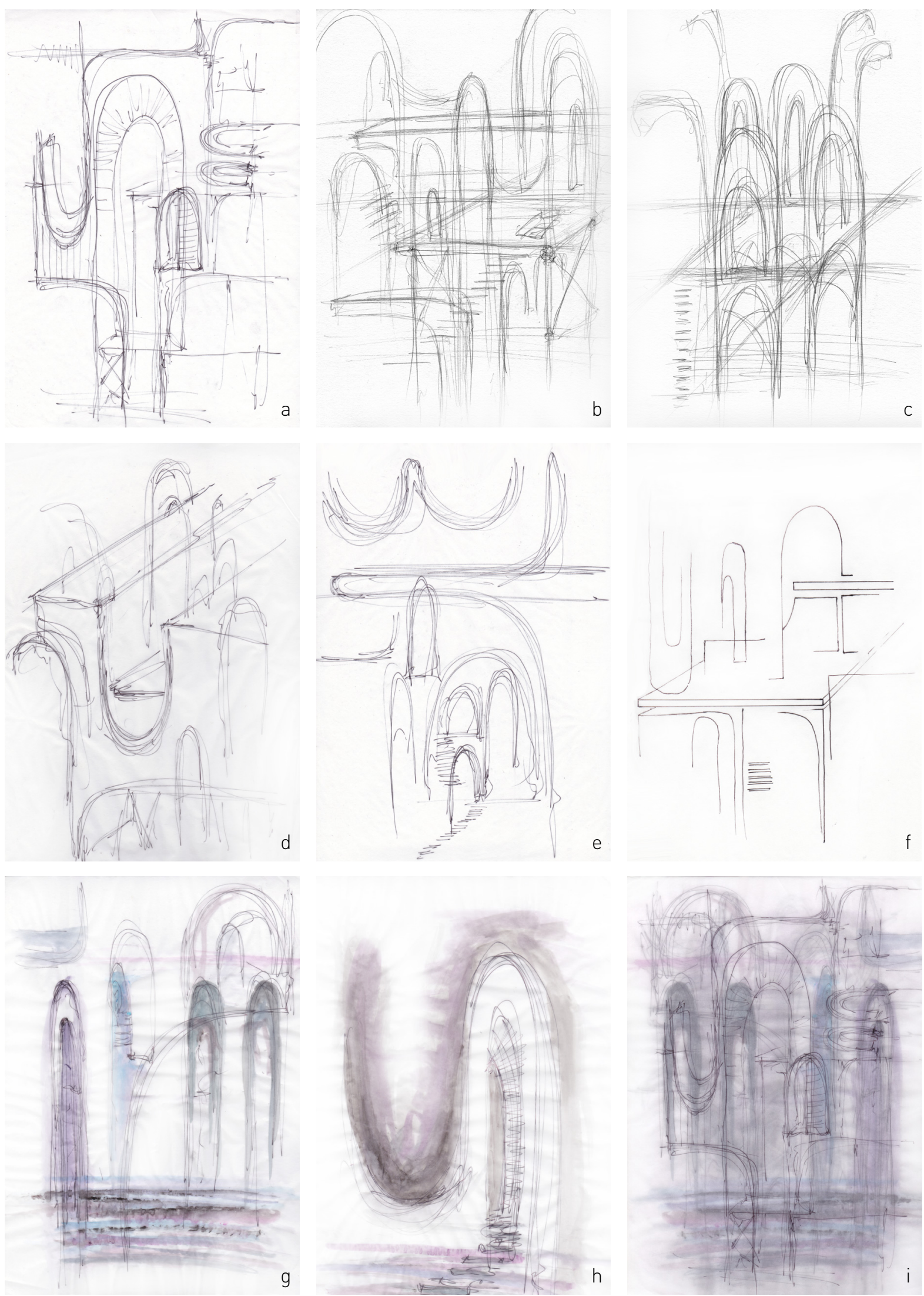

Fig. 83

Rough Sketches of Houses 

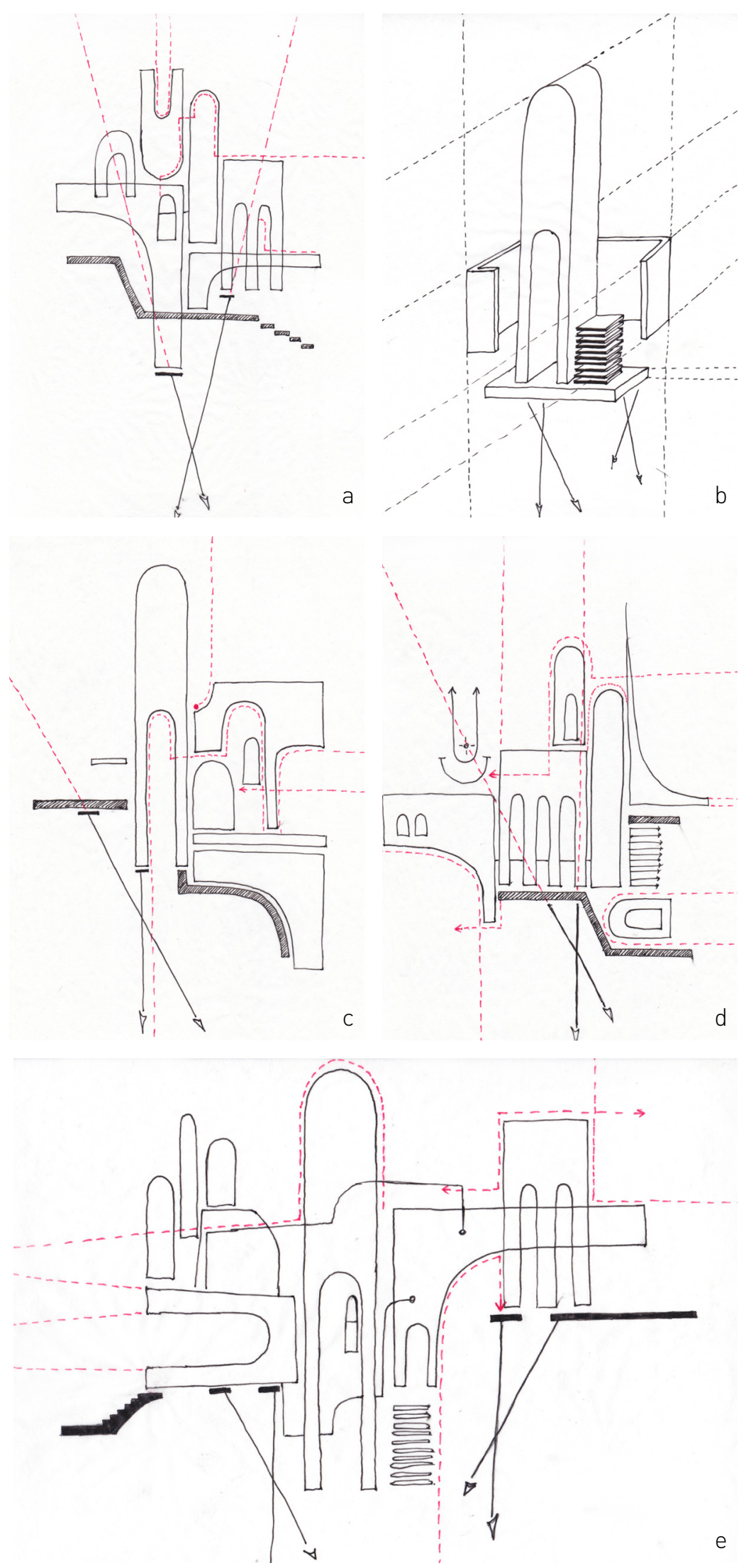

Fig. 84

Rough Sketches of Houses 


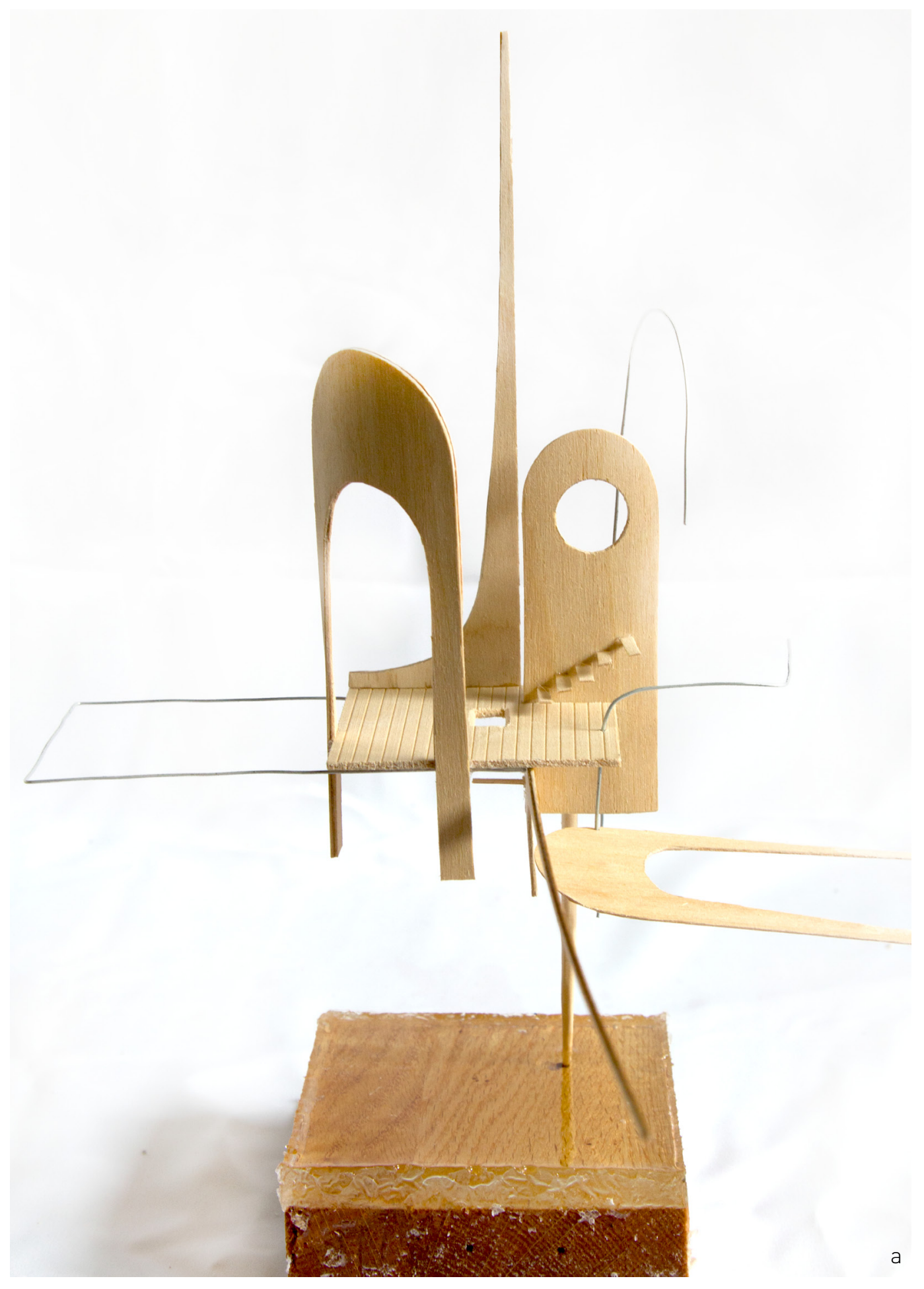

Fig. 85

Physical Models of a Unified Modest Mansion 

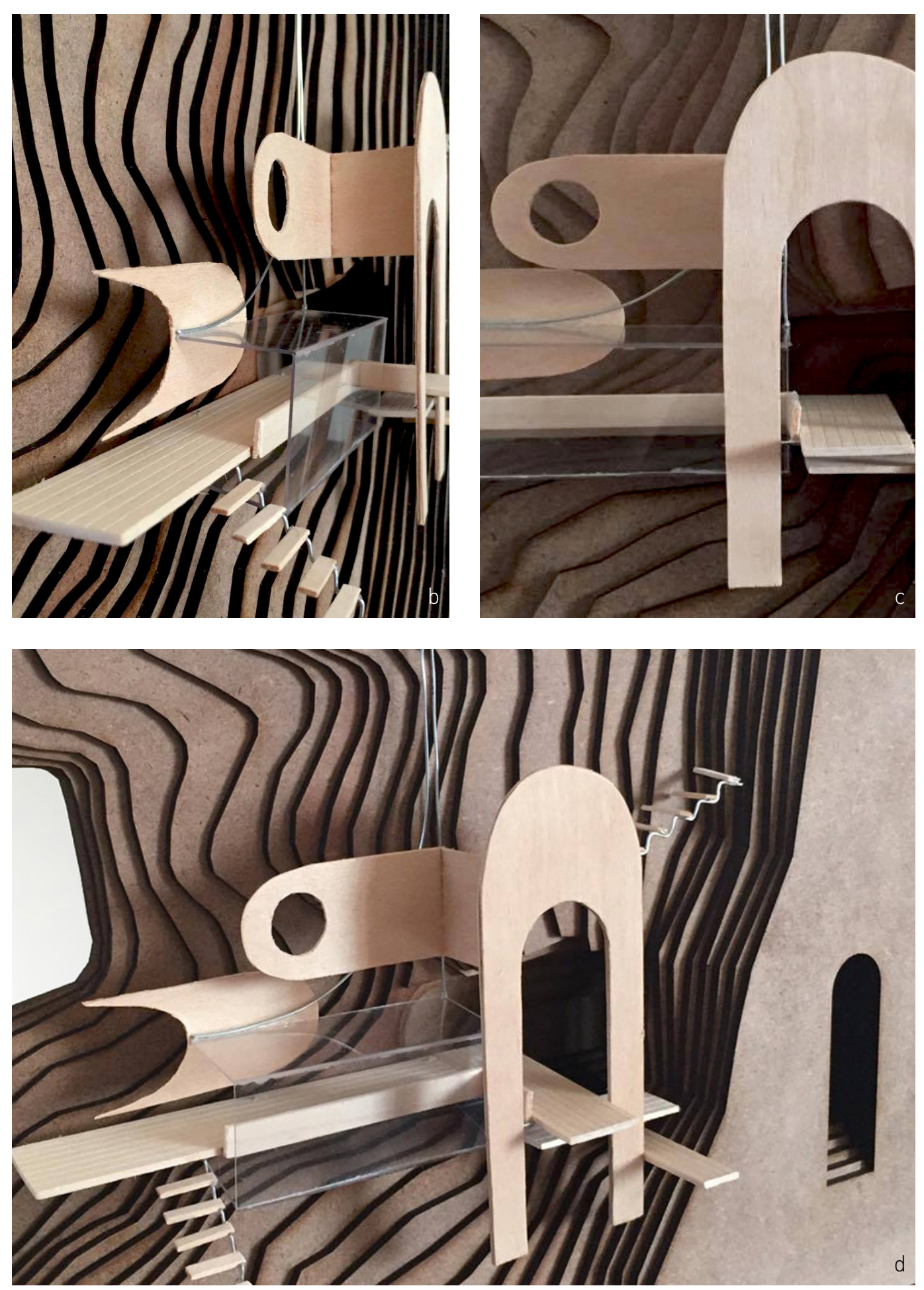

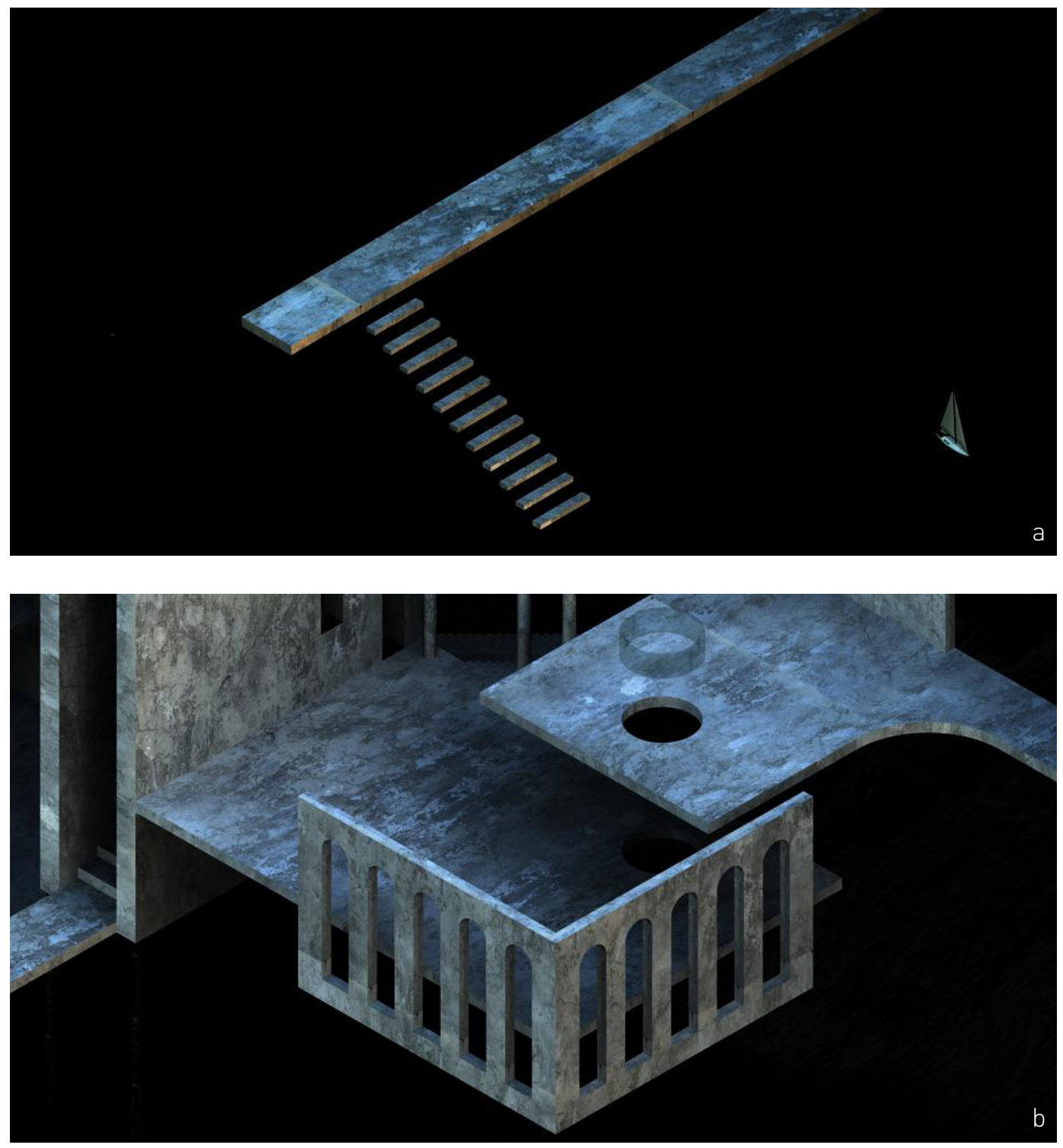

Fig. 86

Digital Model of a Unified Modest Mansion 

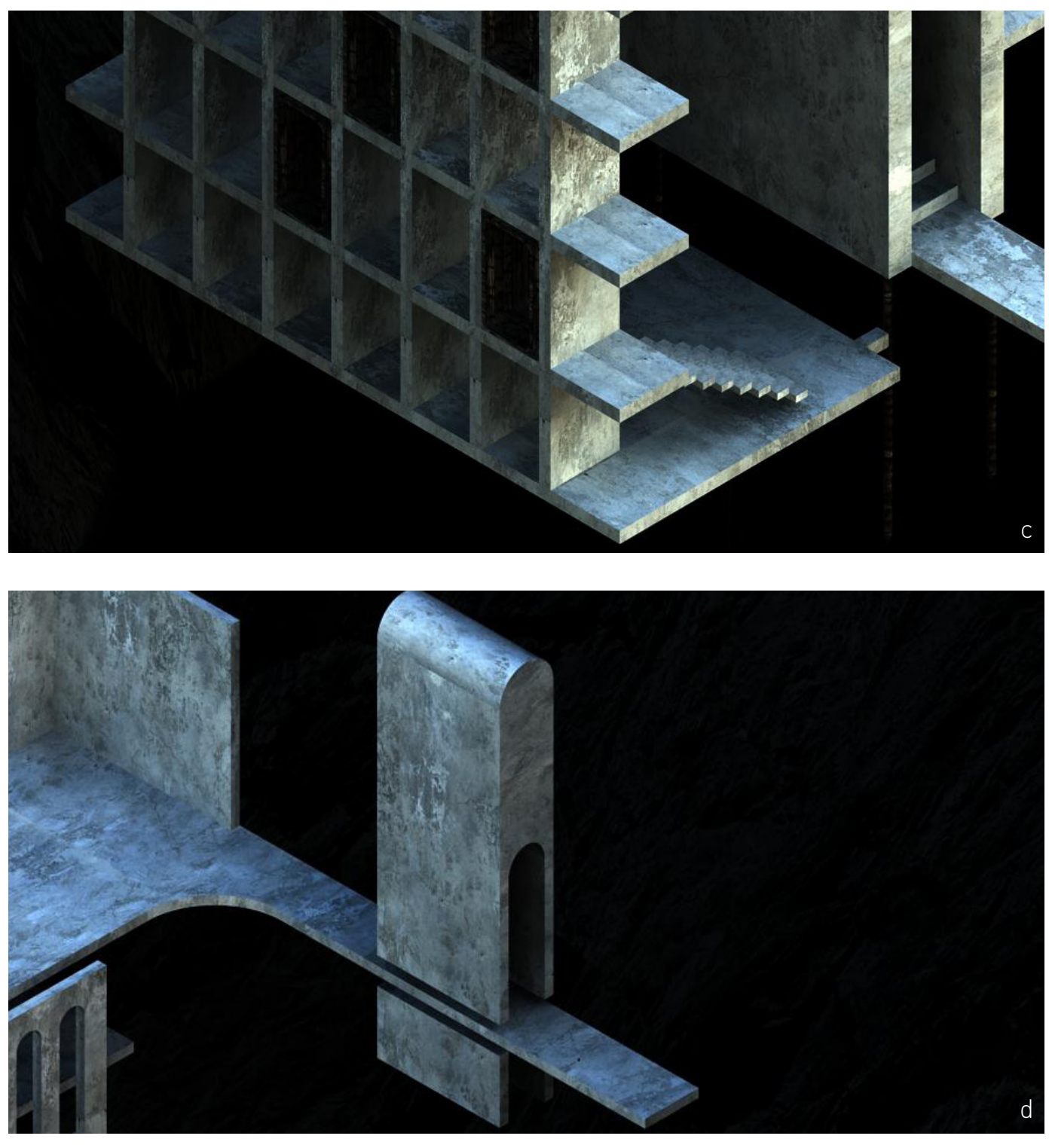

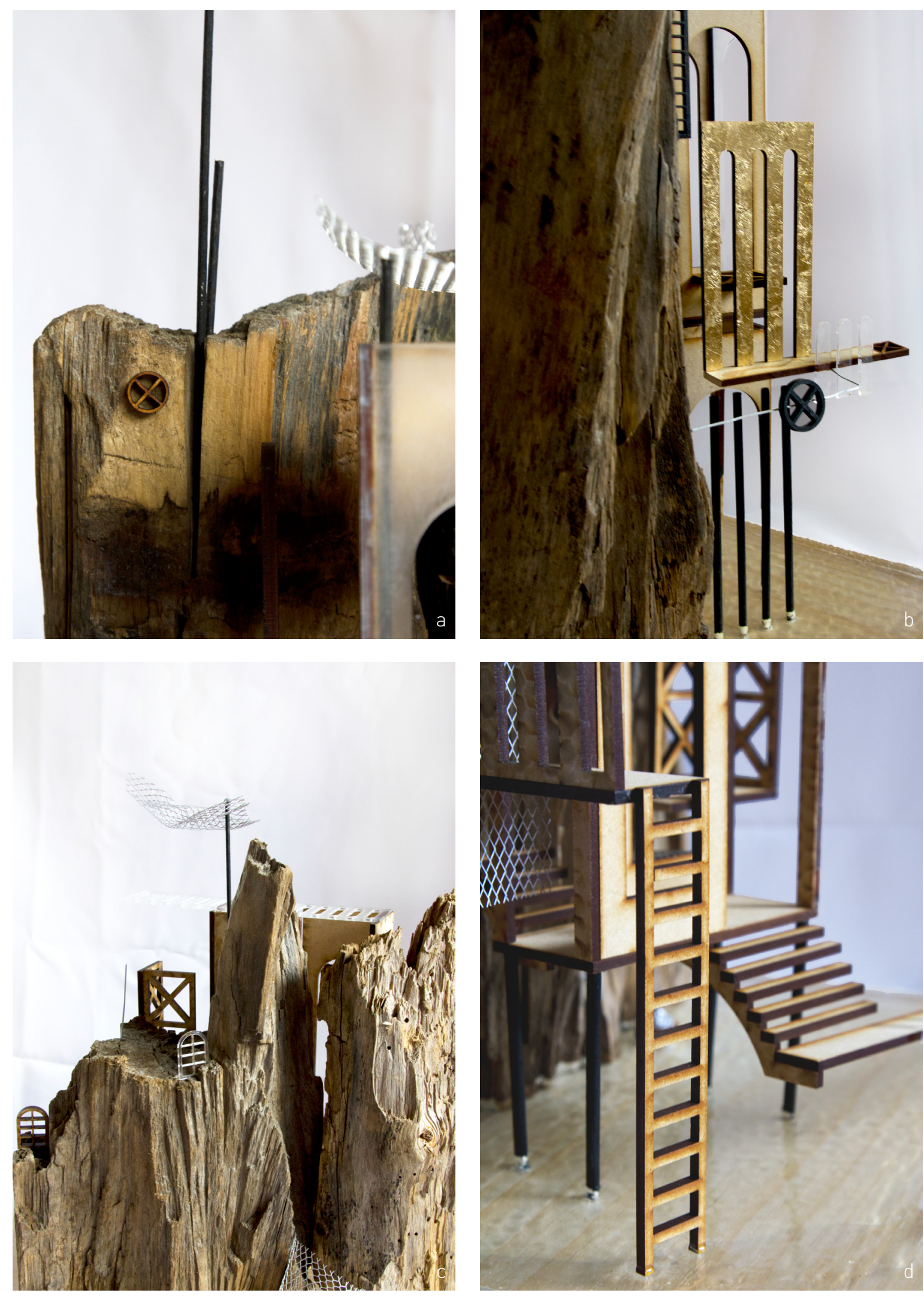

Fig. 87

Physical Modesls of Unified Modest Mansions 

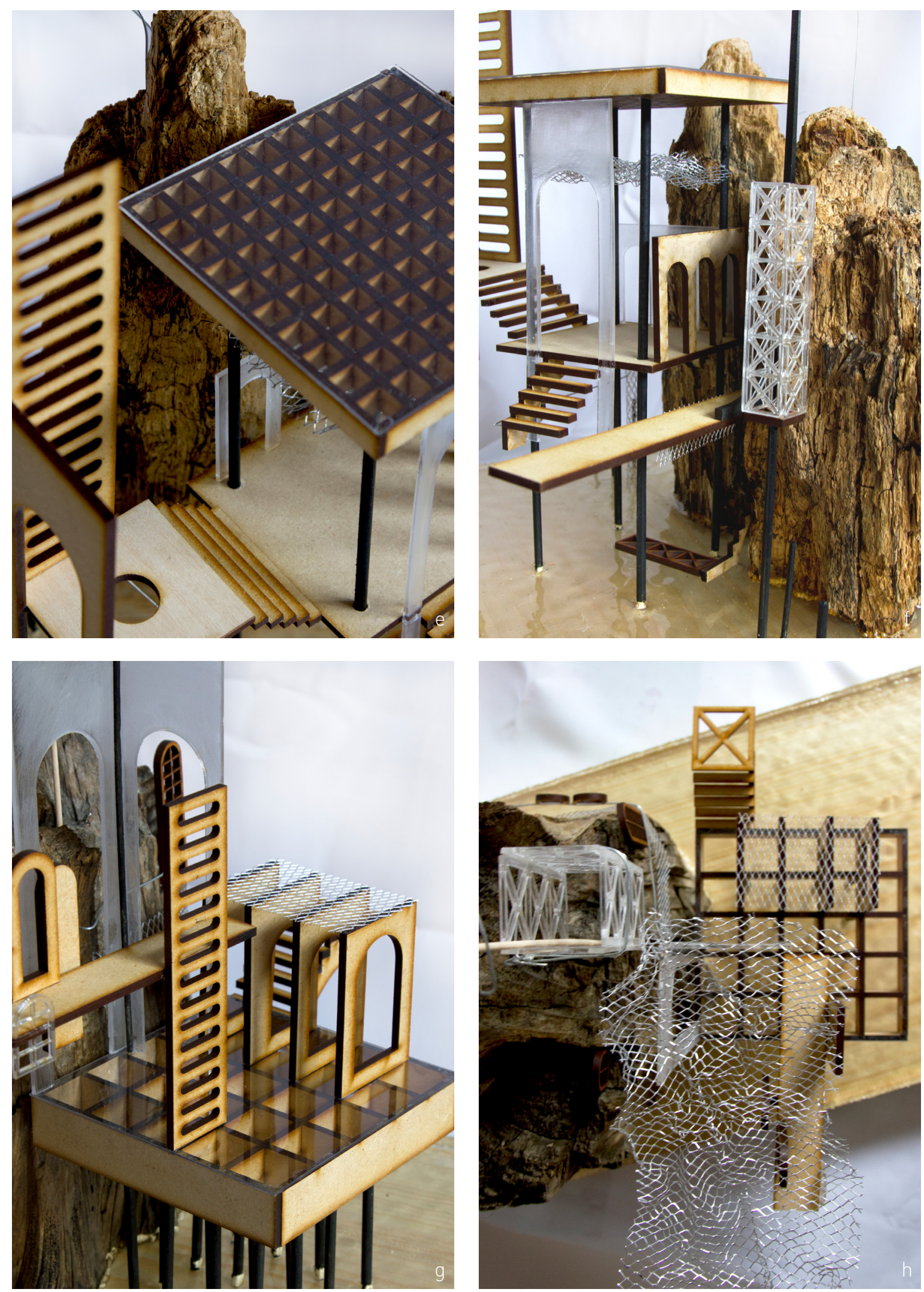

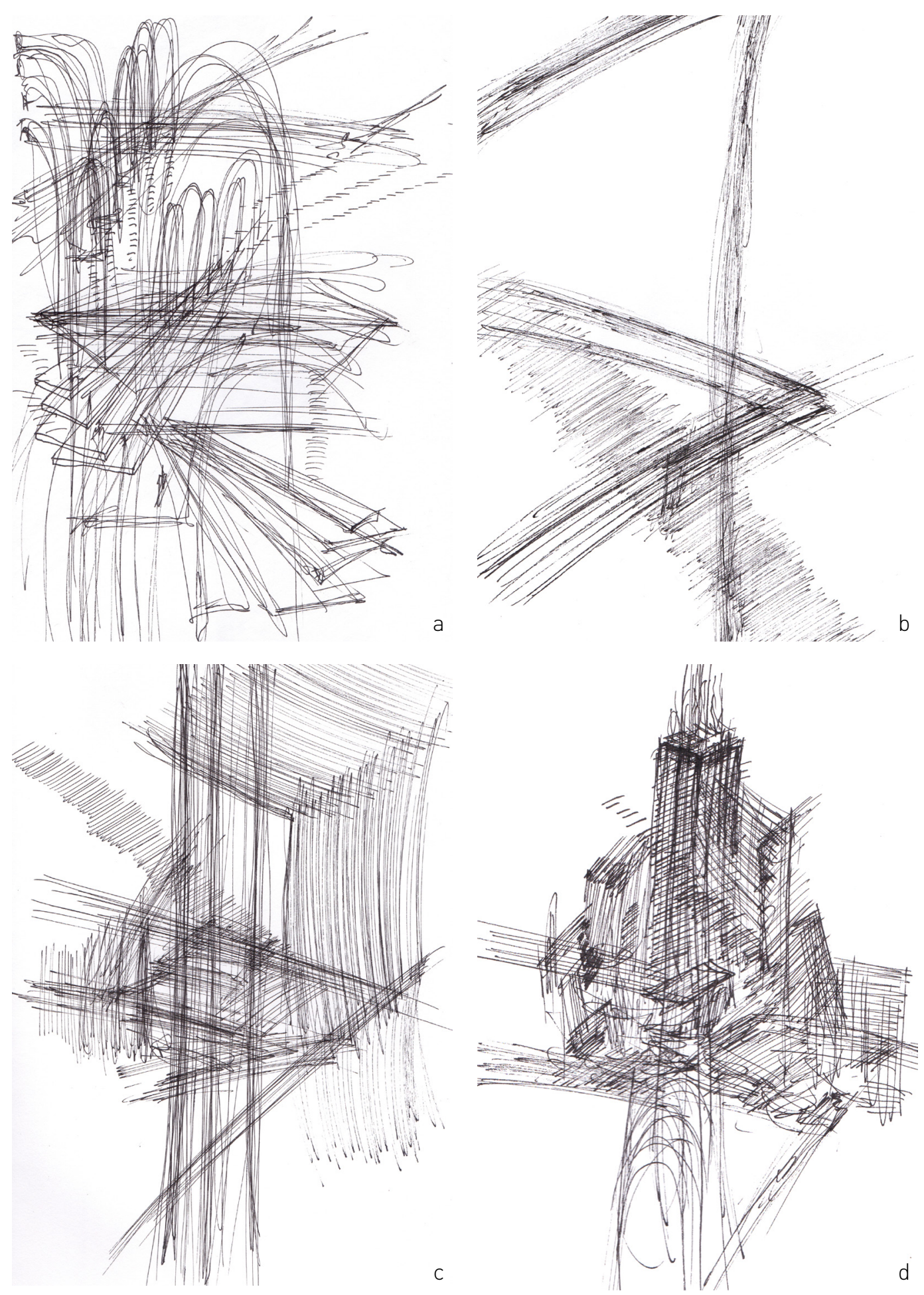

Fig. 88

Rough Sketches of The Modest Mansion 

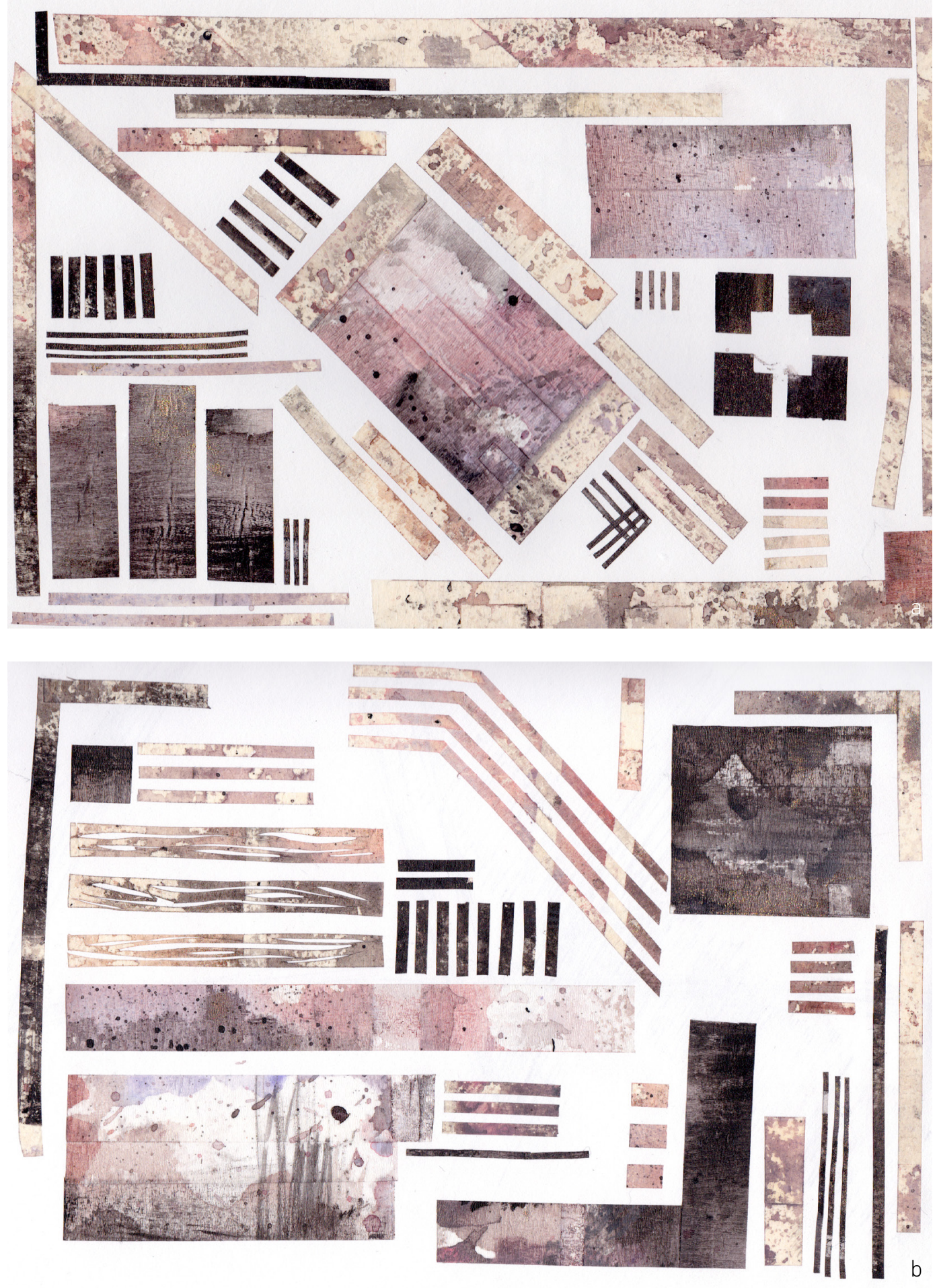

Fig. 89

Painted Tape from Watercolour Iteration of The Mansion 


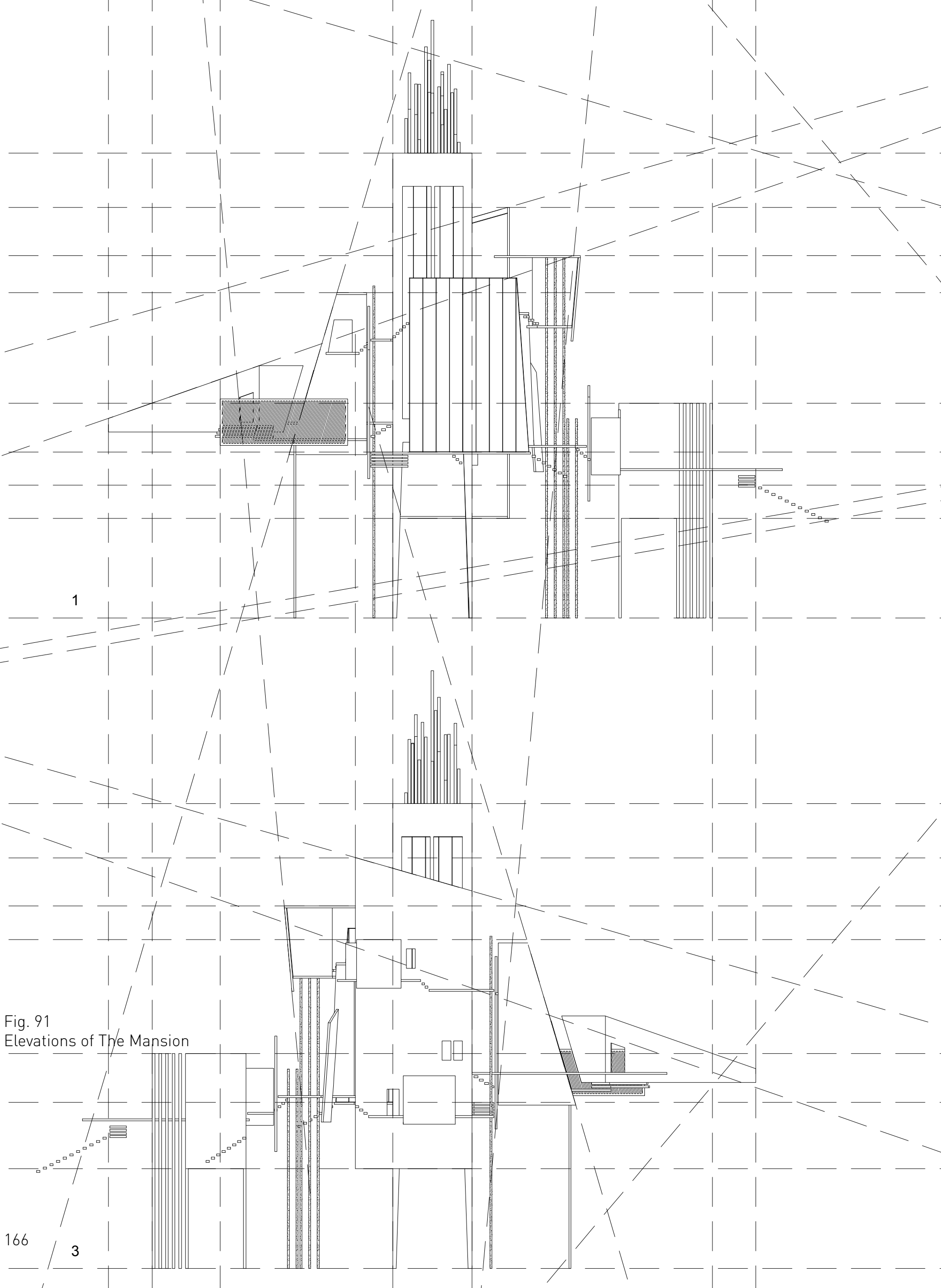




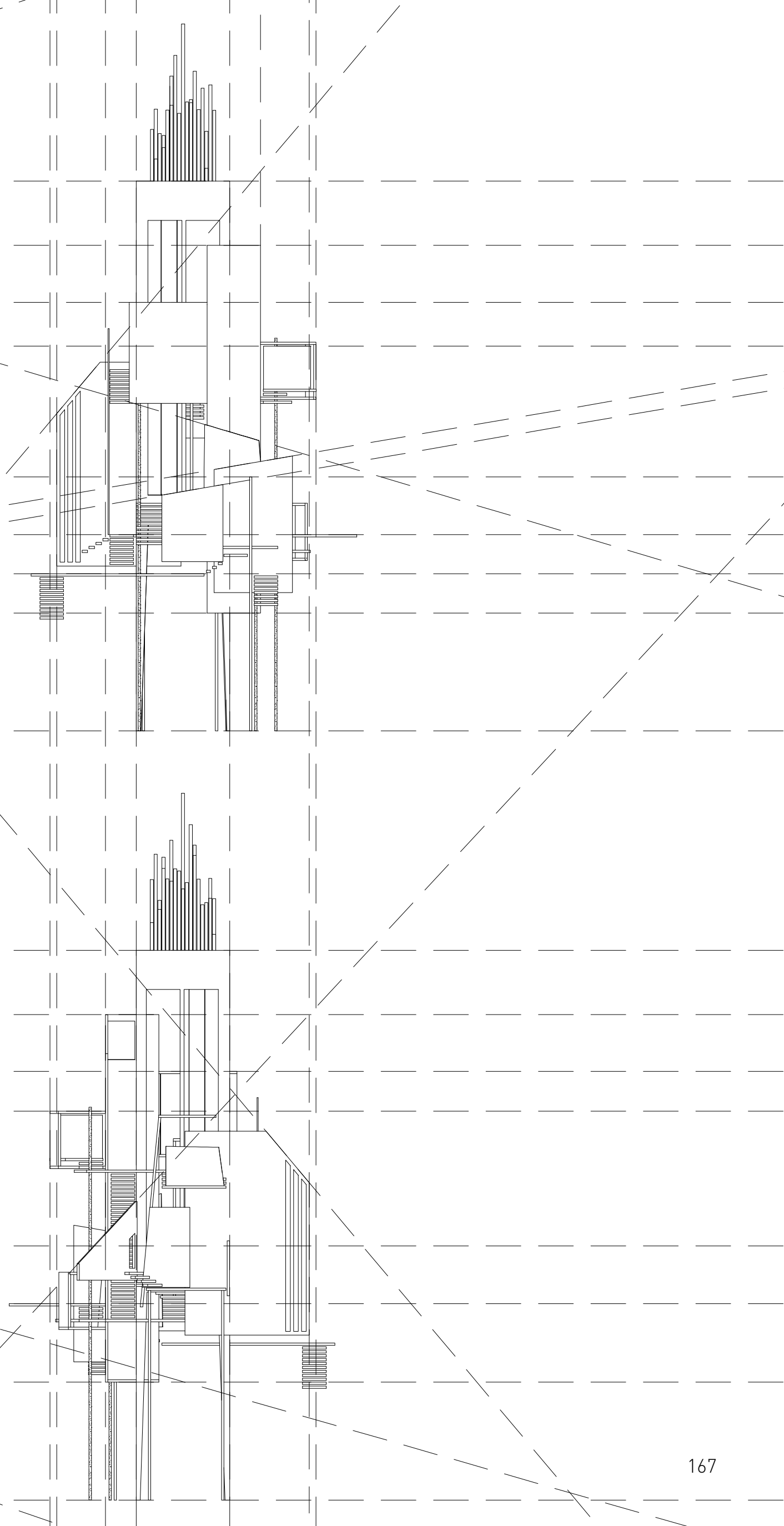




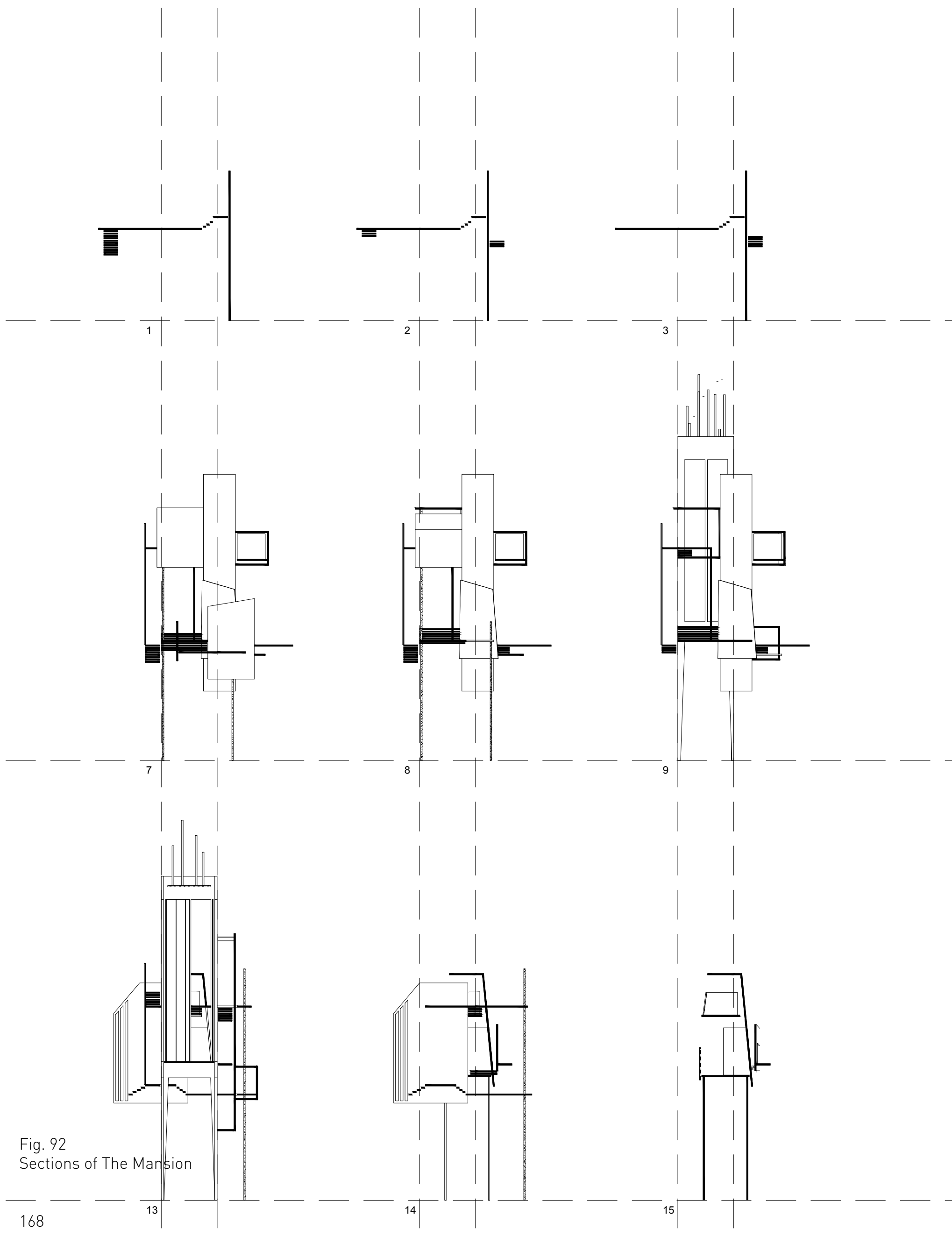




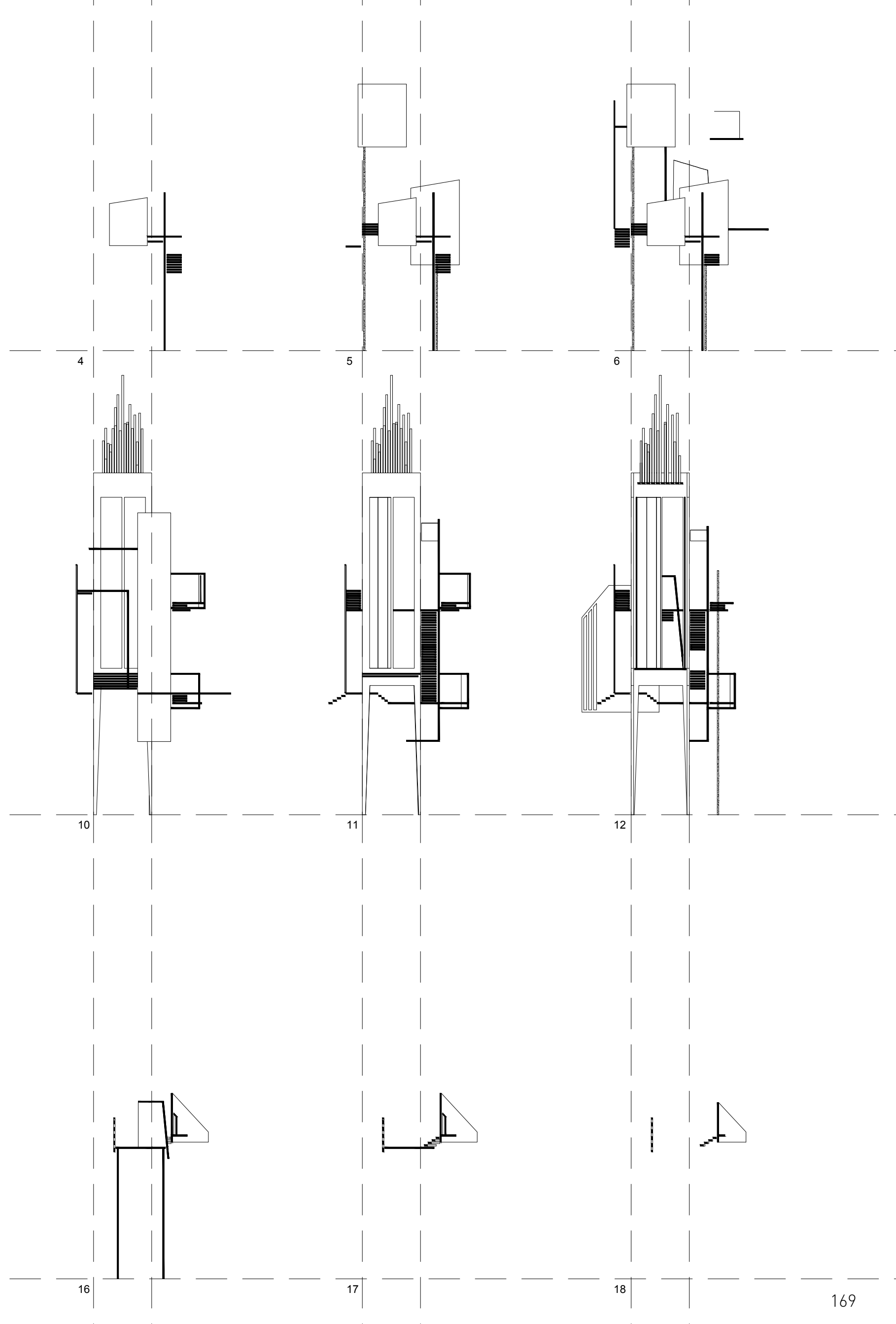




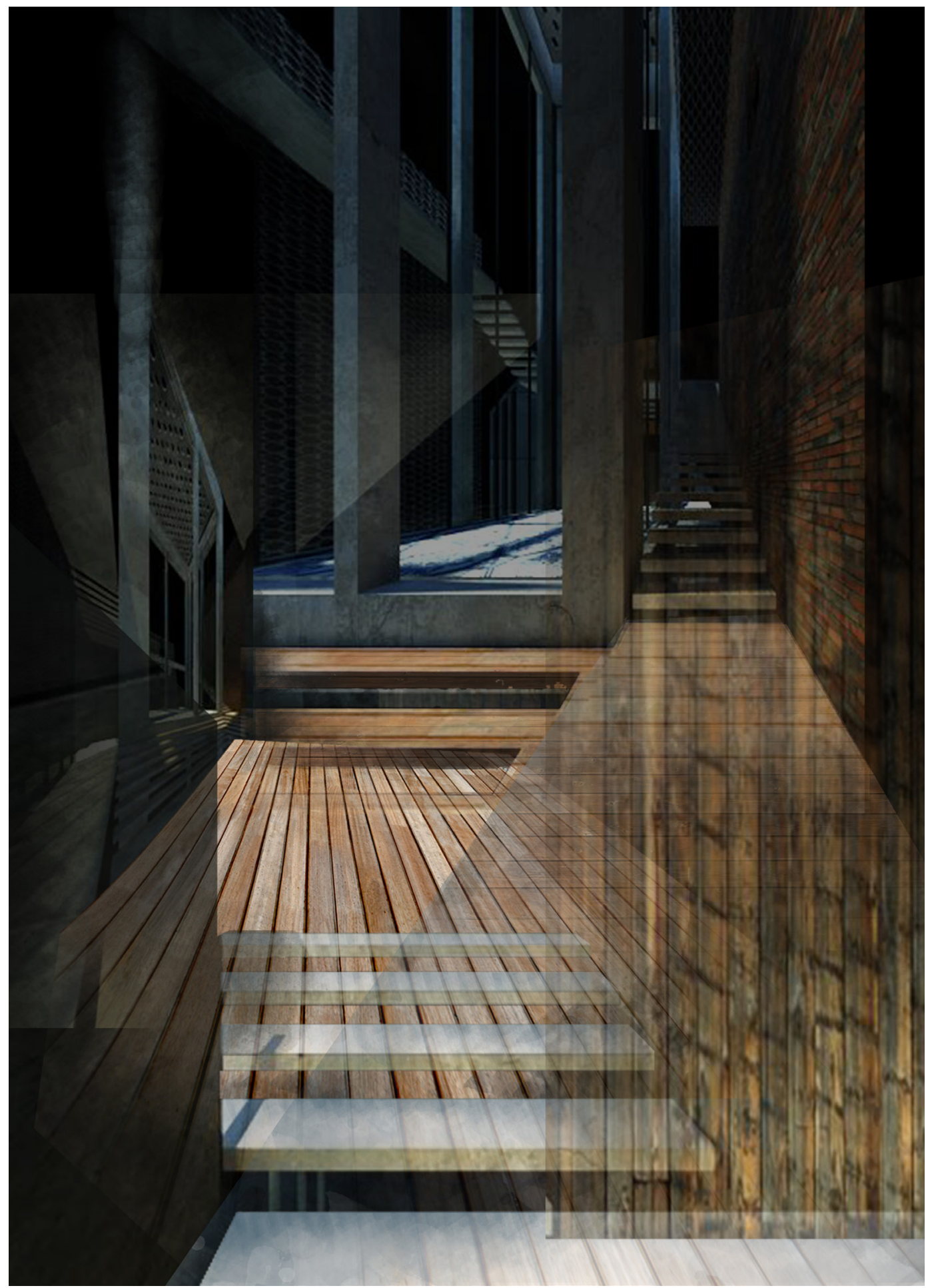

Fig. 93

Render of The Mansion's Entrance / Seating Area 


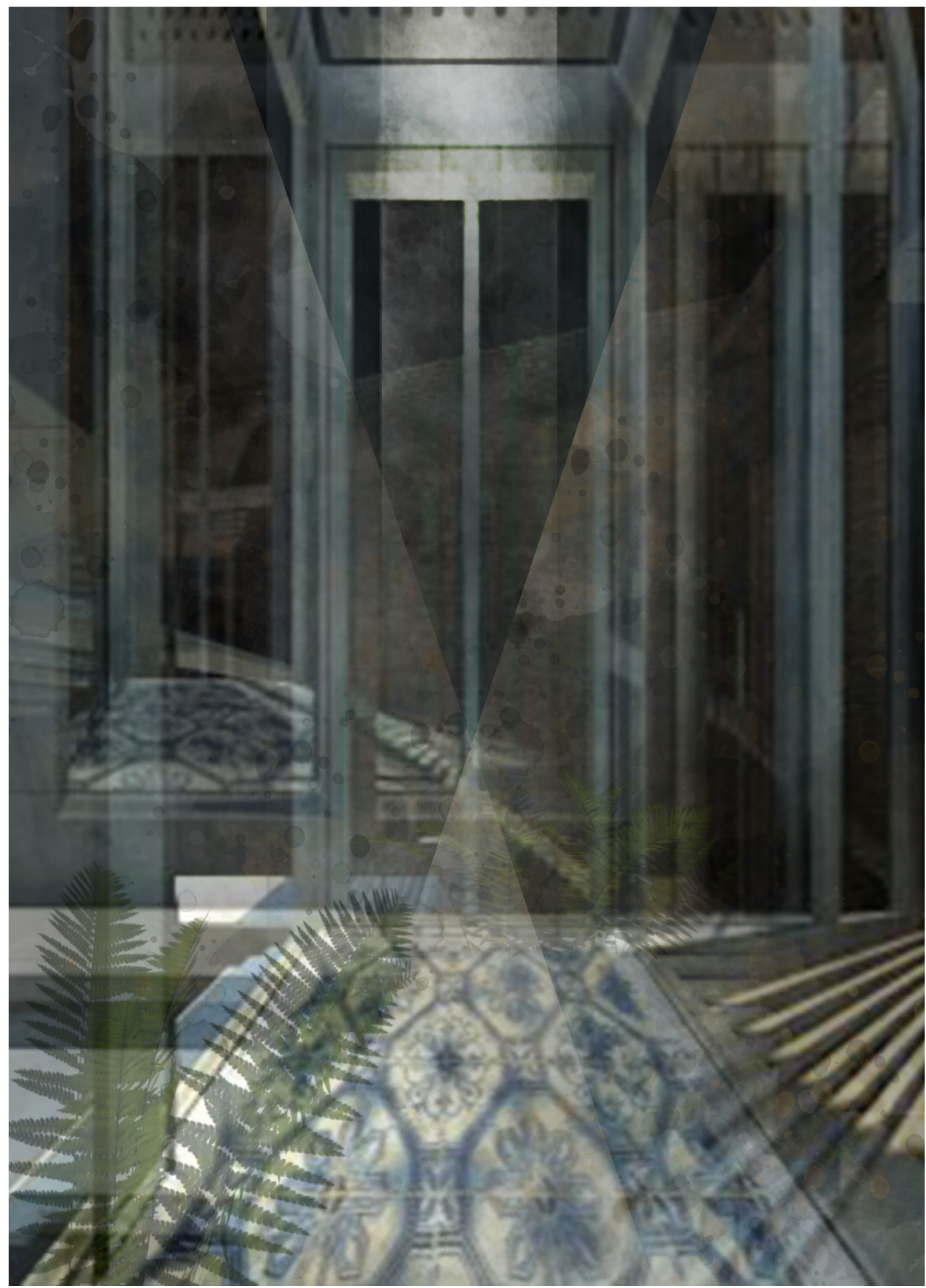

Fig. 94

Render of The Mansion's Courtyard 

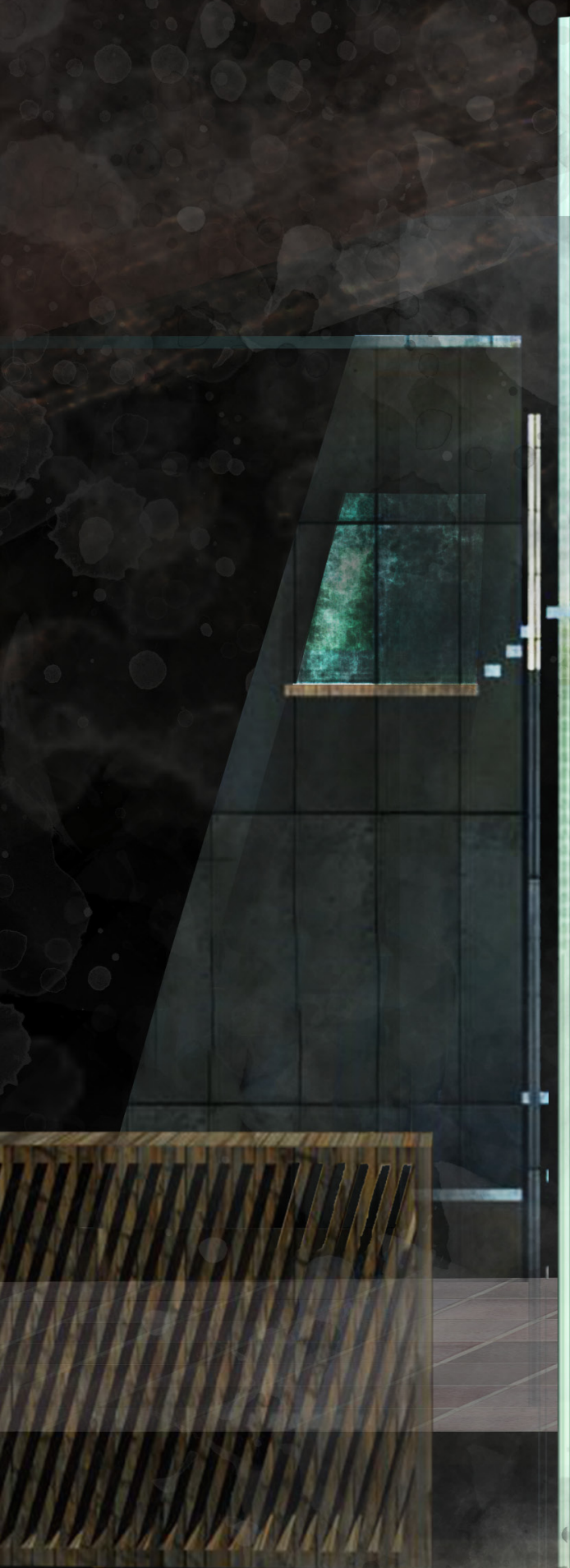



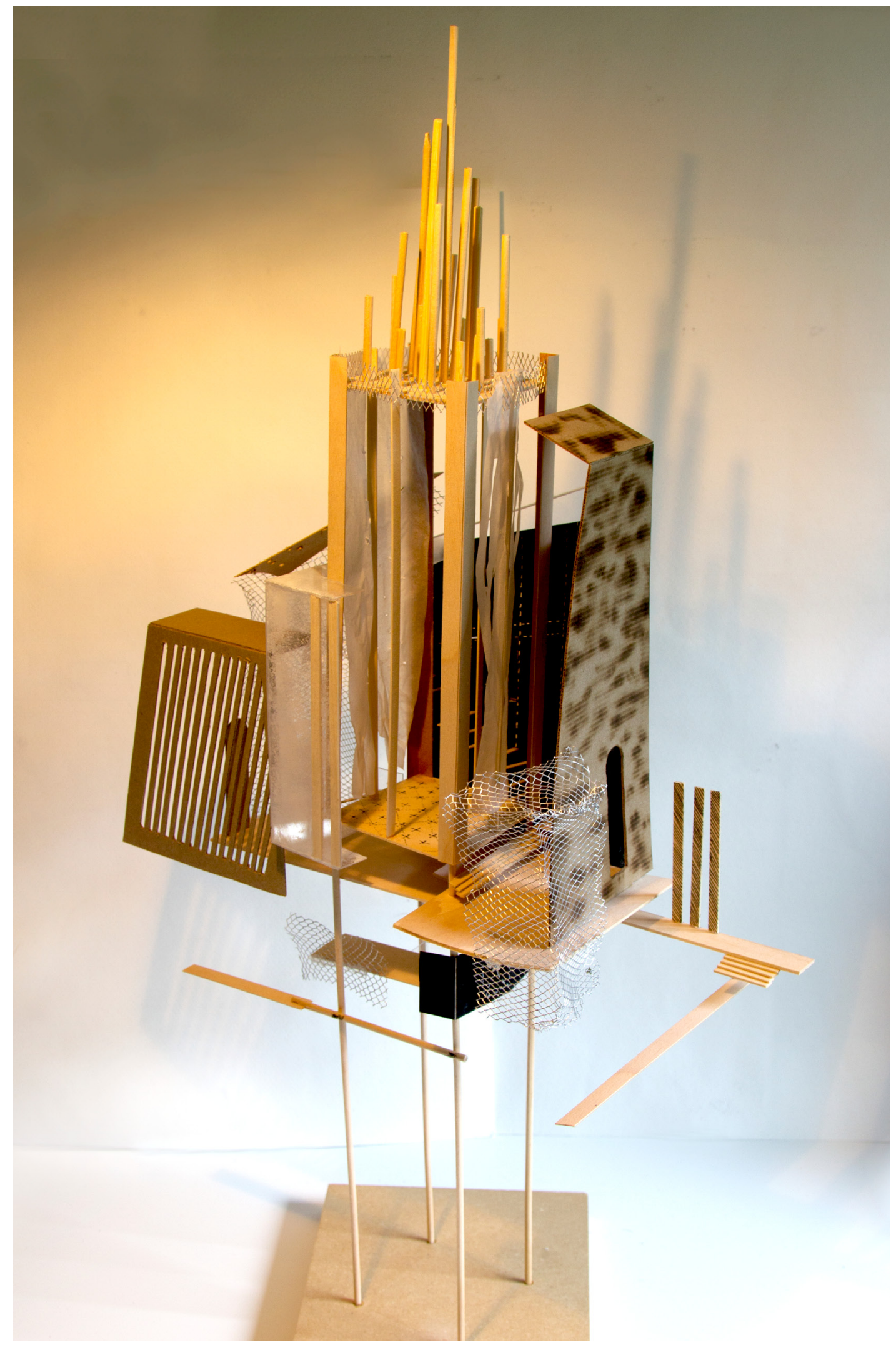

Fig. 96

Rough Physical Model of The Mansion 

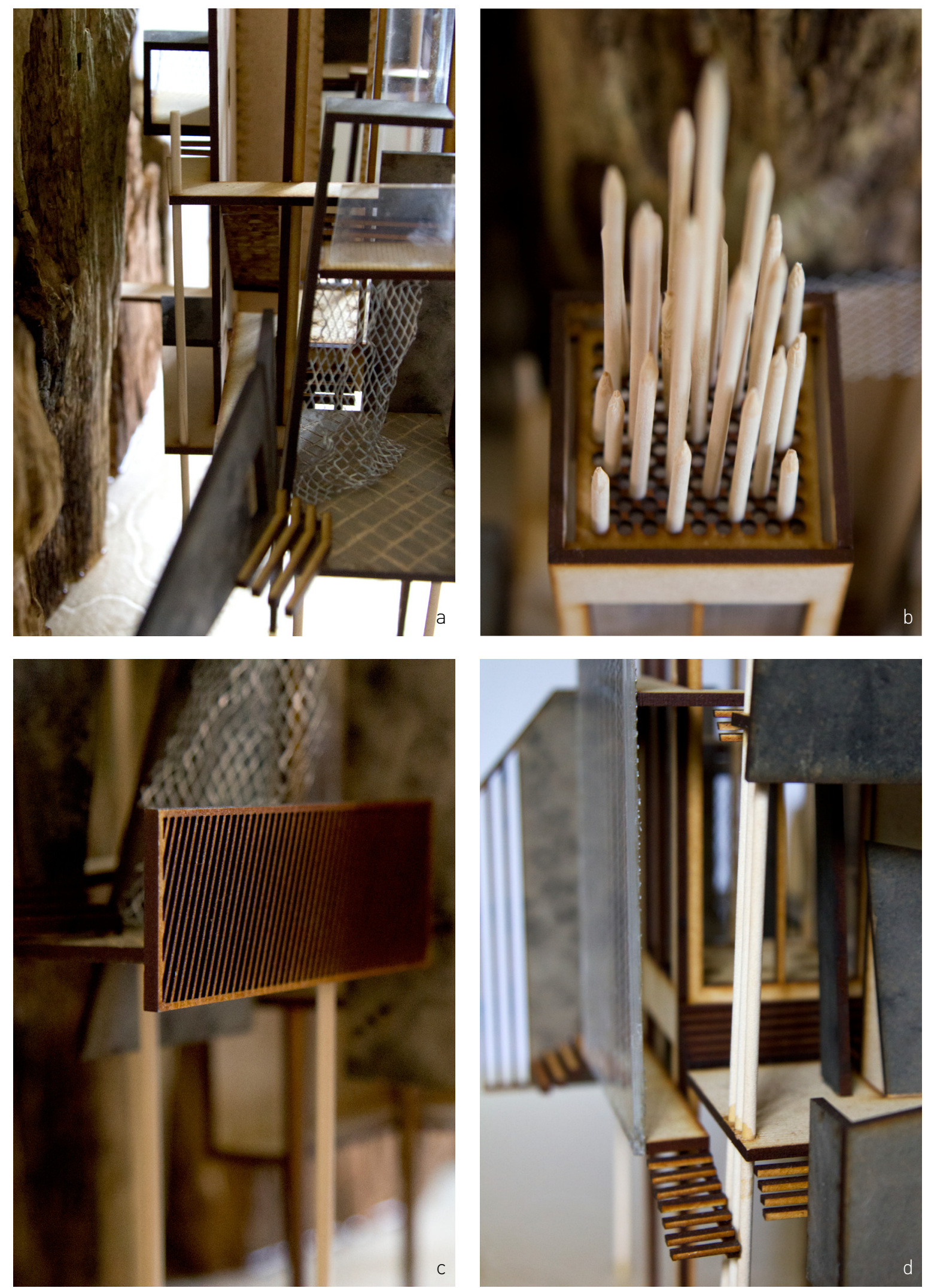

Fig. 97

Physical Model of The Mansion 


\section{Bibliography}

Advanced Vision. "Visual Perceptual Processing Impacts The Ability To Learn.". Advancedvisiontherapycenter.Com, 2017. http://www.advancedvisiontherapycenter.com/services/assessments/binocular_vision_assessment/visual_perception/.

Allen, Laura, and Mark Smout. "LA Recalculated”. Smout Allen, 2015. http://www.smoutallen.com/larecalculated.

Allen, Laura, and Mark Smout. "Home”. Smout Allen, 2017. http://www.smoutallen.com/.

Ansary, Iman. "Eisenman's Evolution: Architecture, Syntax, And New Subjectivity". Archdaily, 2013. http://www.archdaily.com/429925/eisenman-s-evolutionarchitecture-syntax-and-new-subjectivity.

ArchDaily. "Haus-Rucker-Co: Architectural Utopia Reloaded", 2014. http:// www.archdaily.com/582842/haus-rucker-co-architectural-utopia-reloaded.

Artemel, AJ. “Retrospective: Archizoom And No-Stop City”, 2013. http://architizer.com/blog/archizoom-retrospective/.

Bachelard, Gaston. "The Poetics Of Space”. New York: Viking Books, 1964.

Banou, Sophia. "Perry Kulper - 'Spatial Blooms' And Digital Expectations". Drawingmatter.Org, 2017. https://www.drawingmatter.org/sets/drawing-week/ perry-kulper/.

Belardi, Paolo, "Why Architects Still Draw: Two Lectures On Architectural Drawing" Translated by Zachary Nowak. Cambridge, MA, United States: MIT Press, 2014

Benjamin, Walter. "The Work Of Art In The Age Of Its Technological Reproducibility". Grey Room 39 (2010). https://monoskop.org/images/6/6d/Benjamin_ Walter_1936_2008_The_Work_of_Art_in_the_Age_of_Its_Technological_Reproducibility_Second_Version.pdf.

Bingham, Neil. “100 Years Of Architectural Drawing: 1900-2000”. London: Laurence King Publishing, 2013.

Bonte, Isabelle. “De Fer Est Mon Fil”. Deferestmonfil.Com, 2017.

http://www.deferestmonfil.com/.

Bryson, Bill. "At Home: A Short History Of Private Life". New York: Knopf Doubleday Publishing Group, 2010.

Calvino, Italo."Invisible Cities" Translated by and William Weaver. Harcourt Brace Jovanovich, 1974.

Casey, Edward S. "Imagining". 1st ed.

Bloomington: Indiana University Press, 1976. 
Casey, Edward S. "Representing Place". 1st ed.

Minneapolis: University of Minnesota Press, 2002.

Casey, Edward S. "The Fate Of Place: A Philosophical History”.

Berkeley, CA: University of California Press, 1998.

Casson, Hugh, and Paul Hogarth. "Drawing Architecture: A Creative Approach". New York: Watson-Guptill Publications, 1973.

Celant, Germano. "Aldo Rossi". 1st ed. Milano: Skira, 2008.

Cook, Peter. "Drawings: The Motive Force of Architecture".

Chichester, United Kingdom: Wiley, John \& Sons, 2008.

Cook, Peter. "Experimental Architecture". New York: Universe Books, 1970.

Cook, Peter. "The City Seen As A Garden of Ideas".

New York, NY: Monacelli Press, 2003.

Corbo, Stefano. “Peter Eisenman”. Drawingmatter.Org, 2017.

https://www.drawingmatter.org/sets/drawing-week/corbo-peter-eisenman/.

Craig, Megan. "Slipping Glancer: Painting Place With Ed Casey" in Exploring The Work Of Edward S. Casey : Giving Voice To Place, Memory, And Imagination, 1st ed. Bloomsbury Publishing PLC, 2013.

Cruz-Pierre, Azucena. "Framing The Landscape" in Exploring The Work Of Edward S. Casey : Giving Voice To Place, Memory, And Imagination, 1st ed. Bloomsbury Publishing PLC, 2013.

Dernie, David. "Architectural Drawing".

London: Laurence King Publishing, 2010.

"Design Museum Holon - Magazine - Post 4". Dmh.Org.Il. Accessed 29 July 2017. http://www.dmh.org.il/pages/default.aspx?Pageld=401\& catid=-1.

Dictionary. "The Definition of Home". Dictionary.com, 2016.

http://www. dictionary.com/browse/home.

"Drawing - Definition of Drawing In English I Oxford Dictionaries". Oxford Dictionaries | English, 2017. https://en.oxforddictionaries.com/definition/drawing.

Dunne, Anthony, and Fiona Raby. Speculative Everything. 1st ed. [S.L.]: MIT, 2014.

Encyclopedia. "Giovanni Battista Piranesi Facts, Information, Pictures | Encyclopedia.Com Articles About Giovanni Battista Piranesi". Encyclopedia.Com, 2017. http://www.encyclopedia.com/people/literature-and-arts/architecturebiographies/giovanni-battista-piranesi.

Fabricius, Karl. “Archigram's Walking City: A 60'S Architectural Vision Of The Future". Scribol.Com, 2009. http://scribol.com/art-and-design/architectureart-and-design/archigrams-walking-city-a-60s-architectural-vision-of-thefuture/. 
Feireiss, Kristen. "Hand-Drawn Worlds: Handgezeichnete Welten". Berlin: JOVIS Verlag, 2003.

Ferriss, Hugh. "The Metropolis of Tomorrow". United States:

Princeton Architectural Press, 1999.

Fontana-Giusti, Gordana, Timothy Brittain-Catlin, and Gerald Adler. "Scale: Imagination, Perception, And Practice In Architecture". London: Routledge, 2011.

Frascari, Marco, Jonathan Hale, and Bradley Starkey (ed.). "From Models To Drawings". (Critiques; Critical Studies In Architectural Humanities). London: Taylor \& Francis, 2007.

Frascari, Marco, and Federica Goffi (ed.). "Marco Frascari's Dream House: A Theory of Imagination". 1st ed. New York: Routledge, 2017.

Gordon, Eric. "Toward A Networked Urbanism: Hugh Ferriss, Rockefeller Center, And The "Invisible Empire Of The Air"”. Space And Culture 8, no. 3 (2005): 247-268. doi:10.1177/1206331205277398.

Gregory, Paola. "New Scapes: Territories Of Complexity". Basel: Birkhauser Verlag AG, 2003.

Harries, Karsten, Lebbeus Woods, and Tracy Myers. "Lebbeus Woods: Experimental Architecture". Pittsburgh, PA: Carnegie Museum of Art, The Heinz Architectural Center, 2004.

"Haus-Rucker-Co: Architectural Utopia Reloaded". Archdaily, 2014. http:// www.archdaily.com/582842/haus-rucker-co-architectural-utopia-reloaded.

Heidegger, Martin. “... Poetically Man Dwells ...”. in Neil Leach (ed.). Rethinking Architecture: A Reader In Cultural Theory. New York: Routledge, 1997.

Heidegger, Martin. "Building, Dwelling, Thinking” in Neil Leach (ed.).

Rethinking Architecture: A Reader In Cultural Theory. Neil Leach.

New York: Routledge, 1997.

Heydenreich, Ludwig H. "Architecture In Italy, 1400-1500".

New Haven: Yale University Press, 1996.

Hunter, Will, “Ideas And Tools: Architecture \& Representation”, 2013.

http://www.architectural-review.com/view/ideas-and-tools-architecture-andrepresentation/8647118.article.

"Imagination - Definition Of Imagination In English I Oxford Dictionaries". Oxford Dictionaries | English, 2017. https://en.oxforddictionaries.com/definition/ imagination.

Jasper, Michael. "Working It Out: On John Hejduk's Diamond Configurations", 2014. https://journal.eahn.org/articles/10.5334/ah.cb/.

Libeskind, Daniel. “Daniel Libeskind. Micromegas Project, Time Sections. 1979 I Moma". The Museum Of Modern Art, 2013. https://www.moma.org/collection/ works/295. 
Lim, C.J. "Realms Of Impossibility: Air". 1st ed.

United Kingdom: Wiley-Academy, 2002.

Lim, C.J. "Realms Of Impossibility: Ground". 1st ed.

United Kingdom: Wiley-Academy, 2002.

Lim, C.J. "Realms Of Impossibility: Water". 1st ed.

United Kingdom: Wiley-Academy, 2002.

Lochner, R. K., Rod Henmi, and lain Fraser. "Envisioning Architecture: An Analysis Of Drawing". New York: Wiley, John \& Sons, 1993.

Mlicka, Agnieszka. "Painting Architecture: Towards A Practice-Led Research Methodology". Auckland, New Zealand: Auckland University of Technology, 2014. https://www.materialthinking.org/sites/default/files/papers/SMT_ V10_03_Agnieszka\%20Mlicka_0.pdf.

Patricia, Victoria. "Plug-In City (1964). Archigram.". PROYECTOS 7 / PROYECTOS 8, 2013. https://proyectos4etsa.wordpress.com/2013/01/16/plug-in-city1964-archigram/.

Payne, Alina A. "Architectural History And The History Of Art: A Suspended Dialogue". Journal Of The Society Of Architectural Historians 58, no. 3 (1999): 292-299. doi:10.2307/991521.

Pérez-Gómez, Alberto, and Angeliki Sioli. “Drawing With/In And Drawing Out : A Redefinition Of Architectural Drawing Through Edward S. Casey's Meditations On Mapping" in Exploring The Work Of Edward S. Casey : Giving Voice To Place, Memory, And Imagination, 1st ed. Bloomsbury Publishing PLC, 2013

Pérez-Gómez, Alberto. "Architecture And The Crisis of Modern Science". 1st ed. Cambridge, Mass. [u.a.]: MIT Press, 1983.

"Place - Definition of Place In English | Oxford Dictionaries". Oxford Dictionaries | English, 2017. https://en.oxforddictionaries.com/definition/place.

Pratchenko, Paul. "Painting And Drawing As Manifestations Of Visual Perception". Leonardo 16, no. 4 (1983): 273. doi:10.2307/1574952.

Rannells, Edward Warder. "The Study of Architecture As Art". College Art Journal 8, no. 3 (1949): 204. doi:10.2307/772828.

Rattenbury, Kester. "This Is Not Architecture: Media Constructions".

New York: Spon Press, 2002.

Riley, Michelis, DeYong, Antonelli. "The Changing of The Avant-Garde: Visionary Architectural Drawings From The Howard Gilman Collection", Organized By Terence Riley, Departme. New York, NY: Museum of Modern Art, 2002.

Rossi, Aldo, and Morris Adjmi, (ed.). "Aldo Rossi : Drawings And Paintings". 1st ed. New York: Princeton Architectural Press, 1993. 
Scheer, David. "The Death Of Drawing: Architecture In The Age of Simulation". London, United Kingdom: Routledge, 2014.

Søberg, Martin. "John Hejduk's Pursuit of An Architectural Ethos". In Architecture Culture And The Question Of Knowledge: Doctoral Research Today, 1st ed. FOOTPRINT, 2012. http://footprint.tudelft.nl/index.php/footprint/article/ view/753.

"Space - Definition of Space In English | Oxford Dictionaries". Oxford Dictionaries | English, 2017. https://en.oxforddictionaries.com/definition/space

Spiller, Neil. "A World Below". Architectural Design - Drawing Architecture, 2013.

Spiller, Neil (ed.). “Drawing Architecture”. Architectural Design 83, no. 5 (2013).

Spiller, Neil. "Visionary Architecture: Blueprints Of The Modern Imagination; With Over 450 Illustrations". New York: Thames \& Hudson, 2008.

Stöckmann, Jochen. “Top-Drawer Time Bombs”, 2014.

https://www.stylepark.com/en/news/top-drawer-time-bombs.

“The Definition of Drawing”. Dictionary.Com, 2017.

http://www.dictionary.com/browse/drawing.

Turkmenoglu, Dilek. "Visual Perception And Drawing Relationship In Art Education". Procedia - Social And Behavioral Sciences 51 (2012): 849-852. doi:10.1016/j.sbspro.2012.08.251.

Vidler, Anthony. "The Architectural Uncanny: Essays In The Modern Unhomely". 5th ed. Cambridge, MA: M.I.T. Press, 1992.

Volner, lan. “Daniel Libeskind: Drawing A New Architecture.". NUVO, 2014. http://nuvomagazine.com/magazine/autumn-2014/daniel-libeskind.

Wallace, Lewis. "Lebbeus Woods: The Architect Who Dared To Ask 'What If?'”. WIRED, 2013. https://www.wired.com/2013/02/lebbeus-woods-conceptual-architect/.

Wallis, Stephen. "A 60s Architecture Collective That Made History (But No Buildings)". Design \& Interiors, 2016. http://www.nytimes.com/2016/04/04/tmagazine/design/superstudio-design-architecture-group-italy.html?_r=0.

Warlamis, Efthymios. "Poetic Architecture". London: Papadakis Dist A/C, 2006.

Willis, Carol. "Ferriss, Hugh”, 2012. http://www.oxfordartonline.com.ezproxy. lib.ryerson.ca/subscriber/article/grove/art/T028059.

Yifeng, Zhu. "Making Drawings: A Study On The Information Conveyed By Drawings", 2011. http://maad.postgrad.shef.ac.uk/maad10/files/reflections-on-architectural-design.pdf. 

